\title{
Jacob Rodde
}

\section{Russische Sprachlehre}

Verlag Otto Sagner München · Berlin - Washington D.C.

Digitalisiert im Rahmen der Kooperation mit dem DFG-Projekt „Digi20“

der Bayerischen Staatsbibliothek, München. OCR-Bearbeitung und Erstellung des eBooks durch den Verlag Otto Sagner:

http://verlag.kubon-sagner.de

() bei Verlag Otto Sagner. Eine Verwertung oder Weitergabe der Texte und Abbildungen, insbesondere durch Vervielfältigung, ist ohne vorherige schriftliche Genehmigung des Verlages unzulässig.

«Verlag Otto Sagner» ist ein Imprint der Kubon \& Sagner $\mathrm{GmbH}_{\text {acob Rodde - } 9783954791521}$ 


\section{SPECIMINA PHILOLOGIAE SLAVICAE}

Herousgegeben von

Olexo Horbatsch und Gerd Freidhof

Band 38

\section{JACOB RODDE \\ RUSSISCHE SPRACHLEHRE}

Ausgabe Riga 1773

Nachdruck besorgt von

Gerd Freidhof und Bernd Scholz

VERLAG OTTO SAGNER - MONCHEN

1982 
00047288

$z 74.772(38$

ISBN $3-87690-198-7$

Copyright by Verlag Otto Sagner, München 1982. Abteilung der Firma Kubon und Sagner, Müchen. Druck: Erich Mauersberger, 3550 Marburg/Lahn.

$p 81 / 11929$

Bayeriscine

Staatsbibliothok Münctien

Jacob Rodde - 9783954791521

Downloaded from PubFactory at 01/10/2019 05:18:50AM

via free access 


\section{VORWORT}

Mit dem Nachdruck des vorliegenden Titels wollen wir beginnen, einige in deutscher sprache verfabte Grammatiken der russischen Sprache, die in der Folge nach dem Erscheinen der Rossijskaja grammatika von Lomonosov 1757 (1755) erschienen sind, einem breiteren Interessentenkreis wieder zugänglich $2 u$ machen. Lomonosovs Grammatik hat nebst ihrer deutschen Ubersetzung durch Johann Lorenz Stavenhagen (Russische Grammatick, St. Petersburg 1764) die entscheidenden Voraussetzungen hierfür gelegt (vgl. unseren Nachdruck der deutschen Ubersetzung der Lomonosov-Grammatik als Band 27 dieser Reihe, München 1980).

Zu den ins Auge gefabten Grammatiken gehoren neben Rodde die 1789 in Moskau in erster Auflage erschienene "Russische Sprachlehre fur Deutsche" von Johann Heym (weiterhin Riga 1794, 1804 sowie von Sam. Weltzien bearbeitete Ausgaben der Grammatik ab 1816), die 1808 und 1814 in Leipzig erschienene "Praktische Grammatik der Russischen Sprache in Tabelien und Regeln, nebst Ubungsstucken zur grammatischen Analyse, einer Einleitung uber die Geschichte der Russischen Sprache und Anordnung ihrer Grammatik, und Berichtigungen der Heymischen Sprachlehre" von Johann Severin Vater sowie August Wilhelm Tappes "Neue theoretischpraktische russische sprachlehre fur Deutsche mit Beispielen, als Aufgaben zum Ubersetzen aus dem Deutschen in das Russische nach den Hauptlehren der Grammatik, nebst einem Abrisse der Geschichte RuBlands bis in die neuesten zeiten" (die erste der zahlreichen Auflagen erschien in St. Petersburg 1810).

Nach AbschluB der geplanten Nachdrucke wird eine umfangreichere Einleitung oder studie erscheinen, die die Gesamtentwicklung dieser Grammatiken beschreiben wird. 
Be1 Roddes Grammatik handelt es sich somit um die erste deutschsprachige in der Tradition nach Lomonosov, an dessen "Rossijskaja grammatika" sich Verf. sehr stark orientierte (vgl. die Anmerkungen in der Vorrede zu der hier vorliegenden ersten Auflage). In den folgenden Auflagen hat sich der "Secretair und Translateur des Magistrats in Riga", wie er sich selbst bezeichnet, auch der in französischer sprache erschienenen Grammatik von Charpentier bedient, wie aus der Vorrede zur zweiten Auflage hervorgeht. Charpentiers Grammatik war bereits 1768, also noch vor Erscheinen von Roddes erster Auflage, in St. Petersburg unter dem Titel "Élemens de la langue russe, ou Méthode courte et facile pour apprendre cette langue conformément à l'usage" (zitlert nach dem Catalogue général des livres imprimés de la bibliothèque Nationale, Nr. 27, Paris 1906) veroffentlicht worden. Der ElnfluB von Charpentier wird vor allem bel der sehr unfangreichen Auflistung der russischen Verben deutlich.

Jakob Rodde (1725-1789), dessen Geburtsort ungewiB ist (nach Recke-Napiersky kommt möglicherwelse auch Moskau in Betracht), studierte in Halle Theologie und war später Dolmetscher des Magistrats zu Riga mit dem Titel eines Sekretärs (vgl. auch Russkij blografičeskij slovar'). Er ubte elne umfangrelche Ubersetzertätigkeit aus, die sich auf sehr unterschiedliche Gebiete erstreckte ("Anwelsung zur Pflanzung der Erdäpfel...", Riga 1765; "Rechtglaubige Lehre oder kurzer Auszug der christl. Theologie...", Riga 1770; "Wohlthaten gewinnen die Herzen. Drama in einem Aufzuge", Riga 1771; "Peter Rytschkows Orenburgische Topographie...", Riga 1772; "Peter Rytschkows Versuch einer Historie von Kasan...", Riga 1772).

Seine philologische Arbelt erstreckte sich neben der Erstellung der Grammatik auf die Lexikographle ("Deutsch-Russisches worterbuch. Leksikon Rossijskij s Nemeckim 1 Nemeckij s Rossijskim, 1-2, Riga 1784").

Roddes Grammatik erschien in insgesamt 4 Auflagen (Riga 1773, 1778, 1784, 1789). Die von Bledermann, S. 108 angefuhrte Ausgabe von 1790 konnte von uns nicht nachgewiesen werden (sie wird auch in den einschlăgigen werken nicht aufgefuhrt). Die einzelnen Auflagen haben elnen verschiedenen Umfang (248 S., 264 S., 432 S., 431 S.). Nicht berucksichtigt sind hierbel die als Anhang 
abgedruckten Gesprächsanleltungen, die auch in unseren Nachdruck nicht eingegangen sind.

Vom Typ her 1st Roddes Grammatik eine Fremdsprachengrammatik des Russischen "zum Besten der deutschen Jugend eingerichtet" (s. Titelblatt), genauer fur den in Riga und weiteren stadten einsetzenden Russischunterricht (vgl. S. V der Vorrede, wo es heibt: "Denn da allhier in Riga durch die weise und stadtvaterliche Veranstaltung Eines hochedlen Raths bey der Domschule ein besonderer Lehrer der russischen Sprache verordnet 1st, und auch in andern städten hiesiger Provinzen dergleichen Lehrer bestellt seyn sollen: so 1st elne kurzgefabte russische Grammatik von der grobten Nothwendigkeit.").

Von der zielsetzung her kann also eine solche Sprachlehre auch nicht darauf verzichten, hier und da auf Unterschiede der russischen und deutschen Sprache einzugehen.

DaB das Erstellen einer Grammatik fur eine fremde Sprache mit vielen Schwierigkeiten und Problemen verbunden 1st, wissen wir ja nur allzu gut aus der heutigen zeit. Auch Rodde hatte es mit diesen zu tun (von den zahlreichen Druckfehlern einmal abgesehen, die den der russischen Sprache unkundigen Setzern des deutschen Verlages (vgl. Titelblatt und S. 248) zuzurechnen sind).

So hat denn die zeitgenossische Kritik sich auch veranlast gesehen, auf solche Măngel in der Auswahl, bel der Einbeziehung veralteter und 'gemeiner' Ausdrucke durch Verf. hinzuweisen. Gutes Beispiel hierfur ist die bereits zitierte "RuBische Sprachlehre für Deutsche. Von Johann Heym, RuBisch-Kayserlichem Collegien-ABeBor und ProfeBor bel der Moskowischen Universität. Moskau, in der Universitäts Buchdruckerey bey N. v. Nowikow. 1789", in der sich Verf. mit Măngeln in Roddes Grammatik auseinandersetzt.

Wir wollen es an dieser Stelle nur bel zwei Hinweisen belassen. Ein erster Vorwurf betrifft die Anordnung der Gramatik; Verf. wirft Rodde vor, $\mathrm{daB}$ er "eine hochst verworrene und nur in Welsmanns und Nordstets worterblichern befindliche Ordnung gefolgt hat" (S. VII) - es 1st ihm daher nicht verstandlich, "aus welchen Ursachen $\mathrm{Hr}$. Rodde, die ohnglelch leichtere ordnung des Hrn.v. Lom. nicht beybehalten" (S. VIf.) habe. In bezug auf die Auswahl richtet sich seine Kritik insbesondere auf die Konjuga- 
tionsmuster (S. VII: "Was die Conjugationen anlangt; so ist H. R.. in einigen Fällen $2 u$ kurz und in andern, besonders im VerzeichnißBe der zeitwörter, zu weitschweifig.").

Ob bzw. inwieweit Roddes Grammatik einen EinfluB auf die Entwicklung der allgemein-philosophischen Grammatik in RuBland mit ausgelibt hat (vgl. die Bemerkungen Biedermanns, S. 107f.), kann hier noch nicht geklärt werden. Eine solche Annahme scheint auf den ersten Blick jedoch sehr hypothetisch zu sein.

\section{Literatur:}

I.I. Balickij, Materialy dlja 1 storli slavjanskago jazykoznanija., Kiev 1876.

J. Biedermann, Gramatiktheorie und grammatische Deskription in RuBland in der 2. Halfte des 18. und zu Anfang des 19. Jh., Frankfurt am Main/Bern 1981.

Catalogue de la section des Russica, ou Écrits sur la Russie en langues étrangères, 1-2, St. Pétersbourg 1873 (Nachdruck Amsterdam 1964).

Catalogue général des livres imprimés de la bibliothèque Nationale, Nr. 27, Paris 1906.

J. Heym, RuB1sche Sprachlehre fur Deutsche, Moskau 1789.

J.F. V. Recke/R.E. Naplersky, Allgemeines Schriftsteller- und Gelehrten-Lexikon der Provinzen Livland, Esthland und Kurland, Bd. III, Mitau 1831.

Russkij blografičeskij slovar', M. 1896ff. (Nachdruck New York $1962)$. 


\section{शuffiffec}

\section{Eplathlefle, \\ jum}

Beften Der Deutfien Jugend

eingeridtet

o on

Sacob RODde,

Secretair und Iranflateut bes Diagiftrats in Siiga.

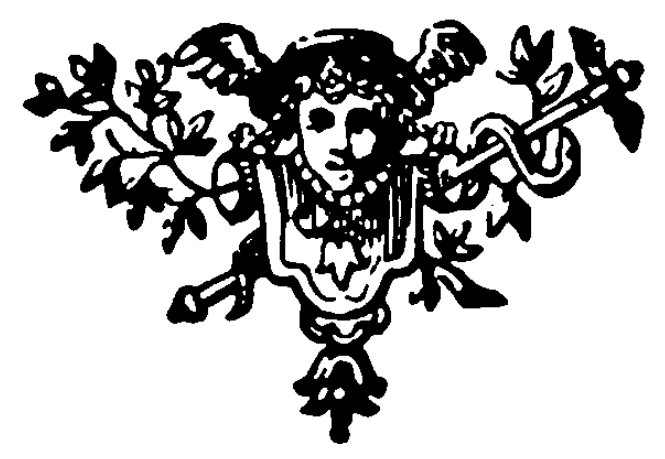

Riga,

bey Job̧ann Friebrid Şartlnod.

1773. 
Den fámmtlid̄en

bodaunébnliden ESliebern

des Magiftats

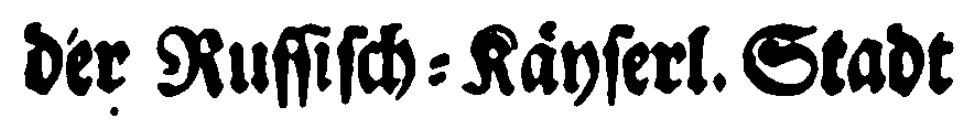

Piga,

feinen bohen $\mathfrak{s}$ dinnern

und $230 b l t b$ átern,

mibmet

biefe ruffiiłe Spradilefre mit tiefiter Ebrfurdt und pflittmáfigfter

Crgebenbeit

Der Berfafier. 


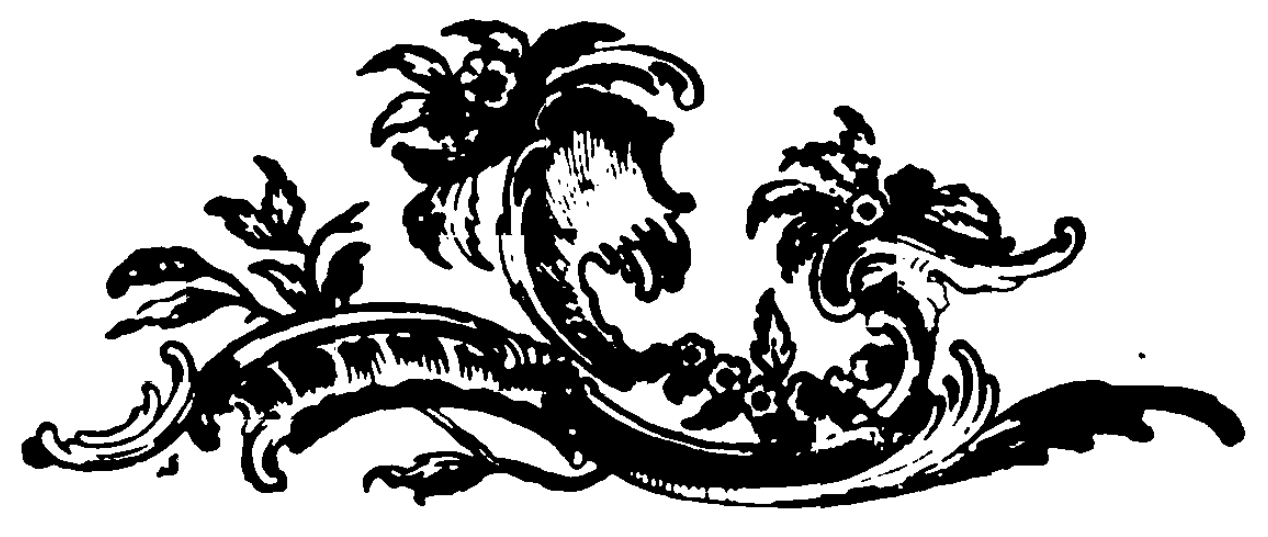

\section{Borrede.}

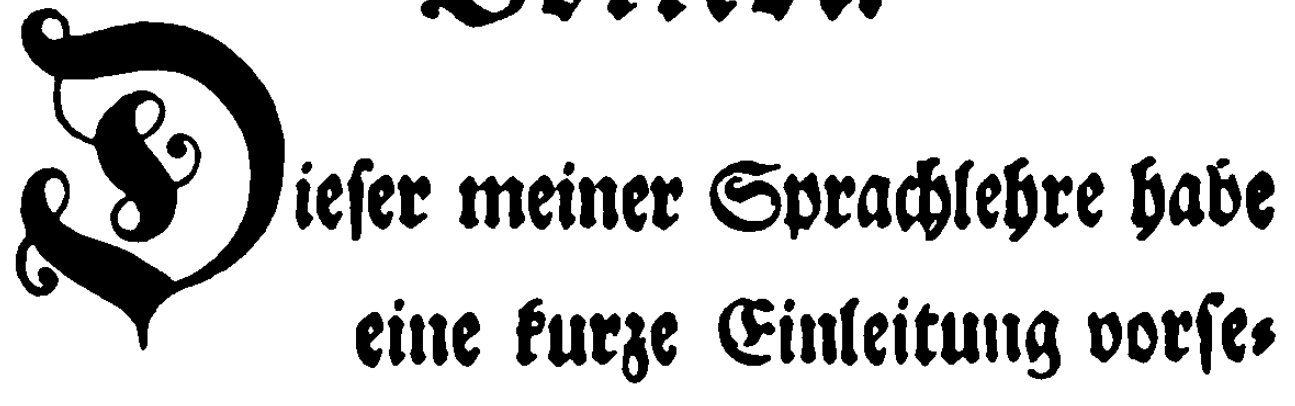

Bent wollen, um fo wobl bein Publico von ifrer Zuverlábigkerit Rectenfdbaft zu gebell, als̀ aud daffelbe zu ibrem Gebraude vorzubereiten. Exftereş balte iđ fiur bie Pllid)t eines (S)ammatifens fabreibers; ; Denn Da er bender Auggabe feineg̊ 2 Berfsi verlangt, daf man die Darinn entbaltenen Siegeln fiuc ridtig

$$
\text { * } 3 \text { antreb= }
$$




\section{Borrede.}

aumegrmen folle, fo ift Dagegen audi bas Publicum berectitiget, von beren SRids tigfeit Rectenf(haft zu verlangen. WBir baben modh feille Urfacte, uns úber bie Menge ruffifíder Gramunatifen zu bes faberen. Diellidt werden fic fiuftig báufiger. Dabey muirde die Sprade Felbft und das $\mathfrak{P u b l i f u m ~ g e r w i n n e n , ~}$ und bey (A)lecten Granmmatifen nies mallo alb ber $\mathfrak{B e r f a f f e r}$ und ber $\mathfrak{B e r}$ leger Shadent leiben. Riebbaber dee ruffificten Spracte find dem uummebro verftorbenen ß̧errn Stnatşratbe Ronios nofforw vielen Dant faulbig, dak ex Durd feine Spradtebre zur grindi= Den Senutnis Der ruffifden Sprade 


\section{Borrede.}

ben $23 e g$ gebabnt bat. Diefe babe bey Derfafiung gegenwártiger Grammatif zum Grunde gelegt; ingmifden aber Diefelbe zum Squlgebraude bequemer zu macben gefudt. Denn ba allbiez in Riga ourd bie weife und ftadtvdtertidje Beranfialtung Eines bodedlen Ratbs ben ber Dobmfaule ein befonderer Regs rer ber ruffifden Spradse verorbuet iff, unt aud in andern Stábten biefiger Provinzen Dergleiden Eebrer beftellt feun follen: fo if eine furzgefabte rufs fifde Grammatif biefigen Drtb von Der gedfften Rotbwendigfeit. Die in Diefer Grammatif entbaltenen Regeln

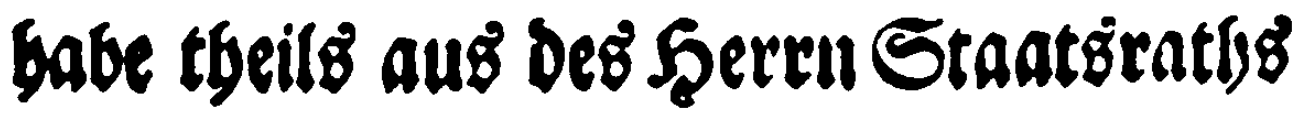

$$
\text { * } 4 \text { Rolno }
$$




\section{Borrebe.}

Romonoffor Grammatif genommen, tbeils feit vielen Jabren benm sefen berwágrter ruffifier Scribenten felbft formirt, unt gefammlet; bet) feiner einzigen babe mict blok auf mein Bes bdr verlaffert. Die meifte Sibmierigs feit in ber ruffifden Grammuatif mas den bie Verba, weldte grd Brenttyeils irreguláir geben. Iđ babe babero bevin Saluke bes axbduitto von ben Verbis eine Tabelle von irregulairen Verbis bengefügt, und angezeigt, wie fie in den verfdeiedenen Prateritis und Futuris, wie aud in Dem Infinitivo und Imperativo, abgeándert werben. SPian weiß, wie viel ben Denl lateinifden Zeits wodes 


\section{Sortede.}

mdeteen Darauf anfdmmt, Daß man von ibnen daṡ Præfens, Perfeetum uno Supinum wiffe; und wie fegr bie MReis ften in ber beutifben Sprade in Dein Imperfecto und Supino verftofen. İ) fameidele mir alfo, dấ felbige Tabelle ber Verborum irregularium von vielem Subsil fevn werbe. Ruffis fabe Spradtebree werden wobl thun, wenn fie Der Jugento diefe Verba, to wie fie nad ibren abgeánberten Temporibus und modis ba fteben, ausimen: dig lernen laffen; fo wie die Declinationes gleiळfalls augiwendig geleriuet wers Den miffen. Dieś fanm den Rernenden Feine SRarter fenn, wur muß man fie

$$
\text { * } 5 \text { mit }
$$




\section{Bortébe.}

mit auswendig letuen grammatifalis

foer SRegelın nicht quálen; bies wäre eben fo feltfam, als̃ wenun ein Sinnftlex feirem Regelinge cine sRenge SRegeln von feiner Runft zum aubiventig lernen vorgeben, und ifn ein ober megrere Jabee fid blok damit befdaftigen lafs fen wollte. So balb bie Rernenden les fen und gut pronuncieren edomen, fo faceite man zum exponizen unb ana= Infiren. Ben lesterm laffe man bie fo wofl bet) Den Nominibus und Verbis als aud in ber Snutax vorfommendent SRegeln fleifig nadidalagen, und gebe ignen fo viele Betsfpiele vor, bis man merft, DaE fie bie SRegeln vollfommen begriffelt 


\section{Bourebe.}

begriffen und inne baben. If cine siegel befonders merfwirbig, und ents ballt einen befondern Jbiotifmus, to fann man fid babety wobt eine balbe Stunbe und lánger aufbalten; um aber die Regeln, bie im Ruめe, weldes expos niret wirb, niфt vorgetommen, mitzus nebinen, fo laffe man bie Grammatif alle 230 oen ein ober zroevmal laut vors lefen, unb madbe bie nod unbefannten Regeln ben Reenenden burd Beyfpiele begreiflid. Rađ Ablaufe cines Jabres werben wenige ober gar feine Siegelin megr feblen, und die Rerwenden werben fie auf eine leidte art gelemt unb ges fast babell. Die Exercicia die man ifs:

netI 


\section{Bortede.}

nen vorgiebt, miffen Imitationes aus Dem jedesimaligen Penfo fenn, und das riment fo wobl bie vorgeformmenten grammatifalifdoen Regeln, als befon. Ders die ber ruffif́ten Sprade eigenen 2usbricte und $23 e n d u n g e n$ ange: bradt werben; wie iđ es benu úters baupt für unictidtid balte, wenn man in Den Saulen zu Den Exercitiis ganz frembe SRaterien nimt, Die mit ben vors gewefenen Rectionen fo wenig in Derbin: Dung fteben, als das Trojanifate Pferd mit Des Bileams Efel. Jđ babe in Die fer Grammatif bie grammatifalifaen Terminos mit gleiß im Rateinifdent berbebalten wollen, weil es cinmal f́on 


\section{Sorrebe.}

Die Safulipradte ift, und die Rernenden mit ben 20 drtern Pronomen, Participium, Adverbium, Præpofitio, ConjunC̣io, Interjectio gefforwinder und mit wenigerm Rabbenfen die bazu gebdris gen Begriffe verbinben formen, als wenn man ignen von gairwodrtern, Mits telwdrtern, Nebenwdrtern u. f. w. vors fagt. I\$ babe meine Grammatif lies ber.meniger neumodifd erfacinen lafs

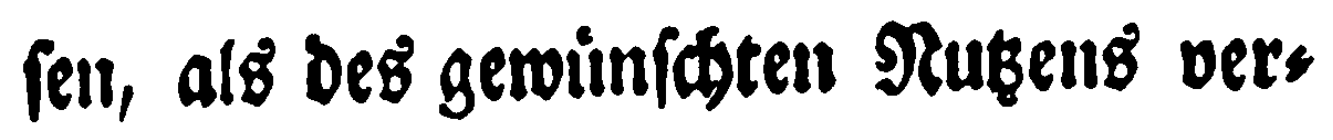
feblen wollen. Bebalten Dod Die graus: zofen und Engelländer, bie Dod fonf in ibren Sadriffen feine frembe $238 d r$ ter leiben, in ifren Granunatifen biefe Iateinifbe Terminologie.

$\mathfrak{D a}$ 


\section{Bortebe.}

\section{Da id úbrigens nidts fo febe}

münfđe, als̊ mit meinen wenigen Siráfs ten meinem Baterlande, und befonders

einer Stadt, Die mir meine Berfor= gung giebt, núblit zu reyn: fo werbe i申 mid) unenblid freuen, wern man Diefe Grammatif für ein nưblides Bud balten, und wenn eine gute 2ufs nabme bem Entzmedte, Den-i申 Dabey getabt, entfprecten wirb. Siga, ben 9. gor. 1773. 


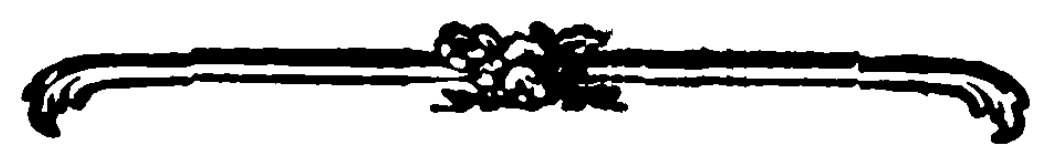

\section{Sinhalt}

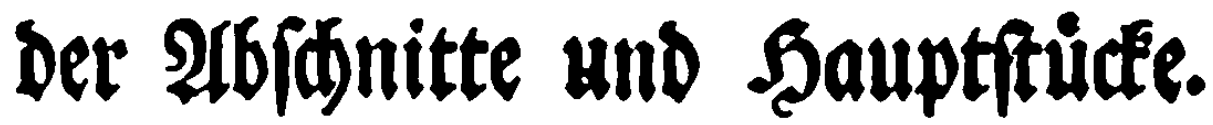

\section{Erfter 2 G6/dnitt,}

Bon Den Budftaben, Deren 2uspipras De, und Der Bedtfthreibung Der ruf= fifien 23 drter.

3wenter $\mathfrak{a b}$ fdnitt,

\section{Bon ben Nominibus.}

I JauptPtudt. Bon ben Eefdoledten, uno wie ans bem Mafculino tin Foemininum gemadt wirb.

2 万auptfita. Bon Den Declinationen.

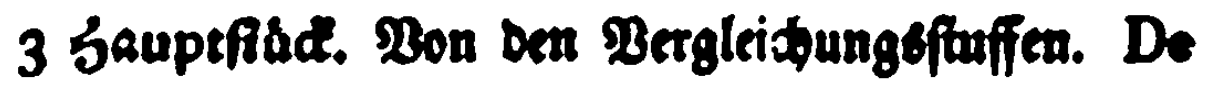
gradibus comparationis.

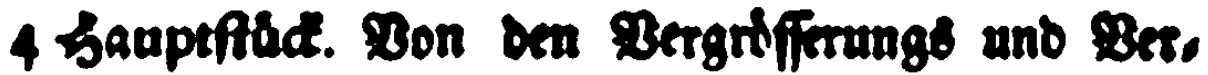
fleinerungsbortern. De Nominibus angmentativis \& diminutivis.

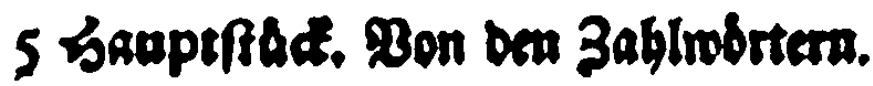




\section{Dritter $\mathfrak{A} \mathfrak{b}$ / \\ Boll Den Pronominibus.}

\section{Bietter 216j6rnitt, \\ Boll den Verbis.}

1 Sauptfiud. Bon ben Verbis überhaupt.

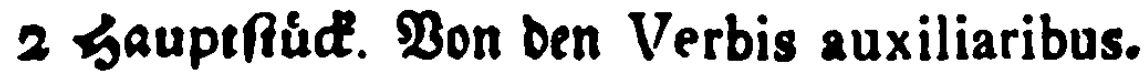

3 Gauptffúd. Bon der erften Conjugation.

4 Ђauptfiud. Bon ber zwenten Conjugation.

5 bauptfite. Bon den Verbis compofitis, irre. gularibus \& defectivis.

\section{Füunfter $\mathfrak{I} 6$ (d)nitt,}

De partibus auxiliaribus orationis.

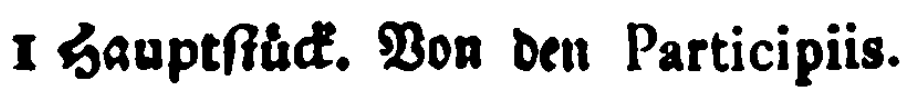

2 Sauptfíct. Bon ben Adverbiis.

3 万auptfitt. Bon ben Prepofitionibus.

4 Gaupeffúd. Bon ben Conjunetionibus.

5 万Ruptfiú. Bon ben Interjectionibus.

\section{Sedjfter 26/dtitt, \\ Bon dee Syntaxi.}

I Sauptffúd. de fyntaxi Nominum.

2 bauptitid. de fyntaxi Verborum.

3 לauptfhat. de fyntaxi partium anxiliarium orationis.

\section{Der}




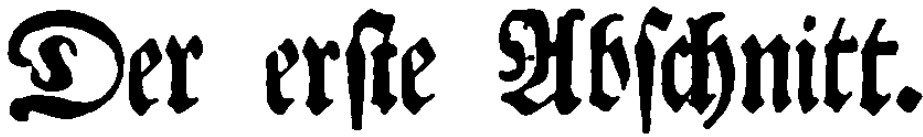

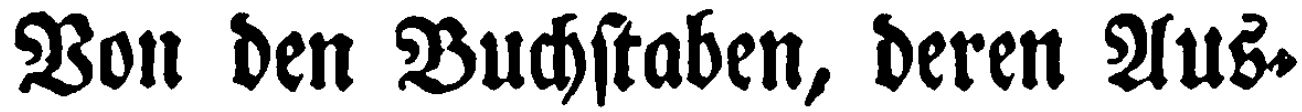

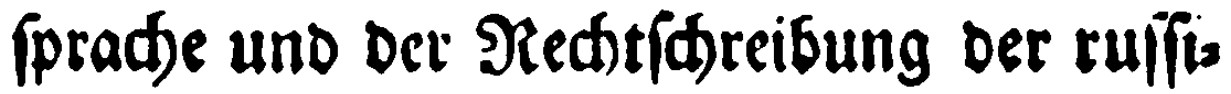

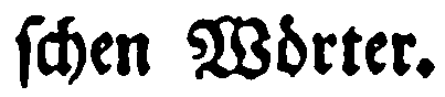

$$
\text { §. } 1 \text {. }
$$

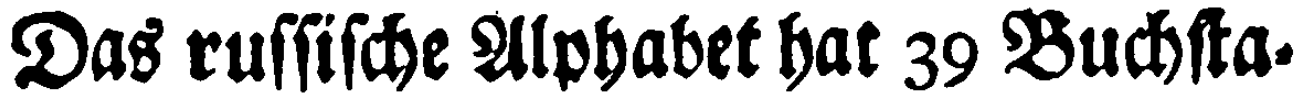
ben, die folgendernmäell geidstieben und genennet werden:

\begin{tabular}{|c|c|c|c|c|}
\hline $\mathbf{A}$ & 2 & $a$ & A3b & $\mathfrak{X}_{8}$ \\
\hline b & 6 & $\sigma$ & Вуки & Bufi \\
\hline B & B & I & ВБАи & $\mathfrak{B j e b i}$ \\
\hline $\boldsymbol{\Gamma}$ & $\mathbf{r}$ & 2 & Гиаголь & B)lagol \\
\hline A & $A$ & A & А,о6ро & Dobro \\
\hline $\mathbf{E}$ & e & $e$ & Ecmb & Seft \\
\hline ж & ж & * & Живеmе & Edjimets \\
\hline $\mathbf{s}$ & $s$ & 8 & Seso & Selo \\
\hline 3 & 3 & 3 & Земля & Eemija \\
\hline И & n & $\boldsymbol{u}$ & Иже & Jfde \\
\hline I & it & $i$ & I & $\mathfrak{3}$ \\
\hline K & $\mathbf{x}$ & $\boldsymbol{x}$ & $\begin{array}{c}\text { Kako } \\
\mathfrak{A}\end{array}$ & Rafo \\
\hline
\end{tabular}




\section{Erfter 2060)}

$\boldsymbol{\lambda}$

$\lambda \boldsymbol{\lambda}$ 入ода

Sjubi

M

$\boldsymbol{M} \mu$

Murcseme

Myplete

$\mathbf{H}$ H $\boldsymbol{H}$

Hawb

O 0

n

Онъ

II I

$\pi$

Покой

P

P $\boldsymbol{p}$

c $\quad c$

Руи

Слово

Na|d

On

T III $m$ Твердо

子 - - Икb

y

y $y$

$\Phi \quad \Phi \quad \phi \quad \Phi$ фepmb

$\mathrm{y}$

$\mathbf{X} \quad \mathbf{x} \quad \mathscr{X} \quad \mathbf{X}$ क $p$

щ у $щ$ щи

$\mathbf{4}$

Y

4

Червь

III III III III

щ य щ Ща

$\begin{array}{llll}\mathbf{b} & \mathbf{b} & \boldsymbol{b} & \mathbf{E} \mathrm{pb}\end{array}$

bl bl bi Ephr

b $\mathbf{b}$ Е

b b 8 Яmb

э 9

10

9

Э

Я

$\mathrm{x}_{\mathrm{w}}-$

$\Psi$

$\psi$

$\boldsymbol{\Theta}$

$\boldsymbol{v}$

$\theta$

$r \quad r$

10

1

A

Xur

IIch

OиIma

Vzuyza

Pof́i

$\mathfrak{R}_{j} \mathfrak{i}$

Elomo

Sroerbo

$\mathfrak{j e}$

$\mathfrak{u}$

Fert

Ehjer

$\mathbf{B} \mathbf{i}$

T他erwo

Sda

Sditrida

Jerr

Jern

Jer

Jat

F

Эu

গa

Rfi

$\mathfrak{P} \mathbb{i}$

Sita

Jifiza

\$. 2 


\section{2on Den Buథfaben.}

\section{2.}

Folgenbe $\mathfrak{B u d}$ )ftaben baben einen gleid)en Saut, als S unb 3; $\gamma$ unb Y; Kunb i; $\Theta$ unb $\Phi$. Man bat aber einen jeben berfelben bier im $\mathfrak{A l}_{1}$ phabete ben befgalten roollen: theils weil fie in ge. brudten, befonbers in Rirdenbidgern unterfdics ben werben; theils weil fie in alten Buddern unb auf alten Münzen Zab̨len bebeuten, uno man fie alfo nothroendig fennen mus. Das $\gamma$ wirb im ḩeutigen Druafe nia)t meø̧r gebraud)t. Das i wirb gefest, wenn bas a meb̨r malen auf ein. anber folget, als: вb ученіи, вb показа. нї an fatt вb ученик, вb показаник. $\Phi$ unb $\theta$ merben wie bas beutfde $\mathfrak{f}$ ausgefpro. den; allein leşteres wirb nur in $\mathfrak{B o ̀ r t e r n}$ griecti. faen Uriprungs gebraudst, und bertritt bie Stelle bes griedifden 9 . Das 3 tann man im ruffifden alphabete gleidffalls nid)t auslaffen: benn ba bas $\mathbf{E}$ unb bas $\mathbf{b}$ am Infange einet Solbe mie je ausgefproden merben, o. F. Ecmb lief jeft; fo brauden bie Ruffen bies 3 in manden eigenen fo moh̨l, als bauptfädlid in fremben $\mathfrak{W} \delta$ rtern, bie fid mit einem an. fangen, uno wo baffelbe nid)t wie je ausgeforoden werben muß, 子. F. Эmomb Эma Эmo biefer, biefe, biefes, ließ Etot, Eta, Eto, EAez6yprb liept man JeDenburg; regen ber ridtigen

$$
\mathcal{X} 2 \text { Xubs }
$$




\section{4 \\ Erfter $\mathfrak{A} \mathfrak{b}$; מ́nitt,}

Xusfprade muв es alfo Эденбургb gefdrie: ben merben. Emba, ein flußs im orenburg: fahen Boubernement, wirb Эм6a gefdrieben; (wie aus ben neueften ruffiften $\mathfrak{B u}$ úd)ern ju er: fehen) in einer gewiffen neuern landdarte aber Pelget Emba five Fैemba, weldjes eben fo peltfam ift, als wenn ein ruffifider Erobefdreiber fegen wollte: Hamburg five Gambusg. Man fief̧et alfo, wie vielen Unridtigfeiten ourd Benbeţals tung biefes Budfftabens vorgebeuget wirb.

\section{\$. 3.}

2 witb ausgeiproden, wie im beutfdent a

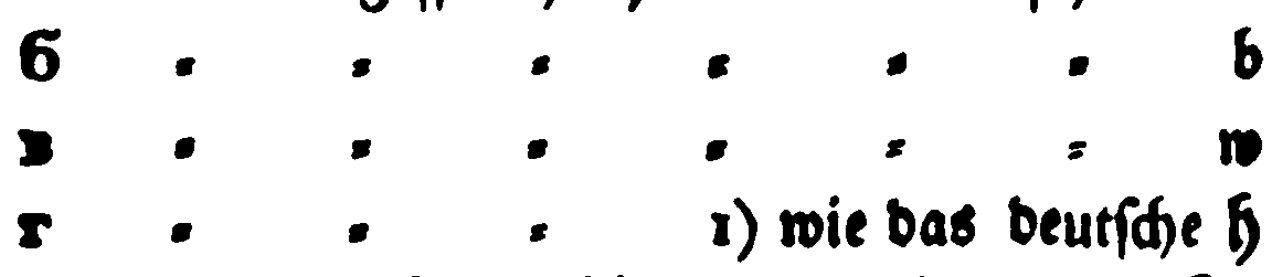
in ben cafibus obliquis bes Borts 6orb. als 6ora, 6ory, 6oromb, 6orx, 6orosb; ließs bofa, bofu, bobom, bohi, boforw; wie aud in ben 2 dbftammungen unb jufam. men gefegten 2 dortern von rocno $\not b$, rлacb,

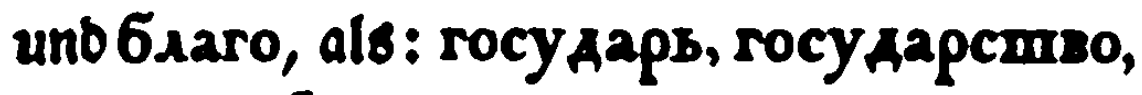
господины, господсшиуго, разгла. mаю, 6лагодашы, 6латословля1о, 6ла. rosapro u. f. m. ließ bofudar, bofudar. frwo, bofpobin. u. f. ro. 2) am Enbe eines Borts wie $f$, als apyrb ließ brul. 3) wie $\Phi$, in 6orb, 20D); Desgleiden in frem: 


\section{Boll Den Buctifaben.}

5

ben Woirtern, bie fid auf yprb enben, als: Mapбyprb ließ פDlarburd).

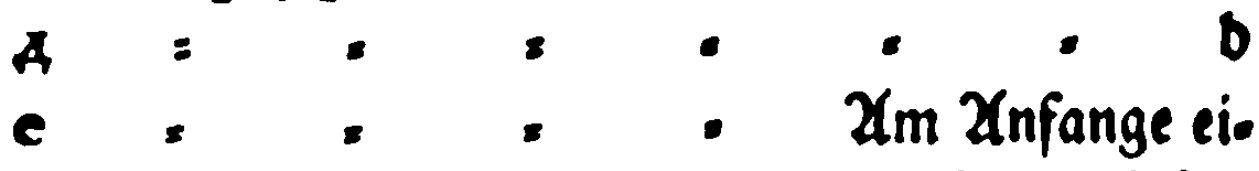

ner jeben Sylbe wie je, als ecmb ließ jefm. 2) In ber Mitte witb es in nadffegenden Wöttern roie 1ô ausgefprodien, fo baß bas i wenig, bas o aber befto meģr ju f̧dren ift: mрехb, sезешb, огнемb, несb, версmb, 6реsнa; ließ triod), wefiof(t), ogniom, nioz, wiorft, briowna. In ben Diminutivis auf exb, als: Kyлexb, Яkopexb, ließ Suliol, Iatoriof. 3) In folgenden

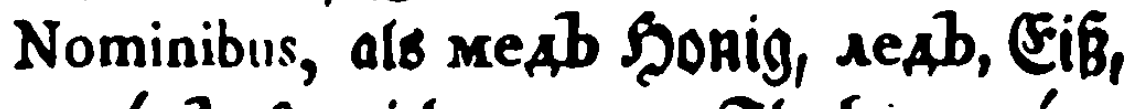

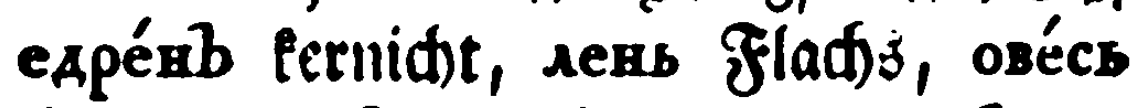
Şaber, necb ein Şund, nepćmb ber Finger, necmpb bund, fitectint, memb warn, mеменb ounfel, Петрb $\mathfrak{P}$ es ter, Өедорb Theodor, се́менb Simon, wirb bas $(\xi$, weld)es ben Xccent hat, wie 1ô ausgefprodien als: miod, owiob, liod u. f. w. 4) zинmbe Dab ('efell, коnbè ein Spieß, мoe, mein, пprémb der Empfang, mbémb, wir níben, exbxa eine tleine Tanne, exbb ein Stweins igel, ließ Sthitio, Sopjo, Mojo, Prijom, Sdjom, Jolte, Jold.

$$
\mathfrak{X}_{3}
$$


6

x ift viel weider als bas beutfafe Sth, unb wirb ausgefprodjen wie bas franjöfifhe $g$ in Général, gélé.

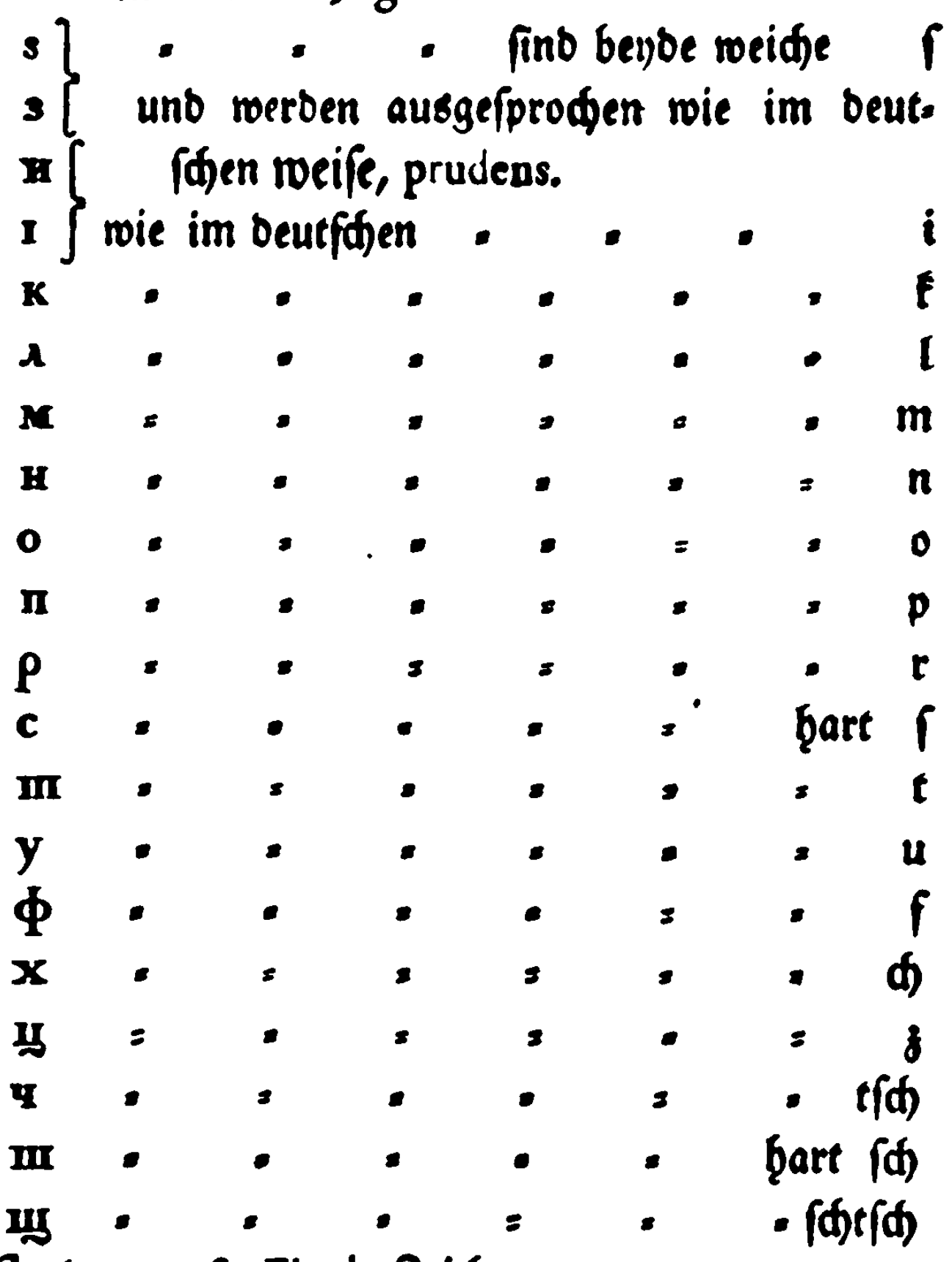

b bas große Final-Zeiden

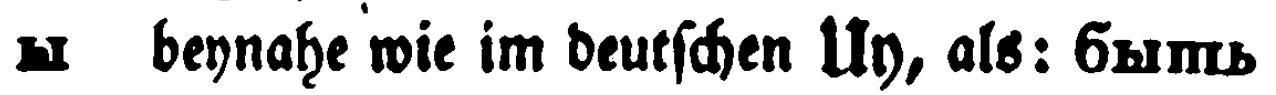
ließ Bunt, fo baß biefe benden Vocales gleidfam jufammen fajmelzen.

gleid)= 


\section{Don DenßBudftaben.}

b Flein Final 3eiden (

b $=\quad=$ ju Xnfange einer Enlbe wie je, als: bay ließ jeou; in ber Mitte und am Enbe einer Solbe roie bey ben franjofen Das é in parlés.

3. - mile,.. e

(*) Son biefen besben Jinalgeiden ift gu merlen,

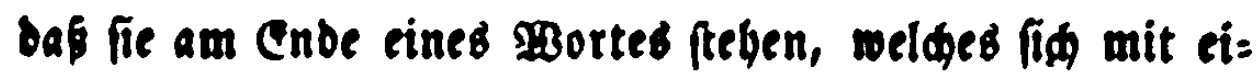
nem Confonante endet, alb: $\mathbf{x} \mathbf{\lambda} \mathbf{6 b}, 6$ pamb. Der Entswed ber Erfinbung berfelben ift robl bey ben Alten gesvefen, um ben Enbigungblaut anjnzeigen. Das großje Finalgeiden bemertet eine barte, und bas tleine eine ge: linbe Endigung. Alle Infinitivi baben am ende ein llei= nes Jinalgeiden als גю6иmb lieben, jum unterídiebe ber britten Perfon Singularis Prxentis онb 1 ко $6 \mathbf{m m b}$, er liebet. Im erfien falle ift bie enbigung gelinbe, bas II fomelst gleidfam mit bem vorbergebenden Vocali su= fammen; im lektern falle ift fie bart, unb das u weniger 3u bören. Diefen verfaicbencn Qaut finbet man aud im Deutfden in ben 230 rteen Dnd, Bon; 2 Bobl, Eobn; bie beyben eritern baben eine barte, lektere aber eine gelinbe Enoung, und mübten im Rusfifien alfo gefdrieben merben: дахb, фонb; воль, сонь. Diefe fi= nalgeiden fteben aud bisweilen in ber MRitte cines $\$$ unb swar nad einem Confonante unb vor cinem Vocali, sum zetden, baß ber folgende Vocalis mit einem i aus: 
- - 3u Xnfange einer Enlbe uno nad) einem Vocali wie ju in Jugeno; nad einem Coufonante aber als ein jufammen. gefdemolzenes iu, fo daßz das $i$ nur gang wenig zu ḩoren.

* - $\quad$ Zu 2unfange einer Gnlbe gans fare wie ja in Jago; in ber Mitte uno nad einem Confonans, als ein jufammen gez fajmoljenes in to Dak bas i faft nidtt gu b̧dren (*)

\section{$\Xi$}

sepprodex wetben mul, alb: ombbxamb thef ots jedbat, ni(t) osed)at; nbю lief pju nidt piu; nbsнын liés pjaun. Das b rebet jwifden aweenen Confonantibus, zum seiden, Daßs ber vorbergebende Confo. nans gefinde ausgefproden meetben muf. Die Deutíden

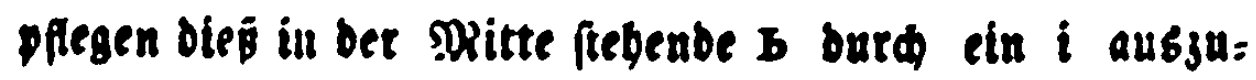

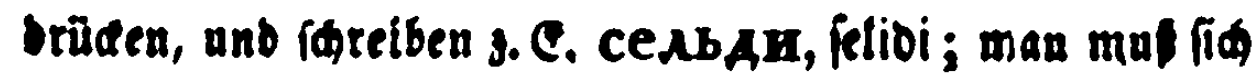
aber bilten, das i ju viel boben za lafere. Die ganj ge; linde ausipratide bes vor been b fiebenden Confonantis läft foon ein $i$ unvermertit unterfiefien.

(") Die tedte uab reine Xusfprade bes 10 wab bes $\Omega$, benu fie cinea Confonanten vor fí baben, fallt einem

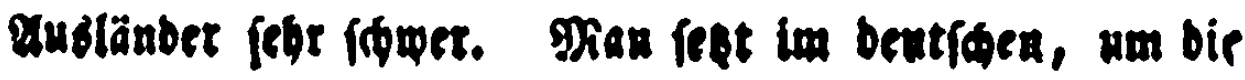
wats 


\section{Bon Den Budftaben.}

$\xi$ wie

$\psi=$

- =

$\checkmark=\cdot$

$\begin{array}{ll}-\quad & -\end{array}$

$\boldsymbol{F}$

$p$ f

wirb in Bortern gebraudft, bie griedifden Uriprungs fino, und in biefer Epradte ein $\vartheta$ baben; im Piuffirfen wirb es wie $f$ gelefen.

Ift bas griediffae ypfillon; wirb aber im ḩeutigen Druafe uno im Sarreiben gar nidt gebraudt.

6. 4.

Die Cintbeilung ber $\mathfrak{B}$ udffiaben in Voca. les uno Confonantes ift aus allen Grammatifen betannt. Tas b und b baben feinen Saut, und find ftumme Budffaben.

$$
\text { 6. } 5 \text {. }
$$

In $\mathfrak{A}$ bfidt ber $\mathfrak{R e d} t\{d$ reibung ber ruffi:

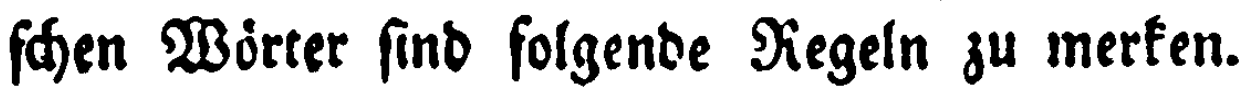

$$
x_{5} \text { 1) Die }
$$

aussprade anjujeigen, ein $t$ vor bem 4 nub $a$, alb люблко liubliu, меня menin; allein in ber $\mathfrak{A n} b=$ fprade ift bas $i$, befonders bey bew $A$, wobl febe wenig zu bören. Die Bunge muk von Jugeno auf gu ber 2us= fprade biefer Budftaben gewöbut fegn; Diegeln belfen vier nidt viel. Diefe Budfitaben fino bas wabte Sdibo= let in ber rufirifden Speade. 
1) Die fremben $\mathfrak{B}$ òrter werben im Ruffifaen, fo viel bie Natur biefer Spractie zuläjt, fo geo fdrieben, wie man fie in ber fremben Spradse aus!pridt, f. F. Bourdeaux fapreibe бypдo. In ben baraus gemadten $\Lambda$ djectivis unb anbern Derivativis aber múffen bie Etammbudfftaben

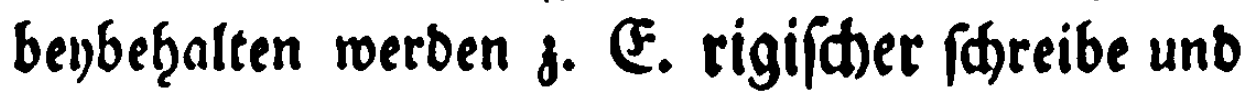
ließz purckoи und nid)t puжcкоn, weil bie Etabt Riga uno nidte Rijcha bqeift. Hmasuaнenb und aзkamrenb ift unredt, uno muß ge: fdrieben werden: итаниянецb, азиятецb; meil bie Ctammmorter nтrasия und aзїя heißen. Es fỏnnen aus bem unridtigen Sdreiben viele Berwirrungen entfteţen. 2) Nad Der mofcauifden Mundart wiro bas $O$ wenn

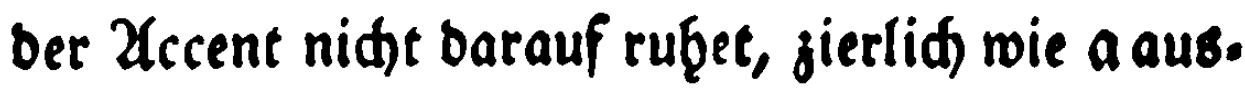
gefprodien, als: rоворю mirb ausgefproden гаварю; хочу. хачу. Man muß aber im Edsreiben feinesweges biefes a mit bem o ber. medffe(n. 3) Der roahre Bebraud bes e und b ift roobl ju unter/deiben. Man tann zwar Eeine eigentlide $\Re$ egeln angeben, in reeld)en Jälo len bas $\mathbf{b}$ und roo $\mathbf{E}$ feteren muß; auffer baß in ben cafibus ber Declinationen ein $\bar{b}$ erfobert mirb, ausgenommen biejenigen $\mathfrak{Z} B$ öter, bie fí im Nominativo auf ie enben; ingmifden iff ber unterfdieb aus fleifigem unb aufmerffamen

Sefen 
Sefen leiфt zu erleenen. Man muß aber biefe ben. ben Budffaben nid)t mit einander verwedffeln, weil fie bie berfdjeone $\mathfrak{B}$ ebeutung mander $ß o r$. ter von einer(el) Xusfprad)e anjeigen, als : ^ey i(t) fliege, abyy id beile; пеню̀ die Strafe,

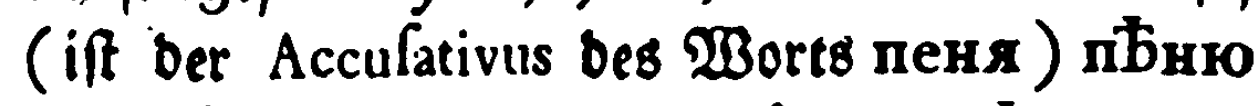
i( ) (đ)állme; neньe die Stámme, nłbue Daß̉ Singen; пленb (Gen. Plur. Des ßorts пле́на die Spalte) плђнb die Sefangen= (đ)ait, 2c. 4) פuk man die Vocales $E$ und $\mathbf{H}$ nid)t mit einanber berwedffeln, und fatt ma. ленькой, малинькой; ftatt хорошенькой, хорошинкой (đ)reiben; wie benn überḩaupt Das a Der Natur ber ruffifaten Sprade zumiber ift: Dahero aud baffelbe in bem Pral. Infinit. und in ber Secunda Perfona Sing. Praf. fojon làngft nid)t meḩr gebraud)t, uno fatt yвmamn, yиmaemи, anjeg̨t yиmamb, yиmaemb ges fdrieben wirb. Zud ift es unridtig, wenn man heutiges Tages in ben Nominibus Subft. gen. neutr. im Nom. Accul. uno Vocat. ein an fatt $\boldsymbol{S}$ braudt, uno учрехsденїв fatt учрехвденіз fę̧еt.

\section{6.}

Es laffen fid einige burd) bie Xusfprade bes $\boldsymbol{X}$ roenn es nad einem $C$ ftebget, berleiten, 
12 Crfter $\mathfrak{A}$ bfanitt, v. Den Budttaben.

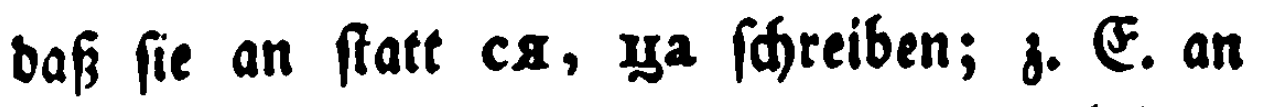
fratt roвopumcs, rosopumma; legtere Sdreeibart ift bem Gebraudfe entgegen, of fie gleid ber Zusfpradie nảger fommen moggte.

\section{\$. 7 .}

Dießß wären alfo bie Şauptregeln, bie man bey ber ruffifden Redtefdreibung ju bemer. fen hat. Das übrige faß̧t bas Bebädtniß

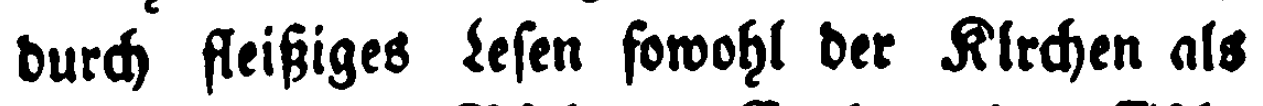
anberer neuern Büder. Es hat bie rufififase

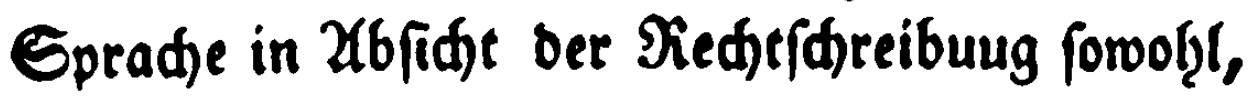
als andern $\mathfrak{A b}$ weidungen, unenolid) weniger Edwierigfeiten, als andere, befonbers bie beuts fade Sprade); und bennod lernt man im Deuts fihen burd. Zufmerffamteit benm lefen orbentlid gefdriebener Büdjer red) fadreiben, ob̧ne fíd mit vielen Regeln zu quảlen.

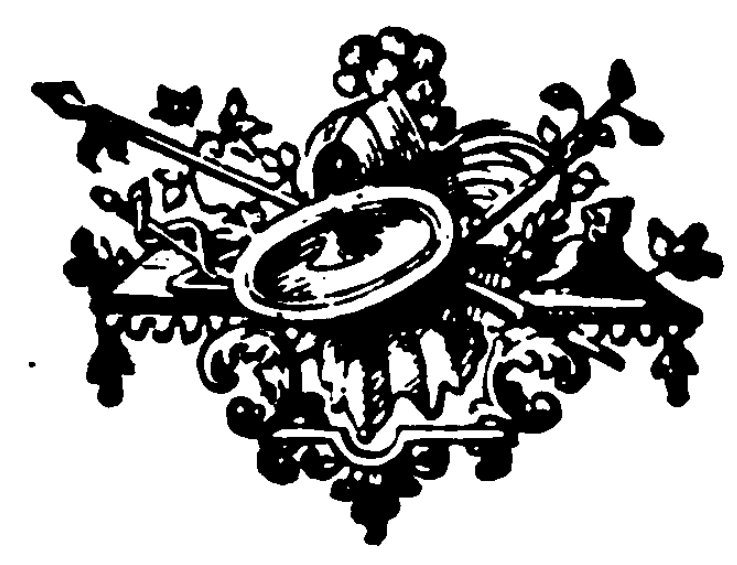

Der 


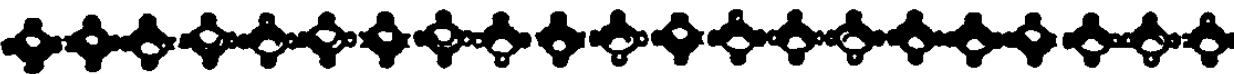

\section{Der zwente $\mathfrak{A}(\mathfrak{G} \mathfrak{d} \mathfrak{d}$ nitt. Bon Den Nominibus.}

\section{Dả erfite Sauptituidé.}

Bon Den Gef(tedten, unl wie aus bem Mafculino ein Fœmininum gemadt) wird.

$$
\text { Si } 8 .
$$

Das Genus ber ruffiffen Nominum if vieterley, nàmlid): Mafculinum, Fomininum, Neutrum, uno Commune.

$$
\text { ๑. } 9 .
$$

Generis Mafc. fint bie Namen ber Mano ner, ber mánnliden Xemter, ber Monate, uno Der $\mathfrak{B o i t t e r , ~ b i e ~ a u f ~ e i n ~} \mathbf{b}$, Genitivo s bat, ausgeţen, als: Buxhma,

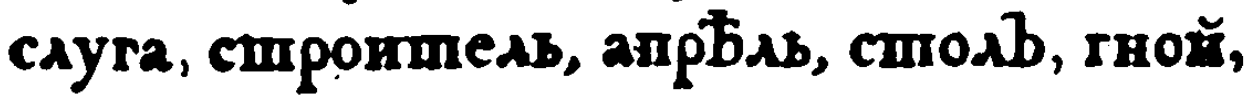
rzosAs.

$$
\text { 6. } 10 .
$$

Farninina find bie Namen ber Frauen, unb beren Debienungen; besgleiden ber länber, unb alle Wörter, fo fid auf a und $s$, weldees 


\section{4 \\ 3wenter $\mathfrak{A} 6$ fđnitt,}

fein $x$ vor fid bुat, imgleiden auf $b$, bas im Genitivo и b̧at, enden, als: Еле́на, пова́pzха, Гишпа́нїя, Россїя, $\lambda$ пфяя́ ндїя, Полша, вода̀, землs̀. Nan nę̧me aus пупь die Reife, weldes $\mathfrak{B}$ ort generis Mafculini ift, ob es gleid) im Genitivo n ḩat; AeHb ḩat $r$ und $\mathbf{n}$, obgleid) gewoobzhlider $\pi$.

\section{§. II.}

Neutrius Generis finb bie Verba, Adverbia unb eine jebe ganje Rebe, fo an fatt einer Sub. Atantivi gebraudte wirb; wie nid)t weniger bie Worter, to auf e, o, und mr ausgeţen, als:

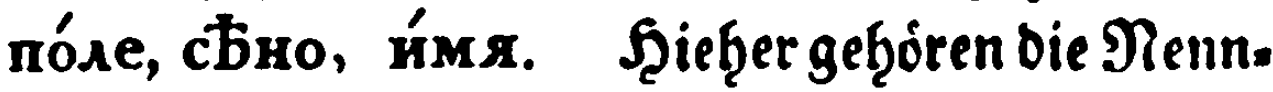
wörter junger lebenbiger Đef đojpfe, 'als: méss Daz Salb, wérs ein Stiegeliz, aúms,

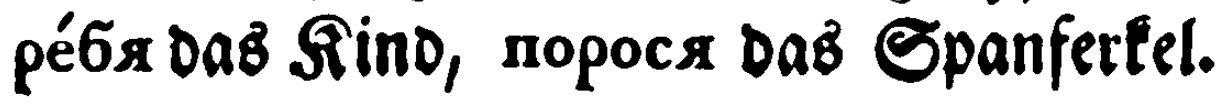

\section{12.}

Generis Communis fint alle Subfantiva, bie nur in ber vielfad)en Bab̧l gebraudft merben, als mmaнh' die Sofen, вилы die Miftga. bel.

$$
\text { 6. } 13 .
$$

Beiblide bon mannlidien abftammente Benennungen enben fid meģrenţgeils auf $\mathrm{xa}$, 


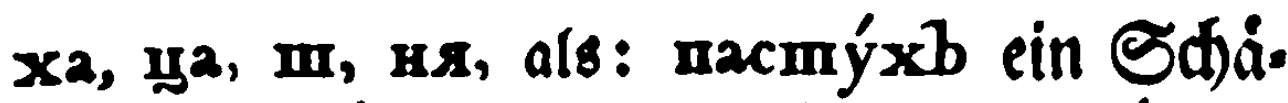
fer, macmýmka eine Sđáferinn; wórosb ein Stukzer, meroxḱxa eine Stukzerinn;

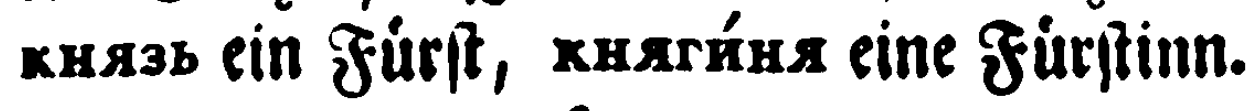

$$
\text { 6. } 14 .
$$

Ruffifde Namen, welder Bürben, Zemter

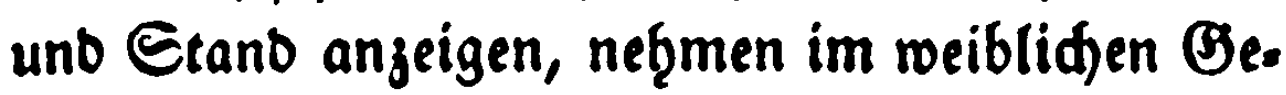
fdiledte meţrenţgeils bie Enbung ya an, als: пари́́у eine Barinn, полко́вница eine

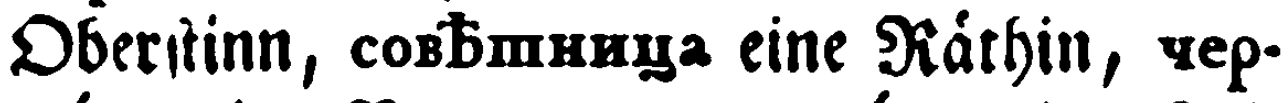

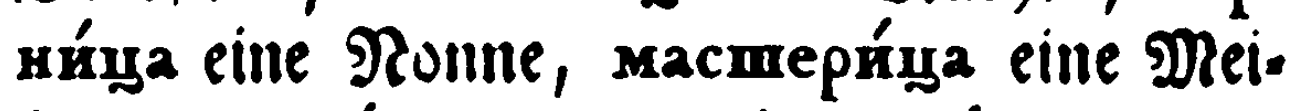
fterinn, mánomниyа eine Míkzenmache: rini, хле6ни́uza eine Brodbáferinn, nopóz. Hиya eine Siud)enbáterinn, mpomonómuya eine Erzpriefterb̧rau, Аья́коница eine Diatons Frau, nономари́ya eine Siujfteriun, ausgenommen nonaabs̆ eine Prie. fterb̧rau.

$$
\text { 6. } 15 .
$$

Srembe Benennungen von Xemtern und Etano bुaben im meibliden Befdledte bie En. bung ma, als: фелsbmapmasma eille $\mathfrak{F}$ elo. marfd)allinn, генеральша eine Beneralinil, гофмейстерша, бригадирига, капитан-

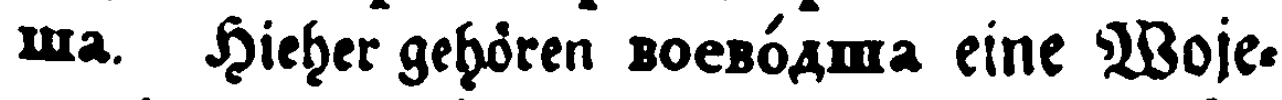
wodinn, uno yripasumeswa cine 2Amtmán. ninn.

§. 16. 
16

§. 16.

Die meiblitien Namen auf $x a$, weldse bon ben mänliden abftammen, baben eine etras verid)tlidje Bebeutung, als : noroגs, weroג xa eine Otuz̧erinn, qecночúxa eine bie Sinoblaud) bertauft.

$$
\text { §. } 17 .
$$

Die Namen ber Thiere, Bògel, Fiftae, uno bes Ungejiefers bringen nur wenige $\mathfrak{B}_{e s}$ nennungen im weibliden (Befdhled)te burd) $\mathfrak{B e r}$ änderung ber Enbungen beroor. Diefe fino folgenbe: opésb ein ^oler, орли́ña; волкb

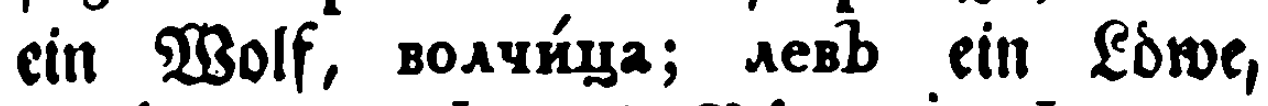

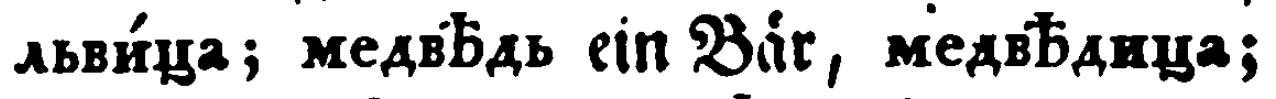
3мb̆̌ eine Sdulange, змbr. Die mę̧reften weiblidjen ḩaben meiftens ifpre eignen Renn. worter, als: конь ein $\mathfrak{P}$ ferd, кобтra eine

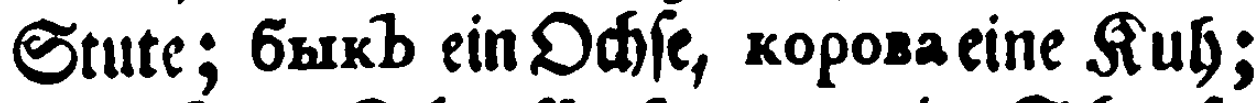
баранb ein St)aafbod, osya ein Sd)aaf; nЂmýxb ein Şabn, xýprya eine Şenne; ко6ess ein Şund, cýxa eilue Şundinn.

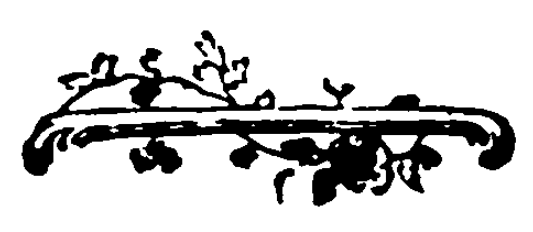

Das 


\section{Bon Den Nominibus.}

\section{Das̉ zmente Scauptitúc์. \\ Boll Den Declinationen.}

$$
\text { ๑. } 18 .
$$

Es find in ber ruffifden Sprade fünf Declinationes, vier bon ben Subftantivis, uno eine bon ben Adjectivis.

$$
\text { 5. } 19 .
$$

Ueberḩaupt ift von allen Declinationen zu merfen, baß

1) in ber ruffifofen Grammatif zroeen Ablativi fino, nämlid Infrumentalis uno Narrativus. Man bुat biefen Unterfacio aud) im Latcini. fhen, obgleid bie Enbungen in benden Fällen gleid fino, als: Cxeditur virga, baculo, pugnis, ift ber Infrumentalis; ivi cum patre, ber Narrativus.

2) Daf ber Vocativus in benben Numeris bem Nominativo gleid fen; ausgenommen in ben felaboniffen, und aus bem felavonifden benbes baltenen Wörtern, in weldeen ber Vocativus biswellen bon bem Nominativo unterfafieben ift, als yчителко fatt учитель, жено ftatt жена, хрисше fatt христосb, боже 


\section{8}

\section{3wevter Sab/onitt,}

ftatt 6orb, yesosbue ftatt yesosbxb, incyce ftatt incycb, u. a. m.

3) Daß ber Accufativus Subfantivorum, Desgleidfen ber Adjectivorum bie fubftantive ge: braudit werben, in belsben Numeris von beleb. ten Dingen bem Genitivo, von leblofen aber bem Nominativo gleid) ift, (ausgenommen bie Namen junger lebenbiger Befdöpfe auf $r$ als жxepe6sì bas Jüllen, ben welden ber Accufativus in benben Numeris mit bem Nominativo übereinf́smmt; besgleiden ben Sing. ber erften und britten Declination, wo ber Accufativus in ber erften Declination feine eigene Enbung ḩat, unt in ber britten bem Nominativo gleid) iff) als кynúmb nomb, ein ḩaus taufen; noपrmámb роди́meseй, bie Zelteen ę̧ren; вй6ранипь слугу̀, ben Diener aus/कelten; свяmbíxb, Der Şeiligen und die Şelligen. Dies verftehet fid) aud) in bem Falle, wenn SubAntiva leblofer Dinge in bem Berftande ge: braudte werben, baßj fie belebte Dinge anjei= gen, als посмотри на болва́на, fief̧ biefen Sloģ an; нашего мbшка̀ обманули, man ḩat unfern ₹ỏlpel angefüb̨ret. Wenn mit Dem Subftantivo ein Adjectivum ober Pronomen confruiret wirb, fo nef̧men biefelben ben calum an, Darinnen bas Subftantivum ftę̧et, nad) ber

befann. 
befannten grammatifalifhen Regel: Das $\Lambda d$ jectivum formmt mit feinem Subltantivo in gleis dem Genere, Numero und Cafu überein; als:

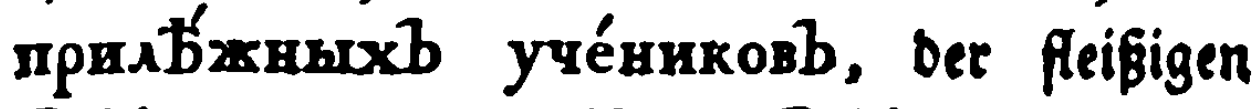
Squuler, unb bie fleißigen Sdúler.

$$
\text { §. } 20 .
$$

Die erfte Declination byat zroo Enbungen

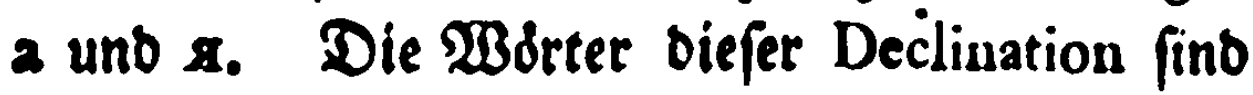
Generis Fominini, ausgenommen bie Namen ber Männer, als: cayrà ber Diener, AяAя Der Dheim.

\section{Safel ber exften Declination auf $\boldsymbol{a}_{\text {, }}$}

Singularis.

Nom. 2

Gen. br ober $\mathbf{a}$

Dat. $\boldsymbol{b}$

Acc. $y$

Voc. 2

Infr. oro ober ox̌

Narr. $\boldsymbol{b}$

\section{Pluralis.}

sir ober $\mathrm{x}$

b

amb

b, br ober a

br ober $x$

and

$2 \times 3$.

B2

Singu- 
Singularis.

Nom. pyxà bie ફ̧añ ,

Gen. pyкѝ ber গ̧ando,

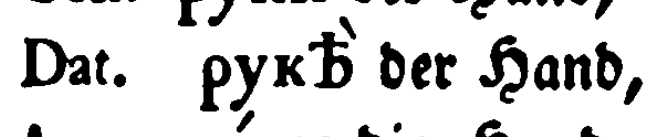

Acc. pýкy bie Şant,

Voc. pyкà Şand,

Inftr. pуко́ю ober pyкóŭ mit ber Şanb,

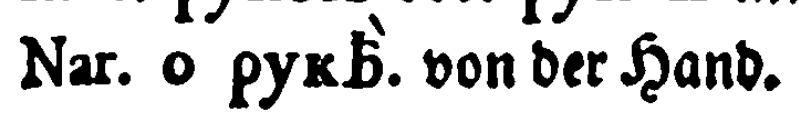

\section{Pluralis.}

Nom. pýku bie Şänbe,

Gen. pýkb ber Şänoe,

Dat. pyкámb ben f̧änden,

Acc. pýkr die Şänbe,

Voc. pýкu f̧ànoe,

Inftr. pyкámu mit ben Şänden,

Nar. o pyxáxb bon ben łänden.

\section{Singularis.}

Nom. Hз6à bie Etube,

Gen. I36hì ber Stube,

Dat. nзбbे ber Stube,

Acc. и́з $5 y$ bie Stube,

Voc. nз6à Grube,

Inft. из6о́ю оber избóй mit ber Etube,

Nar. o избb́ yon ber Stube. 
Pluralis.

Nom. й36r bie Stuben,

Gen. ŕs6b ber Stuben,

Dat. nз6ámb ben Gtuben,

Acc. йзбы Die Stuben,

Voc. и́збы Єtuben,

Inft. изба́мn mit ben Stuben,

Narr. o nзбáxb von ben Stuben.

$$
\text { §. } 21 .
$$

Tafel Der erften Declination auf $\pi$. Singularis.

Nom. $r$

$\mathbf{I}$

Gen. $\mathbf{x}$

b

Dat. $\mathbf{b}$

smb

Accuf. юо

b ober $\mathbf{n}$

Voc. $\pi$

$\boldsymbol{L}$

Infr. eю ober eй

ЯMH

Nar. $\mathbf{b}$

axb

Singularis.

Nom. княти́ня ठie Fürftinn,

Gen. княти́ни Der Sürftinn,

Dat. княги́ib ber Fürftinn,

Acc. княти́ню ठie Sürftinn,

Voc. кнхти́ня Jürftinn,

Inft. княги́неюо ober княги́ней mit

Der Fürftinn,

Nar. O kHяrúrb von ber Jürftinn.

$$
\mathfrak{B}_{3} \text { Plo. }
$$




\section{Pluralis.}

Nom. хняги́нв Die fürftinnen,

Gen. княги́нь ber Súrftinnen,

Dat. княти́нямb Der Jürftinnen,

Acc. княги́нь Die Fürftinnen,

Voc. княги́ни §ürffinnen,

Inftr. княги́нями mit ben Sürftinnen,

Nar. о княги́няхb von ben Jürfinnen.

\section{Singularis.}

Nom. nycmírur bie $\mathfrak{B u f f t e}$

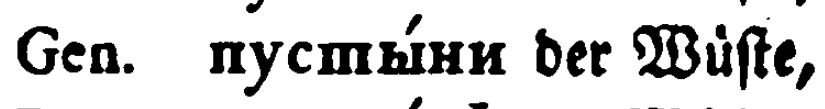

Dat. nycmírb ber 23 úfte,

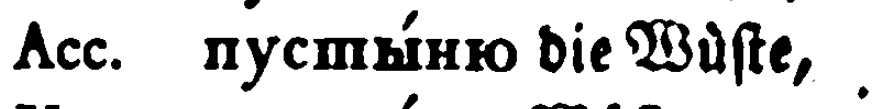

Voc. nycmbíн $\mathfrak{B u i f t e , ~}$

Inftr. пуспи́нею ober nyсmь́́ней mit

Der $\mathfrak{B u}$ úte,

Nar. o nycmbírb bon ber $\mathfrak{B} u \dot{f t e}$.

$$
\text { Pluralis. }
$$

Nom. nycmín bie æuiften,

Gen. пусmъ́́н ber 2 úften,

Dat. пусmи́нямb ber $\mathfrak{B u f f t e n , ~}$

Acc. nycmbíhn bie $\mathfrak{B u ̈ f t e n , ~}$

Voc. nycmhím $\mathfrak{B}$ úften,

Inftr. mycmb́нями mit ben $\mathfrak{B u ̈ f t e n , ~}$

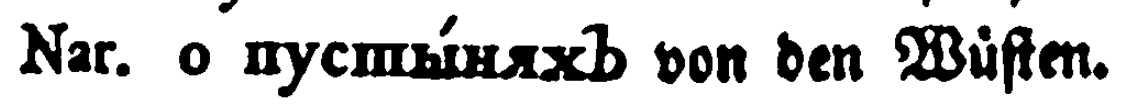




\section{Bon Den Nominibus.}

\section{§. 22.}

Bey oer erfen Declination find folgenbe segeln zu merfen.

1) Die $\mathfrak{B}$ orter, bie im Nominativo Sing. ouf ra, zsa, ka, xa, ya uno ma ausge: ben, baben im Genit. fing. unb im Nom. plur. an fatt hr allemal $n$, als Horà Der $\mathfrak{F} u \hat{\beta}$, Horh̀

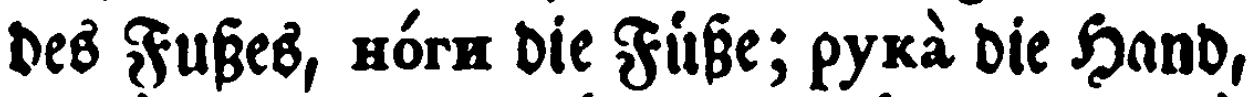
pyкǹ der Sand, pýkn die Şánde; 6roxà

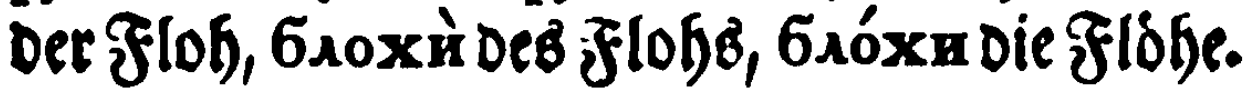

2) Der Genitivus Pluralis wirb gemeiniglid burd) Begwerfung bes $\mathfrak{B u d f f t a b e n s} a$ und $\pi$ im Nom. Sing. gemadt, als nз6à bie Etube, из6b; Княги́ня, Княги́шв. Erftere ба: ben ein b, und leģtere ein b. Injwifaten finb bierbon alle biejenigen Subftantiva ausgenom. men, bie fid) auf ein $k$ enden, und bor biefer Sylbe einen fummen $B$ udfftaben haben, in welo Gem falle vor bem $k$ ein o einge(d)altet wirb, als: Impy6ка eine $\mathfrak{P}$ feife, mpy6okb; дbва

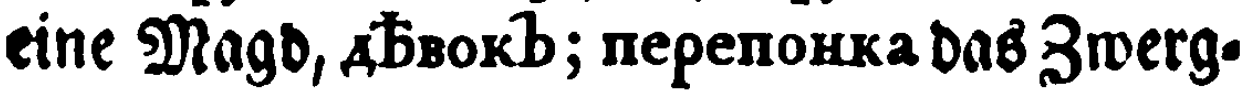
fell, nерепонокb. Wenn aber vor bem Iç̧ten кa ein 2,4 , II unb us ftefget, fo wirb an fatt bes o ein e gefesct, als: 6очкa ein $\mathfrak{F} u \mathfrak{B}$, бочекb; пуmка cine Canone, пymeкb.

3) Wenn vor bem legeten Confonante ein $\mathbf{n}$ - ber $\mathbf{b}$ ftebet, fo werben biefe in e verwandelt, 


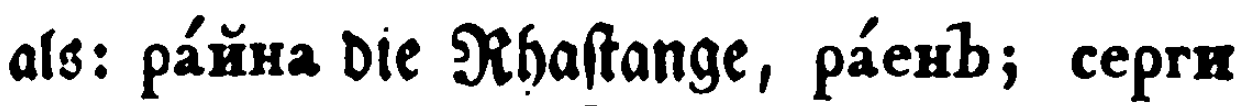
ein Dhrring, ceperb; גsouka ene $\mathfrak{B}$ iege, srosexb.

4) Ben ben $\mathfrak{B} B$ ittern, bie bor ber Ens bung 2 und a groeen confonanites ḩaben, ba.

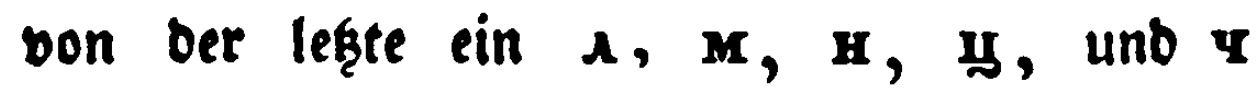
iff, miro im Genit. plur. gmifden benden confo. nantibus ein e gefegt, als: землй die Erde, зе́мель; овца̀ Daв Sđjaaf, ове́ıb; епанyà der Dhantrel, епане́ub. EGen bieß̉ ver. ftegenet fich aud in Dem Falle, menn zwifhen benben confonantibus ein $b$ ftegret, als weldhes in e verwandelt mirb, als: ня́нька bie Rin= Dermago gen. plur. ни́некb.

5) Die $\mathfrak{B o s t t e r , ~ f o ~ a u f ~ ж a , ~ 4 a , ~ m a , ~}$ und ya ausgergen, imgleiden biejenigen, bie yor bem $r$ ein $b$ ober einen Vocalem haben, nef̧men in Genitivo plur. bie Enoung eй an, als: Ханжа̀ ein Stheinfeiliger, ханже́й;

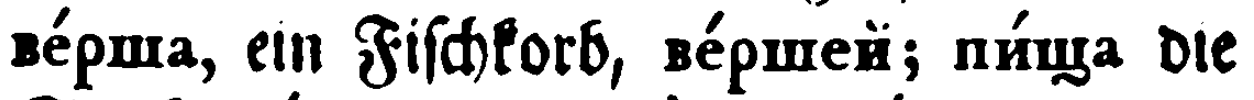
Öвіс, пи́ицей; свиньд̀, свине́й; библія, библей верея еin Thürfooften, верей.

6) $\mathfrak{B o ̈ r t e r}$ bie fid auf a enden, bुaben im Infrumental. ою als : водà dab ঙ̈affer, водо́ю; biejenigen $\mathfrak{B o r t t e r ~ a b e r , ~ b e r e n ~ E n d i . ~}$

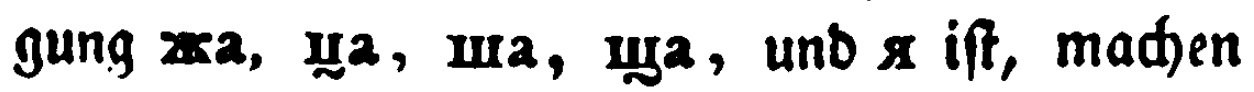
ben Inllrunentalem auf ero als: xoxa bas 


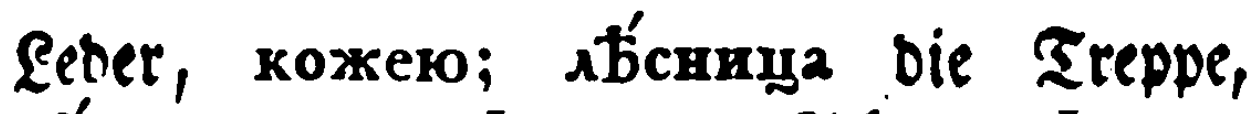

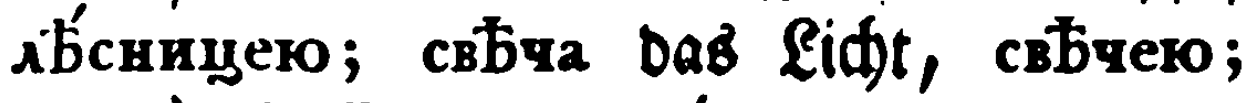
земля̀ die Erde, земле́ю.

\section{§. 23. \\ Don ber zroenten Declination.}

Diefe Declination hat vier Enoungen, nàmlid $b$, e, o, und мr. Die $\mathfrak{B o r t t e r}$ auf b fino generis Mafculini; auf e, o, und m generis Neutrius.

Tafel Der zrwenten Declination. Singularis.

Nom. b e 0 Mr

Gen. 2

2

2

eHr

Dat.

y

y

ени

Acc. $\quad \mathbf{b}, \mathbf{a}$ e

- Mr

Voc. $\mathbf{b}$

e

o

MF

Inftr. oмb emb omb енемb

Nar. $\quad b$

b

b

ени

Pluralis.

Nom. br, a 2

Gen. oBb b

2

ена

Dat. aMb amb amb енамb

Acc. $\mathbf{H}, \mathbf{H}, \mathbf{0 B b}, \mathbf{a}$

a ена

Voc. br, $\mathbf{z}$

2 ена

Iuftr. ámu amp amk eнами

Nar. $\quad 2 \times b$ axb $2 \times b$ eHaxb

B 5

Singu- 
Singularis.

Nom. cmosb ber Tif⿰亻,

Gen. cmosà bes Tiffes,

Dat. cmoxỳ bem ziffie,

Acc. cmosb ben Riff,

Voc. cmosb Tifd,

Inftr. cmoxómb mit bem zifdee,

Nar. o cmost bon bem rifide.

\section{Pluralis.}

Nom. Cmoshì bie Tiffe,

Gen. cmosósb ber Tiffe,

Dat. cmorámb ben riffen,

Acc. cmouni bie ₹ifde,

Voc. cmoshì Siffe,

Inftr. cmosámz mit ben zifósen,

Nax. o cmosáxb von ben Iifden.

\section{Singularis.}

Nom. Aryè bas Befidft,

Gen. Mrnà bes Befidts,

Dat. Aunỳ bem Eefidte,

Acc. Amyè bas Befidit,

Voc. inyè Brefidt,

Inftr. Anyémb mit bem Brefidte,

Nar. O Arubt bon bem Befidete.

Plure 


\section{Pluralis.}

Nom. Anyà bie Brefidter,

Gen. $\lambda$ unb ber Gefidter,

Dat. גmyámb ben Befidtern,

Acc. Anyà bie Bjefidter,

Voc. Anyà Befidter,

Inftr. גnyámu mit ben Befidtern,

Nar. o Anyáxbb bon ben Gefidtern.

\section{Singularis.}

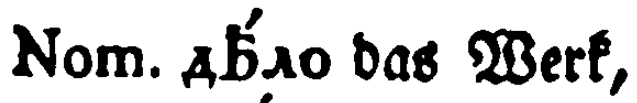

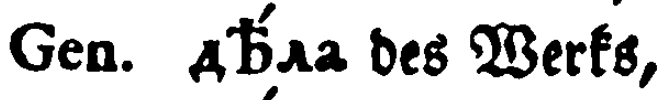

Dat. Ab́ay bem $\mathfrak{B}$ Berfe,

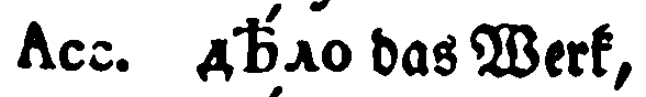

Voc. Ab́,

Inftr. A'́tᄉomb mit bem 2 Berfe,

Nar. o At'Áb von bem $\mathfrak{\text { Berfe. }}$

\section{Pluralis.}

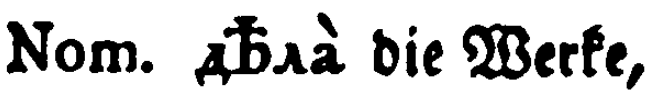

Gen. $A$ $\bar{b} \boldsymbol{A b}$ ber $\mathfrak{B e r f e ,}$

Dat Ärámb ben Berfen,

Acc. Abà bie Berfe,

Voc. Abaà Berte,

Inft. АБАа́ми mit ben $\mathfrak{B}$ erfen,

Nar. o abaáxb von ben 2 Berfen.

Singu- 
Singularis.

Nom. вре́мя die Zeit,

Gen. вре́мяни ber Zeit,

Dat. вре́мяни ber Zeit,

Acc. вре́мя bie Zeit,

Voc. вре́мя Zeit,

$\ln$ tr. вре́менемb mit ber Zeit,

Nar. о вре́мяни von ber Beit.

Pluralis.

Nom. вре́мяна die Zeiten,

Gen. време́нb Der Zetiten,

Dat. времяна́mb ben Zeiten,

Acc. времяна̀ bie 'Zeiten,

Voc. времяня̀ Zeiten,

Jnltr. времяна́ми mit ben Zeiten,

Nar. о времена́xb von ben Zeiten.

$$
\text { §. } 24 .
$$

Die Rennmoirter junger lebensiger Ģe đdip. fe bie fid auf $\pi$, weldses fein $M$ vor fidh hat, enden, find Generis Neutrius, und werben auf folgende $\mathfrak{2}$ ret declinirt.

\section{Singularis.}

Nom. жеребя̀ das filllen,

Gen. жеребя́mи des Fúflens,

Dat. жеребя́mu bem Füllen, 


\section{Boll Den Nominibus.}

Acc. жере6я̀ bas füllen,

Voc. zepe6я̀ füllen,

Infr. жеребя́mемb mit bem füllen,

Nar. o жepe6śmu bon bein Füllen.

Pluralis.

Nom. zepe6я́ma bie füllen,

Gen. xepe6я́mb ber frullen,

Dat. хкеребя́мямb den füllen,

Acc. жеребя́ma bie Füllen,

Voc. жеребя́ma füllen,

Inftr. ххеребя́maми mit ben Füllen,

Nar. 0 жepe6ŕmaxb bon ben füllen.

Xuf gleide Xrt gef̧en mexs̀ bas Ralb, merx ein Stiegeliz̧, nopocs̀ bas Spanfertel, u. a. m. Dod fino biefe $\mathfrak{B}$ drter im Singulari in ben Diminutivis gebràuфlider, als: џуегля́нокb, порося́нохb, пеля́нохb.

$$
\text { 5. } 25 .
$$

Bey ber zwenten Declination find folgenbe Regeln zu merten.

Diejenigen $\mathfrak{B o r t e r}$, bie fid auf $\mathbf{r b}, \mathbf{k b}$, unb $\mathbf{x b}$ enden, baben allemal $\mathbf{z}$ an fatt $\mathbf{b r}$, als pórb Daz Sorn, póm die Sorner; no. póxb Daв Rafter, nopóxn; аухb der Beilf, Aýxa.

5. 26. 


\section{\$. 26.}

Einige $\mathfrak{B} \delta$ rter beränbern im Nom. plur. bas br ober $\mathbf{u}$ in a, als: 6éperb Daz ulfer,

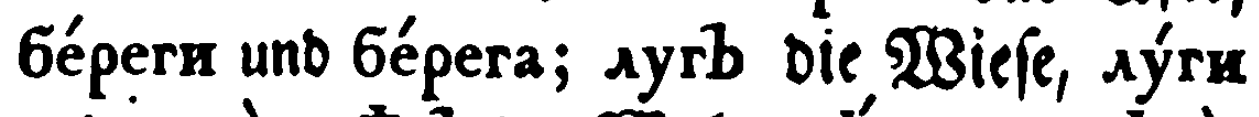

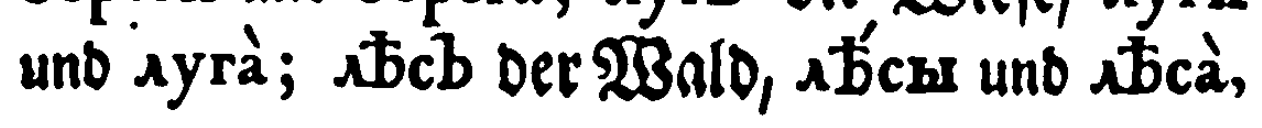
u. a. $\mathfrak{m}$.

\section{§. 27.}

Einige auf $\mathbf{b}$ ausgeg̨ende $\mathfrak{B} \delta$ rter werfen bas e und $O$ in allen Cafibus Obliquis uno burd).

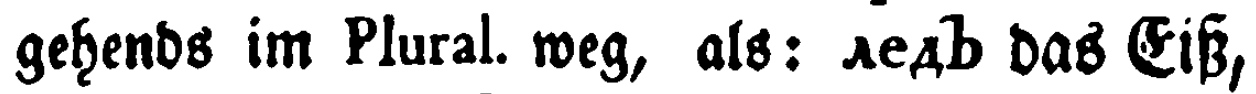
Gen. $\lambda$ Aa; орелb ber $\mathscr{A}$ Dler, орла; овесb

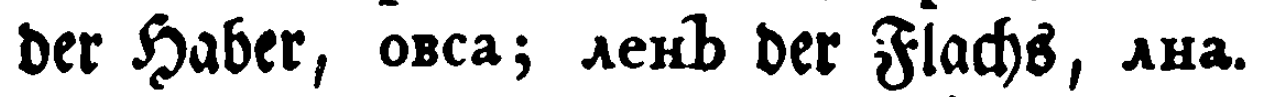
Insbefonbere gefdiefrt bieß̧ nit ben Woirtern auf oxb unb eyb, als: желý докb ber $\mathfrak{M a}$ gen, желу́дка; песо́кb Der S̆ап, песку̀; oméyb oer $\mathfrak{B a t e r , ~ o m y a ̀ ; ~ m в o p e ́ n b ~ D e r ~}$ Sdjópfer, mBopyà. Man neţme aus biejes nigen $\mathfrak{B o r t e r , ~ w e l d j e ~ b u r d ) ~ b a s ~} \mathfrak{B}$ egwerfen bes $e$ unb o viele, unb foldje Confonantes zu: fammen bringen würben, bie ber ruffifden 2lus. fpradpe zumiber finb, als: ymeub ein sefer, nidt ymya, fondern ymena; npowneyb ein Boribergefender, mpomsena; 6oxb die Seite, 6oxa; ómpoxb der Siluabe, ompoка; поро́кb Daв Lafter, niג)t nорка̀, fon. Dern 
bern nорóxa; рокb daż Sđjidłfal, póxa, nid)t pka.

$$
\text { §. } 28 .
$$

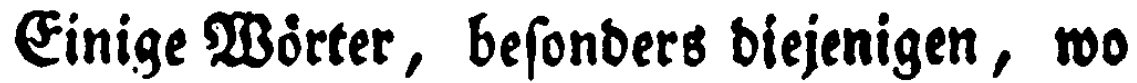
vor e und o zreen Confonantes vorb̧er geţen, beḩalten biefe Vocales, uno fegęen fie im Gen. Plur. zwifhen ben benden Confonantibus, als:

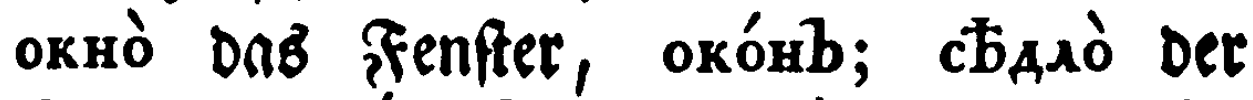

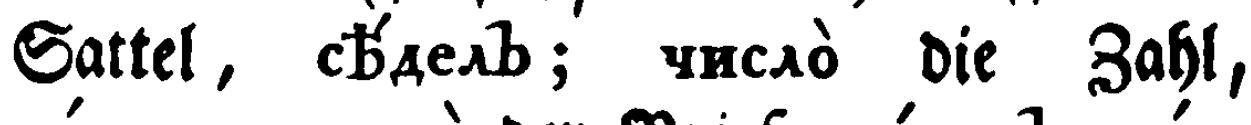
чи́сель; писмо̀ Der Rriff, пи́ceмb; сép-

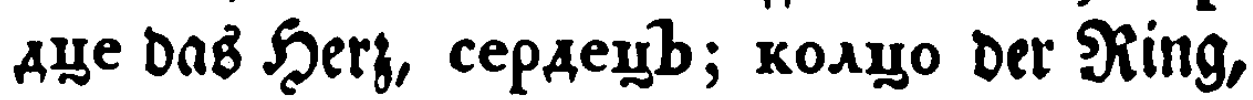
колеub. 2lud wirb ber Gen. plur. in ex vers wanbelt, wenn ber legte confonans ein $\pi$, III, y, ober us iff, als: Hozxb Dab Meffer, ноже́й ; рубе́жb ein Strid, рубе́жей; кирпи́чb ein Biegel, кирпи́чей; харчb Eß̧waaten, харчей; бaphímb oer Eje: winn, 6арь́́ ué́й. Сваmm der Sdwager, hat im Gen. plur. сваппове́й; 6раmb Der ß̉ruber, 6ра́mей; кумb Der Ģevatter, кумовей;

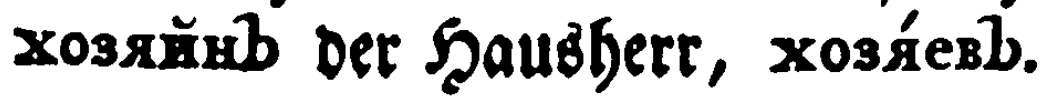

$$
\text { §. } 29 .
$$

Biele Börter biefer Declination bie fid auf ein $\mathbf{b}$ enden, baben im Genitivo fing. ans 
ftatt 2 , und im Narrativo an ffatt $b$ ein $y$, als:

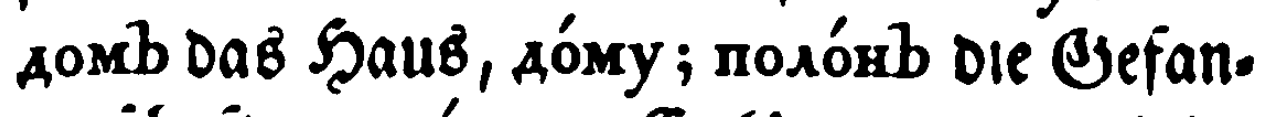
genliकaft, похо́ну. Es fónnten żwar einige Regeln gegeben werben, welde $\mathfrak{B}$ ortter y und weldere a und $\mathrm{b}$ b̧aben; allein ben Diefen Regeln muirben fid wieber Xusnaģmen finben, uno nidts geviiffes feffgefergt merben fönnen. Bon vielen Siegeln, Die ģier Statt baben fönnen, fann man fid folgenbe metten. 1) Subfantiva, bie fid auf $b$ enden, und belebte Dinge angeis gen, ḩaben allejeit im Genitivo Singularis ein $a$, unb im Narrativo $b$, als: человЂkb ber Menlf, человЂка; сынb der Sofn, cúrнa: 2) Man ppridt: : cвяmáro aýxa, beş heis ligen ßSeiffę̧; человb́ческаго Aóxra, Der

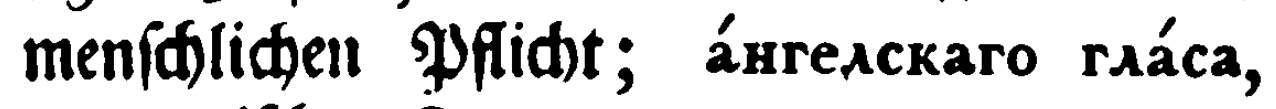
Der engliifdent Etimme; Dahingegen fagt man:

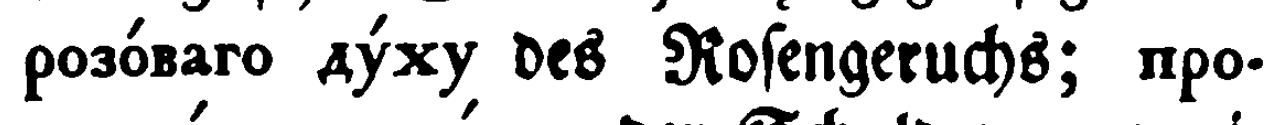
umsoróaнaro á́sry der Sthuld boin bori. gen Jafre; пти́чьs rósocy der Stimme Dess Bogelz. 3) Die $\mathfrak{B o ̈ r t e r ~ b i e ~ f i d ~ m i t ~ Z a b ̧ l e n ~}$ verbinben laffen, haben im Genitivo Singularis a als: mри 6обà dren Bofnen, тири во́ло-

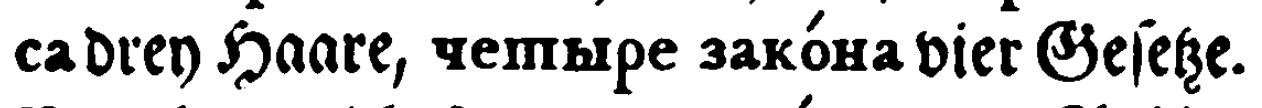

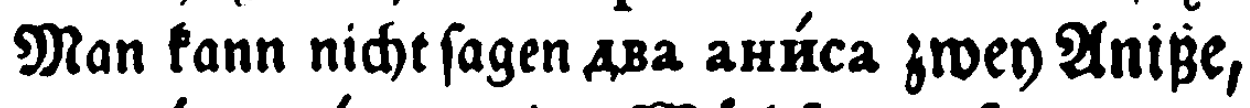
yemśpe sócxa vier $\mathfrak{B a ́ d}$ fe $\mathfrak{u}$. f. w. 


\section{Bon Deni Nominibus.}

$$
\text { 6. } 30 \text {. }
$$

Borter, weldje auf нинb ausgeb̧en, wets ben im Singulari nad) obiger Tajel, im Plurali aber auf folgende Art beclinirt : хреспья́нинb Der Raucr, Nom. und Voc, хрестья́не, Gen. uno Acc. хрестья́нb, Dat. хреспья́намb, Inftr, крестья́нами, Nar. крестья́нах b. Xuf gleid)e ârt geb̧en дворяни́нb

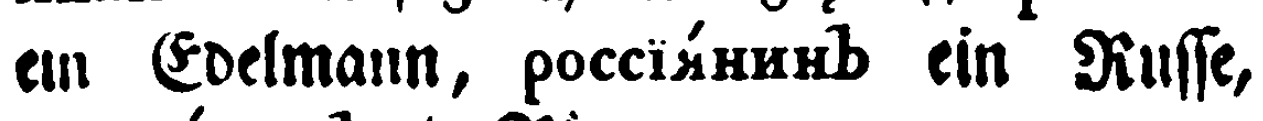

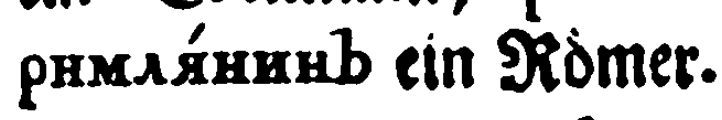

$$
\text { §. 31. }
$$

Einige Subftantiva neţmen im Nom. plur. an fratt bes br ein br an, als: 6pycb ein be. bauener Balten, брусья; лоскуmb ein Enpven, rоскутья Lumpen; колb ein Prinhl, ко́лья; лисmb ein Blatt, лиспья; кycb elli Biffen, хусьд. Zulle biefe Subllantiva werben aud bisweilen in Singulari auf be gebraudt)t, und nef̧men alsoenn bie Bebeutung ber vielfachen Zahl an, als: 6pýcbe, ке́sbe, 入úcmbe. Balten, Pfáfle, Blátter. Sie enden fich im Gen. plur. auf besb, als: 6рycb. 6русья, брусьев ; лоскуш⿱ esb; коль, колья, кольевb и. f. w.

$$
\text { §. } 32 .
$$

Die Borter apyrb Der greund, 6amórb Det Prugel, aucmb bas :Blatt, merben im 


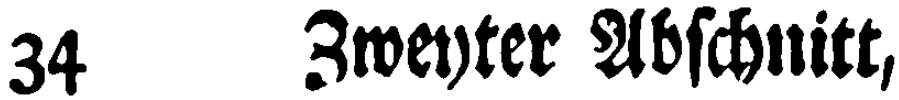

Sing!lari nad) vorftegender Tafel, im Plurali aber auf folgenbe Xrt beclinirt.

Nom. Plur. apýru und apyзbя̀, 6amorǹ

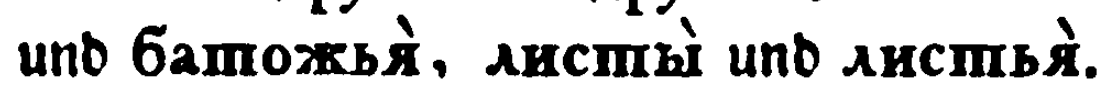
Gen. apyróвb und арузе́и батого́вb unb

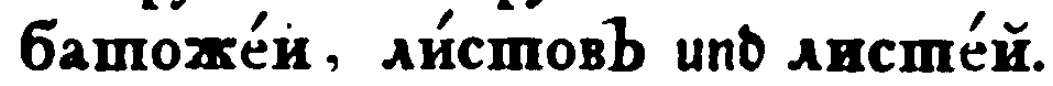

Dat. Аруга́mb unठ Арузья́mb, бапоrámb unc 6amombŕmb, Аसcmámb unb Ансшьи́мb.

Acc. Apyróвb uno арузе́u, бamorì uno

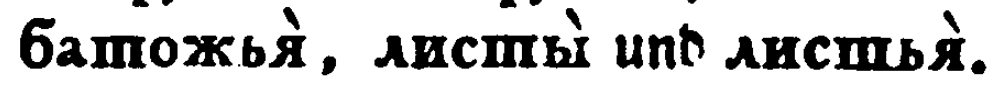

Vocativus mie ber Nominativus.

Inltr. аруга́х:и uno арузья́ми, бamorá-

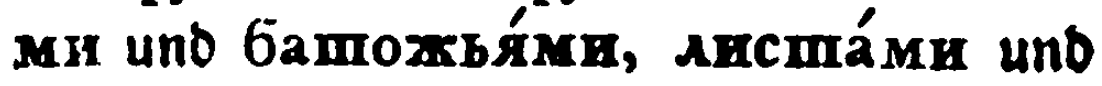
Аисшья́ми.

Nar o apyráxb unb o арузья́xb, o 6amoráxb und o 6amoaxbŕxb, о лис. máxb unঠ o גتcmbя́xb.

\$. 33 .

Господинb roiro im Singulari nad ber Tafel ber zrenten Declination beclinirt; im Pluralt aber meidte es $a b$, und wirb alfo gemadt :

Nom. uno Voc. ro. Dat. господа́mb, спода̀. Infr. rоспода́ми,

Gen. rocnóab, Nar. o rocnoááxb.

$$
\text { \$. } 34 .
$$

Der Accufativus plur. Subft. iff bem Nominativo Pluralis gleid), wenn fie eine $\mathfrak{B}$ eftellung 


\section{Bon Den Nominibus.}

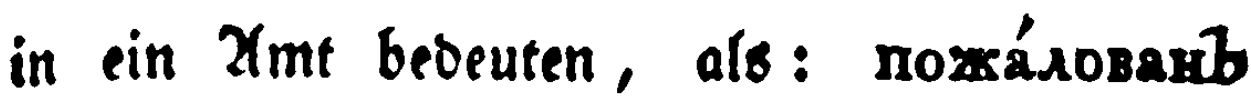
вb полко́вники, ет іf зum DGerifen avan=

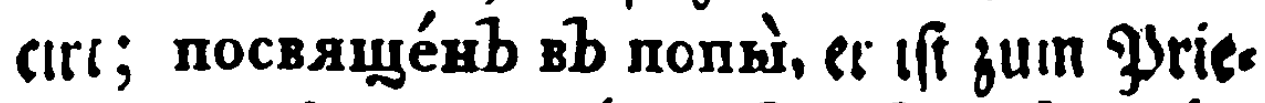

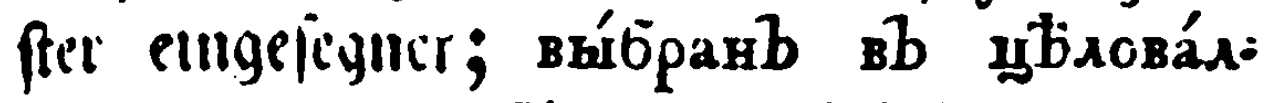
нuku, er lit juni sinn bmer bejiell worden.

\section{35 .}

Börter, bie fid auf se und pe enben, neţ. men allenib̧alben an ftcott $a$, Das $s$, und an fatt y, bas ro an, als:

\section{Singularis.}

Nom. Mópe tas Meer, nóde bas Felb,

Gen. мóps,

Dat. mópro;

Acc. Voc. Mópe,

Inftr. móremb,

Nar. o mopti, nóss, по́люо, nóse, по́лемb,

Pluralis:

Nom. моря̀

Gen. море́й,

o घол或,

Dat. моря́мb,

полx̀ noxéŭ.

Acc. \& Voc. wie ber Nominativus.

Infr. моря́мв,

Nar. o мópsxb,

поли́ми

6. 36 ,

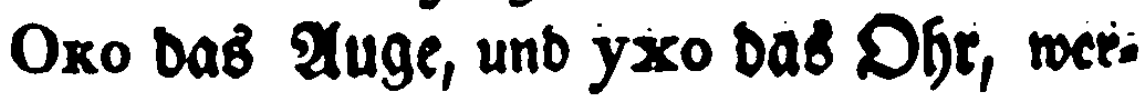
ben im Sing. nad ter Regel, im Plur. abei folgendermajen beclinirt:

Nom: 


\section{6 \\ 3wenter $\mathfrak{A} 6$ 仰uitt,}

Nom. Acc. uno Voc. óqr, ýmr.

Gen. óчeи,

Dat. óqamb

Iuftr. óqaмre

у́шей.

ýmamb.

Nar. o óyaxb,

ушамк, ушымы

0 ýmaxb.

я6локо Der Plpfel, bqat im Nom. Acc.

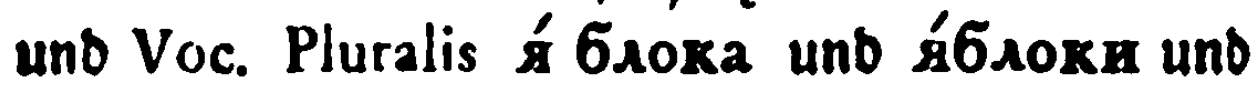
im Gen. я́6локb u॥ठ я́6лоховb.

Судно, ein Fafrijeug, wirft im Plur. das H reg, und mirb alfo beclinitt.

No. Acc. uno Voc. Dat. cyaamb, суда ипо суды, Inftr. судами, Geu. судовb, Nar. о судах menn aber cyano ein B̈efáß beift, beţält es bas $\boldsymbol{x}$ im Plurali.

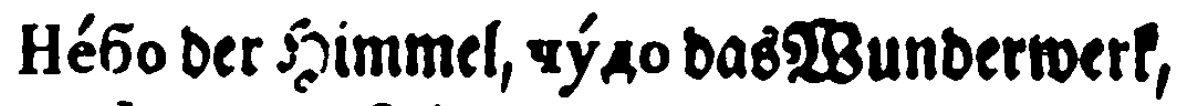
unb mbso Der feit, werben im Singulari wie Abso Dus $2 B e r f$, im Plurali aber alfo beclinirt:.

N. Ac.u. Vo.не6есà, yудесі̀ mb̈recà. Gen. небе́cb, чуде́cb, mbxécb. Dat. пебеса́mb, чудеса́mb, mbıе́самb. Infr, небеса́ми, уудеса́mи, mблеса́ми. Nar. о небесáxb, чудеса́xb, mbıесáxb

Aúmx, Das Sino, b̧at im Nom. plur. A $\$$ mu, und wito alfo beclinirt: mér, 


\section{Bon Den Nominibus.}

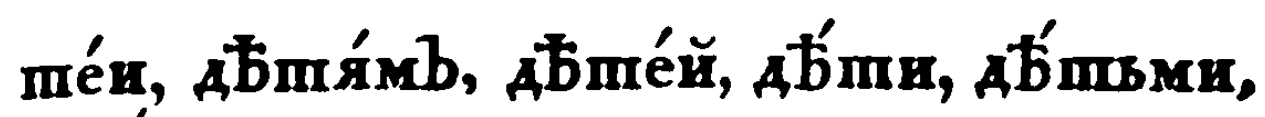
o ab́m mxb.

Ompoya ber Sinabe, wirb folgender. maken flectirt:

Singularis.

Nom. ompoyà, ompoyáma,

Gen. ompoyáme, ompoyámb,

Dat. ompoyámx, отроча́mamb,

Acc. ompoyà, ompoyámb,

Voc. ompoyà, ompoxámb,

Infr. omрочámeмb, отроча́maмв,

Nar. ompoyáme. ompoxámaxb.'

$$
\text { 6. } 37 .
$$

\section{Bon Der Dritten Declination.}

Die oritte Declination ḩat nur eine eingige Enoung, nàmlid bi fo im Gen. fing. auf $\mathrm{B}$ auss gebeet. 2alle 3 örter biefer Declination fino Generis Føminini.

\section{Tafel Der oritten Declination.}

Singularis.

Nom. b

Gen. I

Dat. I

Acc. B

Voc. $\mathbf{b}$

Inftr. Hiso ober bso

Nar. a

\section{Pluralis.}

$\mathbf{z}$

eй

sub

a, еи

I

תMx ober bxr

sxb. 
38

$\begin{array}{cc}\text { Singularis. } & \text { Pluralis } \\ \text { Nom. ^ómaAb, bas } & \text { N. ^ómaAf }\end{array}$

$$
\text { YYfero, }
$$

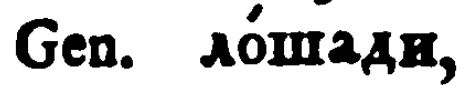

Dat. cómaAn,

Acc. dómaAb,

Voc. sómaAb,

Inftr. cómasïro, ober

$$
\text { NomaAbio, }
$$

Nar. sómadin,
G. мотаде́й,

D. cómaAsmb,

A. somasér,

V. sómaAk,

I. cómaдямr, ober

$$
\text { AOIIRABME, }
$$

N. O dómassxbb.

\section{\$. 38.}

Fs fino nur einige menige $\$ 30$ orter biefer Declination, bie bun ber Regel abroeiden, nàmlid: любósb die Elete, yépковь Dic Sirdbe, somb Die loubs, $10 \times 3$ bie lingen, als welde in ben cafibus obliquis, ben Infrupnentalem ausgenommen, bas o vor bem leşo ten confonante wegrwerfen, als: Nom. ג106ózḅ

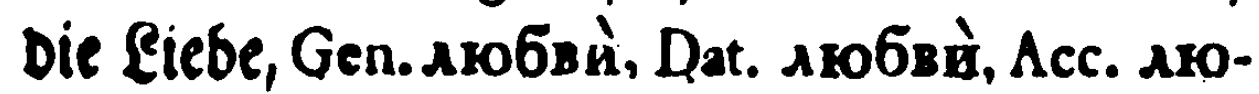

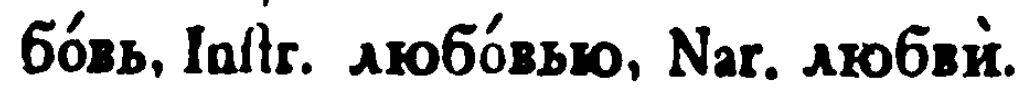

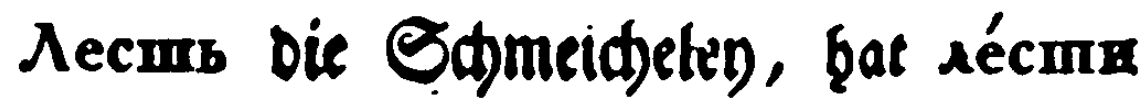
unb גьcmr.

Mamb, Die Mutter, bat mámepz; und

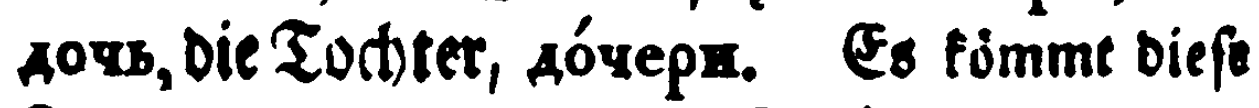
Flerion bager, weil benbes Slavionifate Woirter. fint, unb in cerfelthen Epradie ben Nom. fing. ouf rámeps unb Awepb aben. Uebrigens 


\section{Bon Den Nominibus.}

muß bemerfet werden, baß, ba ber Inftr. Sing ïю und sю, Plur. śm und barz hat, in beliben Fällen bie leģte Enoung gebräudlidjer uno bem Db̧re ertráglid)er ift. Zllfo ift aверью, аверьмп jierlider, als aверїю uno aверямп.

$$
\text { §. } 39 .
$$

Don ber viertell Declination.

Zu ber vierten Declination getgoren bie Woirter, fo im Nominativo auf $b$, reldjes im Genitivo $я$ ḩat, besgleidgen auf ie und ein fur. jes म̆ (*) ausgeţen.

Die, พBorter, bie fid) auf bunb ň enden, find generis Mafculini; bie aber, fo auf ein ie ausgeţen, fino Generis Neutrius.

\section{Tafel Der victen Declination.}

Singularis.
Pluralis,

Nom. b, ц̆, їe. $\mathbf{n}, \quad$ n, іл.

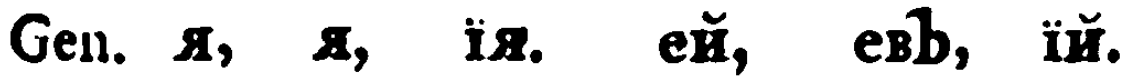

Dat. 10, 10, ію. ямb, ямb, 1ямb.

Acc. $ь, я$, й, я, їе. и, ей, и.евb, ія.

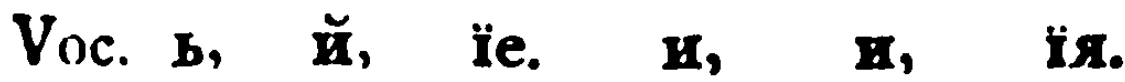

Inftr. емb, емb, їер. ями, лми. іями.

Nar. b, b, п. $\pi \times b, \pi \times b$, isxb.

$$
\text { (c) } 4
$$

Singu-

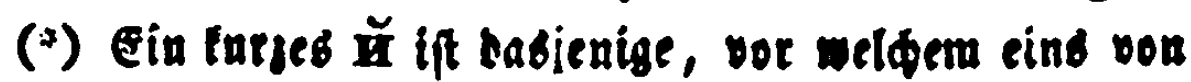
ben Vocalious a, e, $0, y$, und $\bar{b}$ Reget, al6: край, рой, 210дбй. 


\section{0

Singularis.

N. rBo3ab ber Nagel,

Gen. rBO3Ar̀,

Dat. rBozatò,

Acc. TBO3Ab,

Voc. TBO3Ab,

Infr. rвозде́mb,

Nar. O rBO3Abे.

Singularis.

Nom. 310A t́k

Miffetḩàter,

Gen. 3нoдbr,

Dat. 310A6̆́ro,

Arc. 3мод ह́r,

Voc. 3АОд ந́й,

Inltr. 3моA क́емb,

Nar. o 3roabb.

Singularis.

Nom. poжде́ниe bie Geburt,

Gen. porsде́нгx,

Dat. роххде́нӥю,

Acc. рожде́ние,

Voc. роххде́нде,

Infr. pcasáénuemb,

Nar. o pozxде́вïr.
Pluralis

rBo3an bie Nägel,

гBO3AеЕ,

ГВ0зАяMb,

TBO3AR,

ГBO3AF,

ГВОЗАЛМЕ, ГВОЗАБ-

- гв03Аяхb. (мA,

Pluralis.

310д6́n, die Miffes

3нодb̆esb,

thăater,

змод Б́, ямb,

злодбевb,

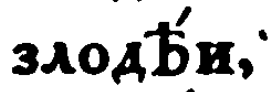

злодб́́ям,

злодБяхb.

Pluralis.

роххденї, Die Bூe.

butten,

рожде́ній,

рохде́нїямb,

роххе́ниї,

рохде́нї,

рогхаенйлми,

- foжséнїхxb.

Singu- 


\section{BOn Den Nominibus.}

Singularis.

Pluralis.

Nom. yaps ber Rơnig, yápr, bie Rönige,

Gen. म्ये भे

Dar. मूapiò

Acc. मूаря

Voc. मूapb

Jnfr. मूаре́мb

Nar. o yар $\hat{b}^{\prime}$

п्раре́й,

मарархxb,

עаре́й,

yари,

\#аря́ми,

Singularis.

- yapáxb.

Pluralis.

Nom. poù ber Bienen. por̀, die Bienen. (d)warm,

Gen. pór ober póro, poésb,

Dat. póro,

Acc. рой,

Voc. poй,

Infr. póemb,

роя́mb,

Nar.o pób ob. вb póro. Bb pośxb.

$$
\text { \$. } 40 .
$$

$\mathfrak{B}$ en biefer Declination fino folgende Siegeln ju merfen:

1) Einige im Nom. fing. auf ein $b$ ausge. henbe Börter berlieģren in ben cafibus obliquis Das e unb o in ber legten Sylbe, als: cme6exb Der Elengel, Gen. cme6גs; день Der Tag, Aня; гребень ber Sianm, гребня; камень 
Der Stein, хамня; хремень der Riefelftein, кремня; ремень der Юiemen, ремня; пень Der Pfabl, nнs; огонь das feeter, огня; yroab bie Siohle, yras.

Князь Der F́firti, unо хамень Der Stein, werien im Plur. auffer ber gerwoóngnididen 2 Beife, now auf folgenbe att decliairt:

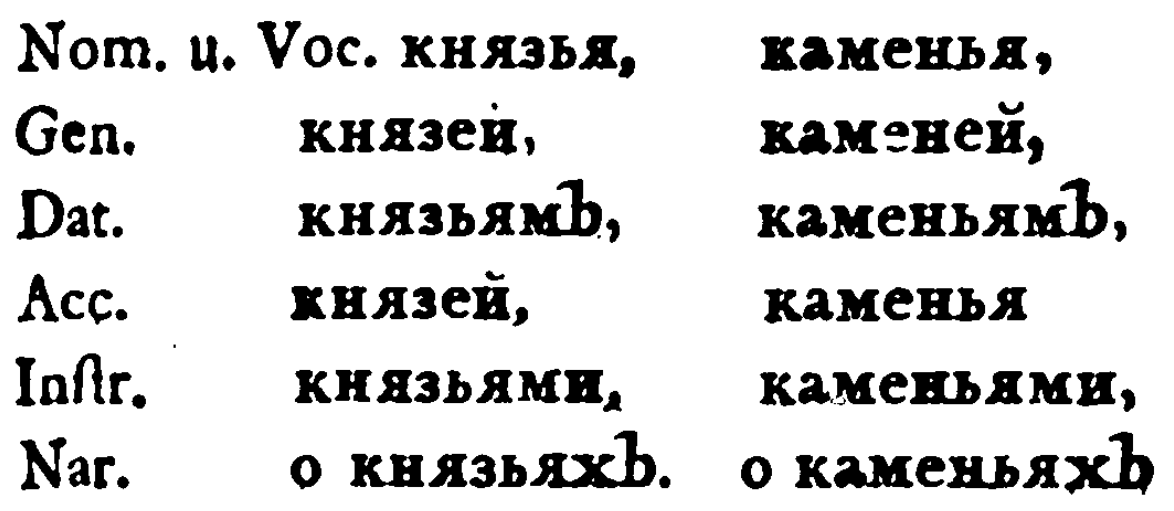

2) Es giebt Wörter, welde bie Enoung bes cafus Inlitumentalis im Plurali \$MK in bMK verwandeln, als: rso3ab ber Ragel, Inftr. rвозаbяMn ober rвозАbMи; rocmb ein Saff,

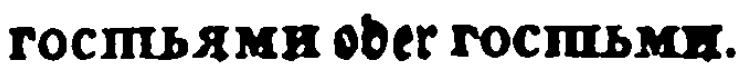

3) Die Subftantiva, bie auf ein ň ausgeģen, weiden bon ber Regel ab; benn

a) Die einfilbigen 2 Borter netegmen im Gen.

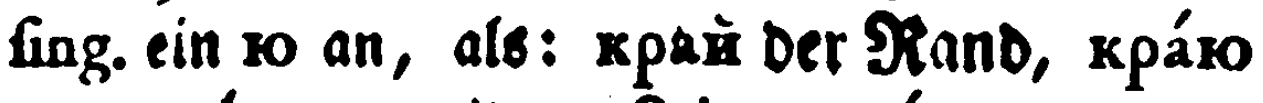

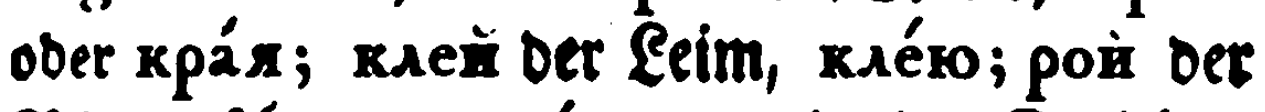

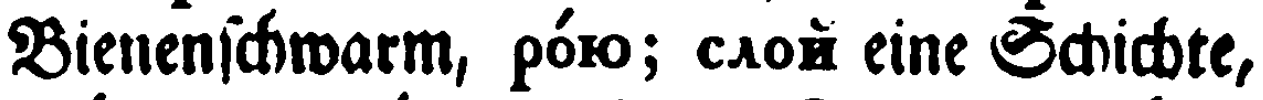
cлór ober cлóю; бой die Sdladt, 6óю;

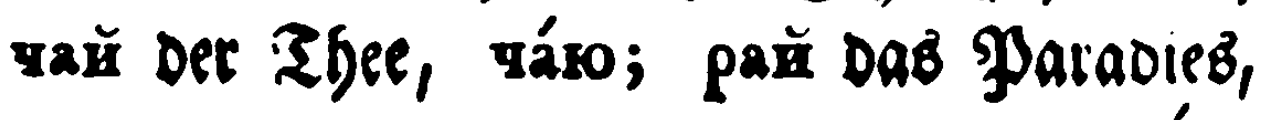
pás, 


\section{Bon Den Nominibus.}

pár, ober pázo. Diefe ḩaben im Narrativo alle: mal ein 10, als: - н2 póro, н2 6óю, вb yáro, b ра́ко, на кuѐк; змей die Sd)lange, bqat allejeit змés nidt змézo.

b) Die ben Participiis uno Adjectivis d̨̧n. lide Subflantiva auf oй unb eй werben wie bie

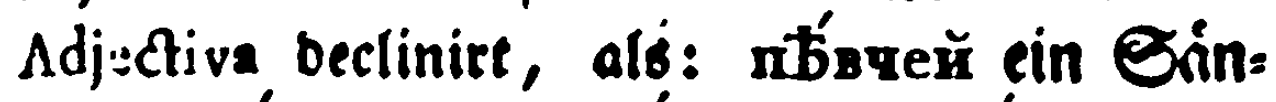

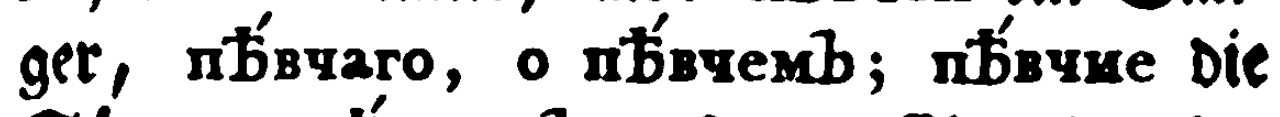

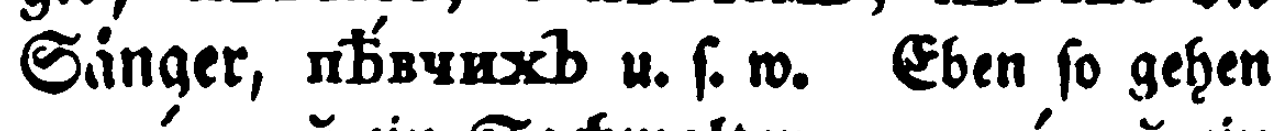
стря́пчей ein Sađwalter, подья́чей ein

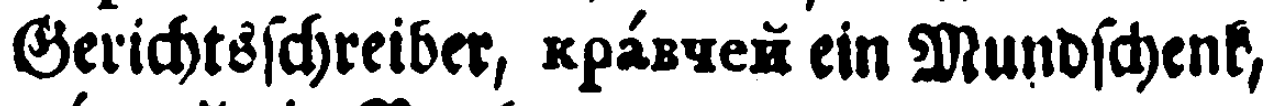
ни́щей ein Bettler.

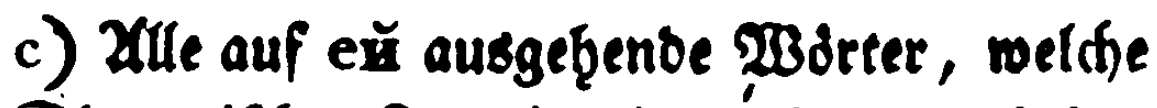
von Elabonijßen Rerminationen in ï beribiret merben, werwedffeln in ben cafibus obliquis bas e mit b, als: воробей, Der Sperling, Gen. воробья; соловей Die Rathtigall, соловья; муравей dieথtmeife, муравьл, и. f. ю.

Inumie, Dab Getráll, miro alfo beclinirt:

Nom. numïe, ober numbe,

Gen. пиmbя̀

Dat. nหmbrò u. f. m.

Plur. Nom. виmb̀̀

Gen. muméŭ,

Dat. mumbśmb, u. f. w. 
44 31wev)ter $2(66$ (\$) nitt,

$$
\text { \$. } 4 \text { t. }
$$

Znlangend bie fremoen in ber ruffifden Epradie angenommenen $\mathfrak{B}$ drter, fo fino bavon folgenve Regeln gu imerten:

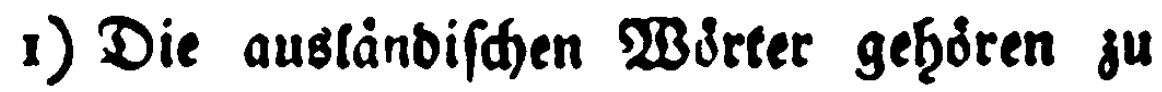
benjenigen Declinationeu, Deren Enbung fie

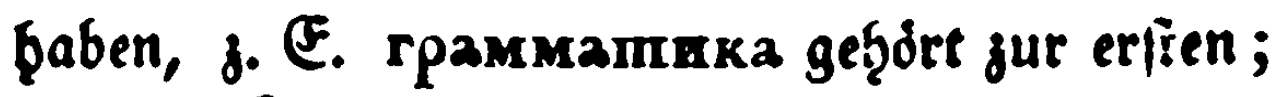
болверкb jur zwenten, uиb Гораулїи, Horatius, jur vierten Declination.

2) Frembe $\mathfrak{B} \delta$ rter, bie auf ium ausgeb̧en, veranbern im Rufififen bas um in $\pi$, unb merben alfo nad ber erften Declination gemadt. Jeood bethalten biefe 230 rter oft im Nominativo, Accufativo und Vucativo bas ium, als: kodsernymb. Diejenigen 23 orter aber, fo in if. rer eigenen Spracte auf ein $\Lambda$ ausgeb̧en, weldes nod einen andern Vocalem bor fid bुat, verandern bieß $A$ im $\Re u f f i f d e n$ in $x$, als Geometria, reomempїя; Plilofophia, $\Phi$ muосо $\Phi$ ïr.

3) Die auf as, es, unb o ausgef̧enbe lateiniffbe Nomina propria berwanbeln, wenn fie ruffifd werben, unb Mafculina finb, bie lateinifde Enoung bes Genitivi is, irrb; fino fie aber im Lateinifden Generis Fominini, fo wirb bie Enbung bes lateiniffien Genitivi in a berän= bert, als: Pallas, Gen. Pallantis, ruffifh Mau- 


\section{Bon Den Nominibus.}

raumb; Pallas, Palladis, Iáduaдa; Sucrates, Socratis, Coxpamb.

4) Die latemifajen Nomina propria in as unb us, nebgmen, wenn bey felbigen bor biefen Enlben einige Vocales vorb̨ergeந̧en, im ruffifden an fatt as unb us ein $\mathbf{x}$ an, als : Eneas, өнeй; Ptolomxus, nmoломей, u. f. ro.

5) Die tibrigen lateinifden Nomina propria auf us, neţmen an fatt biefes us ein $b$ an, als: Epicurus, эпикурь.

6) Ariftoteles, ruffifa apromomens, geb̧dret zu ber vierten Deciination.

\section{42.}

\section{Boll Der fiulften Declination.}

Diefe enthălt alle Adjectiva von allen breben Befdledten, wie aus folgenber Tafel unb Bespipielen zu erfegen.

Singul. Mafculin.
Sing. Fœmin. ar, $\pi \pi, b \pi$, br, oй, is, ex, о̀̀, ей, yю, 1010, 120, b.0, as, $\pi$, bs, ого, ег, bero, oxo, ой, eй, lezo. 
Singularis Neutr.

\author{
Pluralis.
}

per tria genera.

Nom. oe, ee, le, be, bre, wr, le, iq, bn,

Gen. aro, oro, яro, bxb, $\mathbf{u x b}$

Dat. oмy, eмy, sumb, nub,

Acc. oe, ee, іе, be, ыxb.

Voc. oe, ee, іе, ье, ыre. ыr, іе, ія, bx,

Infr. nmb, имb, sми, имк,

Nar. oxb, emb, sixb, uxb.

\title{
Erftes Benfpiel.
}

\section{Sing. Mafc.}

Nom. Aóбрий ober sóброй bet gute,

Gen. Aó6рато ober só6рово, bes guten,

Dat. Aó6pomy, bem guten,

Acc. aóбрtrin, unb sóбparo, ben guten,

Voc. Ао́брый, guter,

Infr. sóбрымb, mit bem guten,

Nar. o дó̄ópomb, von bem guten.

Fæminn.

Nom. дó6рал, bie gute,

Gen. sóбрыrя obet soбро́й, ber guten,

Dat. so6pói, ber guten,

Acc. Aó6рyв, Die gute,

Voc. до́брая, gute,

Inttr. до́брою. oì, mit ber guten,

Nar. O Aó6poř, bon ber guten.

Neutr. 


\section{Bon Den Nominibus.}

\section{Neutr.}

Nom. Aó6poe, bas gute,

Gen. sófparo, bes guten,

Dat. Aó6ромy bem guten,

Acc. Aó6poe, bas gute,

Voc. дóбpoe, gutes,

Inltr. до́брымb mit bem guten,

Nar. o só6pomb, von bem guten.

\section{Pluralis.}

Nom. до́брые, оber до́брыя, bie guten,

Gen. sóf́ptxbb. ver guten,

Dat. Aóбрымb, ven guten,

Acc. Aóбphre ober Aóбphr, bie guten,

Voc. sófpse. gute,

Inftr. 九о́брыми, mit ben guten,

Nar. o só6phrxb, von ben guten.,

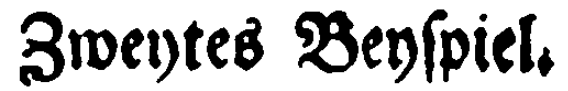

Sing. Mafc.

Nom. пре́хшней ber vorige,

Gen. пре́жняго,

Dat. пре́жнему.

Acc. пре́жнято обег пре́хкней,

Voc. пре́хкней,

Inftr. пре́хкнимb,

Nar. o пре́zвнемb.

Fomi: 


\section{3wenter $\mathfrak{A} 6$ 低nitt,}

Fœminin.

Nom. пре́zкняя, bie vorige, Gen. пре́жнйя, пре́хкней,

Dat. пре́жней,

Acc. пре́хкную,

Voc. пре́жняя,

Inftr. пре́хннек, пре́хиней,

Nar. о пре́zкней.

Neutr.

Nom. пре́zкнеe, bas vorige,

Gen. пре́жняго,

Dat. пре́жнему,

Acc. пре́жнее,

Voc. пре́жнее,

Inftr. пре́хнимb,

Nar. o пре́zкнемb.

\section{Pluralis.}

Nom. пре́хвніе, пре́хннйя, bie vorigen,

Gen. пре́хкнихb,

Dat. пре́жнимb,

Acc. пре́жнихb, пре́хкнїе, пре́хнй,

Voc. пре́жниіе, пре́жніия,

Inftr. пре́хними,

Nar. о пре́жнихъ.

3. Bey $=$ 


\section{Bon Den Nominibus.}

\section{Dritteo : Benfpiel.}

Sing. Mafc.

Nom. Gómeuั, ber gottlidje.

Gen. 6ózвьеro,

Dat. Gózвьемy,

Acc. 6ómbero, 6óжей,

Voc. 6ózxeri,

Inftr. 6ózвьнmb,

Nar. o Góasbemb。

Fœmininum.

Neutrum:

Nom. 6ómsxi,

Gen. бо́хьей,

Dat. бóжьей,

Acc. бо́жью,

Voc. 6о́zхья,

Inftr. 6óxвеко,

Nar. o Gózвьей.
Nom. 6óxzie,

Gen. 6ómbsro,

Dat. Gózқbemy,

Acc. 6ózвie,

Voc. 6ómine,

Infr. 6óxsbumb,

Nar. o 6ómbemb.

Pluralis.

Nom. 6ózxbr,

Gen. 6ózxbaxb,

Dat. Gózxbиmb,

Acc. 6ózxbaxb, 6ómbri,

Voc. 6ózebr,

Inftr. Gómbrnma,

Nar. o 6ózasuaxbi 
Весь, всл, все, oller, alle, alleb, wirb irregulariter auf folgenbe $\mathfrak{x}$ rt beclinirt:

Mafc.

Nom. весb,

Gea. cerò ober Bcesò,

Dat. sсемỳ,

Acc. весь,все. ró, rcesò,

Voc. secb, Inft. Bcbub. Nar. o scemb.
Fœm.

BCA,

sceś,

sce:̌,

BCro,

BCA,

вceró,

- sсей.
Neutrum. sce, scerò ober всевò, всемyे, sce,

sce, вcbib,

o scemb.

Pluralis, per tria genera.

Nom. sçb,

Gen. $\mathbf{c} b \mathbf{x b}$,

Dat. scbmb,

Acc. scb, Bcbxb,

Voc. sct,

Infr. sc bma,

Nar. o вcbxb.

$$
\text { §. } 43 .
$$

Ben ben Adjectivis find folgenbe Regeln zu merfen.

1) Diejenigen Adjectiva, welde burd) $2 \mathfrak{a b}$. Fürjung ber Enoung brì ober où auf erb, orb, 
orb, oxb ober oxb ausgef̧en, werfen in ben cafibus obliquis benber Numerorum, unb fo roht im weibliden, als mittlern (Jefdledite, bas $\mathbf{E}$ uno $O$ meg, als : xpómoxb milde, кpómкой (nid) кро́токой) кро́mкая, кро́mкое; xpómkaro, u. r. r. Xuf eben diefe Beife

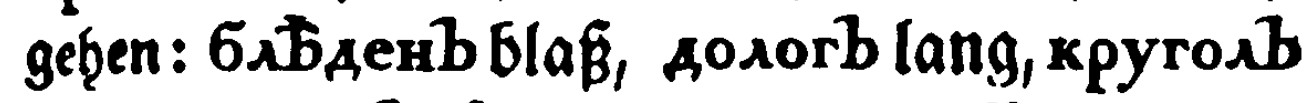
rund, xucesb fauer, u. a. m. Man nef̧me aus mupóxb breit, вbrcóxb bod), sóporb theuer, sécesb luftig, unb einige anbere.

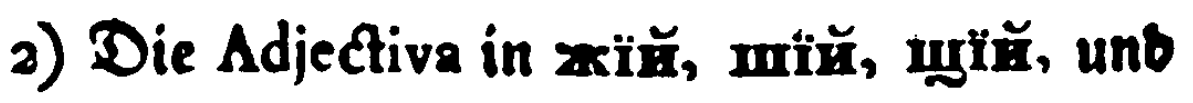
чїй formiren į̧re Fom. auf ax, uno bie Neutra auf ee, als: приго́zвiй, прито́zкая, при. róхее; ни́шїй, ни́щая, ни́щеe; отчй̆, omqar, omyee. Die auf нїй ausgeţen, enden fid im Fœm, auf sr, unb im Neutr, auf ee, als: си́нйй bimmelБlau, си́няя, cи́неe.

3) Die Enoung bes Nom. Sing. Malc. iff

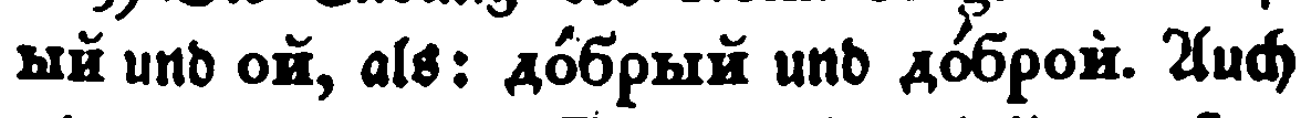
wiro ber Dat. Sing. Foem. meţrentheils an ftatt bes Gen. Sing. Farm. gebraudt, als: an ftate

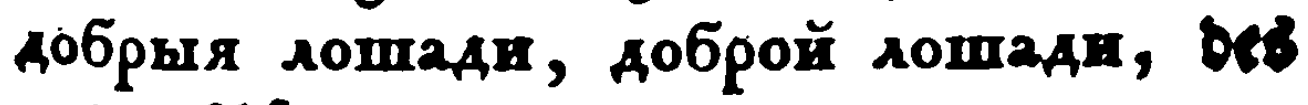
guten $\mathfrak{P}$ ferdeb.

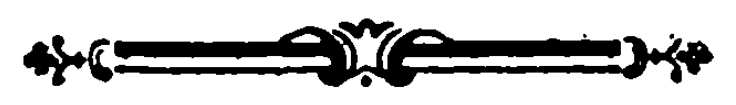

D $>$ Das 


\section{Dag Dritte Sauptftúč.}

\section{Bon den Dergleithung gfuffen.} De gradibus Comparationis.

\section{§. 44 .}

Es fino im Ruffifden, eigentlid zu reben, nur zmen Gradus, nimlid) Pofitivus uno Superlatıvus, indem bie Adjectiva feinen Comparativum zu. laffen; ob man gleid in Bergleidung ber Sa. den unter fid), Da roo ein Comparativus nòthig iff, fid) ber Adverbionum Comparative bebienet, als: er ift fluger, onb yмнt́e; ef if theurer, cie дорóze. Folglid werben bie Comparativi im Jiuffichen nidte Declinirt, fonbern find blose Advervia; uno menn id) j. $E_{\text {. im Deutfhen fage, }}$ ein relderer Mann: fo mus es im rufififien ber $\mathfrak{B e r b i n d u n g ~ b e r ~ g a n j e n ~ \Re e b e ~ n a d ) ~ u m ( d ) r i e . ~}$ ben werben.

$$
\text { ๑. } 45 .
$$

Die Elavonier formiren ben Comparativum bom Pofirivo baburd, baß fie vor beffen Enoung bu ober ì bas m rorfegen, uno bas by in $\ddot{i}$ vermandeln, als: yecmub́i im Comparativo уестншйи. Zlllein biefe 2 art ben Comparativurn zu maden, ift im Ruffificen niфt meģe gebräudlid.

$$
\text { ๑. } 46 \text {. }
$$




\section{Bon Den Nominibus.}

$$
\text { §. } 46 .
$$

Der Comparativus wirb alls bem Nomina. tivo Fæm. bes Pofitivi burd) Beräberung bes $a$ in be gemad)t, als: cmpámenb furdtbar, страшна̀, страшн b́e.

$$
\text { ๑. } 47 \text {. }
$$

Die auf $a b$ und $r b$ ausgebenden Adjectiva beranbern biefe Enoung in me, als: xyab

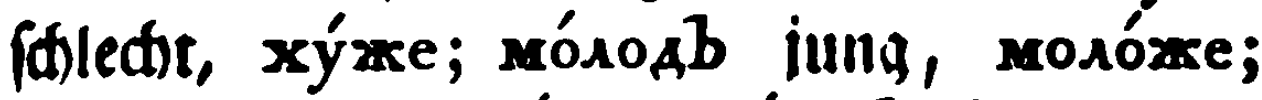
myrb framm, mýze; Aóporb theuir, sopóxe; cmporb jitrenge, cmpózxe; mвераb.

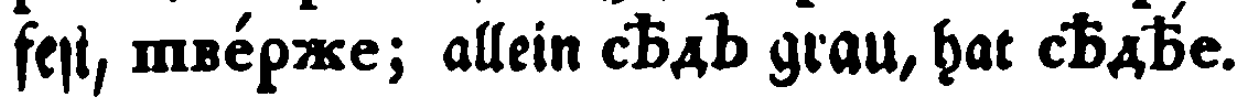

\$. 48.

Die Endung auf oxb berainbert im Comparativo bas kb in $\mathbf{y b}$, als: xpénoxb, хре́nчe; мérokb, sérye, u. 1. ro. Indeffen ḩa= ben сла́ докb füüe, сла́üe; ýзокb enge, ýже; ráдокb hek̉liç, ráжe; rıádокb glatt, rлáже; жи́докb dúnnе, жи́хке; ни́зокb niе: orig, ни́же.

\section{49.}

Die Enoung cmb wirb in we bertoandelt, als: rycmb oicte, rýme; npocmb fallectit, gemiii, mpówe; yacmb sidht, чáuse; yucmb rein, чи́uе ; mолсmb Diđ mósuуe.

$$
\text { D } 3 \text { S. } 50 .
$$




$$
\text { §. } 50 .
$$

$\mathrm{Xb}$ wirb in we veránbert, als: ray $\times \mathbf{b}$ taub, глýwe; cyxb trocfen, cýme; $\curlywedge$ и́xb bofe, zornig, ańme; mnxb ftille, muwe; nлoxb (d)led)t, mıóme.

$$
\text { ๑. } 51 \text {. }
$$

Irregulariter werben compariret: sesúxb

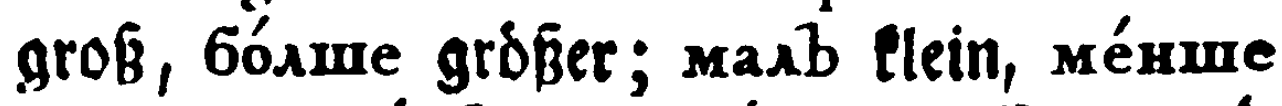
lleiner; xopómb gut, aýmue fiefier; кра́. сенb rothan farbe, б̆at краснб́,; кра́сенb . (d)óll, крáme. Benñ aобрый fo viel b̧eí̧en foll als gut, fo bzat es im Comparátivo aymue; bebeutet es aber to viel als gutig, geneigt, to bat es ao6pb́e.

\section{§. 52.}

Der Superlativus miro auf brenerley Xre formirt :

1) Indem man im Comparativo bas lef̧= te e megläbt, und bie Enbung umïr ans bàngt, als: cшрашнђе, страшнђишіи; свлmbе, сляпђишіи; чесшиђе, честнbиmïn, u. f. w. Dies ift eigentlia bie Ela. poniffoe $\mathfrak{Z}$ rt ben Superlativum ju maden, uno wirb berfelbe ben Adjectivis, beren Bebeutung ete was geringe ift, nidt gebraud)t.

2) Das Pronomen са́мой, са́мая, са́моo, vor einem Adjectivo, madt bie zroepte Art bes 
Superlativi, als: са́мой скве́рной, Der भ6= fđeuliđjite, са́мая скве́рная, са́мое скве́рное. Man fagt aud) самой сквернђишей.

3) Die britte Xrt ben Superlativum zu ma. den, gef́lieḩt burd Borfeşung bes Borworts пре, vor bem Pofitivo, als: бorámbй reiqf, пре6оrámmй der reidfte; вели́кїй groß,

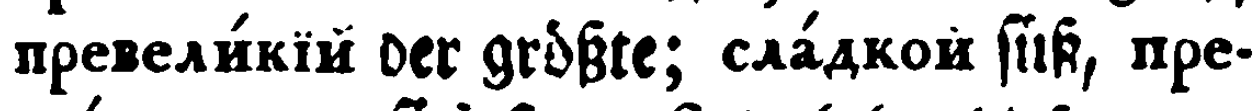
cráakon der füiefte. Jebod hat biefes npe nid)t to wobl ben Nadjorud eines Superlativi,

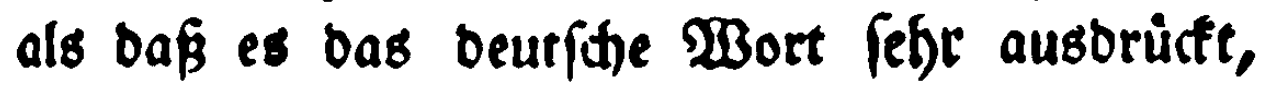
als: пре6огашти jebr reid), превеликїй febr gró̧, u. f. w.

Enolid) pflegt man aud ben Superlativis ber erften Battung Das наи anzuhäangen, als: наикраттаитїи ber ailerfingelte. Dies ift aus Dem Polnifden genommen, uno findet nidft bey allen Börtern ftatt.

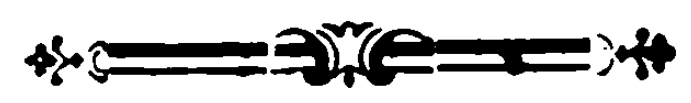

$D_{4}$ 
$56 \quad 3$ wevter $\mathfrak{A}(\mathfrak{b}$ [Anitit,

\section{Das̉ vierte Şauptitúç}

Bon Den vergrd́gerungs und verfleines rungswodrtern.

De Nominibus augmentativis \& diminutivis.

-5. 53 .

Der ruffififen $\mathfrak{B e r g r o ́ b e r u n g s w o r t e r ~ f i n d ~ n u r ~}$ menige, befto meg̨r aber gebraudsen bie Biuffen bie Berfleinerungswórter. Erftere enden fich) auf нuе, ина, unb инище, als: cmoлb ber হіћ), столи́ше, столи́на. столи́нище, ein großerer Tifă); pyкá die Şand, pyчúme, ручи́на, ручи́нище, еine groß̣e Љ̧and.

$$
\text { §. } 54 \text {. }
$$

Die Berfleinerungswörter endén fíd,

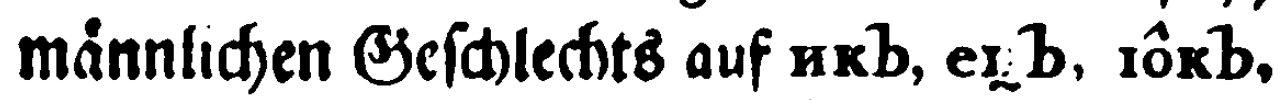
oxb, uno yuxb, als: cmósuxb ein Tifd)=

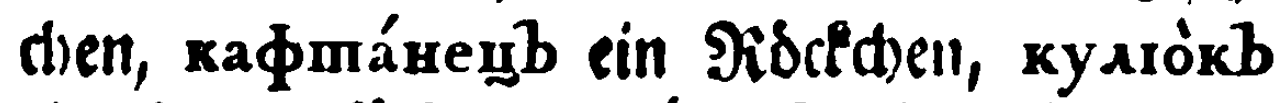
cill Mattelliádethen, sý6oxb ein Báhuchen,

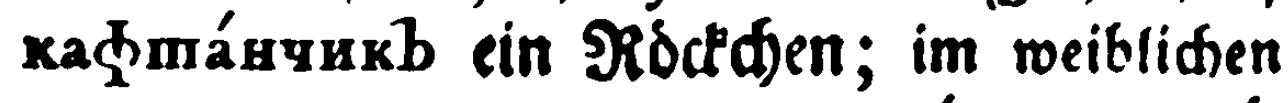
auf ка, нька, уuка, als: rоло́вка, rоло́.

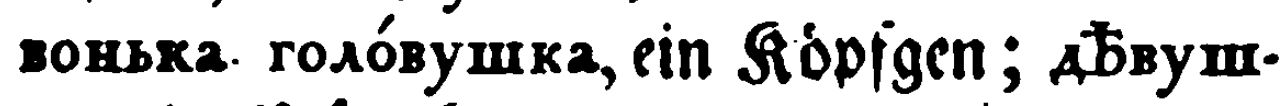
xa ein Mágdden; im Neutro auf ko, yo, чко, ушко, als: серде́чко, се́рденько. серде́чушко, ein Serzden. Einige, beren Oefdledts 


\section{2on Den Nominibus.}

Befdiled)t zroeifelţaft ift, enben fid auf nmko, uno eнyо, als: cmosи́wко ein fleiner

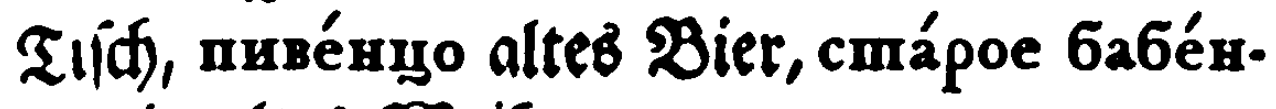
מo ein altes $\mathfrak{\text { Beib. }}$

\section{55 .}

Nidbe weniger werben bie ruffifden Adjectiva im Diminutivo gebraudt, unb enben fid) auf Bamb unb некb, besgleiden auf хонекb unb шенекb, als: кра́сенb rotb, краснова́mb rótblid), красе́некb jiemlid rotf; nлохb f(fled)t, плохобámb, плохо́некb; сырb rof, сырова́mb сыре́некb; мале́хонекb, мале́шенекb ; сладе́хонекb , сладе́ше. некb, u. .. m.

\section{56.}

Die Berfleinerung geffiegrt aud burd Borfeguny bes Borworts no, als: noxpénye etwas bárter, nosopóme etroab ţ̧eurer.

$$
\text { §. } 57 \text {. }
$$

$\mathfrak{B}$ ie biefe Augmentativa und Diminutiva von ihren Stammwörtern abgeleitet werben, foldses fann burd feine Regeln genau beftimmet wer. ben. Denn bey ber großen Menge berfelben

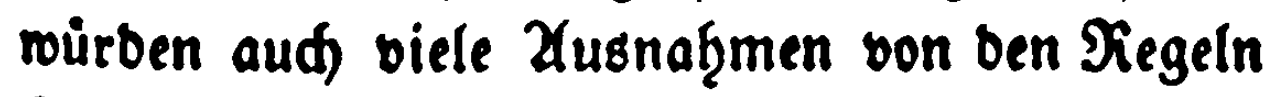
ftatt baben, unb baburd) unenblide Edprierig. teiten verurfadte werben.

D 5

Då̊ 
58

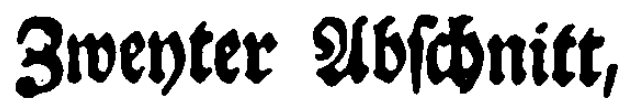

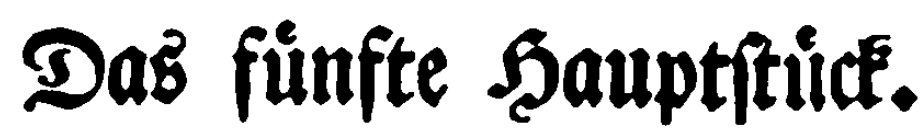 \\ Bon Den 3ablwodrtern. \\ 9. 58.}

Die Bab̧lwoirter werben eingetgeilt in Cardinalia, ober Stammjał̧troötter, uno Ordinalia, ober abgeleitete Bab̧lioortet.

\section{59.}

Die Cardinalia fino folgente:

оди́нb, eins,

ABa, zmey,

mpr, bren,

yembípe, vier,

пяпь, fünf,

mecmb, fedfs,

семь, fieben,

осмь, adt,

де́вя пाь, neun,

де́сятьи, јебৃn,

оди́ннатпуать, eilf, авена́mиаmь, зrodlf,

mрина́myamb,

oreuseţn, zemmpнámyams, viergeţn,

мяпна́mщamb, funf.

jeb̧n,

mecmrámyamb,

fedisjegn,

ceмнámuamb, fieben.

zef̧n,

ockrámmamb, adjt. девяmнámúamb,

neunję̧n,

двámyamb, jmanjig, 


\section{Bon Den Nominibus. $\quad 59$

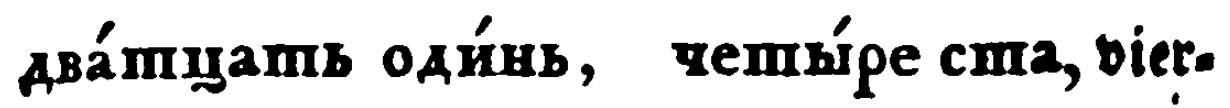
ein u. jwanjig u. .. w.

mpи́myamb, oreißig, пxmb comb, fünf̧̧un. cópoxb, vierjig, bert,

пяпдеся́mb, funfzig, mecmb comb, fedbs шестдеся́mb, \{еф)s

bunbert, jig, cемь comb, fieben. семдеся́mь, fiebenjig, осмьдеся́mb, adtтig, осмь comb, adtţun. девяно́cmo, neunjig, cmo. bunbert, aвécmu, jmenbqundert, mpи cma, brengun. mbícsya, taufeno, Drengun: mb́csya, taufent,
bert, mbsa, jeg̨ntaufeno.

\section{60 .}

Die Ordinalia, fimplicia und compofita, fint:

де́рвой, ber erfte, Aруго́й, oder вmopóŭ ber zroente,

mpémeй, Der britte, पепве́рптой, ber vierte,

ля́moì, ber fünfte,

mecmóü, ber fedffte,

седмо́и, ber fiebende,

ocsóú, Der adte,

де́вяmb comb, neun. bunbert, bunbert, Dert, 
девяmтой, Der neunte,

деся́mои. Der jel̨nte,

оди́ннаmýamou der eilfte, aвeна́muanon. Der jwólite, mрина́mцаттои, Der orenzegnnte, yembrpyámyantron. Der vierjeb̧nte, пяmна́mijamon Der funfzeb̧nce,

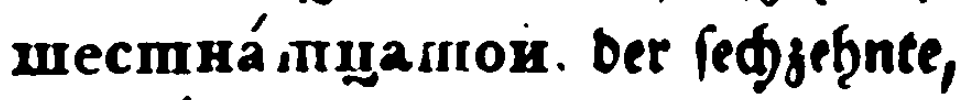
семна́mйтои, Der fiebenjebnte, осмьна́müamou, Der adțeb̨nte, деssmmáminamon, ber neunjeģnte, ABamyámor ber jwanjigfte, impumuámoì, ber orenpigigite, сороково́и, орет чешыредеся́mой, Der vier. jigfte,

пяпдеся́mой, Der funfsigfte,

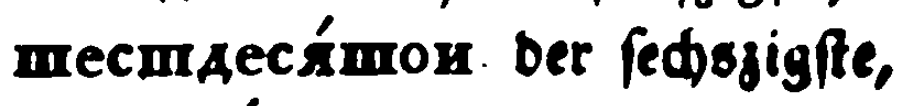
семдеся́mой, ber fiebenjigite, осмьдеся́mon், Der adifigfte, девятдеся́mой, орег девяно́стой, бек neunjigfte,

cómoй, ber buntertfte, mbícящной, ber taufendfte.

Şieḩer gebòren abóe iffrer żoey, mpóe ifrer orev), чémsepo iffer bier, u. f. w. noגıno- 


\section{Boll Den Nominibus.}

pà anbertfialo, nosmpens drittethalb, nos. secrmà jebutebalb, u. f. w. (*)

$$
\text { §. } 6 \mathbf{r} \text {. }
$$

Die Ordinalia von eilf his neunzefgn werben aud) mit 'Inb̧àngung o's на́десяmb gemadt, als: пе́рвои на́десяпь vet elltti, второ́й на́десяmb Der jivollte, u. Ү. w. clli in vieß geid):ci.jt nur in ernem widtigen $\mathfrak{R}$ orttage, uno ben ien j) Jonatsnamen, als: Ealt ber jwilfte, Карль втоорыи надесяmb; Den 16. Dcto. bet, Октября шестаго наяесять.

$\S 62$.

(") In alten Sitchenkiudern, wie and auf Milinsen, merben bie zablen butd Budftaber aubgebrüat, uno uwar bebenten:

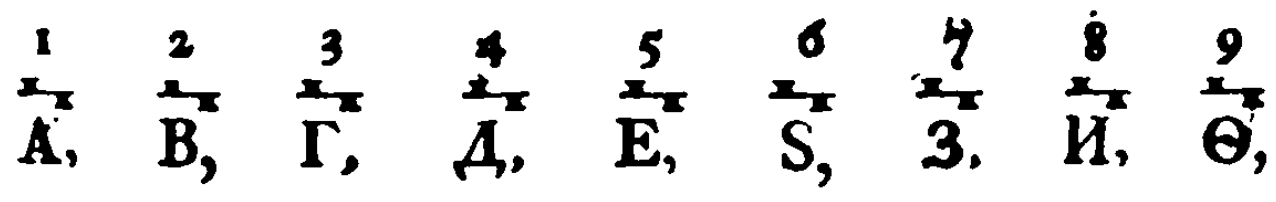

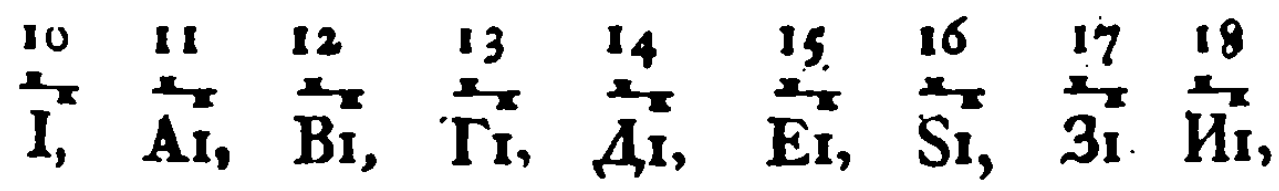

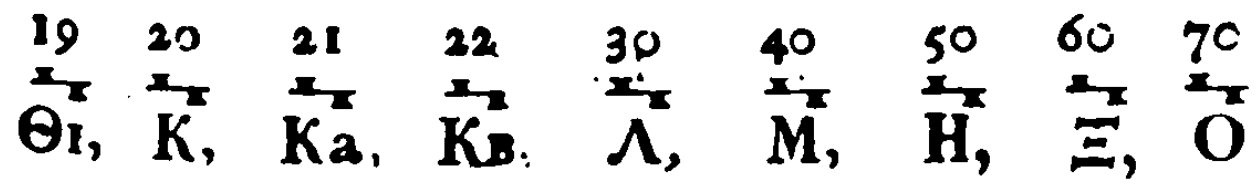

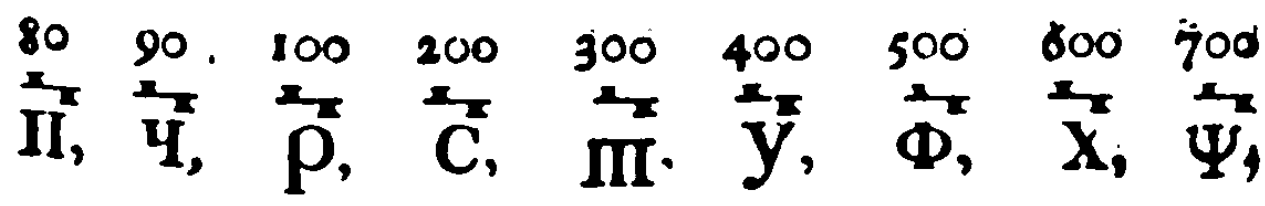
8009001000200030004,0035000

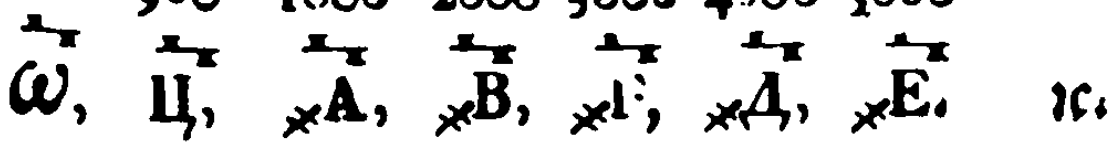


62

\section{3twenter 2(b/anitt,}

\section{62.}

Одинb орег единВ, ава, тори, тетиpe werben mie bie Adjectiva in srù, erferes in beyben Numeris, bie úbrigen bingegen nur im Plurali bectinirt. Zffle anbere Ordinalia, auffer cópoxb, девяно́cmo, cmo, gef̧en nađ ber oritten Doclination im Singulari.

Singularis.

Mafc.

Nom. oди́rb,

Gen. OAHorò, ober одново̀,

Dat. одномyे, Acc. OAH́HB, OAHOró, oder OAHOBò,

Voc. ОАи́нb,

Infr. одни́mb,

Nar. O OAнómb;
Fœm. ОАНй, ОАНоे, OAHÓ:̆, OAHOrò obet одновò, OAHÓ:̌, OAHOMỳ, OAHỲ, ОAно̀, OAHà, OAHÒ, ОАно́์, ОАни́мb, О ОАно́й, О ОАно́мb.

Pluralis, per tria genera.

Nom. OAH मे

Gen. oAiuŕxb,

Dat. ОАн и́mb,

Acc. OAHì,

Voc. OAHй,

Inftr. ОАНи́мद,

Nar. O однúxb. 


\section{Bon Den Nominibus.}

Mafc. \& Neutr. Fœm.

Nom. два,

Gen. AByxb,

Dat. Авумb,

ABБ. IIPr,

mpexb,

mpemb,

Acc. Ава, Аву $\mathbf{x b}$, Авb. mpr, mpexb,

Voc. ABa,

Inftr. AByмяे,

Nar. ABý $\mathbf{x b}$.

АВБ. mpr,

тремя,

impexb.

Eben fo gef̧et aud xembrpe; bloß im Infrumentali wirft es das e weg, unb bleibt Yemrpмя̀, mit vieren.

6. 63.

Die übrigen Ordinalia werben nad) ber brife ten Declination alfo Deelinirt:

Nom. пяmb fünf, де́cяmb, zеђৃn,

Gen. пяmì десrmin,

Dat. nяmrì,

Acc. nяmb, десяmì,

Inftr. пяmbro, де́сяা⿱一𫝀), Nar. o пrmir. десямйоे, - десяmі.

\section{§. 64.}

Cópokb viergig, девяно́cmo neungig, сто fundert, geben nađ ber jwenten Declination. Nom. cópoкb, девяно́cmо, сіно, Gen. cópока, девяно́сті, стп, Dat. cópoкy, девяно́cmy, сmy, Acc; 


\section{3wenter $\mathfrak{A} \mathfrak{b}$;}

Acs. cóporb, девяно́cmo, сmо,

Inftr. со́рокомb, девяно́стомb, спомb, ober cof̧okbrò,

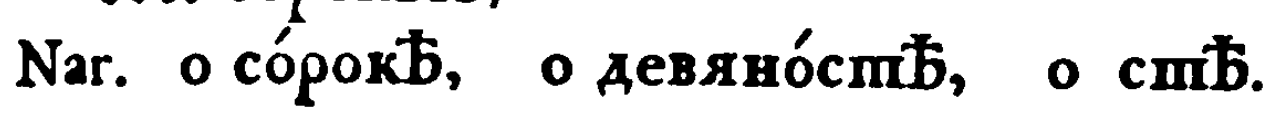
Pluralis.

Nom. cópoxk, eine $3 a \not ̧ l$ bon 40, cma,

Gen. сороко́вb,

Dat. сорока́мb, comb,

Acc. cópokz, cmamb,

Inftr. copoxámu,

Nar. o coporáxb,

cIrra, спами, o cmaxb,

Tыcяya, taufenb, wirb alfo becliairt:

Nom. \& Voc. mи́cяча,

\section{Singularis.}

Gen. \& Dat. ши́ссячn,

Acc.

Inftr. mи́cячy,

Nar. mbíc ячb\%,

- mb́cяqb ober o mb́csqu.

Pluralis.

Nom. Acc. \& Voc. mbícячa,

Gen.

Dat.

Inftr.

Nar. mb́cячей ober mbícsчb, mbícячамb, Iи́́с ячами,

- mb́cячaxb.

Mïлroнb mit feinen Compofitis geţen nad ber zroenten Declination.

6. 65. 


\section{Boll ben Nominibus.}

65

\section{\$. 65.}

Д,в

Nom. ABbcmr ober ABa cma,

Gen. Aвycomb ober AByxb comb,

Dat. Aвумb стамb,

Acc. Aвbcm и ODer ABZ cma,

Inftr. АВум іे стाами,

Nar. O AByxb cmaxb.

und alfo mpu cima, uno yembrpe cma; nber nяmb comb, imecmb comb, u. f. w. haben nяmu comb, mecmin comb, пятью спами, шестью стамн.

\section{\$. 66.}

Ilosmopà allbertfinal6, nosmpembr̀ brittefalb, noлsecsmà zeffnteffalb, u. fo m. bes. gleiden óбa bende, aвóe zwen, mpóe brey, nя́mepo fưlif, secŕmepo łefn; werben wie bie Adjectiva in Plural. beclinirt, als: Nom. noxmopà añ. noxmpembr̀̀, berthalb,

Gen. полýmорихb; полýmpembиxb, Dat. полу́mорымb, полу́mрепьимb, Acc. полmора̀, полmрешья⿱, Infr. полу́ порымиi, полу́mрепьйки, Na. o полу́mориххb. o noxýmpembrxb. (F) Norr. 
66 3wenter $\mathfrak{Q}(\mathfrak{6}$ (d). vont Den Nomin.

\section{Mafc.}

Nom. ó6a,

Gen. o6oи́xb,

Dat. o6oúmb,

Acc. oбoи́xb,

Infr. обои́ми,

Nar. o6oúxb,

Nom. aóe,

Gen. Aвои́xb,

Dat. АВои́mb,

Acc. ABoи́xb,

Inftr. Авои́ми,

Nar. ABoúxb,
Fœm.

о6), oб h́uxb, о6̆́nub, o6t́nxb, обб́ими, o6t́uxb.

mpóe, mpoúx, mpoúmb, mрои́xb, трои́ми, mpońxb.

$$
\text { 9. } 6 \%
$$

П̈ятью̀, девятью̀, десятью̀, и. f. w. fino ber Infrumentalis von nяmb, Аéвяmb, Aécяmь, mit fúnfen, mit neunen, mit zefnèn; пи́mbю, девя́mbro, деси́mbю aber, finb Ad. verbia, unb ḩeißt пя́mbю fünfmal, девя́mbю neunmal, secśmsso zefnnmal, u. f. m.

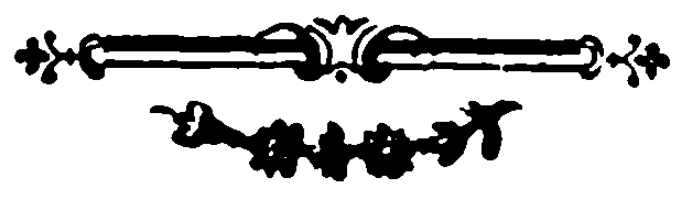

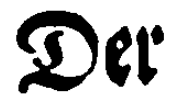




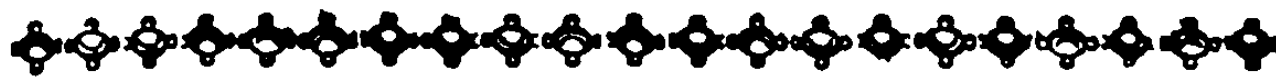

\section{Der Dritte $\mathfrak{A}(\mathfrak{f} \mathfrak{d})$ nitt. Bon ben Pronominibus.}

\section{\$. 68.}

Das $\mathfrak{B o r t}$ Pronomen joiget fíton an, baß es ein Bort bebeute, weldes an ftatt eines Nominis gebraudft wirb. Es finb bie Pronomina 1) Perfonalia, 2) Poffeffiva, 3) Demonfrativa, 4) Interrogativa, 5) Relativa, 6) Reciproca.

\section{69.}

Pronomina poffeffiva gef̧en auf bie Perfon felbft, als: $a$ idf, mb $D u$, oub er, u.f.ro. Eie werben folgenbermaßen fiectirt:

Sing.

Noin. $\boldsymbol{s}$ iळ),

Gen. меня̀ meiner,

Dat. MHb mir,

Acc: мен r̀ miф,

Voc. caret,

In凡r. мно́ю mit mit, нámu mit uns,

burd) mid,,

Nar. O mHb yon mir. o Hacb yon uns.
F 2

Plur.

Mhr wir,

Hacb unfer,

Hamb uns,

Hacb uns,

Singu- 
68

Sing.

Nom. mb ou,

Gen. me6 be beiner,

Dat. me6bे bir,

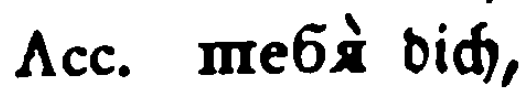

Voc. Imb o ou!

Inftr. mo6óro mit bir, Inftr.
Nar. o me6b von bir. Nar.
Singularis.

Mafc.

Nom. orb er,

Gen. erò feiner,

Dat. eмỳ i̧̧m,

Acc. erò in̨n,

Voc. - -

Inftr. uMb mit if̧m,

Nar. о немb von ingm.

\section{Neutr.}

Nom. oHò es,

Gen. erò feiner,

Dat. exy ibzm;

Acc. oнò es,

Voc. - -

$\ln$ fr. umb mit if̧m,

Nar. o zexb von if̧m.
Plur.

Nom. Bhr if̧r,

Gen. Bacb euer,

Dat. Bamb eud,,

Acc. Bacb eud,,

Voc. Bhr o ig̨r!

Infr. вáми mit cứ,, Nar. o вacb von eud.
oHà fie,

es̀ ober eè î̧rer,

ей i็̆r,

è̀ fie,

Fœm.
- -

exò mit i̧̧r,

о ней von i็̨r.

Pluralis. Mafc. Fœm.

Nom. онй, он⿺⿻一⿰冫⿰亅⿱丿丶丶⿱⿰㇒一乂 fie,

Gen. axb iqurer,

Dat. nMb if̧nen,

Acc. uxb fie,

Voc. - -

Infr. rimu mit iønen,

Na. 0 Huxbb von iģnen.

$$
\text { 5. } 70 .
$$




\section{Don Dell Pronominibus.}

69

$$
\text { \$. } 70 .
$$

Die Pronomina posfeffiva, bie ben $\mathfrak{B e f i f z}$ einer Sadje anjeigen, werben wie bie Adjectiva beclinitt, als:

Singularis.

Mafc. Fœm. Neutr.

Nom. мой mein, мой meine. мoè mein, Gea. moerò ober moéŭ ober moerò ober моево̀, моея், моево̀,

Dat. моему̀, мое́й, моему̀, Acc. моего̀, мой, мою̀, моè, Voc. мой, мояे, моѐ, Infr. моќм́, мое́ю, мои́мb, Nar. о мое́мb, о мое́й, о мое́мb, Pluralis.

Nom. мой meine, Acc. мои́xb, мой, Gen. мои́xb, Inft. мои́мк, Dat. мои́мb, Nar. о мои́xb.

6. 7 I.

Demonfrativa fino, womit man alf efroas zeiget, als: Эmomb (*) Diter, momb i aler, сей Diefer, оный jener, самый er felbit.

$$
\text { है } 3 \text { Singu- }
$$

(") Эmomb, эma, эmo, wirb von einigex Yeuern emomb, emra, emo, sefífrieben, iedod das e, wie im beutfien, e nubsefproden. Sh weip leinen 
20

\section{Dritter $\mathfrak{A} \mathfrak{6}$ 他itt,}

Singularis.

Malc.

Nom. э́momb biefer, momb jener, сей biefer, Gen. эmorò, əmoвò, morò, moвò, cerò, cesò,
Dat. эmомyे,
mомуे, семуे,

Acc. э́mоmb, эma-momb, mo- ceи, cerò,

$$
\text { rò эmовòn rò, mовò, севò, }
$$

Inftr. э́muмb, пाठмb, симb,

Nar: о э́mомb. moмb, семb,

\section{Fœm.}

Nom. э́ma,

ma, cì̀,

Gen. э́mhя, э́той, Пая̀, той, сея̀, сей,

Dat. э́mой, той, сей, Acc. э́my, my, cirò.

Indtr. э́mов,

Nar.: э́mой,

móko, céro,

moй, cẹ̆,

\section{Neutr.}

Nom. śmo, mo, ciè,

Gen. эmorò,эmoвò, morò,mosò,cerd,

Dat. эmoмỳ,

Acc. ämo,

помуे, сему̀,

Infr, ómumb,

Nar. כ̇moмb, mo, ciè, mibub, симb, momb, cexb,

Plur.

Orunb, warum man efner Budpteben aus bem rufififen alshabete verbannet, ber bie richtige fubfprade genat Teptimmet. 


\section{Bon Den Pronominibus. $\quad$ 7I}

Plural. per tria genera.

Nom. э́mr, mb,

cïr,

Gen. э́muxb,

$\mathbf{m b x b}$,

Dat. э́muмb, mbmb, cuxb,

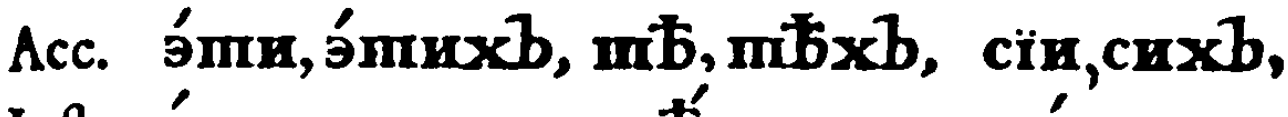
Inftr. э́mими, mb́m, симе, Nar. o э́muxb. o mbxb. o crexb.

\$. 72 .

Die Pronomina interrogativa xmo, wer? ymo, waż? werben alfo beclinirt:

Nom. кmо, ymo, Dat. кому̀, чемỳ,

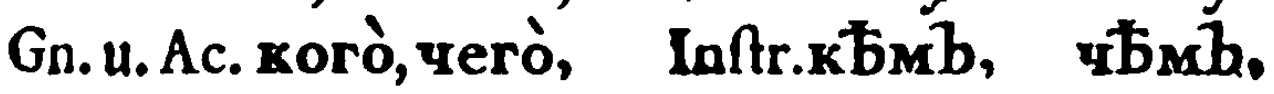
оb. хово̀, чево̀, Nar. о комb, чемb.

Eben fo gefeen aud beren Compofita, wbкmo jemano, нuкmo, niemallo, wbumo et. waż, Huymo nidjtz.

\section{Singularis. Pluralis.}

Mafc. Fœm. Neutr. p. tr. gen. Nom. чей чья, чье, чьи, reffen,

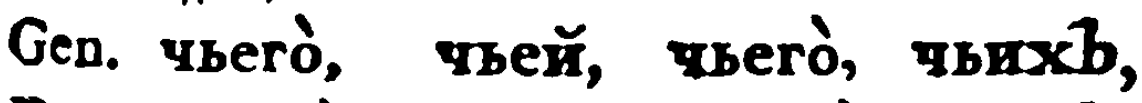
Dat. чьемуे, чьей, чьемуे, чьимb, Асс. чьего̀,чей чью, чье, чьихһ, чьи, Infr. чьимb, чье́ю, чьимb, чьи́ми, Nar. чьемb, чьей, чьемb, чьихb оbеr yobxb.
F 4
6. 73 . 


\section{§. 73 .}

Relativa, roomit man fidf allf etwas bejies bet, fino: коmópoì, кото́рая, коmópoe ; кой, ка́я, ко́e, we(d)er, welt(f)e, weld)ez; нб́ккоторый, нБкоторая, нб́которое, irgeno jemn!l; какїй, кака́я, како́e, wos̀ für einer; нйкакїй, никакая, никакое, feiner; вся́кїй, вся́кая, вся́кое; ка́ждый, ка́ж аяя, ка́ждое, eill jeder. Zlle biefe merben mie bie Adjectiva beclinirt, als:

Singularis.

\section{Mafc. Fœm. Neutr.}

Num. кото́рой, кото́рая, кото́рое, Gen. коmораго, которыя кото́раго, ob. кото̣́рой,

Dat. кото́рому, копоорой, кото́рому, Acc. коmóparo, кото́рую, коmópoe, коmópoŭ,

Infr. кото́рымb, кото́рою, кото́рымb, Nar. о кото́ромb, о кото́рой, о кото́ромb. Plur. per tria genera.

Nom. кomópte,

Gen. кomópbxb,

Dar. кото́рымb,

Acc. коmóptxb, коmо́рые,

Inftr. xоmо́рыми,

Nar. o kоmóphxb.

camb, 


\section{2on ben Pronominibus.}

camb, сама̀, самò, er, fie, es feloft, wirb auf folgenbe $\mathfrak{B}$ eife beclinirt:

Singularis,

, Mafc. Fœm. Neutr,

Nom. camb, camà, camò,

Gen. camarò ober camórs, camarò ober самово̀, само́й, самово̀,

Dat. самому̀, само́й, самому́, Acc. camorò ober camýn, camò, camosọ,

Inftr. сами́мb, само́ю, сами́мb, Nar. о само́mb, о само́й, о само́mb,

Pluralis; per tria genera.

Nom. cámu wir felbft,

Gen. camúxb,

Dat. camsímb,

Acc. сами́xb,

Infr. сами́ми,

Nar. о сами́xb.

$$
\text { ؟. 74, }
$$

Sum Befdlußge biefes $\mathfrak{a b}$ ffinitts ift nod anjumerfen: 1) Daß bie Pronomina ce6rs fict) uno cBoň fein fid) zu allen brenen Perfonen, und zu beuben వał̧len fdiden, als: $\pi$ ce6 $b$ нe

$$
\text { €. Abuy, }
$$




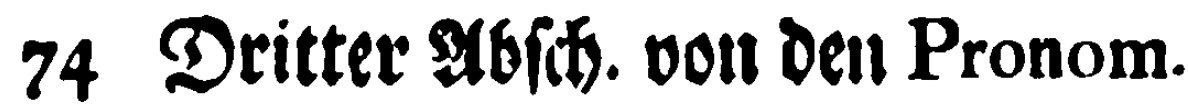

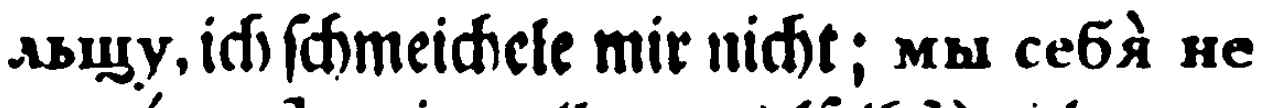
oc па́ви мb, wir wollen uns (feltifit) nidet ver. lafien; я свои́х роди́mелей почита́ю. id) vereffre meine (Eltern; онb cie cвое́ю руко́ю писа́sb, ev hat ez̉ mit eigener Şand

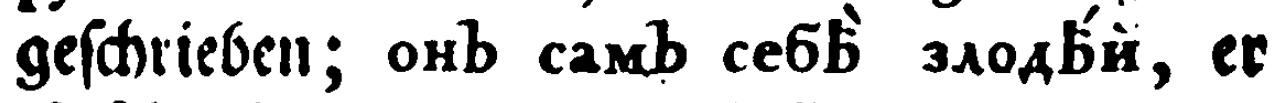
ift fein eigener Freind. 2) Einige Pronomina nef̧men bie Rraft von Nom. Subfantivis an, als: онb емуे свой, er ift fein 2ertuander; онb са́мой обма́ниикb, er if ein $\mathrm{Er}_{\mathrm{g}}$ : betriger; самb домо́й прів́халь, Der Serr ift nad) Sạufe gef́ommen.

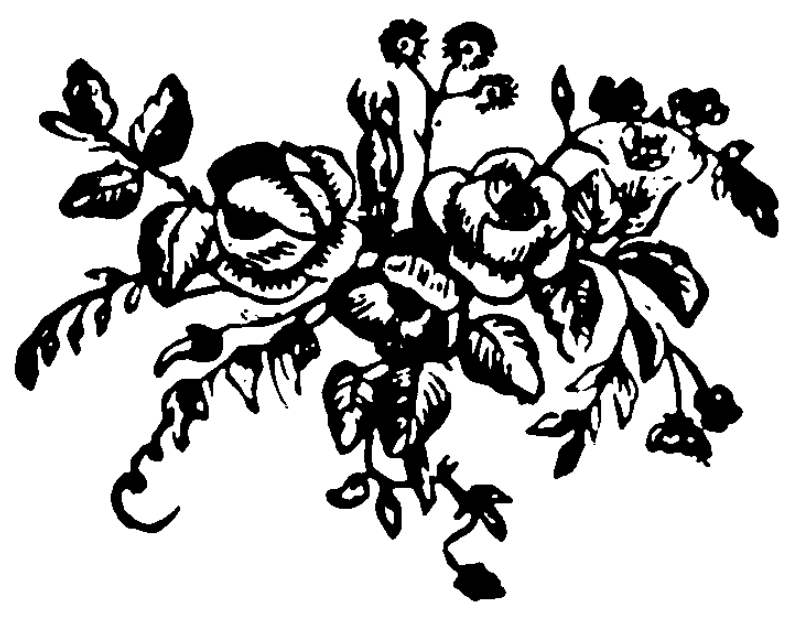

Der 


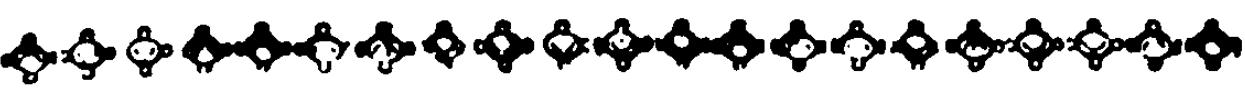

\section{Der vierte $\mathfrak{A} \mathfrak{b} \mathfrak{i}$ nitt. Son Dem Verbo.}

Dab erfte Şauptitúc.

Bon ben Verbis íberbaupt.

\section{75.}

Die Verba finb entroeder Regularia ober Irre. gularia, (ridtrige ober unridtige) Completa, Drefectiva uno Abundantia, (bollftänoige, unooll. ftáubige und úberflúsige).

$$
\text { §. } 7^{6 .}
$$

Was Verba Regularia und Irregularia, Completa uno Defectiva fino, fold)es ift aus an. Dern Brammatifen befannt. Verba abundantia find in ber rufficiden (Brammatil bergleiden Verba, oie in einerlen Bedeutung eine jwevfade $E_{n=}$ oung haben, als: колé6лю. und коле6а́ю, id) madbe walltell; мauty uno мaxáro, id) fdinunge, wulle mit ver Şand; 6brỳ und 6 bxy id lauffe. Diefe Abundantia mi:fen mit ben Frequentativis nid)t verwechfelt merben, als: 6 brỳ id lauffe, 6b́ras id) lauffe oft; 


\section{Bierter $\mathscr{A} \mathfrak{b} \not \mathfrak{a n i t t ,}$}

мeчỳ iđ fliege, remáro iđ) fliege oft; póню id) laffe fallen, poнśro id laffe oft fallen.

$$
\text { §. } 77 .
$$

Das Verbum if im Ruffifaen, fo wie in anbern Spraden, entweber ein Perfonale, wel= des alle oren Perfonen bat, als: 1 ro6גsò id) liebe, ^ró6numb ou liebelit, ^ró6umb er liebet; ober Imperfonale, to nur in ber oritten Perfon gebraudt wirb, als: наділежumb, man mu仍, naso6aemb eś gefdret fid).

$$
\text { S. } 78 .
$$

Der Generum Verborum finb fünf, nàms (id): Activum, Paffivum, Neutrum, Deponens, und Reciprocum,

Das Activum, weldes ein ₹̧̧un anjeiget, enbet fid im Prxfenti auf y unb fo, als: ynmák id) lefe, numý id) jâreịe.

Das, Paffiyum wirb von bem Participio Paffivo. Przelentis mit $\mathfrak{A}_{\text {uslaffung bes sru ges }}$ madte, unb barunter bas Verbum auxiliare ecmb id Gin, ober 6msaro id) werde, berftanden, als: von sroбимыrì einer ber geliebet wirb, fómmt heer bas Profens Paffivi a Aro6umb, fcilicet ecmb ober 6 brsaso, (*) id) werbe geliebet.

Das

(*) Cs itren alfo Diejenigen, welde bas Prefens Pafl. burdgethene von bem Yrxf. Activi, burd Anbängung ber

Enlbe 


\section{Boll bem Verbo.}

Das Neutrum ift ein foldses Verbum, mel. des feiner Natur nad, fein Paflivum b̧abentann,

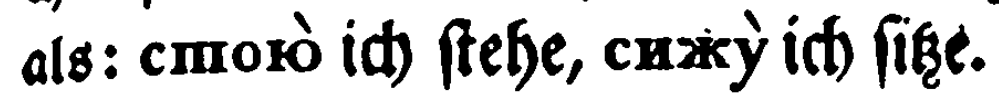

Das Deponens b̧at bie Bebeutung eines Activi, ober Neutri, unb enbet fid, auf cs, als obne reldje Enbung ein foldses Verbum nidit fenn tann, als: бorócs id fúrdte, cepzxýcs id) gưrne.

Verbum reciprocum ift ein Verbum, irelo des eine J̧anblung anjeiget, bie auf fid felbft wieder jurúc wirfet. Es entftehet aus bent Activo und endet fid, auf $c r$, als: мórocb id

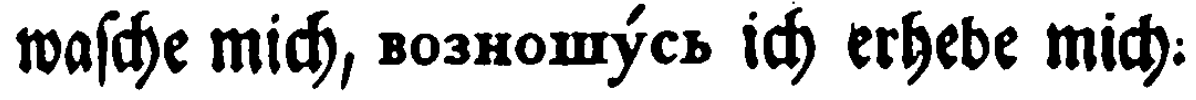

$$
\text { §. } 79 .
$$

Ben jeber Conjugation ber ruffifalen Verbo: rum fino zu merfen, Modi, Teimpora, Numeri, Perfon $x$, Genera:

$$
\text { §. } 80 \text {. }
$$

In ber ruffifden Epradie finb niur breil) Modi, nàmlid Indicativas, Imperativus, unb Infinitivus. $\mathfrak{X}_{n}$ ftatt bes Conjunctivi uno Opta. tivi braudjen fie ben Indicativum mit ber Particuld

Gylbe cr maden; benx man tann nidt fasen $\Omega$ dro.

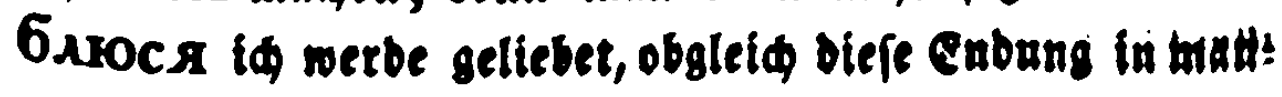
dẹ Verbis bas Pallivum formitets 


\section{8}

\section{Dierter Mbfanitt,}

cula 6ы ober 6b, als: желако чтообb онb

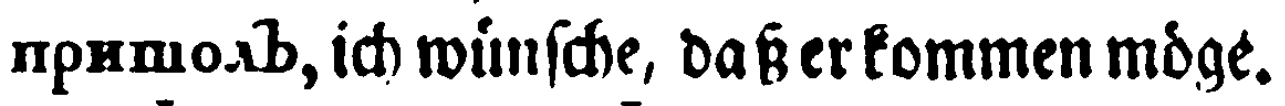
извнб угры, печенбги, татарскія орAh, извнутрь домашнїя несогласія не могли maxb ymомить россї, чпо бы силь свонху не возобновнла. (ङв fonnte Rußlanb von auffen Durd) Die $\mathfrak{H g}$. rer, Pet/deneger, und bie tatarifhen $\mathfrak{S o r}$ ben, bon innen aber burd bie cinfeimifden Uneinigleiten niddt fo febr entÉrátet werdent, DaBes fid) nidt allemal wieber etbolet bátte.

\section{§. 8I。}

Die ruffifáen Verba ḩaben zeţn Tempora, adte entftehen aus ben einfachen, uno zwer aus ben zufammengefézten. Zus ben einfahen

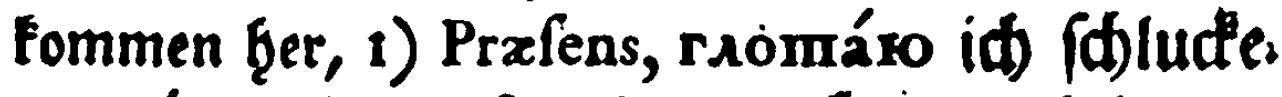
6роса́ко iф) werfe. a) Imperfectum (bie un= beftimmt vergangene Beit, ) rлomásb, 6pocáxb id) (đđluctte, id) warf. 3) Prateritum lin. gulare unitatis (bje ein mal bergangene $\mathfrak{Z}$ eit)

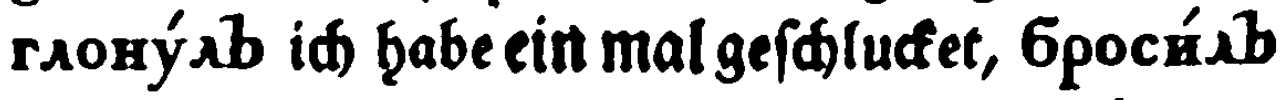
id) habe ein mal getworfen. 4) Plusquamperfertum primun, raámbrsarb iđ babe efeoem mebr: malen gefdiludet, брасыва.八b - - gewor. fen. 5) Plusquamperfectum Secundum, 6hвá: do rsomásb id babe porzeiten gefdluafet; 
6bmáıo Gроса́sb - geworfen geţabt, 6) Plusquamperfectum tertium, 6ыráa rıámbisalb id) haatte borgeiten mefrimalen ge.

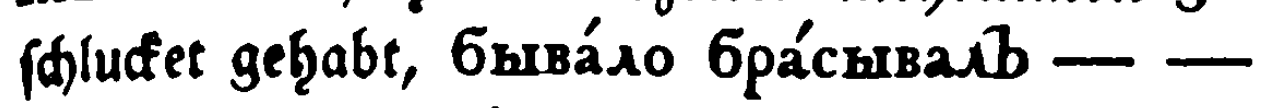
geroorfen gebabt. 7) Futurum Imperfectum, 6yAy rsomrámb id werbe (kủnftig mefrmalen) fiflufen, 6pocámb - werfen. 8) Futurum Simplex, глонуу idf werbe ein mal fáfucten, 6poury - werfen. Bon ben jufammen. gefegten entffeten 9) Prateritum perfectum, als: написа丿s id habe volltig gefforieben, von mumỳ id (f́reibe. 10) Futurum perfecturn, нanumry id werbe bs dlig forreiben.

\section{82.}

Rad ben Temporibus ridten fid aud bie Modi; benn es haben faft alle Verba oreg Prxl. Infinitivi, eben fo viel Imperat. zroeg Participia, und zwey Gerundia Praterita. Inzwifáten mad)t bie Menge berfelben bie Sadje nid)t fdfoer; benn erftlid fommen bie Infinitivi und Imperativi mit ben ingnen verroanbten Temporibus überein, als mit bem Imperfecto \& дви́raxb Das Prof. Infia. abŕramb betwegen, Part. Aви́rasmu einer Det beroegte, Gerund. aвйrasb indem man berweget hat; Imperat. ABúrar berwege Du. Mit Den Prat. unitatis a asńmyab 


\section{0}

нysb iđ babe ein mal beweget, tỏmmt überein Der Infin. Aви́ну ушь ein mal bewegen, Part. Aви. ну́вшїй einer, bet ein mal beweget ḩat. Gerund. Ави́нувши indem man ein mal berveget ḩat, Imper. Aвинь berwege; unb mit, bem Plusquam. perfecto primo aви́rubasb, ber Infinit. Aви́. гиваmb. Ziveiiens jind bie Fälle, in melden ent. reber ein ober bas andere Tempus ober Modus zu gebraudjen, im Rulfiføen leid)t ju unter/hei. ben; benn bas Imperfectum und das Plusquamp. primum, wie aud) das Futurum Imperfectum, ind, fo mie bie iz̨nen verwanten Modi, nid)ts unbers als Frequentativa; mie benn einige Verba Iud) im Prxfenti frequentative gebraudit wer= sen, als: 6 brỳ id lauffe, 6b́raso id) lauffe oft ober viel. Man tönute alfo füglid ber Temporum und Modorum meniger madjen, unb bie Tempora frequentativa zu eigenen uno befonbern Verbis frequentativis zăb̧len, bie ent. weber if̧r Przefens baben, ober beren Prxfentia obfolet finb; allein baburd mutben bie Sdyies

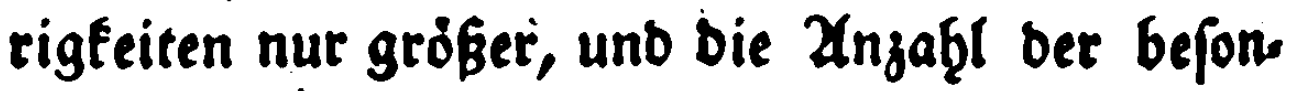
bern Verbotum unendid, werben.

\section{\$. 83.}

Numeri unb Perfonx find in ber rufinfenen Spradje eberi 10, ioie in allen úbrigen, nàmlid, jweij Numeri und brey Perfonen, als: Singul. 


\section{2on Dem Verbo.}

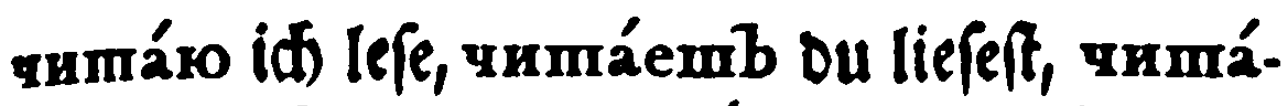
emb er liefet; Plur. чиmáemb wir lejen, чиmáeme ther lefet, yиmáromb fie lefen.

\section{84.}

Die Verba b̧aben in ber ruffifien Spradge in ben temporibus prxteritis oren Genera, ndm. lid: Mafc. Gusb er war, Fom. Gurà fie war, Neutr. 6hiò es war.

\section{85.}

Die ruffiffen Verba baben zroen Conjugationes, bie erfte bzat in ber zrenten Perfon Sing. Praf. Indic. bie Enoung in emb, bie zwente Conjugation aber in nmb.

\section{§. 86.}

Bur erften Conjugation geţören bie Verba bie fid auf ro enden, und einen Vocalem vor fid baben, als: aýmaro id Denle, aýmaemb; жела́о i(t) wúniłhe, жела́emb; поюे id) finur, nоéub; пóльзу ко ít) heile, nóльзуemb. Zusgenommen kserò iक leime, клeńmb; sorò iđ) mellee, sówub; xpoxò íto fdureide zu, кро́ишb; nò̀ id) tránte, noи́mb; cmpór id) balle, cmpónumb; поко́ro id) berubige, noxónum; cmorò id) ftefe, cmońmb; crmóю id bin werth), cmónmb; rhorò (d) laffe faulen, rHońurb; Asosò irfi ver. 
82

\section{Dierter $\mathscr{A} \mathfrak{b} / \not$ mitt,}

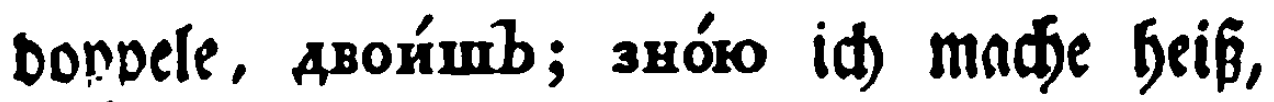
зHónumb.

$$
\text { §. } 87 .
$$

Die Verba, bie fíl) auf $y$ enben, vor wel. dem fein $\%$, y, m, und us fiefret, gebören zur erften Conjugation, als: rpe6ỳ ic riloere, rpe6éub ; зову̀ ic rufe, зовémb; cmparỳ

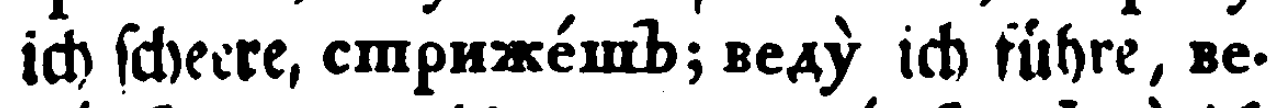
á́mb; грызy iđ) nage, грызémb; cbxỳ iđ Gaue, cbuémb; naxнy id riecte, náxнeumb; дерỳ 'd) reike, sepémb; нecỳ idh trage, не. cémb; nstbmỳ it) blube, nsbinémb. 2usges nominè 6 brỳ uth laute, 6 barúmb; ymỳ id ebre, ymúmb ; imgleidgrn Die aui ixay ausgehen,

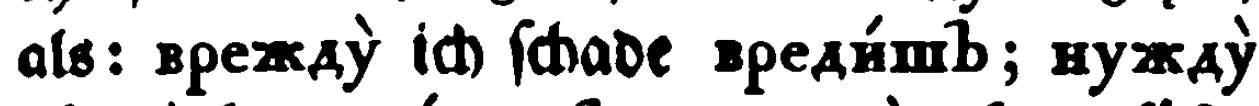

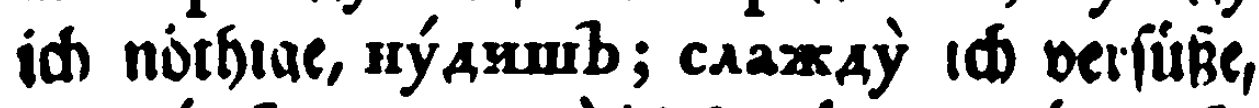
слади́mb; mруахау̀ (đ) bemúbe, тру́ дншb.

$$
\text { 6. } 88 .
$$

Die Verba, bie auf ein so ausgeb̧en, unb einen Confonantem bor fid haben, geb̧ören jut zmenten Conjugation, als: kmmuro id toche,

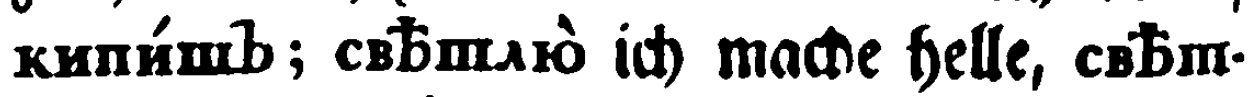

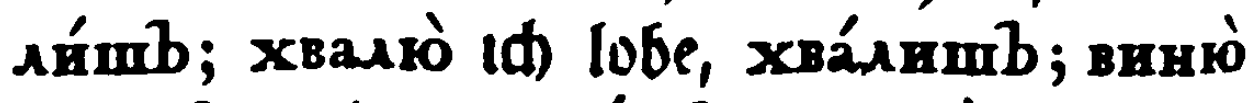
id befituloige, внни́mb; храно̀ (t) ber. wahre, храни́mb; говорю⿱宀 (i) iprecte, rово́pumb. Ausgenommen aремльо id) falum.

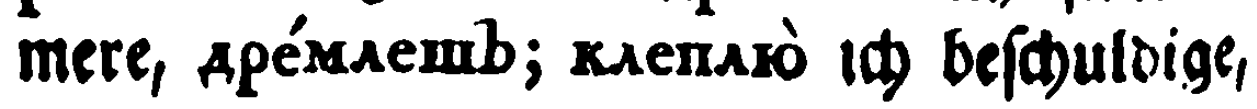


кле́пremb; коле́бльо idf madfe wantello, коле́блеши ; колю̀ id fleche, ко́лешib;

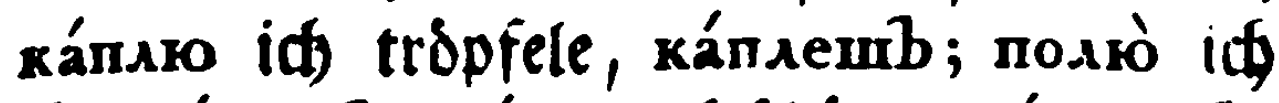

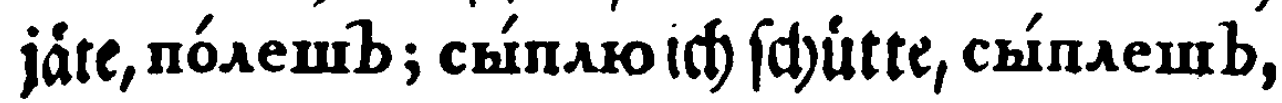
und einige andere.

\section{§. 89 .}

Femmer geḩören jur zroenten Conjugation bie Börter, bie fid auf $x y$, uy, ury, und wy en-

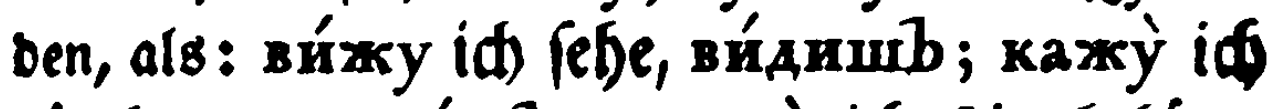
ráudere, кади́mb; myжỳ id bin befium: mert, mýжишb; вожу̀ iф) fúfre, во́диüb.

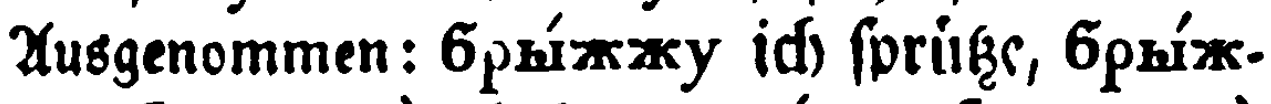
жешъb; вяжу̀ (t) binde, ви́жешb; гложỳ id benage, rмóжemb; kázy id) keige, xá. zкешb; Аижу̀ id) lecfe, 九и́жешb; мáжу

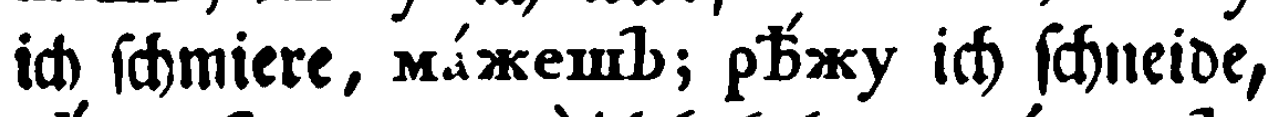

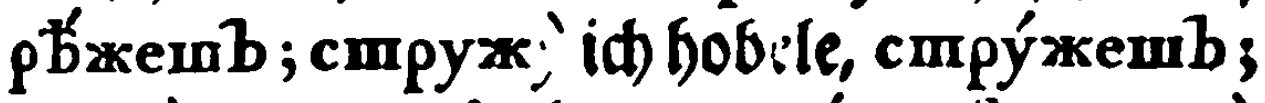

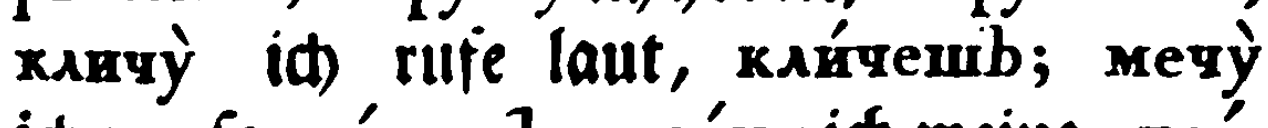
id) werfe, мéчemb; maáyy id) meille, maá-

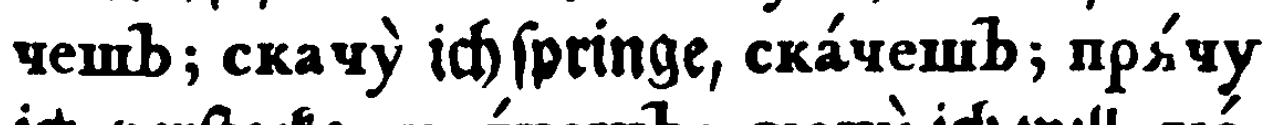
id berfterte, nрर́чemb; xoyỳ id) will, xó. чemb; пашỳ iq príge, пámeumb; пишy iđ

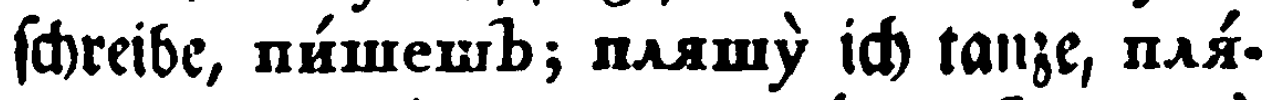
umemb; memỳ if bebaue, mémeurb; yemỳ id) fámme, frake, yémeumb; nuy̆ỳ id fudse, и́шешb; свишу̀ id) pfeife, сви́шешb, unь einige andere. 
84

\section{Dierter $\mathfrak{A} \mathfrak{b}$ [anitt}

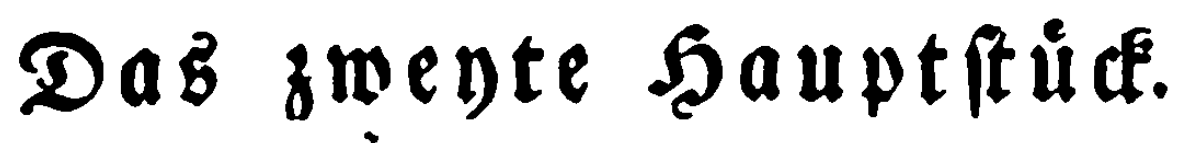
Bon Den Verbis auxiliaribus.

§. 90.

Bir fönnen füglid in ber ruffiffen Bram. matił bren Verba auxiliaria anneb̧men, nảmlid):

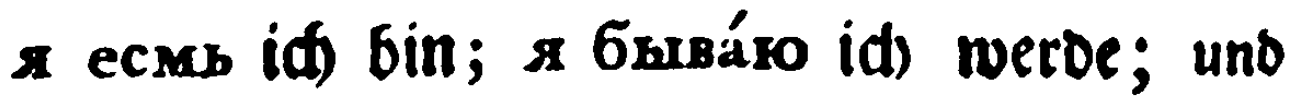
s uмbro id fabe. Das erfte wirb als ein Szùliswort bor ben Futuris imperfectis gebraudie, als: s 6ýAy rлomámb, id werde mebrmas Ien fduluttell. Я бывағо fteģe vor bem Paffivo, over wirb wenigftens barunter verftanben, als: $x$ aви́z zемb (бываюо) id werbe mehr= mals beweget. Имbro wirb auxilialiter vor ben Verbis gefeget, ba es fo viel b̧eift, als id) foll ober id reerbe, als: имbю чиmаmь, id) foll oder werbe lefin; имbю озтиалmь omstimy, it) foll ober id) werbe eine Antwort erroarten.

$$
\text { 9. } 9 \text { r. }
$$

Die Paradigmata ber Verborum auxiliariun fino folgente:

1) $\mathfrak{D a \mathfrak { b }}$ 


\section{Bon Dem Verbo.}

1) Das Verbum s ecмs iđ bin.

Indicativus modus.

Prafens.

Singularis.

ecMb, id bin,

ecù, ou bift,

ecmb, er, fie, es ift, cymb, fie fino $\left(^{*}\right)$.

\section{Prateritum.}

Singularis.

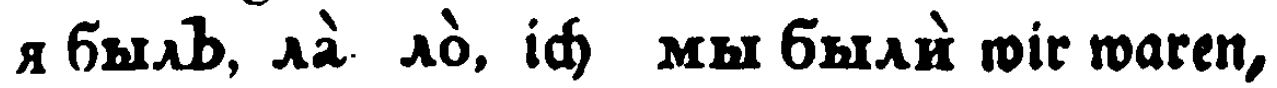
mar, bilt gewefin,

mы 6 brsb, à ò, ou shr 6hrsì if̧e waret, mareft,

онb, она̀, оно̀,6нıb, онй быsѝ fie waren. $\grave{a}, \grave{o}$, er, fie, es rar,

\section{Futurum.}

Singularis.

Pluralis.

бу́ду, id werbe fenn, бу́демb, wir werben fenn,

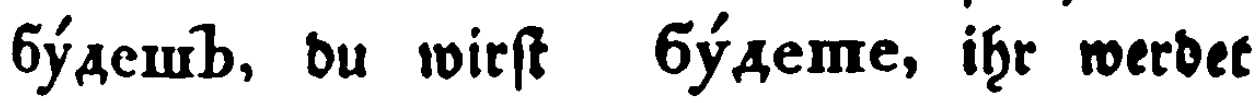
penn,

бýsemb, er, fie, ев бýaymb, fie werben roirb fern,

F 3

pern.

renn,

Impe-

(") Das Pref. biefes Verbi ift nut in bet britten per= fon Singularis uno Pluralis, iebod and diefe in wentgex

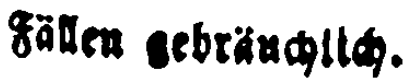


86

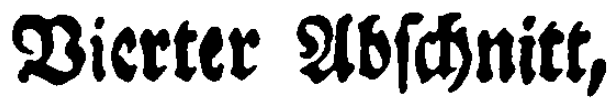

Imperativus.

Singularis.

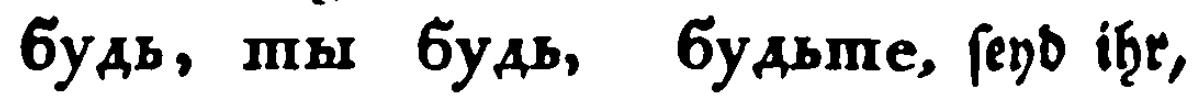

(en bu!

онb будљ, ољет пус- пуска́й онѝ бу. ка́i онb будетb, aymb, fie mògen fen er, laßst înn fenn, fernn.

\section{Infinitivus.}

Praf. 6hmb, feun.

Particip. Praf. cýüĭ̌, einer ber ift,

- Prx.6ríbuïrì, einer ber gewefen iff,

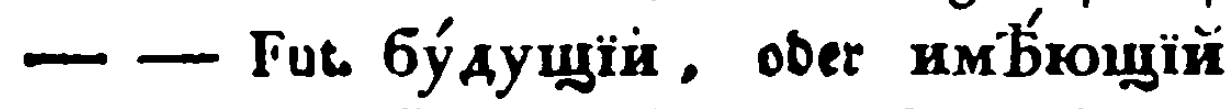
6himb, einer ber fenn wirb.

Gerund. Przf. бý дучи, im fern,

- Prxt. 6́risur, ober 6hrb, nafbem man geweren ift.

2) Daz Verbum я 6rráio, id weerde.

Indicativus modus.

\section{Prafens.}

Singularis.

Pluralis.

a 6ursáro, if werbe, mu бursáemb, wir

mux 6hxáewrb, ou mirft, oнb,2,o, 6bráemb, er, fie, es roirb, werben, вы бъва́eme, iூ̧e werbet, онѝ Ğва́รоmb, fie

merben.

Prate- 


\section{Bon Dem Verbo.}

Prxteritum.

Singularis.

Pluralis.

ת бывásb, 2, o, іф мы быва́ли, mir fino

bin geroorben,

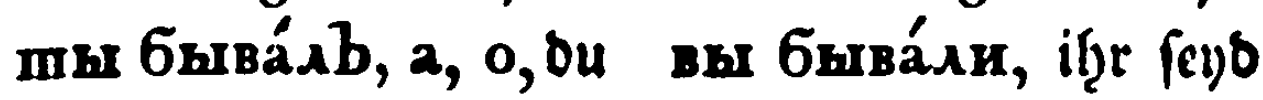

biff gemorden, онb,a,o. бнва́^b.a о, они быва́ли, fie fino er, fie, es ift gemorden,

geroorden.

Futurum.

Singularis.

я побына́ю, id) mer. мhr побыва́emb,

be werben,

mhr noбыsácurb, ou
wirft merben, овb, 2, о, побыва́ они побнва́ютb, emb, er, fie, es wirb reerben, wir werben werben, вы побыва́eme, iб̧r werbet werben, fie merben werben.
Imperativus.
Singularis.

Inperativus.
Singularis.

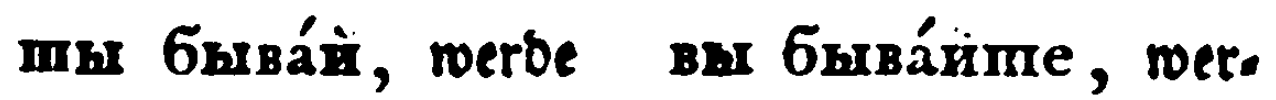
ou! bet ifr, онb, a, o, быва́й, laß̧ пуска́й онш бнвáifn, fie, es werben, romb, lape fiemerden. Infinitivus.

Prxf. 6ыsámb, werben.

Particip. Prxf. бunáromïn, einer bet iff,

Pixte. 
83

\section{Dierter 20 (d)uitt,}

Particip. Prxt. 6ыrвáswï̌̆, einer ber ift worben,

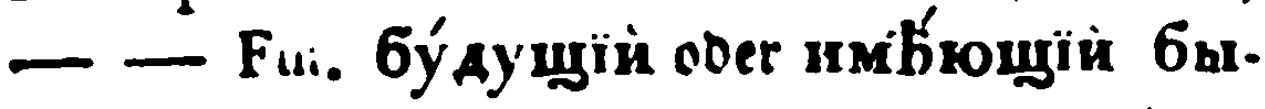
вamb, einer ber werden wiro. Gerund. Prxf. быва́лочи, ober 6hва́я, im werben, - Prxt. 6hsásure, nadoem man geroor. ben ift.

3) Das Verbum um tó i(b haje, Indicativus modus. Prafens.

Singularis.

Pluralis.

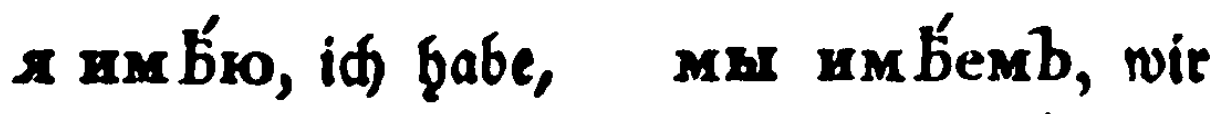

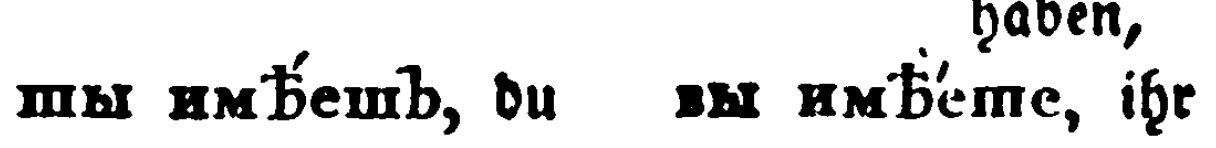
baft,

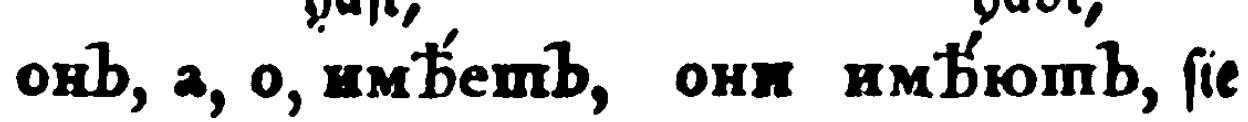
er, fie, es hat, baben.

\section{Prateritum.}

Singularis.

Pluralis.

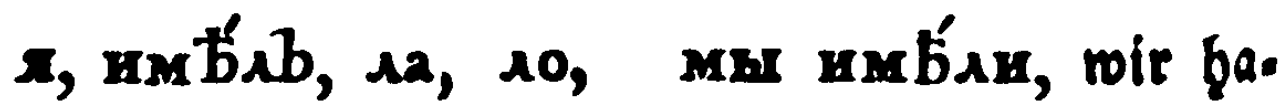
id babe geţabt, ben gefabt,

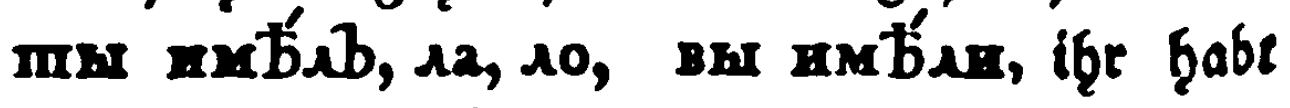
bu b̧aft gebabt,

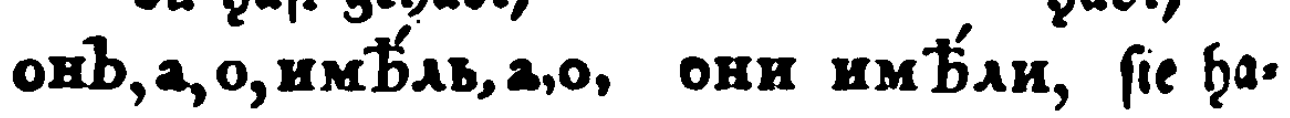
ex, fie, es ḩat geţabt, ben geţabt.

Futu- 
Futurum.

Singularis.

Pluralis.

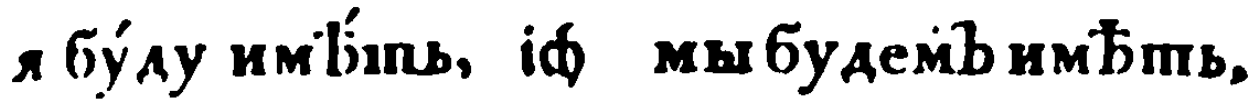
locrbe baben, wir merben haben,

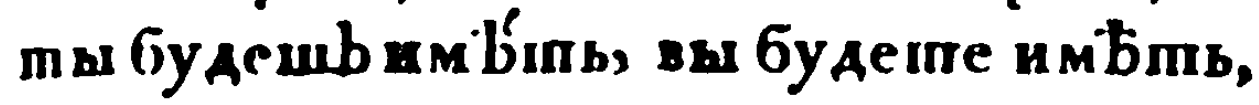
ou mirf baben, ifr merbet baben, oub, 2, о, будетb они будутb иunibinb, er, fie, es mbimb, fie merben wirb baben, baben.

Imperativus.

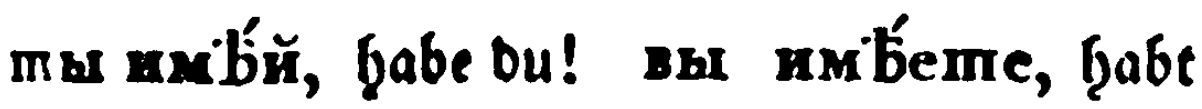
ifr,

онb uмbй laß iøn пуска́й онй имظ́. haben, romb, laßjt fie baben.

Infinitivus.

Prxf. unib́mb, baben.

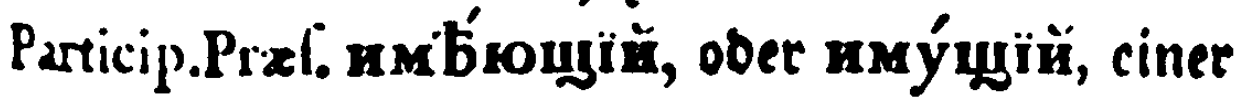
Der ba bat,

- Prxt. uxtóburĭ, einer ber ba gebabt bar,

- Futur. 6ý ay üій nubmb, ciner ber ba baben wirb.

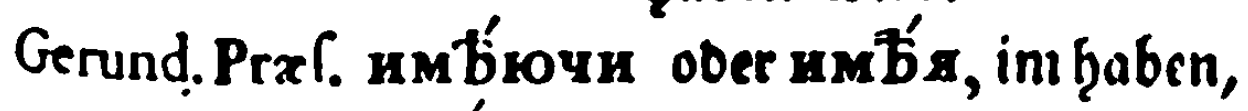
- Pret. umb́suru, nadben man gef̧abt bat.

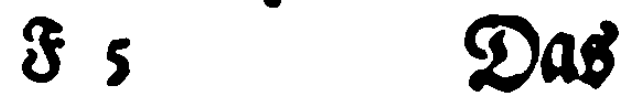




\section{Dab Dritte Sauptititá,}

\section{2on Der eritell Conjuðation.}

5. 92.

Ueberf̧aupt ift ben ben ruffifhen Verbis ju merten, baß bie wenigiten Regillaria unb Completa fino, inbem ben meb̧reften eins oner meţrere bon ben Temporibus ieflen, aud oie meiften in ben Temporibus uno Perlunia bielen $\mathbf{X b a ́ n b e r u n . ~}$ gen unterworfen finb. Diefe abainbcrungen fo roobl, als bie Derivation ber temporum weit= läuftig zu befdreiben, ift miber Den Entzroed biefer Brammatif; uno überb̨aupt lernet fid Die Derivation beffer uno leid)ter aus Der Ulebung, als burd) Regeln, Die wieber viele Xusnahınen iaben, uno bem lernenben bie $E_{a d j e}$ (d)rieriger mad)en.

$$
\text { 6. } 93 .
$$

Paradigma ber eriten Conjugation.

\section{A ct ivum.}

Indicativus.

Prxlèns.

Singularis.

a aви́raro, id be. rege, IIm дви́raewb, bu bewegeft, онb, 2, o, дв и́таеmb, et, fie, es berweget,
Pluralis.

м⿻一 дви́raenb, wir berwegen, вы дви́raeme, if̧rbes reget, Oна aвḱraromb, fle benoegen. Inper- 


\section{Imperfectum.}

Singularis.

Pluralis.

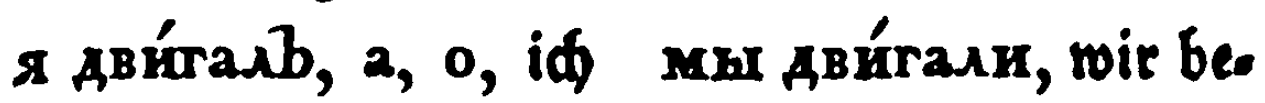
berogre,

mы дви́rasb, 2, O, вы Ави́rast, if̨r bes bu bernegteft,

онb, 2, о, ави́талb, они ави́гали, fie bes 2, o, er, fie, es wegten. beroegte,

Prateritum unitatis.

Singularis.

Pluralis.

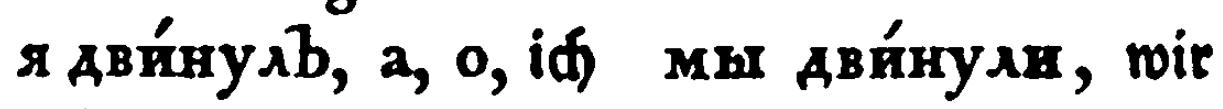
habe (einmal) berweget,

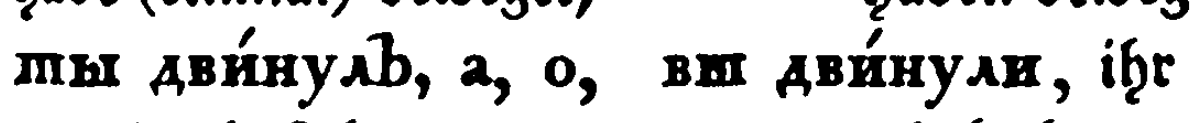
bu haft berweget, habt berweget, онb, a, o, ави́нуль, они ави́нули, fiе бৃa: 2, 0 , er, fie, es hat ben beweget. berweget,

Prateritum Perfectum caret.

Plusquamperfectum I. Singularis.

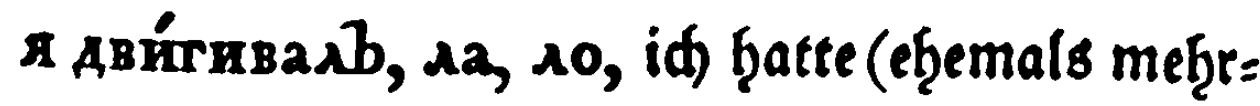
malen) beweget, шы дви́тиваль, ^2, ^о, Du ḩatteft berweget, онb, a, O, ави́rивалb, 12, 10 , er, fie, с8 batte beroeget.

Plura- 


\section{Pluralis.}

мы двйтивали, wir ḩatten beweget, мы ави́гиваí, ị̆ ḩattet beweget, они дви́гивали, fie batten beweget.

\section{Plusquamperfectum II.}

Singularis.

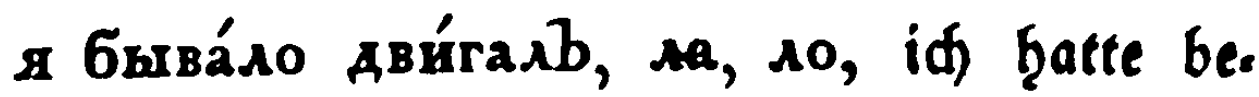
weget,

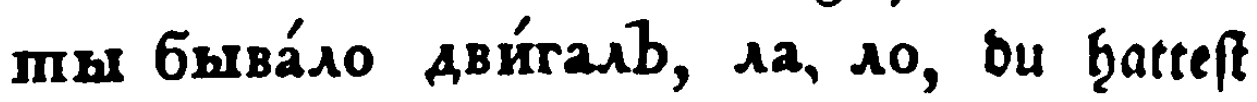
bereget,

онb, a, 0, бывало дви́raıb, ^а, ^о, ет, fie, es batte beneget.

Pluralis.

мы бщва́ло дви́raun, wir ḩatten beweget, вы быва́ло дви́rauи, ig̨r hattet bemeget, они быва́ло дви́гали, fie batten berweget.

\section{Plusquamperfectum IIX.}

Silizularis.

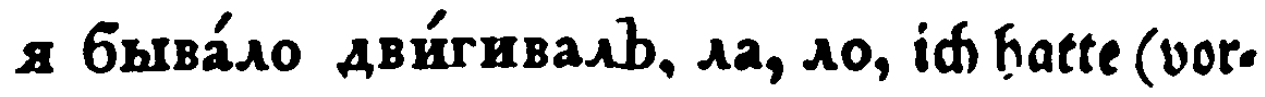

längf mefgrmalen) beweget,

пи быва́ло дви́rивалb, ^а, ло, оu দৃatteft

bereget,

онb, a, 0, бива́ло дви́гивалb, 1а, 10,

er, fie, es batto beroeget,

Plu- 
Pluralis.

мы быва́ло двй́rввали, wir ḩatten beweget, вы быва́ло Ави́гивали, į̧r b̧attet bemeget, они бывало дви́гивали, fie bqatten berosget.

Futurum Imperfectum.

Singularis.

^ бу́ду ави́ramb, iф) merbe (mit ber Zeit, mę̧rmalen) bervegen, mы бу́ дешт ави́гать, bu wirft bewegen, онb бу́ деmb asúramb, er wirb bemegen,

\section{Pluralis.}

мы бу́ демb ави́гаmь; wir werben bewegen, вы 6) aеme aви́ramb, ihr wetder birwegen, они бу́ ауmb ави́ramb, fie werden bewegin.

\section{Futurum Sirr:plex.}

Singularis.

^ ави́ну, iq merbe (ein mal) berwegen. ты Aви́нешb, ou wirf beregen, он ави́нетा, er wirb berwegen.

$$
\text { Pluralis. }
$$

мы ави́немb, wir werben berwegen, вы ави́нете, ihr werbet bewegen, они ави́нуmb, fie rerben beroegen.

Impera- 
Singularis.

Ави́тай, тाт Ави́raй, beюvege bu! онb, a, O, Ави́raй, оbеr пуска́й Авига. emb, er, fie, es berwege,

Pluralis.

Ави́raйmе, вы Ави́тайmе, bewoget iૃ̨, пуска́й они ави́raromb, fie mögen bervegen. Imperativus Fut. Imperf.

\section{Singularis.}

стань шиы ави́ramb, beroege ou, стань онb, a, o, дви́rаmb, орег пуска́й cmákemb aвúramb, laß̧t if̧n, fie, es bewegen, Pluralis.

cта́демb мы дви́тать, laßpt uns betregen, спи́́ныте вы ави́ramb, werbet beroeget, пуска́й ста́⿴囗у mb aви́r Imperativus Fut. Simpl. Singularis.

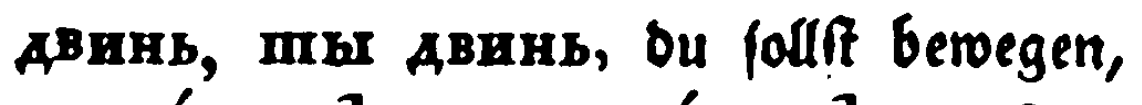
nуска́⿱ онb, 2, O, Aви́нemb, er, fie, es foll beroegen,

\section{Pluralis.}

Ави́ньте, вы дви́ньте, iğt folt beroegen,

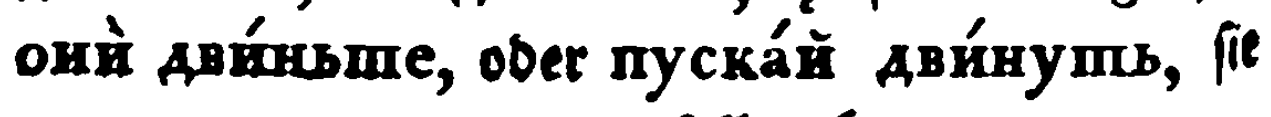
follen berwegen. 


\section{2on Dem Verbo.}

95

Infinitivus modus

Prxf. aви́ramb, bewegen, (mehrmalen)

Ави́нуть, beroegen (einmal)

Ави́гивапт, beregen, (meţrma:

len, und ju reridjebnen Beiten.)

Particip.Præf. abи́гағошїи, ar, oe, ein beroes gender,

- Imperf. Aви́raвmїй, as, oe, einer ber beroegte,

- Przt. ави́нувшій, aя, oe, einer ber (einmal) berweger hat.

Gerund. Prxf. Аьи́гая. Ави́гаючи, im lewegen. - Imperf. Aви́raвb. Aви́raвwu, indem man beweget hat.

- Perf. дви́нувшии indem man (einmal) bemeget ḩat.

$$
\begin{gathered}
\text { 9. 94. } \\
\text { Paftivum. }
\end{gathered}
$$

\section{Indicitivus Prx.}

Singularis.

я Ави́химb, ма, мо, $\left({ }^{*}\right)$ iđ neebe beroeget, пाы Ави́жимb, 2, 0 , ou wirft beweget, oнb, a, o, ави́химмb, 2, o, er, fie, es wiro berweget,

Plto

(") Şietunter wito allemal ecmb obor 6 hrsáro yet: iranter. 


\section{Pluralis.}

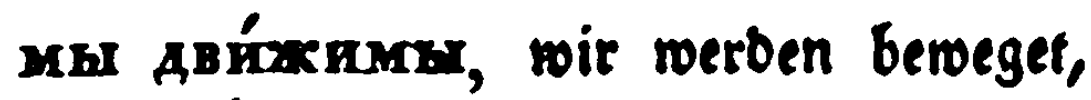
вы ави́кимы, iбr werbet bemeget, онп дви́zкимь', fie merben berweget.

\section{Imperfectum.}

\section{Singularis.}

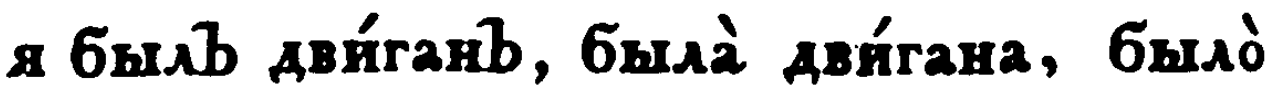
Aви́raно, id) wurbe (melgrmalen) berveget,

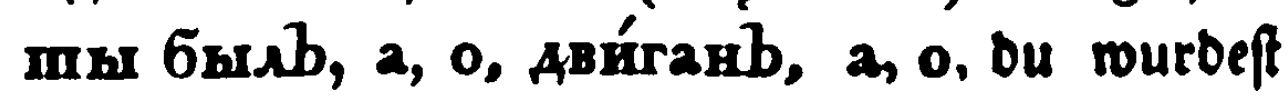
benorget,

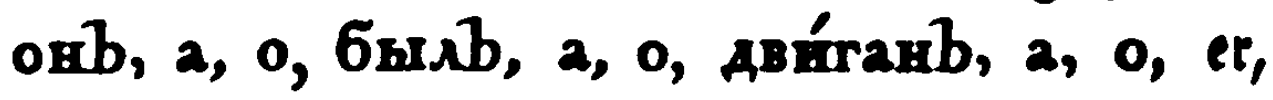
fie, es murbe berweget, Pluralis.

мы былѝ двйтаны, wir murben beroeget, вы былй ави́ганы, iб̨r murbet beweget, они́ былѝ дви́raнh, fie murben beweget.

\section{Prateritum unitatis.}

Singularis.

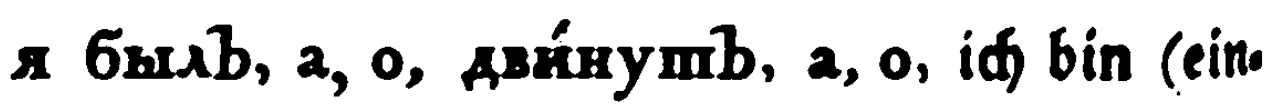
mal) beweget worben,

шы былb, a, o, Авннушы, 2,0 , bu bif berveget roorben,

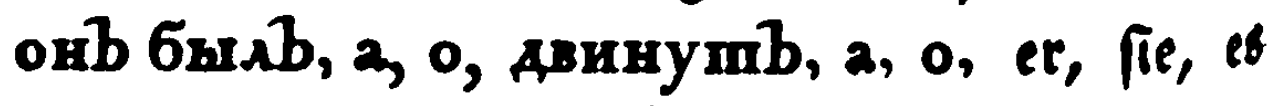
ift berweget morben, 


\section{Zoll Den Verbo.}

Pluralis.

ма бйли ави́нушы, wir finb beroeget roorben,

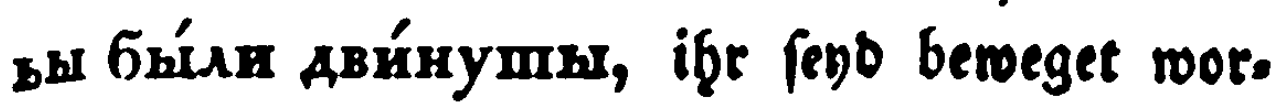
ben,

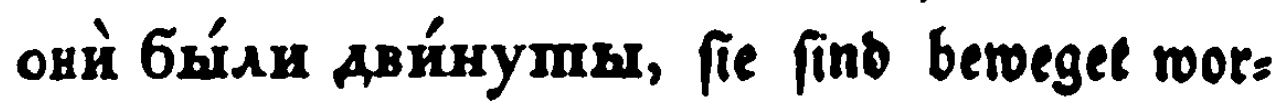
ben.

\section{Plusquamperfectum.}

Singularis.

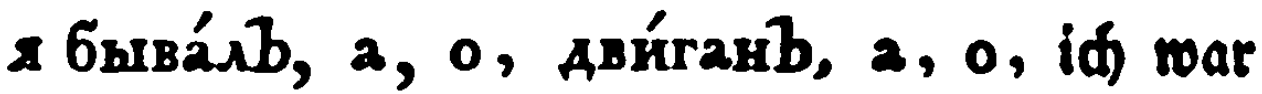
(meḩrmalen) berweget worben,

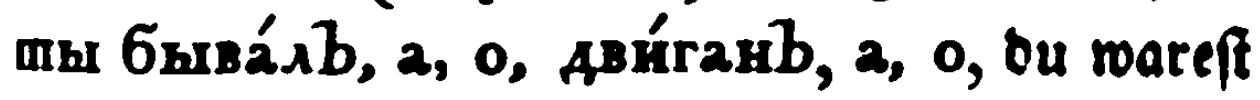
beweget worben, онb быrвásb, 2, 0, Aви́raнb, 2, 0, er, fie, es war beweget roorben,

\section{Pluralis.}

мы быва́яи дви́raнh, wir waren betweget roorben,

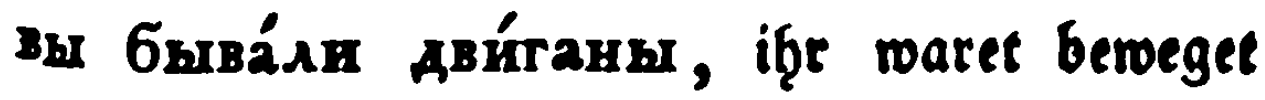
morben, онѝ бщва́ли дви́rаны, fie maren beroeget worben. 
98

\section{Bierter $\mathfrak{A} 6$ f́dnitt,}

\section{Futurum Imperfectum.}

Singularis.

\& бу́ду Ави́ганb, a, o, iđ) werbe (meḩrmalen) berweget werben, mы бу́дешb дви́raнb, a, o, ou wirft bewe: get werben, онb, a, o, бу́детा ави́ганb, a, o, er, fie, еs wirb beweget werben,

Pluralis.

мы бу́демb дзи́ганы, mir werben beweget rerben,

вы бу́детте дви́ганы, iб̧ werbet beroeget werben,

онѝ бу́дуmb діи́raны, fie merben beroeget werben.

\section{Imperativus.}

Futurum Imperfectum.

Singularis.

пуска́й я бу́ду Ави́ганъ, a, o, laß̧t miф

(mefrrmalen) berweget werden,

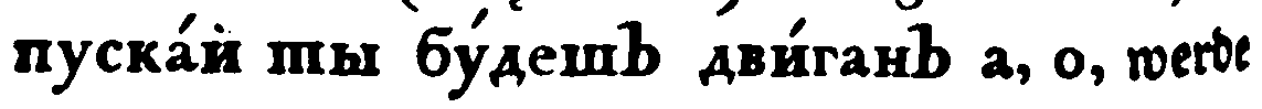
ou berveget,

пуска́й онb, a, o, бу́детъ Ави́ганb, 2, 0, laß î̧n, fie, es beweget werben,

Plur2: 


\section{Donl Dell Verbo.}

Pluralis.

пуска́й мњ бу́демb дви́ганы, Іа三 ипь beweget werben, пуска́й вы бу́дете дви́ганы, юетbet iб̨r beroeget, пуска́ц̆ онѝ бу́дуmb дви́ганы, Іа三 fie bereget werben.

\section{Futurum Simplex.}

Singularis.

пуска́й я бу́ду дви́нутb, a, o, laß̧t miф (einmal) beroeget roerben, пуска́й пы бу́дешъ дви́нутb, a, o, werbe bu beroeget, пуска́й онb, $a, 0,6$ детb дви́ну $\mathbf{b}, a, 0$, laß̧ ibn, fie, es berweget werben,

Pluralis.

пуска́й мы бу́демb дви́нуты, laß̧t uns beroeget werben, пуска́й вы бу́дете дви́нушы, werbet if̧r beroeget, пуска́й она̀ бý дуты дви́нуты, laßt fie beweget werben.
(3) 2
Infini- 
100

\section{Bierter $\mathfrak{A} \mathfrak{b}$ f}

Infinitivus modus.

6hть ави́raнy, (mę̧rmalen) beweget

werben,

быпь ави́нуту, (einmal) beweget werben,

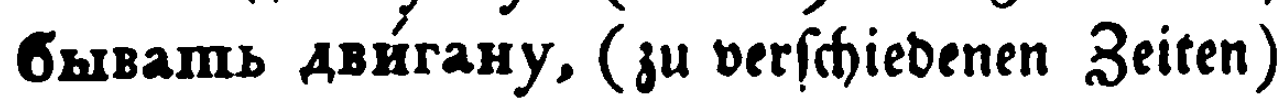

beweget werten.

Particip .Prxf. ави́жемый, мая, мое, оbеt Ави́жемb, ма, мо, einer ber beroget wirb,

- Imperf. Aви́raнhй, aя, ое, ober АВи́. ганb, 2, o, einer ber (inę̧rs, malen) ift berweget rocrben,

-Przt. Simpl. Ави́нутый. 2я, ое, ober Ави́. nymb, a, o, einer ber (einmal) ift beweget roorben.

Gerund. Prxf. бу'аучи дви́жемb, 2, o, in。 Dem er, fie, es berweget wirb,

- - Imperf. бу́дучи ави́rанb, a, o, indem er, fie, es, (meḩrmalen) beroget morben,

-Prot. unit: бу́ аучи ави́нуmb, a, o, in bem er, fie, es, (einmal) berweget morben,

- Plusquamp бу́дучн дви́гиванb, 2, 0 , in. bem er, fie, es (meţrmalen) berwe. get roorben. 


\section{§. 95. \\ Genus Relativum five Reciprocum. \\ Indicativus modus. \\ Prafens.}

Singularis.

\& Aви́rapocs, id beroege mid, шы дви́raewcя, bu bewegeft Diф, онВ ави́гается, er beroeget fid,

Pluralis.

мы Ави́гаемся, wir beroegen uns, вы дви́raemecя, į̂r beroeget eud́, онй дви́гаютाся, fie bewegen fid.

\section{Imperfectum.}

Singularis.

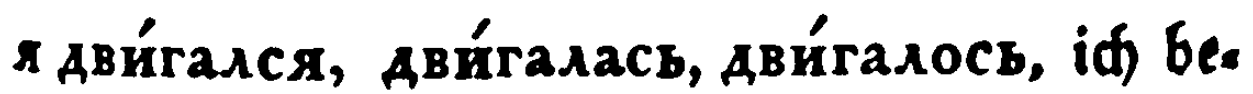
regte mid), (meţrmalen)

ты дви́гался, Аась, лось, оu berwegteft bid,, онb a, о, Ави́гался, Аасb, Аосb, et, fie, es be. roegte fidf,

Pluralis.

мы ави́гались, wir berwegten uns, вы ави́ганись, i̧̧r betwegtet eud,), ониे ави́гались, fie beroegten fí.).
(S) 3
Prxte- 


\section{Bierter $\mathfrak{A b f t b n i t f , ~}$}

\section{Prateritum unitatis.}

Singularis.

я дви́нулся, лась, лось, iф б̧абе miф

(einmal) beweget,

mhт дви́нулся, лась, лось, bu ḩaft biф beweget,

онb, $a, 0$, дви́нулся, лась, лось, er, fie, es,

hat fid beweget,

Pluralis.

ми дви́нулись, wir நৃaben uns beroeget,

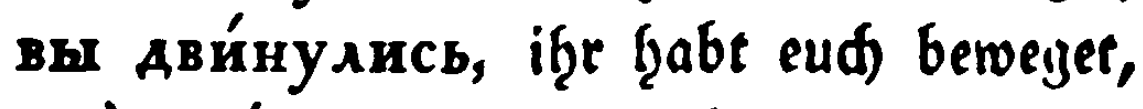
онѝ дви́нулись, fie ḩaben fid) beroeget.

Plusquamperfectum-I.

Singularis.

я дви́rввался, Аась, Аось, if batte miф

(meḩrmalen) beroeget,

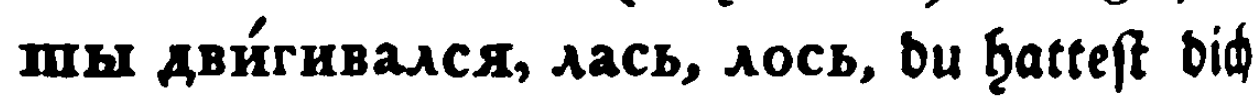
berveget,

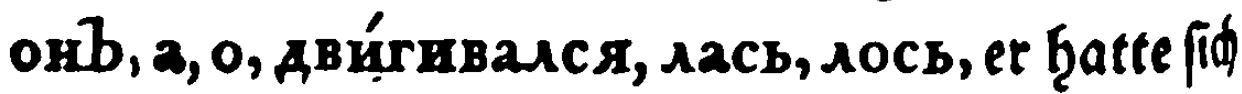
berwaget,

Pluralis.

ми ави́гивались, wir ḩatten uns beweget, вы дви́гивались, if̨r ḩattet eud) beweget, онй дви́rивалисв, fie ḩatten fid beweget. 


\section{Don Detn Verbo.}

103

\section{Plusquainperfectum II.}

Singularis.

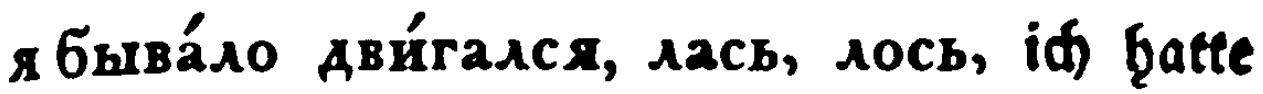
mid) (vorlangft) beweget,

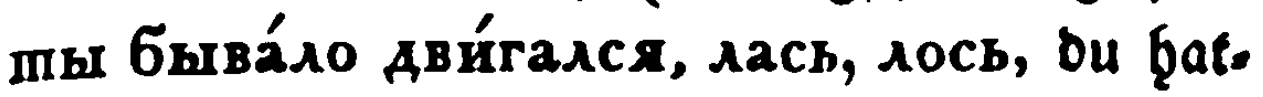
teft biđ berweget, онb, a, o, бива́ло дви́raхся, 1ась, лось, ет, fie, es bqatte fid beroeget, Pluralis. мв быва́ло дви́гались, wil Ģatten unв bes roeget, вы быва́ло дви́rauись, if̧r batiet eud̆ be: roeget, онѝ быва́ло дви́гахись, fie bৃatten fíd be. roeget.

\section{Plusquamperfectum III.}

Singularis.

я быва́ло дви́гивался, ^ась, ^ось, iđ hৃatte miđ) (zu verfaiebenen Seiten meţrmalen) beroeget.

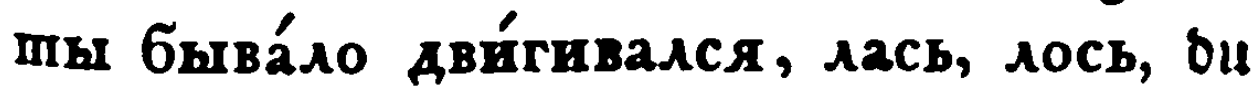
நatteft did beroeget, онb, a, о, бива́ло дви́гивался, лась, лось, er, fie, es b̧atte fid beroeget,
(B) 4 Plu- 
104 Dierter 916 (ळ) nitt,

Pluralis.

мы быва́ло дви́rивались, mir ḩatten uns berweget,

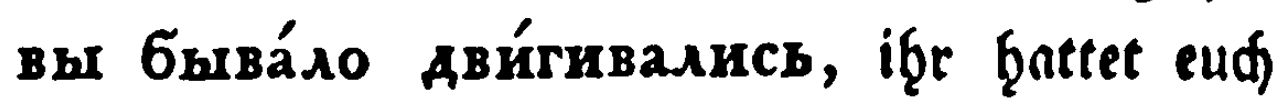
beweget, онѝ б̆ва́ло ави́тивались, fie hatten fíf berveget.

Futurum Imperfectum.

Singularis.

я бу́ду ави́гатся, іФ) merde miф) (mef̨rma. len) bewegen, mы бу́дешъ ави́ramcя, ou mirft bid) bewegen, онb, 2, о, бу́детв ави́ramcя, er, fie, ев wirt fid beroegen,

\section{Pluralis.}

мы бу́демb Ави́ramся, wir werden uns berwegen,

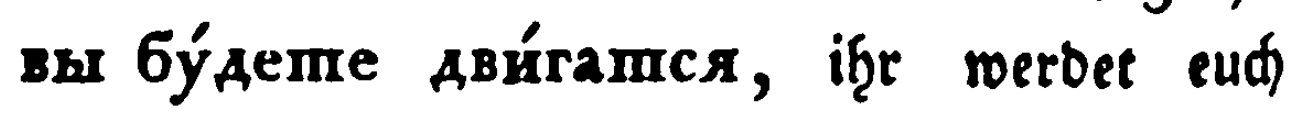
berwegen, онй бу́ дуmb aви́ramcя, fie merben fí, bewegen.

Futll- 


\section{Futurum Simplex.}

Singularis.

я ави́нусь, iф werbe mid) (einmal) bewegen, ты Ави́непाя, bu wirft bid) berwegen,

онb, 2, o, Aви́нештcr, er, fie, es wirb fí,

bewegen,

\section{Pluralis.}

мы дви́немся, wir werben uns berwegen, вы ави́нетесь, iூ̧r werbet elld berwegen, онй дви́нутся, fie werben fid) bewegen. Imperativus modus.

Prxfens.

Singularis.

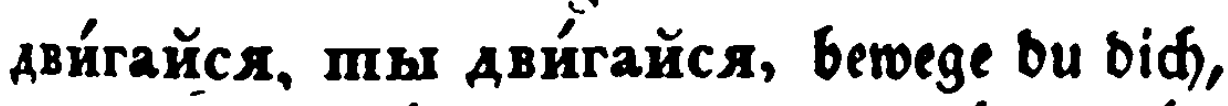
онb, a, o, Ави́гайся, орег пуска́й Ави́гаemcs, er, fie, es berwege fidf,

$$
\text { Pluralis. }
$$

Ави́raйmесь, Ави́rайmесь вы, beweget iб̨r eud),

онй Ави́raйmесь, оbеr пуска́й Ави́rаromcr, fie migen fid bewegen. Imperativus Imperfect.

Singularis.

стпань тық ави́таmся, berwege bu biф,, стань онb, 2, о, Ави́гашся, оbеr пуска́й

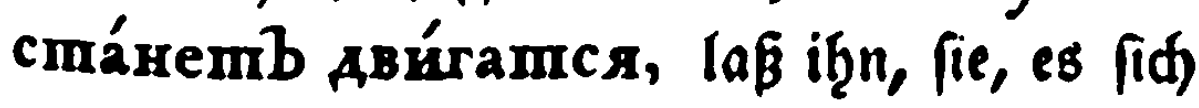
bewegen, 
Pluralis.

cmáнemb м⿻ Aви́ramca laß uns uns betoes gen,

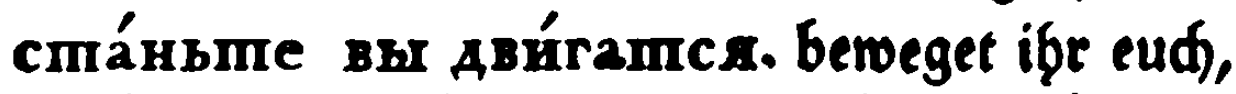
cmáнbme онй, ober nуска́ì cmáxymb ABúramcs, lafit fie fid bewegen.

Imperativus Prat. unitatis.

Singularis.

дви́ньсл, пы дви́нься, бенеge bu bid, онb, $a, 0$, Ави́нься, обег пусть дви́неш. cs, la

Pluralis.

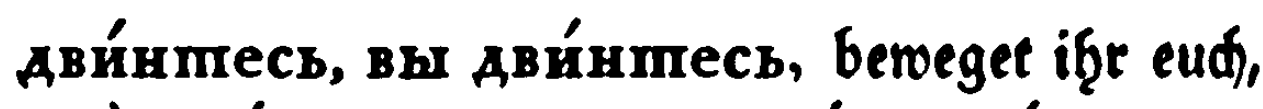
онй дви́нтесь, обеr пуска́и Ави́нушся, laßj fie fid beroegen.

\section{Infinitivus.}

ABи́ramcs, fid (mę̧rmalen) beroegen, дви́нутся, fid (einmal) bereegen, дви́ruваmсs, fid) (meḩrmalen unb zu vets fdiebenen Zeiten) beroegen. Particip. Prxl. дви́raroüййся, ался, ееся, cin fid beroegenber, eine fid bes wegenbe, ein fid bewegenber. - Imperf. Ави́гавтїйся, аяся, ееся, einer, eine, eines, ber, bie, bas fid) berwegte, 


\section{Bon Dem Verbo.}

Particip. Przt. unit. дви́нувшійся, аяся, ееся, einer, eine, eines, ber, bie, bas fid) (einmal) beroeget b̧at.

Gerund. Prxf. дви́raroyncв, inbem er, fie, es (idi) beweget,

- Imperf. Авй́raвuисв, inbem er fí beroegte,

- Przt. unit. Ави́нувшись, inbem er fí (einmal) berweget bुat.

$$
\text { 5. } 96 .
$$

Die meţreften ruffifonen Verba fino DefeCiva, bas find folde, benen es an gemiffen Temporibus feb̧lt. Befonders b̧aben nidt alle bas Prxteritum unitatis unb bab Prxteritum perfectum nebft ben if̧nen berwanbten Modis. Das Prateritum unitatis auf Hy $\boldsymbol{A b}$ baben folgenbe Verba, als:

áxаю, iф àdze, áxry $\mathbf{b}$, болmáro, iф fđúttele, болmнý $\mathbf{b}$, бреха́ю, id belle, бре́хнулb, бря́каю, iđ Flinge, брякну́ $\mathbf{b}$,

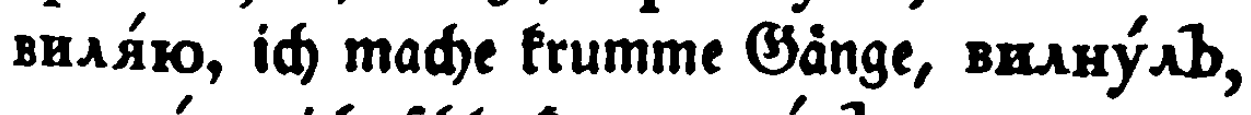

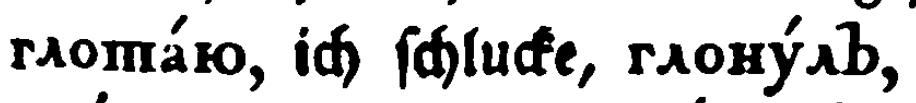
АВíraю, iф berege, дви́нуль, дерза́ю, id erfüb̨ne mid), дерзну́яb, де́ргаю, іф геiвe, діебе, де́рнуль, ика́ко, iф fфluffe, ихну́

xonáro, 


\section{Bierter $\mathfrak{A} 6$ 他nitt,}

копа́ю, id grabe, копну́ль,

кача́ю, id miege, качну́ $љ$,

кива́ю, iq minfe, кивнј'ја,

кияа́ю, iđ) merfe weg, ки́нулъ,

колеба́ю, iđ) maḑe mant́tn, коле́бнуль,

ло́паю, iđ jerplaze, ло́пнуль,

мара́ю, id befdmiere, марну́хъ,

ныря́ко, id taude unter, нырну́я

пина́ю, id froße mit bem Suffe, пнулb,

плю́скаю, id madje glatt, плю́снуль,

пиха́ю, iđ ftofe fort, пихну́ ^b, пхнуль,

пыря́ко, iq merfe, пырну́ $ы$,

рыга́ю, iđ rủlpfe, pыrнуды,

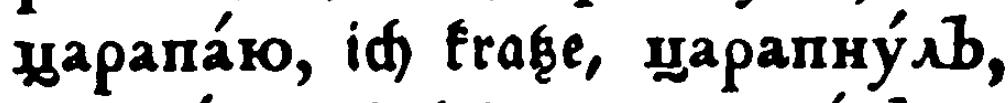

сверка́ю, iđ bliže, сверкну́ль,

сморка́ю, id fóneuze, сморкну́ль,

cmpexáro, id fánelle, стрекну́

сту́каю, id flopfe, стукнулb,

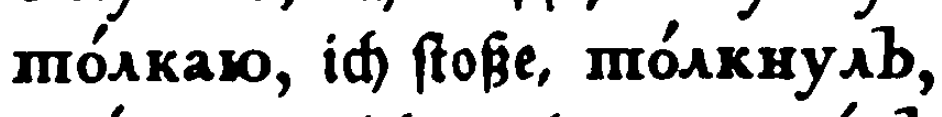

хва́стmaю, id prale, хвасну́ $\mathbf{s}$,

хлеба́ю, id effe mit soffeln, хлебну́ль,

хло́naю, id frade, ххо́nнуль,

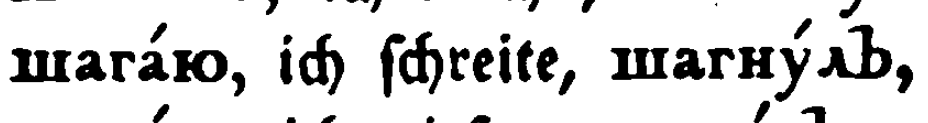

чиха́ю, id niefe, чихну́х

мига́ю, id winke mit ben Augen, мигщýab,

прита́каю, iđ beją̧e, прита́кнуג’,

wamáro, iđ made wanten, wamнý $₫$, 
00047288

Don Denı Verbo.

109

дýro, id blafe, дýнулъ,

клю́ю́, id) beißc, еffe, клю́нуль, (wirb bon

23ögeln und Jifdeen gebraud)t),

блю́ю, iđ) befpene miф), блю́нуль,

плю́ю, iq) (рере, плю́нуль,

су́ю, (d) fđiebe ein, су́нуль.

гребỳ, id) rubere, гребну́ $\lambda$,

скребу̀, id) (d)abe, скребну́

жrу, id) brenne, жегну́ $љ$,

стригу̀, id) fdeere, стіригну́ $ъ$,

6оду̀, id) foßze, бодну'лb,

зђва́ю, iđ jäne, зЂвну́хъ,

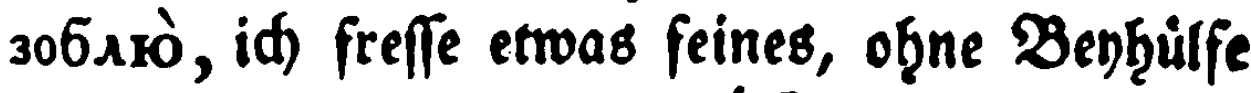

ber Şände, зобнý $\lambda$ b.

ка́шляю, іФ бұfte, кашляну́ $b$,

колю̀, id) ftedie, колну́ль,

ка́плю, ка́naю, iф trơpfele, ка́пнулb,

храплюо, iđ rảufpere, храпну́sb,

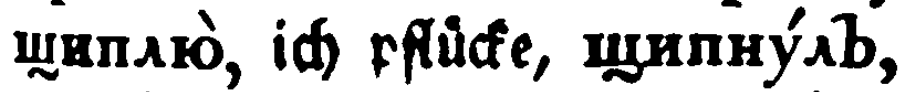

щепа́ю, iđ fplittere, щепну́х b,

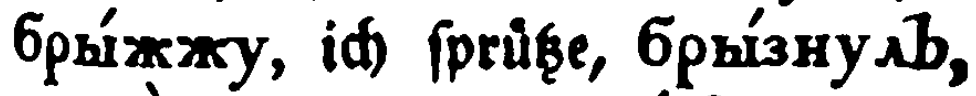

лижу, id lecfe, лизну́ $ъ$,

мáжy, id fđmiere, мазну́ $\lrcorner$,

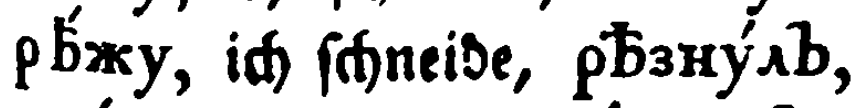

кли́чy, id) rufe, кли́кнулb,

лочу̀, iq lecte, локну'хb,

мáyy, id tunte sil, маквý $\triangleleft$,

cxary,

Jacob Rodde - 9783954791521

Downloaded from PubFactory at 01/10/2019 05:18:50AM

via free access 


\section{IIo

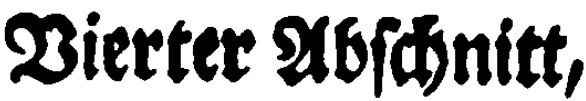

скачу̀, id fpringe, скокну́ль, mb́ry, idffede hinein, mb́кнулb,

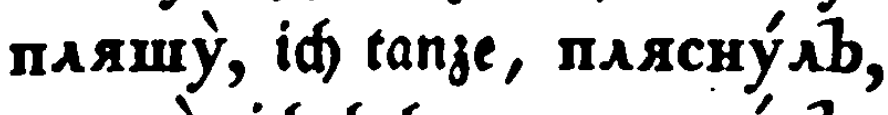
memỳ, id begaue, mecrýs $\lrcorner$, чewry, id fámme, чесну́ $\lambda b$, блеuyỳ id blinfere, блеснý $\lrcorner$, свищу iq pfeife, свисну́ $邓$, xлешу̀ iđ flatfá, хлесну́

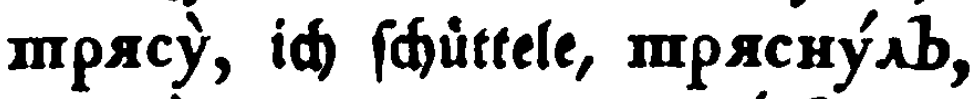
Abmỳ, id nţ̧me, Abxнý $\lrcorner$, мamỳ, id wenfe, webele, мaxнýsb, mро́таю, iđ berúb̨re, mро́нулb,

Zuffer biefen werben wanige gefunben.

$$
\text { §. } 97 .
$$

Folgende Verba exḩalten i̧̧e Prateritum perfectum von bem Imperfecto, mit $\mathfrak{B}$ enfügung eines Borworts, weld)es fich in bem Prxfenti eben beffelben Verbi nidt befindet, als:

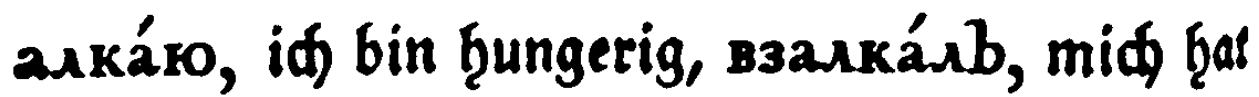
gef̧ungert,

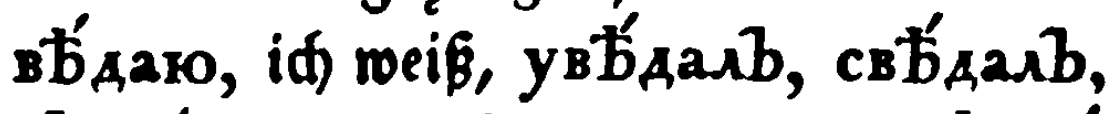

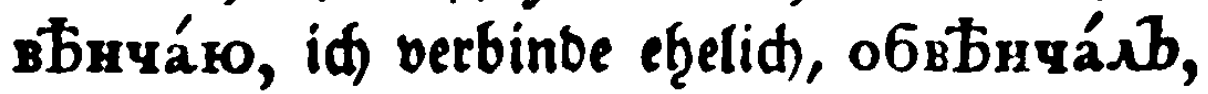
вЂmча́ко, iđ) werbe alt, обвظmчáxb, obet oбemuásb, голода́ro, iđ ḩungere, проголода́rb, ropчáro, iđ merbe bitter, oropyásb, 


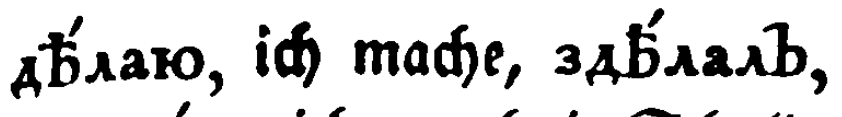
должа́ко, iđ geratţe in Squulben, одолжа́রb, ду́маю, iф benfe, взду́махb, жеспоча́ю, iđ merbe ந̧art, oжеспочáłb,

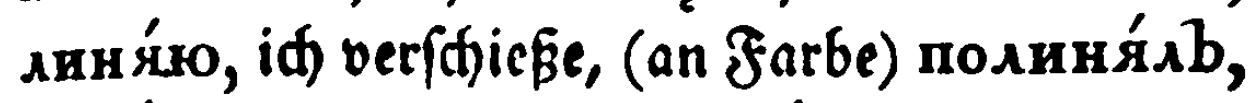
ıома́ю, iф) breche, излома́גb, мужа́ю, iđ morbe mánnliф, взмужа́sb, мара́к, iđ fđjmiere, замара́^b, позда́ю, iđ verfpàte, опозда́גb, пыла́ю, iф) lobere, вспилаád, руга́ю, iф đđjimpfe, oбpyrásb, изруга́^b, csámaю, id) ftifte eine Selvrath̆, сосваmá^b,

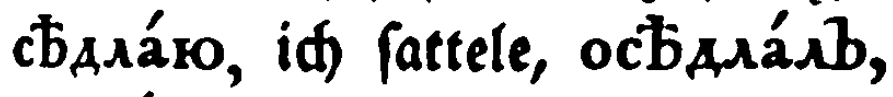

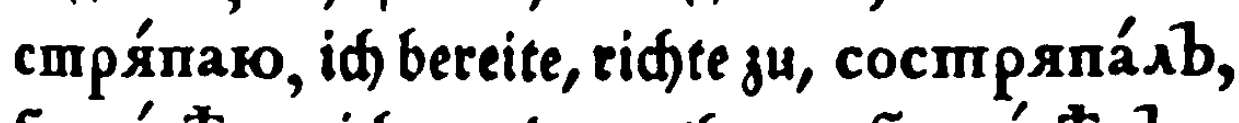

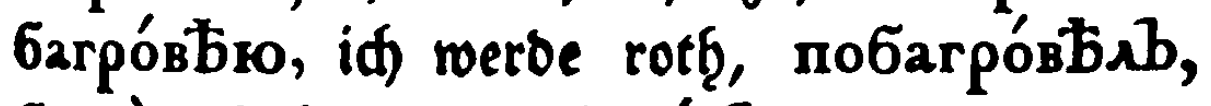
блеко, iđ blode, взблея́ $b$,

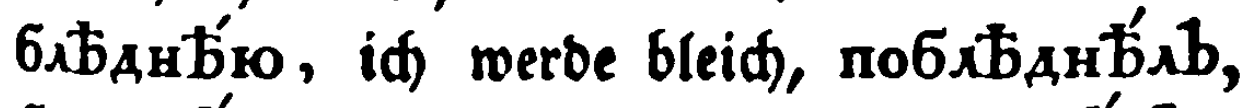
6oromb́ro, id merbe reiф, pas6oromb́丶 1 , 6орода́mbro, iđ befomme einen Bart, o6o. рода́míbıb,

sorocámbю, id́ werbe baarigt, ososocá. mibıb,

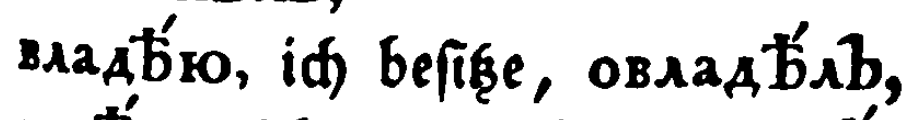

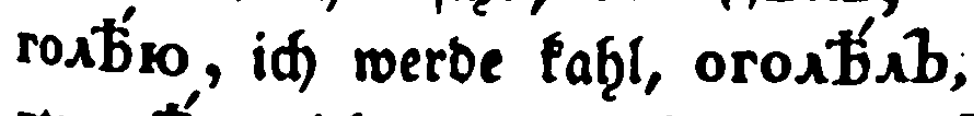
rycmb́ro, id merbe oidt, orycmb́丶

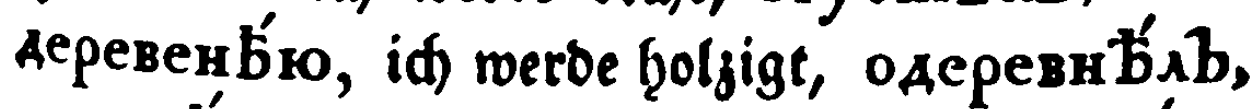

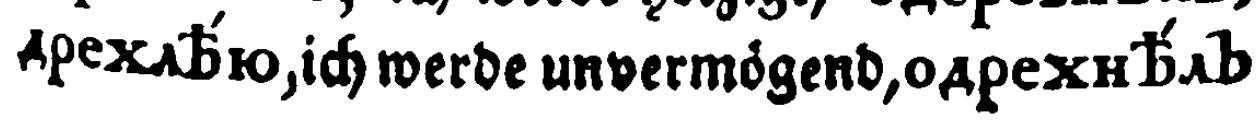




\section{2}

\section{Dierter 246 他nitt,}

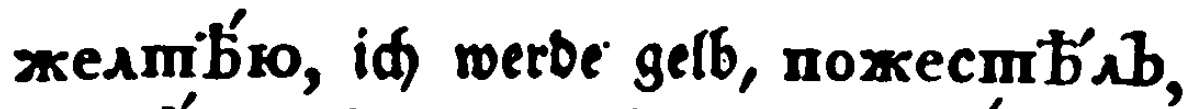

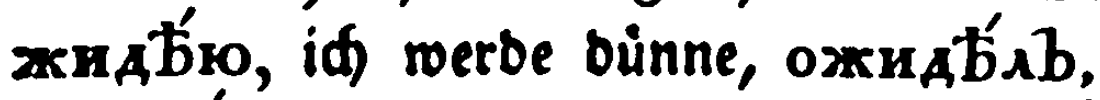
зеленб́, id тегье grün, позеленб́,

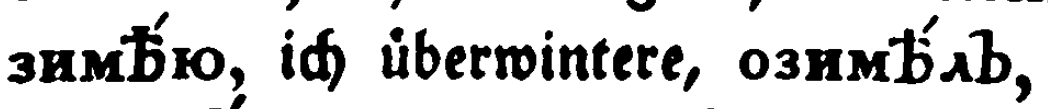
каменбю, iф werbe зи Stein, окамен $b^{\prime} \wedge$,

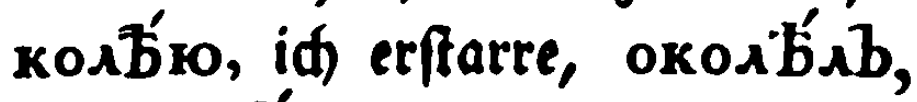
костенБ́к, iф werbe ju Rnod)en, oxоcme. н南b,

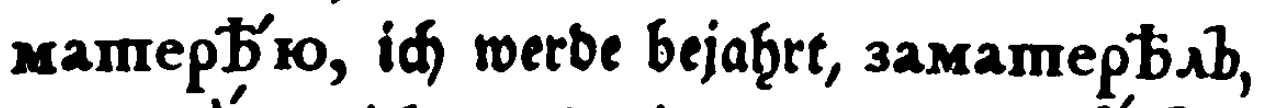
молодб́ко, id werbe jung, помолод t́s, мохнаmb́ro, id) werbe raud, обмохнá mbsb,

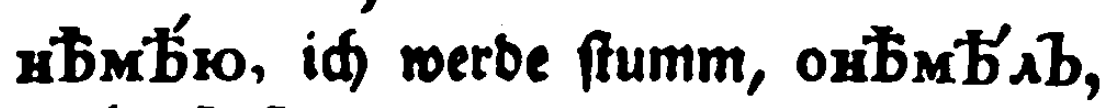

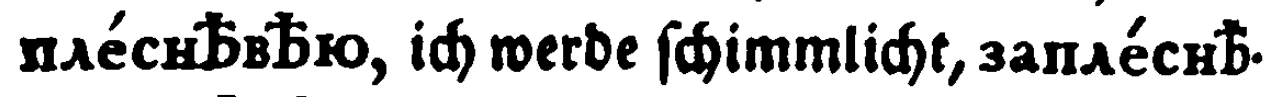
stab,

nycmb́ro, iq werbe wúfte, onycmb́rb, 32 . nycmb́sb,

paxásbro, id werbe roftig, заржа́вbsb, pastíro, id gơnne, пораa t'ab, poбt́ro, id verzage, орабt́sb, cmb́ro, i由 barf, nосм'́'sb, ḉro, id) fäe, посб́яsb, синБ́́, id werbe blau, посинб́, cupomb́, id verwaife, осиропты́, мерзб́к, id werbe abfheulid), омерз $\tilde{b}_{\wedge} b$,

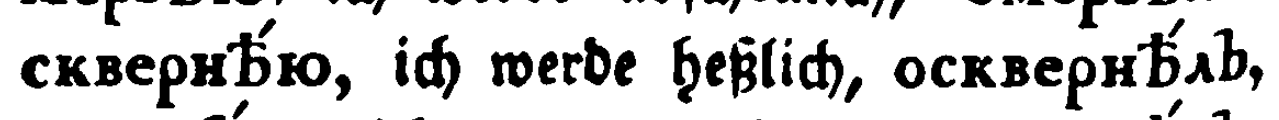

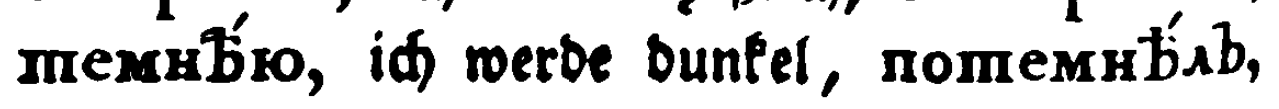




\section{2on Dem Verbo.}

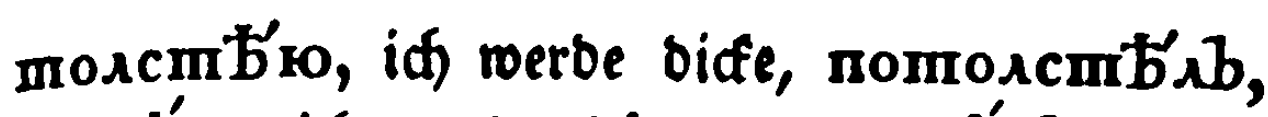

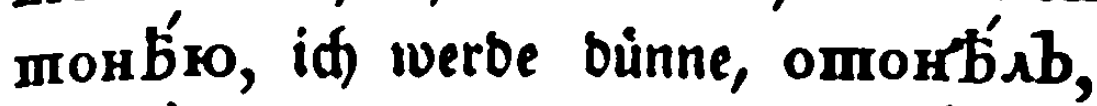
поню̀, iđ mad) oùnne, отони́лb,

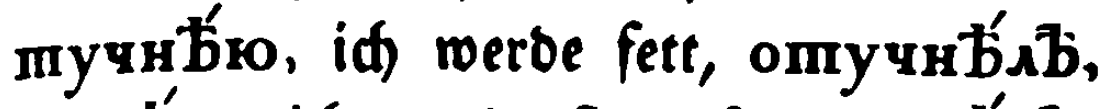

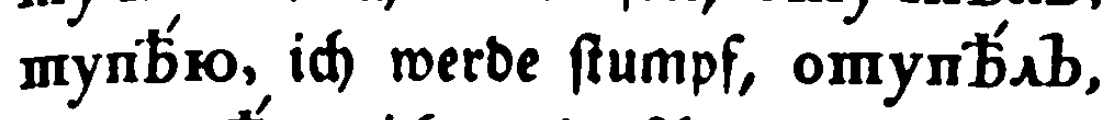

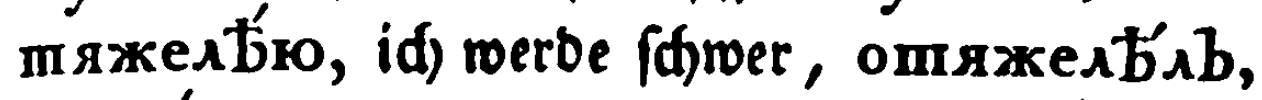
чернб̆́, id werbe (d)warz, почерн $\mathbf{b}^{\prime} \wedge$,

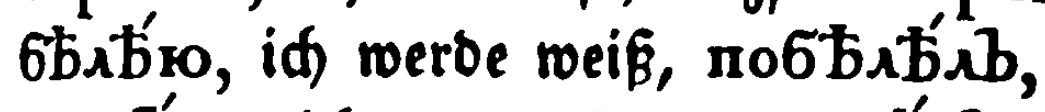

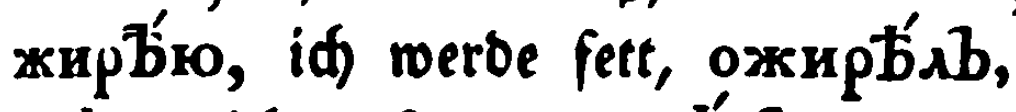
nabro, id verfenge, ons b́rb, noro, id finge, пpontísb, сную̀, iđ grúnbe, основа́лb.

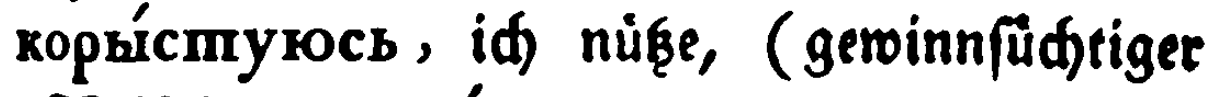
Beife) покори́стовался, волнуюे, id mađe Wellen, взволнова́лb, sopýro, id ftę̧le, сворова́גb, дово́лствую, іФ беfriebige, удово́лспвоBaAb,

ха́хуюсь, iđ) beflage miф), пожа́ловался, zásyю, id begnabige, пожáıовалb, кую̀, iđa fđamiebe, скова́ ^b, ми́лую, id begriabige, поми́ловалb, негодýro, iđ werbe.unwillig, вознегод ова́גb, ра́дуюсв, iф егfreue mid, возра́довался, рису́ю, iф) zеiфne, нарисова́лb, macýro, iđ mifde bie ßarten, cmacosárb, mpé6yю, id fobere, nampéбoвaגb, 


\section{4

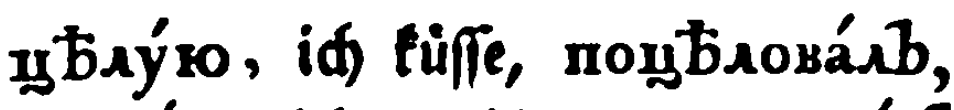

малю́́, iđ тақ̆le, намалева́sb,

mолку́ко, iđ erflàre, протолкова́лb,

чу́встввю, id empfinbe, почувспвова́s,

Агу, id ligge, солга́ $b$,

éAy, id fahre, noéxasb,

храду, id fteţle, укра́ib,

cmpazsy, id leibe, постраданы,

уро́дую, id made zu Śjanden, изуро́. дosarb,

дремлюо, id fđlummere, вздрема́ль, клепльо, id befdulbige, поклепа́sb,

6oprò, ida ringe, no6opósb, глохxỳ, iq benage, зглода́rb, pжy, id mieģere, взоржа́রb, пря́чy, iđ vetwah̆re, сапря́masb, спря́maus, xoyỳ, id will, . 3axomb́rb,

иuу̀, id fude, сыска́^b, mpenéwy, id zittere, встрепеша́mb, деру̀, iđ reiße, изодра́łb, бле́кну, iđ) relfe, побле́кb, cúnнy, iđ merbe ḩeifer, ocúnb, брю́згну, id) verfalle, ofрко́згb, cat́nuy, id merbe blino, ocstínb, слйзну, іф теebe fळlüpferig, осли́зв, мя́кну, іф werbe теiф), умякну́ $ъ$, помя́кb, чáxнy, iđ bৃabe bie Edmwinofudtt, пcчáxb, 


\section{Don Dem Verbo.}

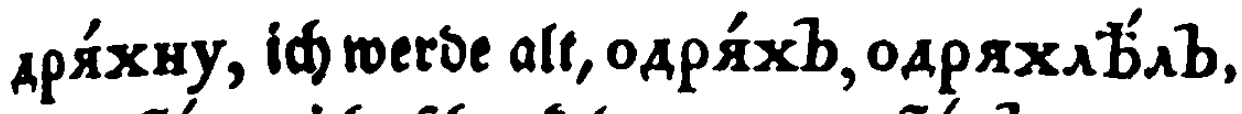
холебáro, id fíautele, nоколебásb,

nиmỳ, id fofreibe, нámucarb, ха́юос, iq bereue, пока́ялся.

$$
\text { §. } 98 .
$$

Solgenbe Verba neḩinen in bem Prxterito Perfecto tein Borioort an, als:

бpccáro, iđ) werfe, бро́силb, Aáro, id gebe, aasb,

прсша́ко, id vergebe, прости́нb,

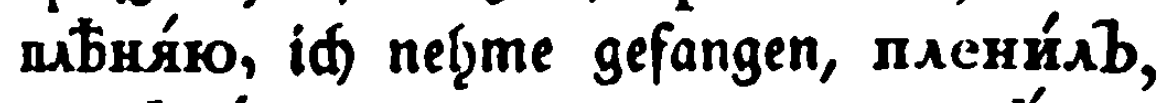

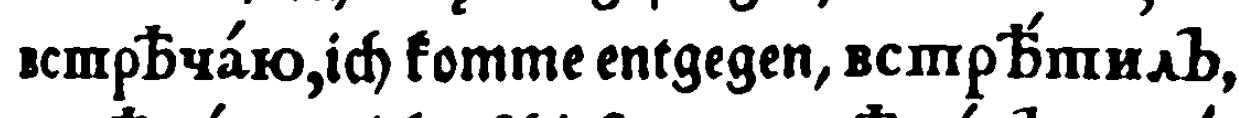

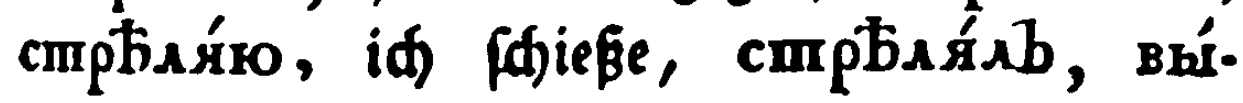
стрелия

xваmák, id faffe an, xвámияb, освобожка́ю, iđ) befrene, освободи́лъ, abвáro, id laffe, „Ђвárb.

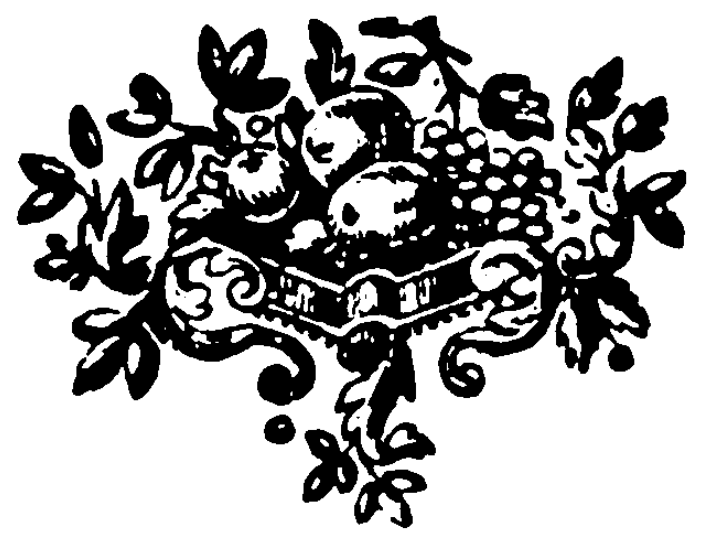

รุ 2

Dab 
116 Dierter $2(6)$ (h)nitt,

\section{Då̉ vierte Şauptifúck.}

Bon Der zroenten Conjugation.

$$
\text { §. } 99 .
$$

Die Verba ber zmenten Conjugation bie auf $y$ und so ausgetgen, und vor bemfelben eis nen Confonantem ḩaben, veränbern in allen $\dot{u}$. brigen Perfonen bes Prefentis indicativi bas y ober so in umb, иmb, имb, иme, яmb, ober amb, als: кричỳ id fabrene, кри. чи́mb ou \{dorenelt, кричи́mb er id)renet, хричи́mb wir fajreven, хричи́me ift fdiever, кpuyámb fie fafregen.

$$
\text { \$. } 100 .
$$

Die Bòrter auf $\lambda$, welde bor bem $\lambda$ einen ober zreen Contonantes ḩaben, werfen in allen

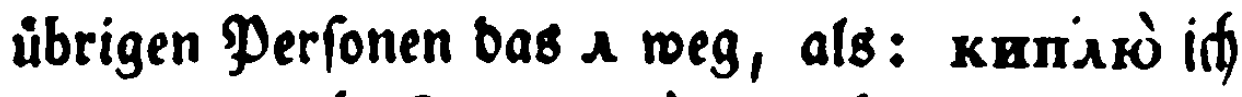
fod)e, кипи́mb; давлภò iФ Drúcte, Аа́вишb. Jeond) mb́csio id finne, bुat mbícsnub;

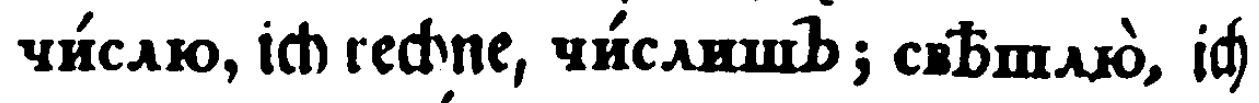

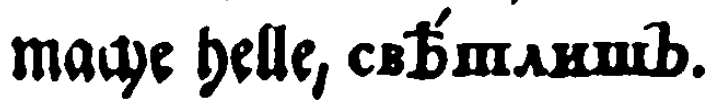

6. 101. 
\$. 10r.

Paradigma ber jiventen Conjugation.

\author{
A Et i vum. \\ Indicativus modus. \\ Prafens.
}

Singularis.

a sepuỳ, id brę̧e,

mы верпи́mb, ou

oretgeft,

онb, a, o, верти́́mb,

er, fie, es orehet, oнѝ вepmx́mb, fie

\title{
Imperfectum. brę̧en.
}

Singularis.

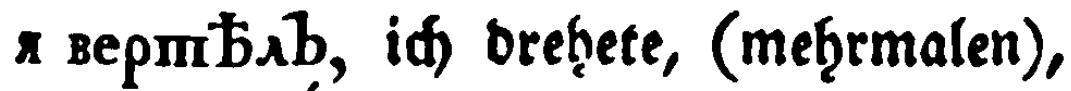

mы верmb́, $\wedge b$, ou bref̧eteft, онb, a, о, верпт́́, $b, \wedge a, \wedge 0$, er, fie, еs bref̧ete,

Pluralis.

мы sepmb́tın, wir brȩ̣eten,

вы верmb́an, if̧r orelgetet,

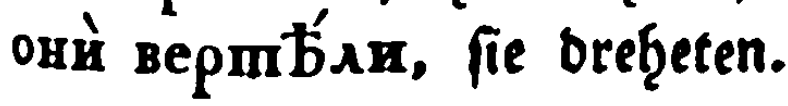

Prxteritum unitatis.

Singularis.

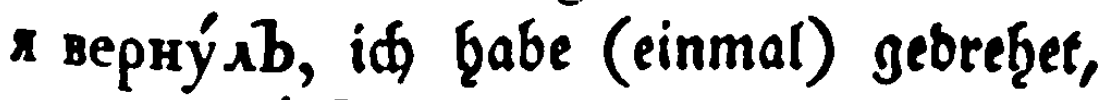

п:ы верну́ $А$, bu ḩaft gebreḩet,

онb, a, о, верну́ 1 , ла, 10, er, fie, es bqat

getoref̧et.

胥 3

Plna- 


\section{Bierter $\mathfrak{A b}$ fdnitt,}

Pluralis.

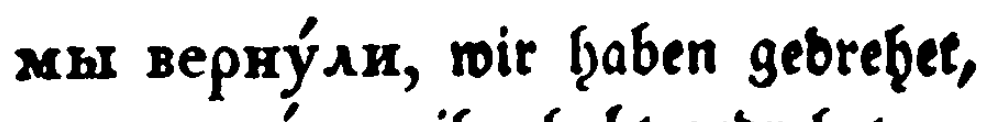

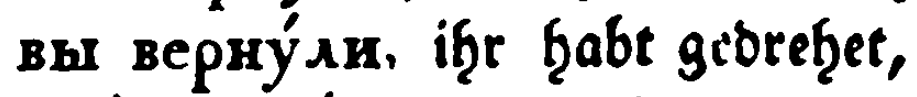

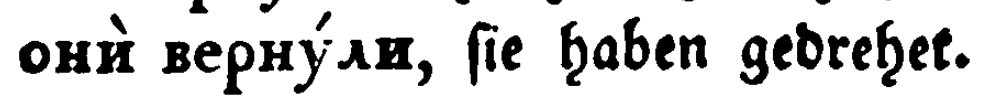

Plusquamperfectum I.

Singularis.

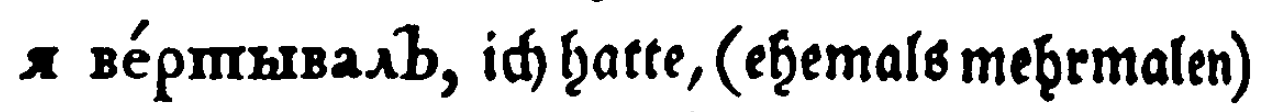
getreḩet,

mbr вépmbrsaגb, ou ḩatteft getref̧et, онb, 2, o, ве́рпввалb, 12, 1о, er, fie, н ḩatte gebref̧et,

Pluralis.

мы ве́рпmвалд, wir দ̧atten gebrę̧et,

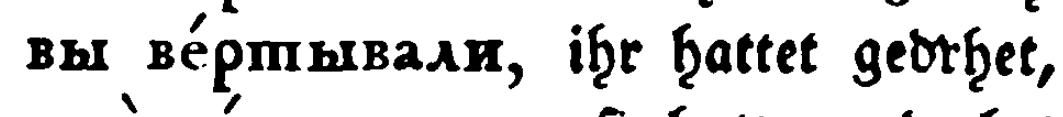
онй ве́ртывали, fie ḩatten gebrę̧et.

\section{Plusquamperfectum II.}

Singularis.

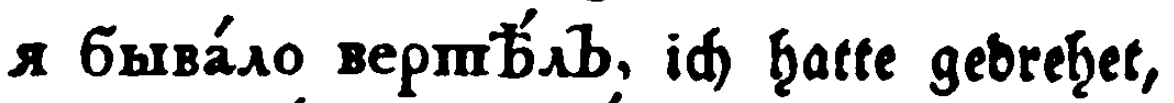

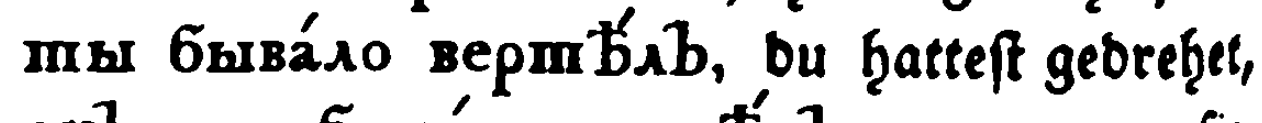

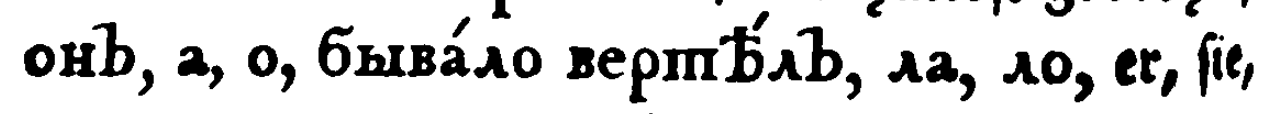

es b̧atte gebreb̧et,

Pluralis.

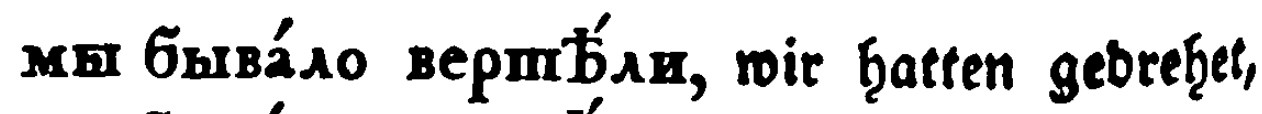

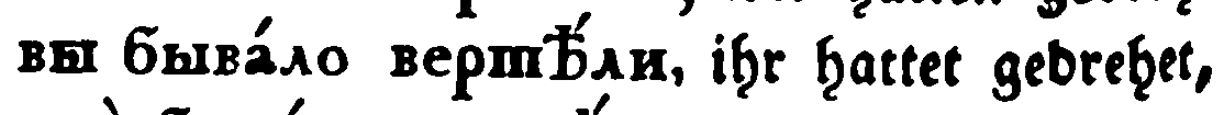

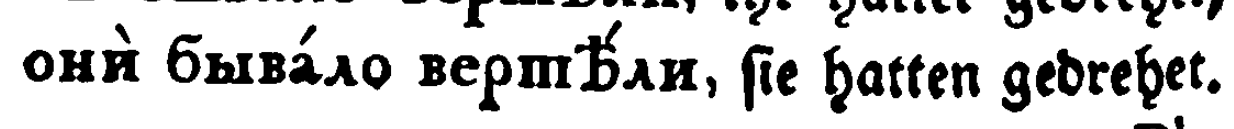

Plus- 


\section{Bon Dem Verbo. \\ Plusquamperfectum III.}

Singularis.

я бива́ло ве́ртввалb, iq) ḩаtte (vorgeiten meḩrmalen) gebreḩet,

пы быва́хо ве́рпывахъ, bu бৃatteft georef̧et, өнb, а, о, быва́ло ве́ртывалb, ла, ло, ет,

fie, es ḩatte gebrehtet,

Pluralis.

sы быва́ло ве́ртвнвахи, wir ţatten georehget, вы быва́ло ве́ртывали, iб̨r দ̧attet gebreḩet, они быва́ло ве́ртввали, fie ḩatten gebrę̧et.

Futurum Imperfectum.

Singularis.

я бý malen) oreḩen,

mы бýsешы верmb́mb, ou wirft breb̨en, oнb, a, o, бу́детb вертї́ыь, er, fie, es wirb breben,

Pluralis.

мы бу́ демb вертй́mb, mir werden brefien, вы бўдете sepmb́mb, iந̨r werbet brę̧en,

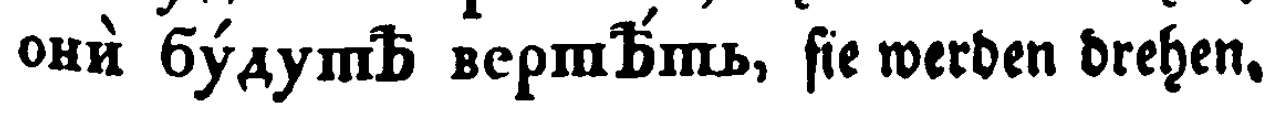

$$
\text { Sุ } 4 \text { Futu- }
$$


Futurum Simplex.

Singularis.

$x$ вернуे id merbe (einmal) bref̧en,

пы верне́mb, ou- wirft oref̧en, онb, a, о, вернémb, er, fie, es wirb bre⿻̧en,

Pluralis.

мы верне́мb, wir merben ore⿻̧一ฺn, вы верне́me, if̧r merbet orę̧en, онй верну́mb, fie rerben orę̧en.

Imperativus modus.

Prafens.

Singularis.

вертй, mhr вepmì, orę̧e ou; вepmì oub, a, o, ober пуска́й sepmŕmb, er, fie, es bref̧e,

\section{Pluralis.}

sepmúme, ober вы вepmńme, oref̧et iø̨r, sepmúme onѝ, ober пуска́й sepmśmb, lapt fie oreḩen.

Imperativus Futur. Imperf.

Singularis.

стань mbr верmb́mb, brę̧e ou,

стань онb, a, о, обег пуска́й ста́нетb sepmb́mb, laß̣t į̂n, fie, es orę̧en.

Plura- 
Pluralis.

ста́немb мы верmб́́mb, laßßt uns orę̧en,

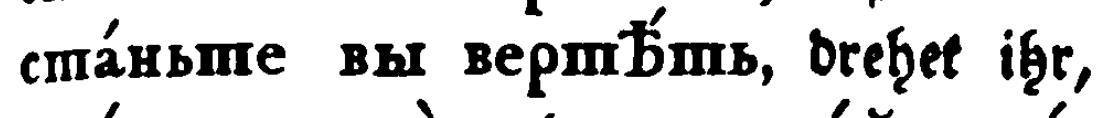

сmáньmе онѝ, ореr пуска́й сmáнymb вepmb́mb, laßjt fie brę̧en.

Imperativus Futur. Simpl.

Singularis.

вернй, ты вернй, bref̧e bu, (finftig einma) онb, a, o, вернй, обеr пуска́й верне́mb, laßst i̧̧n, fie, es breģen.

Pluralis.

верни́mе, вы верни́mе, oreḩet į̧r,

онѝ верни́mе, обеr пуска́й верну́mb, laßt

fie brę̧en,

Infinitivus modus.

sepmb́rmb, breb̧en, (meţr als cinmal)

sepнýmb, orę̧en, (einmal)

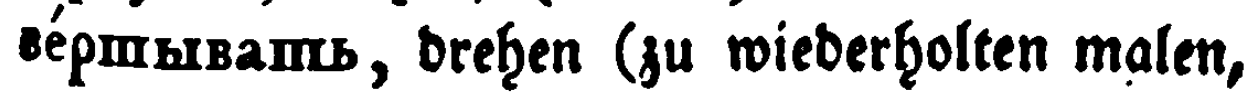
und verffiebenen Beiten).

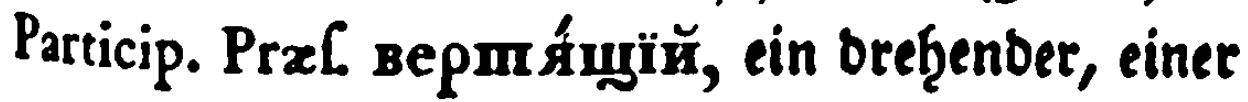
ber oa breģet,

- Imperf. верты́впійй, einer ber ba bref̧ete,

- Perf. верну́вшійй, einer ber (einmal) gebrę̧et b̧at.

Ş 5 Gerund. 
122 Bietter 246 佸nitt,

Gerund. Praf. sepmŕ, sepmróun, im bref̧en, - Imperf.sepmbsb, sepmb́swn, indem man brehete,

- - Perf. sерну́sb, sерну́вшв, inbera man gebreģet bुat.

\section{102. \\ Paffivum. \\ Indicativus modus:}

Das Prafens mangelt; weil bas Paflivum fein Participium Prefentis ḩat.

\section{Imperfectum.}

Singularis.

я бнль ве́рченъ, бниа̀ ве́рчена, бино ве́рчено, id war gebrebet,

mar 6 rab, a, o, sépuemb, a, o, bu roareft gebref̧et,

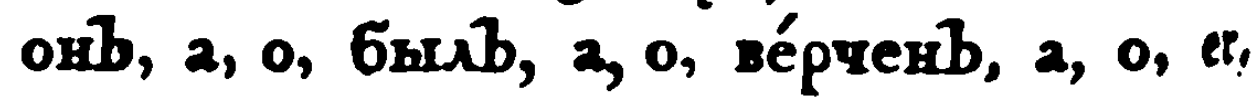
fie, es mar gebrebet,

Pluralis.

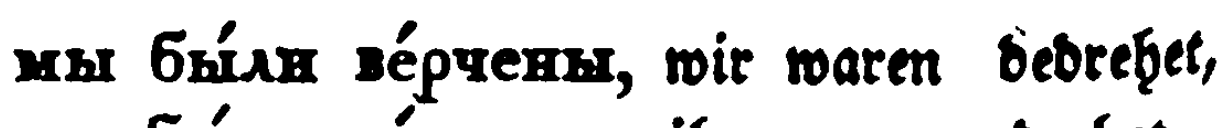
sw бъ́ ouи би́ли sepqeнm, fie maren gebref̧et.

Prate- 


\section{Bon Dem Verbo.}

\section{Prxteritum unitatis.}

Singularis.

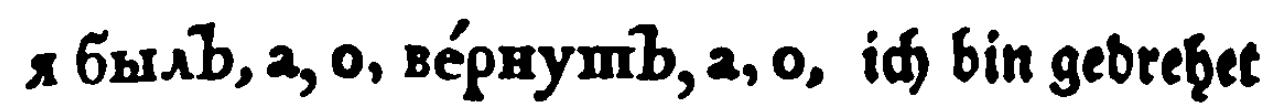
geroefen,

пы быrлb, 2, 0, ве́рнуты, 2, 0, bu bift gea gebreb̧et getwefen,

oub, a, 0, 6нub, a, 0, ве́рну mb, 2, 0, er, fie, es ift gebref̧et gewefen,

Pluralis.

xhr Gŕ́sz вépнymm, wir finb gebref̧et gerwefen,

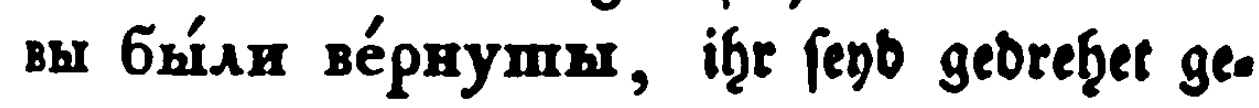
mejen,

онѝ 6hís ве́рнуmbr, fie fino gebreţet gea weren.

\section{Plusquamperfectum.}

\section{Singularis.}

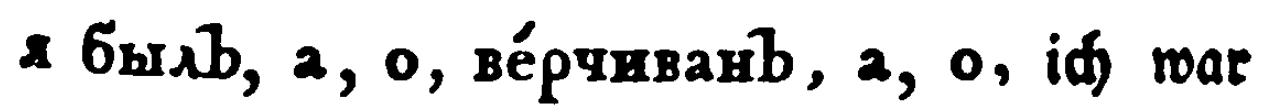
gebreḩet gemefen,

пық быль, 2, o, ве́рчиванb, 2, o, ou wareft gebrehet gewefen,

oub, 2, 0, 6urb, 2, 0, ве́рчиванb, 2, 0 , er, fie, es war gebref̧et gerweren,

Plura- 


\section{4}

\section{Bierter 20\}中nitt,}

Pluralis.

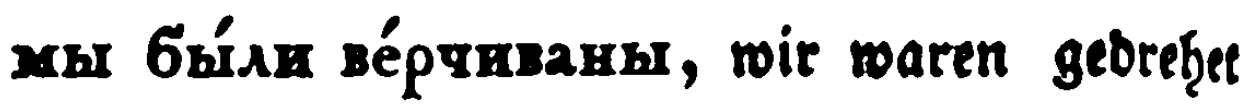
geroefen,

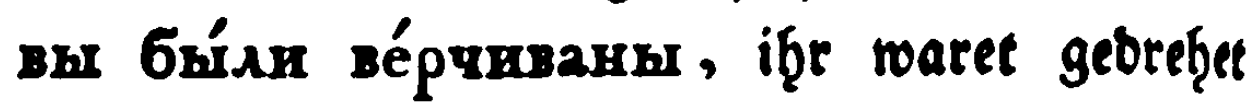
gewefen,

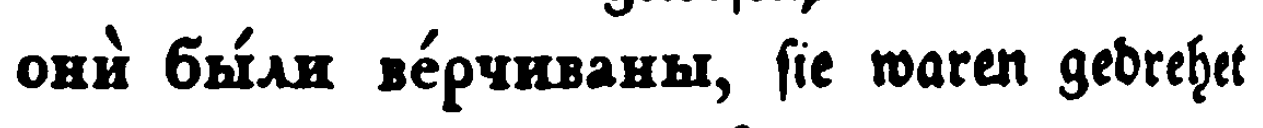
gewefen.

\section{Futurum Imperfectum.}

Singularis.

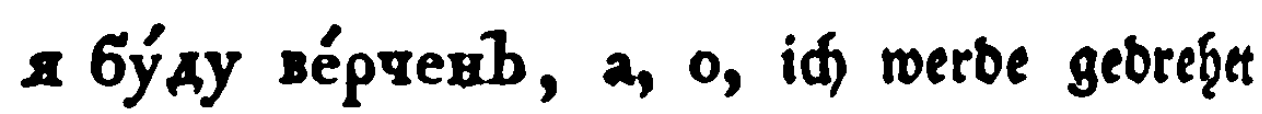
werben, mы бу́ деmb ве́рченb, a, o, ou wirft gebre, bet roerben,

oнb, 2, 0, 6ýдеmb ве́рченb, 2, o, er, file, es wirb gebreb̧et werben,

\section{Pluralis.}

мы бу́демb sépченh, wir werben gebrę̧et werben,

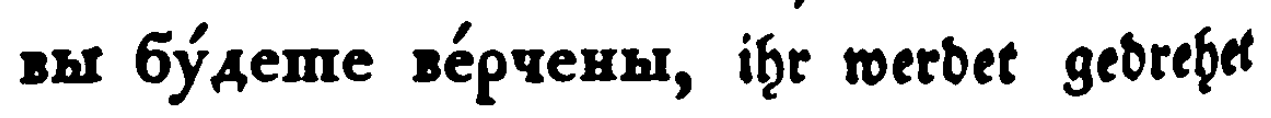
werben,

онѝ бу́ дуmb séрчень, fie werben gebreģet werben.

Futu- 
20n Dem Verbo.

\section{Futurum Simplex.}

Singularis.

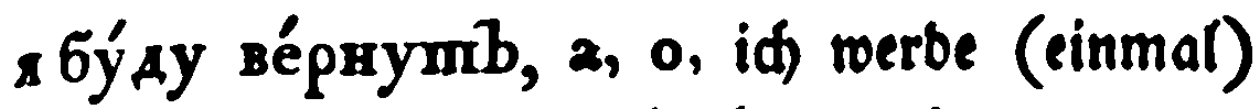
gebreţet werben,

шы бу́дешb ве́рнутb, 2, o, ou wirft ges orefetet merben,

онb, a, o, 6у́детв ве́рнушы, 2, o, er, fie, es mirb gebrefoet werben,

Pluralis.

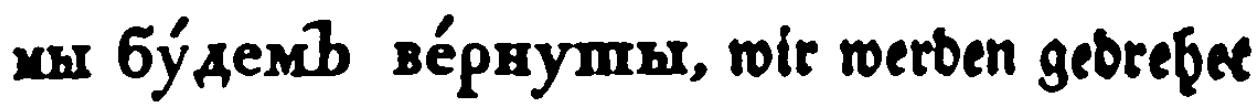
werben,

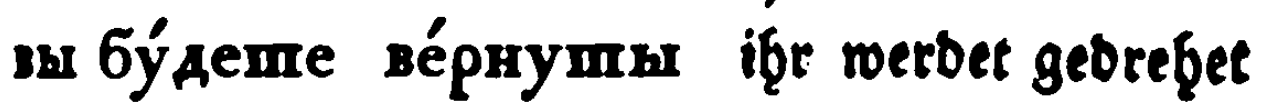
werben,

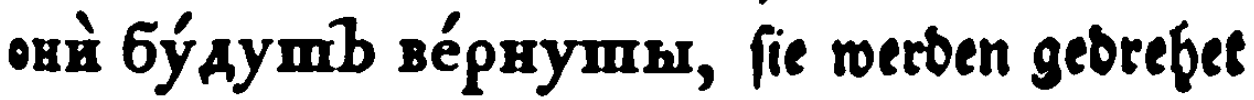
rerben.

Imperativus modus.

Futurum Imperfectum.

Singularis.

пуска́й з бу́ду ве́рченb, на, но, Іаß тіф

gebrefet merben,

- - mы бу́дешb ве́рченb, на, но, merbe bu georefeet,

- онb, 2, 0, бу́детb ве́рченb, на, Ho, laß ingn, fie, es gebreget werben.

Plura. 
126

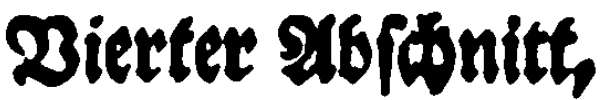

Pluralis.

пуска́й мx бу́демb ве́рченњ, lä̈ uns ges bref̧et werben,

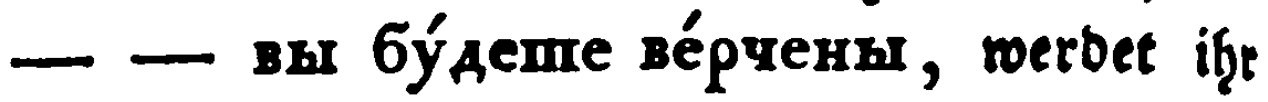
gebref̧et,

— — онй бу́ аушы ве́рчени, laß̧ fie ge. oref̧et werben.

Imperativus Futur. Simpl.

Singularis.

пуска́й х бу́ду ве́рнуmb, ma, mo, Іаß mid) georeḩet werben, - - mы бу́дешb ве́рнуты, ma, mо, werbe bu gebrehet, пуска́й онb, a, o, бу́детъ ве́рнушт, ma, IIo, laß̧ į̂n, fie, es gebreģet werben.

Pluralis.

пуска́й ми бу́ вемb sе́рнушй, laß̧ uns ges bref̧et merben, пуска́й вњ бу́деште ве́рнушт, теrbet iб̨ пуска́й онѝ бу́ дуmb sépнyшы, Іа三 fie gebref̧et werben.

Infini- 


\section{Bon Dem Verbo.}

\section{Infinitivus modus.}

6алmь ве́рчену, gebreţet werben, (mę̧rmalen) бынь ве́рнупу, georehet merben (einmal) быпь ве́рчивану, bielmal georef̧et werben.

\section{Participia.}

Imperfectum. ве́рченой, ar, ee, ein gebref̧e. ter, einer ber gebref̧et war, Prxt. unitatis. вépнymoй, 2r, oe, einer ber

(einmal) gebreb̧et gewefen, Plusquamperf. ве́рпыванной, ал, ое, einet ber gebrefget geroefen war.

\section{Gerundia.}

Imperfectum. бу́дучи, бывb ве́рченъ, in. bem man gebrefget roar,

Prat. unitatis. бу́ дучи, 6ывb ве́рнуты, in, bem man ift georefet worben. Plusquamperf. бу́дучи ве́ртыванb, indem man ift gebretget roorben.

$$
\text { \$. } 103 .
$$

Die Reciproca werben mit bem Bufnģe bon cb ober cr, fo mie bie Verba ber erften Conjugation, conjugirt, als: sepuýcs, ids orefe mid); sepmb́scs, id) Drebete mid); верну́лся, id habe mid) (einmal) gediefet; ве́pmbrвascs,

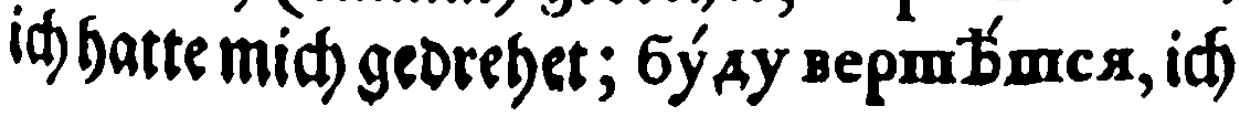




\section{8}

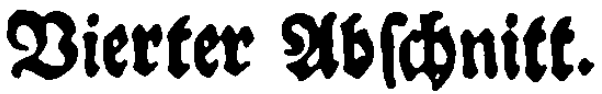

werbe miđ) (mefrmalen) brefen; верну́сь, iđ) werbe mid) (einmal) brefen, u. f. w.

$$
\text { S. } 104 .
$$

(Es fino nur wenige Verba fimplicia ber zmeleten Conjugation, bie bas Prateritum Per. fectum auf Hysb haben, als: rssжỳ id) pe:

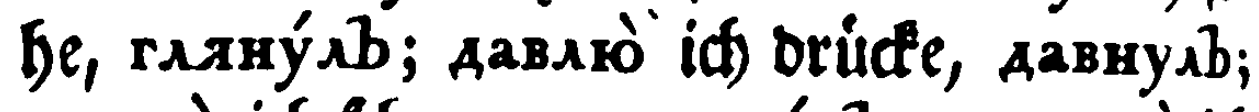

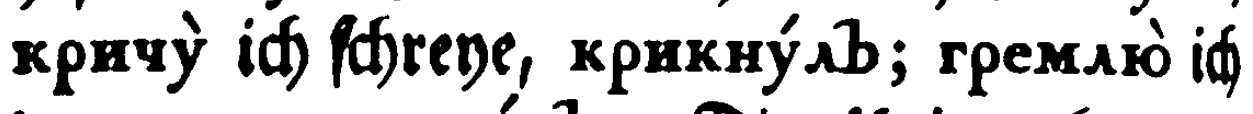
Donnere, грямну́ $љ$. Die übrigen fommen bon iḩren Frequentativis bon ber erften $C$ onjugation her, als: 6pśuy, id tlappere, 6pśx. нуль, von бряка́ю; глочу̀, iđf (đ)luđ̛e, глону́ аро́тнулb, von аро́гаго.

$$
\text { ๑. } 105 .
$$

Folgenbe Verba maden in̨r Prxteritum Per. fectum aus bem Imperfecto, unb einem $\mathfrak{B}_{0,}$ worte, weld)es fie in bem Prxlenti nidft ḩaben, als :

6ozxýcb, iqf fquroire, noбoxхи́лся, бою́сь, iđ fürdfte mid), убоя́лся, бранио id fofelte, sиíбранияb, 6pţжy, id fantafire, взбрб́,

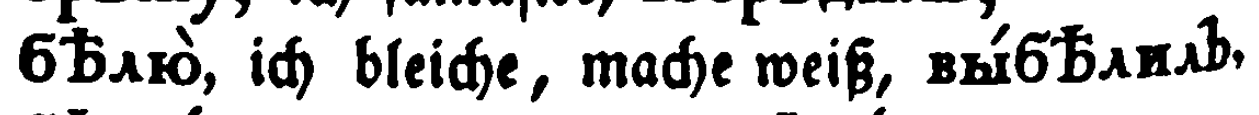
бЂшу́сь, iq bin toll, вsбБси́лсs, 


\section{Bon Dem Verbo.}

sаню̀, iđ melze, повали́лb,

saprò, id) fode, свари́лb,

веселго, iф beluftige, возвесели́⿴囗.

sи́жу, id fę̧e, уви́дыль,

suwỳ, id bange, пови́cb,

sоплко̀, id бeule, взвопи́ль,

sopozxỳ, id jaubere, сворожќxb,

rázy, iq verderbe, изгадиль,

rноюे, id mad)e faul, згнои́sb,

rosozxy', id laffe bungern, orosoди́яb,

голю̀, id mad)e tąl, orоли́sb,

горху́ссь, id bin ftolz, возгордъ́,

гра́блго, iф beraube, orpá6nıb,

гpéasy, iđ mad)e etras ungereimtes, взгре́зияb, гру6лго, id bin grob, corpy6úлљ,

ry6ırò, iđ beförbere ben Untergang, nory6úsb,

давлко, id brúce, задави́хb,

даркò, id) fđente, подари́лb,

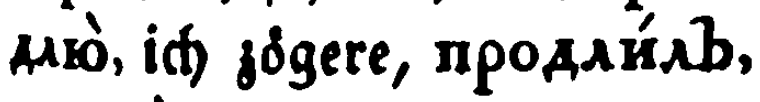

долаху, id mad)e verbintid, одолаки́лb,

4010, iđ melfe, подои́^b,

дружу́сь, id made freunofdaft, подру. жийся,

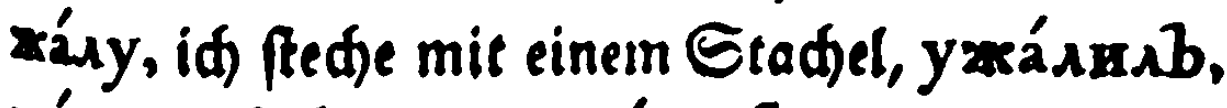
xápro, id brate, пзжа́puגb,

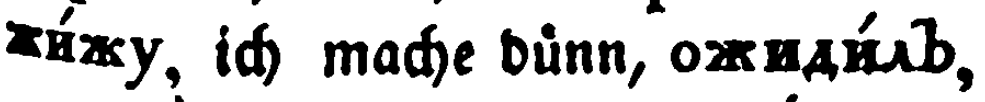

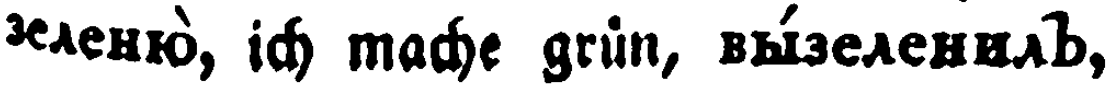




\section{0

зноблю̀, iq med)e friercn, озноби́лb,

злюсь id) ethoß̧е mid), озли́лся,

казнюо, id belege mit ₹ocesftrafe, сказни́r b,

ккámy, iq fäure, сквácusb,

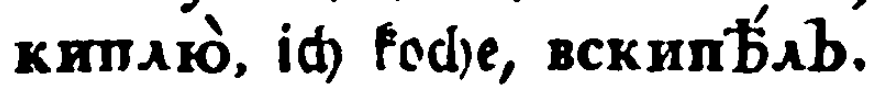

клеимrò, iф madje ein Merf jeidjen, закией.

ми́sb,

копчỳ, id beríudere, закопти́лb,

копліо, iđ fammle, скопи́лb,

кормлю, iФ fрeife, накорми́sb,

кошу̀, id mábe, скоси́s $b$,

кра́my, id färbe, ви́rкрасиıb,

xреuу̀, id taufe, окрести́sb,

кpowỳ, id fdnneibe, bacte flein, nckpowńsb,

хроко, id fáneide зи, скрои́rb,

кручи́нкось, iФ betrübe miळ, воскручи́.

нился,

курю̀, iq räuqere, накури́лъ,

лужу̀, id verginne, ви́́лудия b, люблю̀, id liebe, полюби́ль,

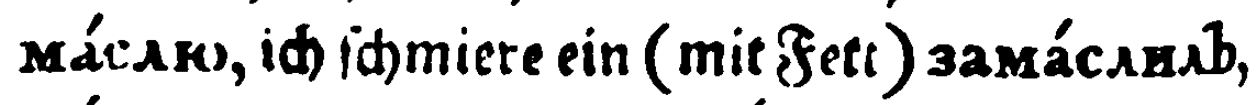
ме́длю, id) zanbere, уме́длияъ, молчỳ, id) fđweige, замолчásb, soprò, id tobte, (burd) Sçunger, mit (Biftr) мorỳ, id fann, возмórb, умори́rb, по́мнко, id) erinnere mid), вспо́мнияв, 


\section{Bon Dem Verbo.}

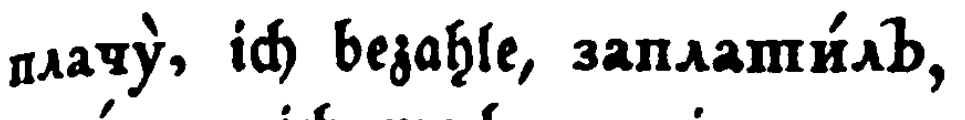
пога́ню, id) made unrein, испога́нихb, поко́ю, id) таđ)e rub̧ig, успоко́ияb, nópyy, id) verberbe, испортиль, nýuy, iđ mad)e erḩaben, blafe auf, shímyчusb,

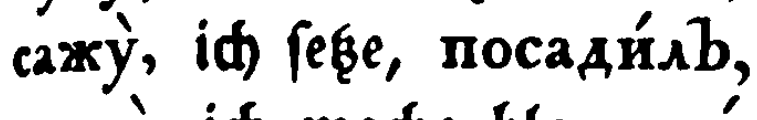
синю, id madje blall, вbícинияb, скоблsо, id fđabe, виісскорбияb,

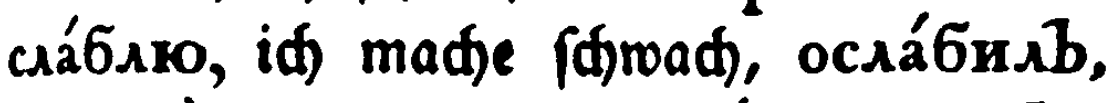

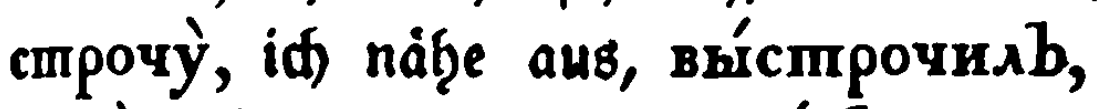
сульо, iФ berfprede, посули́лb, cymỳ, id) trodne, ssícyшusb,

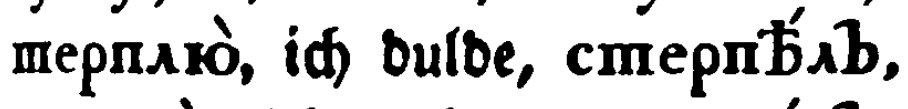
топлю̀, iđ) erfäufe, уmопи́sb, mра́чу, iđ) verliere, истра́mихb, myплю, id made ftumpf, ssímymisb, mymỳ, iđ lòfde bas feuer aus, samyшúub, ymю́жy, id) glätte, buggele, ви́ушюжилb, хоронюо, id) verffecfe, vermab̧re, захорони́ив,

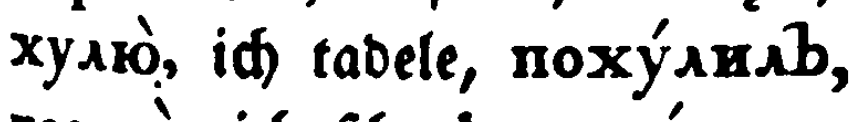
чернко, id fámårze, вычернияb.

$$
\text { §. } 106 .
$$

Das Plusquamperfectum primum mirb aus Der erfen Perfon Singul. Indicativi turd) Beranterung bes ro unb y in uвarb gentadts, als:

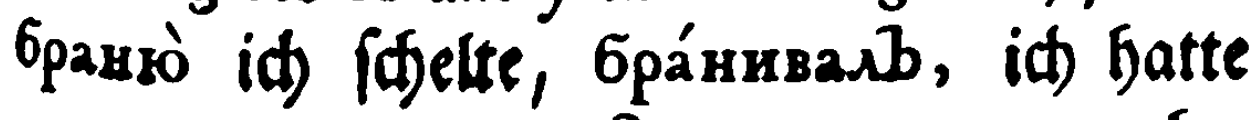

$$
\text { Эo }
$$

megrs 
mefrmalen gefítolten; stópro iđ glaube st. puвasb; rлázy id madre glatt, rsázzв.

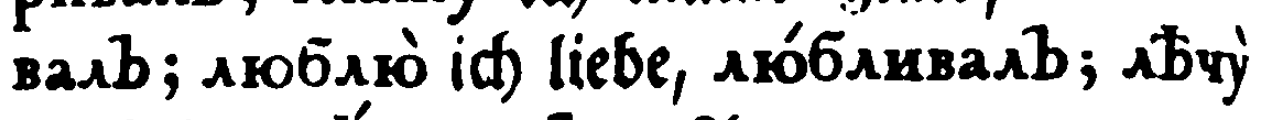
id) brile, 九б́чuвasb. Zlusgenommen craro

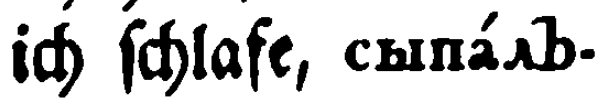

\section{§. 107.}

Benn in bem Plusquamperfecto ber Accent auf bas borb̧ergeb̧enide o jurúd geworfen wird, fo veránbert fid biefes $o$ in 2 , als: 6onso id

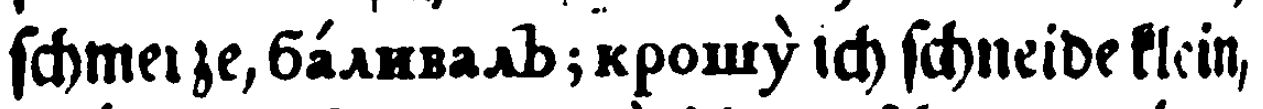
кра́muвалb; молочỳ id oref(te, молáqn. вasb.

\section{§. 108.}

Zule Futura Simpllicia ridften fíd fämmtlid nad) ber erften Conjugation, menn fie gleid) allen Temp.sribus uno Modis nad) zur zroensen Conjugation geb̧dren, als: давнỳ, давнémb, (nid) давни́mb) давне́mb, Аавне́мb, Аав. не́me лавну́mb. Кричу̀, кри́чеmb, кри́. четb, хри́чемb, кри́чеше, хри́кну ты.

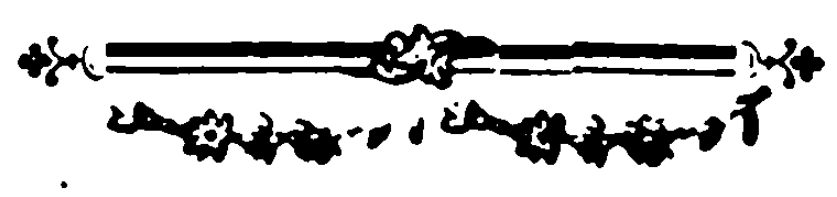

Daต์ 


\section{Bon bem Verbo.}

\section{Daß̉ fïlfte Sauptitúcீ.}

Bon Den Verbis compofitis, irregularibus \& defectivis.

Q. 109.

Benn bie Verba ein Borroort ober anbere Seberbeile anneţmen, fo erģalten fie, nad biefer Bujammenfeğung, eine berfáiebene Bebeutung, als: 1) wiro bie Enoung an Enlben bermeghrt, als: mekỳ ith) fließ̉e, mpomexáro id fließ̧e Durd); воzxỳ id) fubre, провожка́ro ids bes gleite; ḉro id) fäe, просbва́ro id fiebe

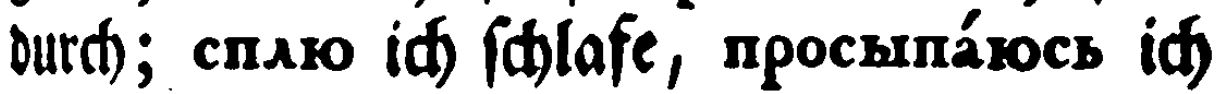

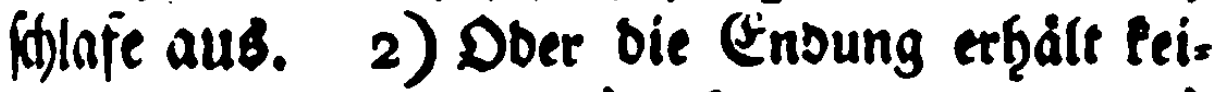
nen Zufaß, als: xomxỳ id gebe, omxomỳ

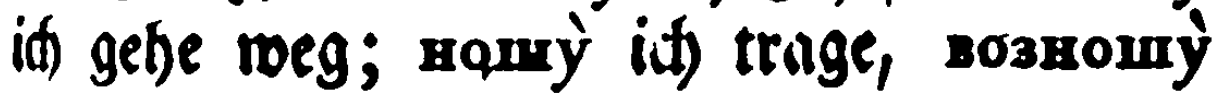
id) erfebe.

\section{§. 110.}

Die jufummengefegeten Verba metben ein. getheilt in beftänbige und veränberlide (Verba Compofita fixa uno mutabilia). Die beftảnbigen bleiben in allen Temporibus ben einer unb eben Deffelben Conj. gation; bie veränberlidjen bage. gen find in bem Prxfenti bon ber erften, im Futuro aber von ber zweenten Conjugation; inbem Die einfadjen Verba ber zmenten Conjugation, wenn fie am Enbe meģr Enlben befommen,

$$
I_{3}
$$


nad ber erften Conjugation geben; fo balo fie aber in bem Futuro ben $3 u[a \beta$ am Fnbe verlieren, wieberum nad) ber zwentin conjugiret reeben. Bevipiel vom erften.

Помога́ю id) Gelfe, помога́emb, помо. ráemb; познáro, познáemb.

bom jlucyten.

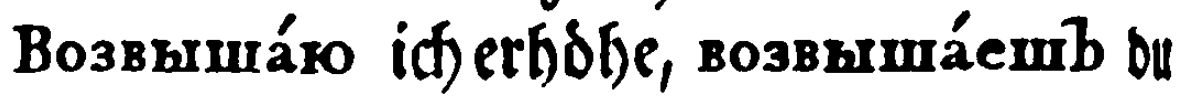

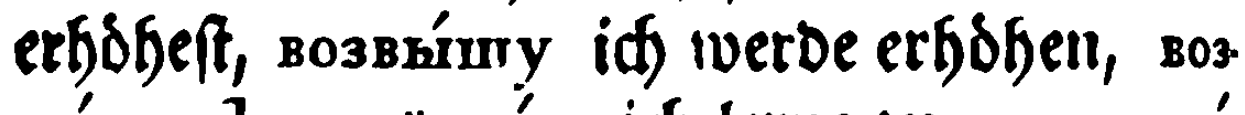
ви́́сишb ; прїуча́ко iđ( lerne zі1, приуча́. emb Dul lerneft $z u$, : npïyчỳ id werde zulet: nen, прїуччитb.

ઈ. $\mathrm{III}$.

Xus Verbis Neutris, wenn fie ein Borwort ans nef̧men, werben bismeilen $\Lambda$ ctiva, als: omseжámb 6okà, fith die Seiten múbeliegen; 32. crámb rлазà, fíd) Die Augen berfajlafen; om. споя́mb нórn, fíd die fitiße mübe fteben. 6. 112.

Beyfpiel eines Verbi compofiti fixi.

Activum.

Indicativus Modus.

Prælens.

Singularis.

a пока́зsrвaro, id) zeige, m пx пока́зиваешb, ou jeigeft, oнb, a, o, пока́zываеmb, er, fie, es zeiget! 
Pluralis.

мы пока́зывдемb, wir zeigen, вы пока́зываете, î̧r jeiget, онй пока́зываютыb, fie zeigen.

\section{Imperfectum.}

Singularis.

в пока́зываль, вала, вало, iф zеigre, mы пока́зыrвалb, 12, ло, ou jeigeteft, онb, a, o, пока́зывалb, 12, 10, er, fie, ев jeigte,

Pluralis.

Mh пока́зывали, wir jeigten, вы пока́зывали, ig̨r zeigtet, онй пока́зывали, fie jeigren.

\section{Prxteritum Porfectum.}

Singularis.

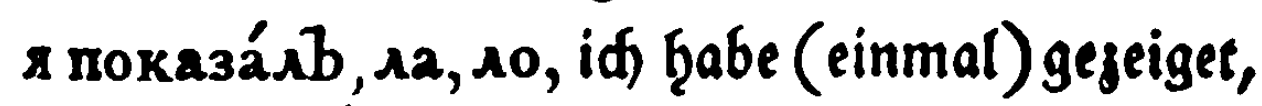
ты показа́^b, $1 a, 10$, bu ḩaft gejelget, онb, a, o, показа́ b, 1a, 10, er, fie, ç ந̧at sezeiget,

Pluralis.

мы показа́sи, wir ḩaben gezeiget, вы показа́ли, i̧̧e b̧abt gejeiget, өнй псказа́хи, fie ţaben gejeiget. $\Im 4$ Plus- 


\section{Dierter $\mathfrak{A}($ f \\ Plusquamperfectum II.}

Singularis.

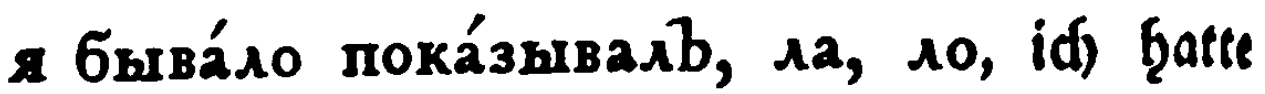

(meţrmalen) gezeiget,

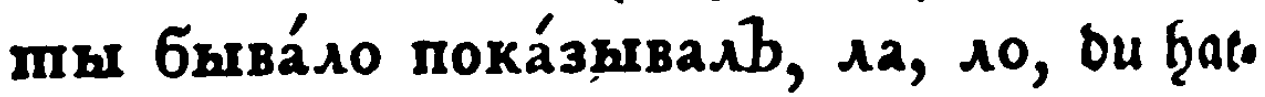
teft gezeiget,

онb, 2, 0, бива́ло пока́зывалb, ла, 10, ft fie, es b̧atte gezeiget,

\section{Pluralis.}

мы бъва́ло пока́зывали, wir ḩatten ges jeiget,

вы быва́ло пока́зывали, į̧r ḩattet ge: zeiget,

оні̀ бъва́ло пока́зщвали, fie b̧atten ges jeiget.

Futurum Imperfectum.

Singularis.

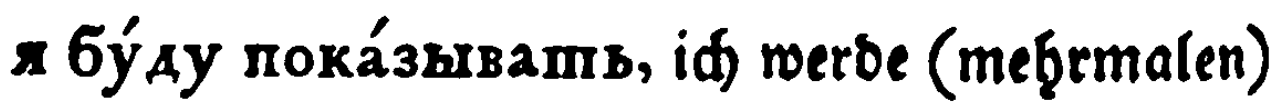

zeigen,

пи бу́дешb пока́зивапь, ou roirft zeigen, онb бу́детb пока́зиватв, er wirb zeigen,

Plura. 


\section{Don Dem Verbo.}

Pluralis.

мы бу́ демb пока́зывашь, тir toerben jeigen,

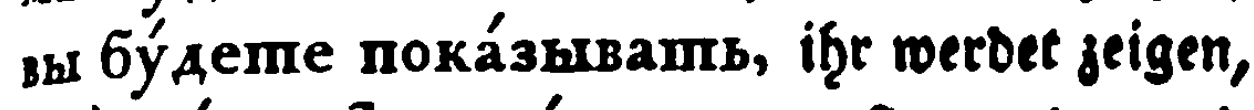
онй бу́ дуmb пока́зивать, fie merben zеi=

Futurum Simplex. gen.

Singularis.

s nokazxỳ, iđ werbe (gewißi) zeigen, mы noкázemb, bu wirft jeigen, онb nока́жеmb, er witb jeigen,

Pluralis.

мы noкázжемb, -wiw merben jeigen, ы пока́жеme, iør roerbet jeigen, онѝ пока́ху mb, fie merben jeigen.

Imperativus modus.

Præfens.

Singularis.

поха́зһвай, ти пока́зщвай, деige ou, онb пока́зивай, орет пуска́й пока́зива. emb, laß̧ if̧n zeigen, Pluralis.

пока́зњвайще, ви пока́зивайте, јеiget if̧r,

онѝ поха́зъвайmе, оbеr пуска́й пока́. зивакоmb, laßjt fie zeigen. Is Impera- 


\section{8}

\section{Bierter $\mathscr{A} 6$ f̧nitf,}

\section{Imperativus Futur.}

Singularis.

покажкиे, mhr покажй, jeige ou, онb покажкѝ, ober пуска́и пока́жетb,

lapss ip̧n jeigen,

Pluralis.

покажи́mе, вы покахи́me, zeiget ih̆t, онѝ покажи́me, оber пуска́и пока́жушы, lapte fie zeigen.

Infinitivus modus.

пока́зыrвamı, (inę̧rmaleń) zeigen, показа́mb, (einmal) jeigen.

Participia.

Prxโ. показу́юugï̀, ein jeigenter, einer tet oa jeiget,

Imperfect. пока́зывавшїй, einer ber zeigte, Perfect. показа́вшїй, einer ber gejeiget bqat.

\section{Gerundia.}

Pรxf. пока́зивая, пока́зываюючп, показу́я, im jeigen,

Imperfect. пока́зывавb, пока́зывавшш, indem er, fie, es jeigte,

Perfect. показа́вb, показа́вши, inøem et, fie, er gejeiget hat. \$. I13. 


\section{Bon Dem Verbo.}

\section{§. 113 .}

Diefes Verbum b̧at im Paffivo Fein Przefens Indicativi. Das Imperfectum ift $\boldsymbol{\Omega} \mathbf{6 m} \boldsymbol{b}$ пока́зиванb, iff war gefeiget; bas Przteritum perfectum я быль пока́занb, iđ) bin gezeiget gensefen; bie benben Plusquamperf. я бнва́ $\mathbf{b}$

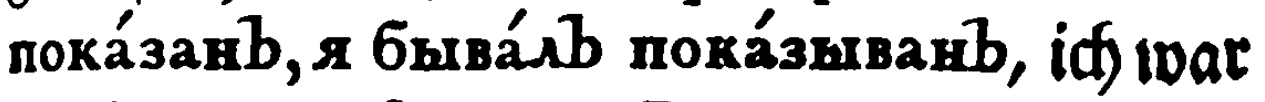
gejeiget getweren; bas Futurum perfectum a бу́ду пока́занb, iđ werbe gefeiget werben; Imperativus Fut. nусmb я бу́ ду пока́занb, laß̧ mid) gezeiget werbell; Infia. Grmb nokáзывану, пока́зану, gezeiget werden; Part. Prxl. показу́емmì, einer ber gezeiget woirb, Imperf. пока́зиванный, eitter Der gefeiget wai, Perf. пока́занный, Der gezeiget gewefen. Die Reciproca werben aus bem Activo burda Anḩängung bes cb ober ca gemadit.

$$
\text { 6. } 114 \text {. }
$$

Beyfpiel eineb veránberliđgen Verbi

Compoliti.

\section{Activum.}

Indicativus modus.

Prafens.

Singuiaris.

s прїуча́ю, ids lerne zu, mb прїучáemb, ou lerneft ju, онb, a, o, прїуча́emb, er, fie, es lernet qu, Plura. 
140

\section{Dierter $\mathfrak{A} \mathfrak{G}$ 低nitt,}

Pluralis.

мы прїуча́емb, wir lernen ju, sm npïyчáeme, ị̧r lernet ju, онѝ nрїуча́romb, fie lernen ju.

Imperfectum.

Singularis.

я прїуча́ıb, $12, \wedge a$, id lernte gu,

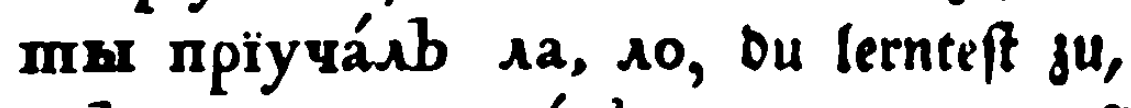
онb, a, o, прїуча́лb, ла, ^о, еr, fie, es lernte ju.

Pluralis.

мқ прїуча́лx, wir lernten ju, въ прїуча́ли, iø̨r Jerntet zu, онѝ прїуча́ли, fie lernten zu.

\section{Præteritum Perfectum.}

Singularis.

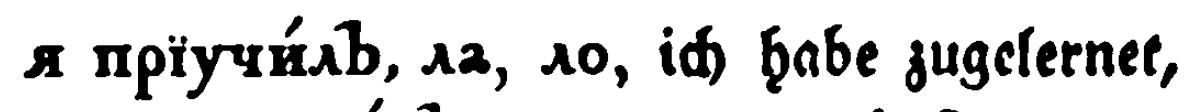
ты прїучи́хb, ^а, ^о, оu ḩaft jugelernet, онb, $a, 0$, прїучи́ $b, \wedge a, \wedge 0$, er, fie, es jat jugelernet,

Pluralis.

мы прїучи́ла, wir bৃaben zugelernet,

вы прїучи́ли, ił̧r babt jugeternet, онй прїучи́ли, fie ந̧aben zugelernet.

Plus- 


\section{Ben Dem V'erbo. \\ Plusquamperfectum I.}

Singularis.

я прїуччивалb, ^а, ^о, idf ந̧atte zugelernet, mы прїу́чивалb, ^а ^о, bu দৃatteft gugelernet, онb, $a, 0$, прїуччваль, ла, 10 , er, fie, еs batte zugelernet,

\section{Pluralis.}

иы прїу́чввала, wir ḩatten zugelernet, вы прїу́чивали, ibr bi.tet jugclernet, онй прїуччивала, fie batten zugelernet.

\section{Flusquamferfectun II.}

\section{Singularis.}

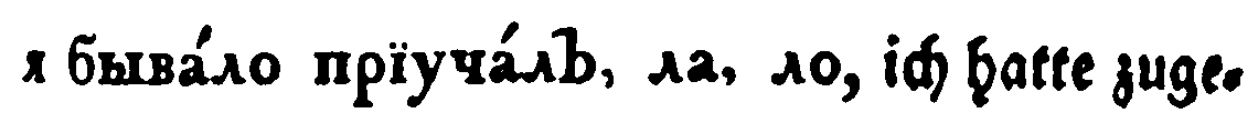
lernet,

шы быва́ло прїуча́৯b, גа, ^о, bu ḩatteft zu gelernet,

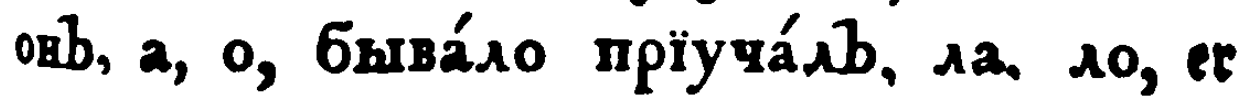
fie, es ḩatte jugelernet,

\section{Pluralis.}

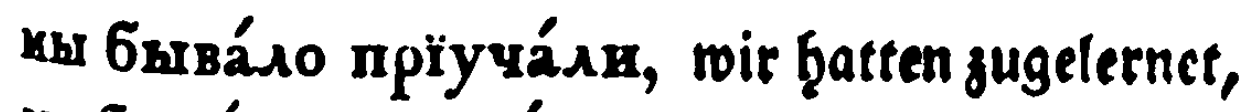
ы быва́ло прїуча́ли, ị̧r b̧attet jugelernet, онѝ быва́до пріуча́dв, fie batten jugelernet.

Plus- 
142

\section{Bierter Abfanitt,}

\section{Plusquamperfectum III.}

Singularis.

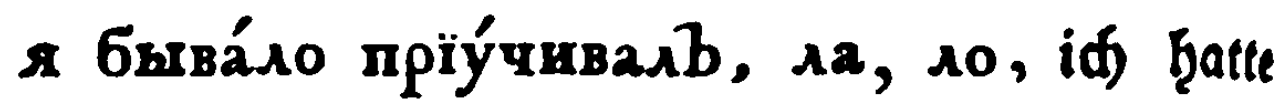
jugelernet,

шы быва́ло прїу́чивалb, ла, ло, bu ḩat. teft jugelernet,

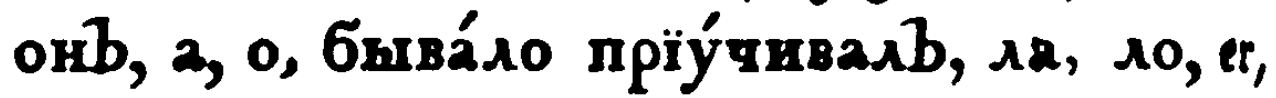
fie, es ḩatte jugelernet, Pluralis.

мhг бъва́ло прїу́чuвала, wir ந̧atten ju: gelernet,

вы бива́ло прїу́чиваגи, iந̨r ந̧attet zuge lernet, онѝ бива́ло прїу́чивали, fie. ģatten zuge: lernet.

Futurum Imperfectum.

Singularis.

я бýay mpїуча́mb, iđ werbe zulernen,

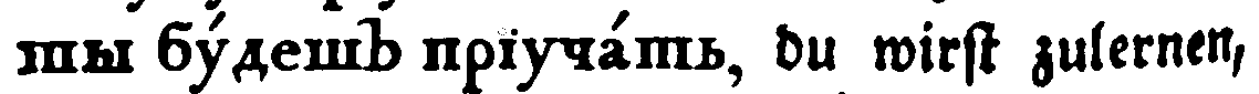
онb, a, o, 6ýдеmb прїуча́mb, er, fie, es wirb julernen,

Pluralis.

мы бу́демb прїуча́mь, wir werben julernen, вы бýдеme npïyqámb, į̣r merbet zulemen, онй бýaymb ipïyчáms, fie werden zulernem.

Futu- 


\section{Donl Dem Verbo.}

Futurum Simplex.

Singularis.

s mpïyчỳ, id roerbe julernen, шы пріу́чи онb, a, o, прїуччиmb, er, fie, еs mirb julernen,

Pluralis.

мы прїу́чимъ, wir werben zulernen, ын пріучите, iøge werbet julernen, онй прїу́чаmb, fie werden julernen.

Imperativus modus.

Pixfens.

Singularis.

прiуччáŭ, mы прїуча́ï, lerne ou ju, овb прїуча́и, ореr пуска́и прїуча́emb, er lerne ju,

Pluralis.

пріуча́йmе, вы прїуча́йme, lernet i̧̧r ju, онй пріуча́ume, орег пуска́й прїуча́юmb, laßit fie zulernen.

Imperfectum.

Singularis.

стпань пріуча́mb, lerne ou zu, стань онb прїуча́mb, орег пуска́й ста́. нетьb прїуча́mb, laßjt ithn julernen.

Plura. 


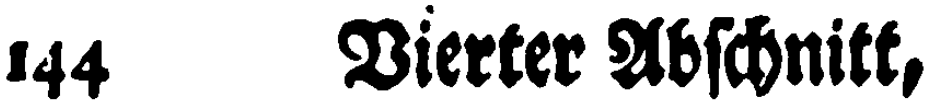

Pluralis.

ста́немb прїуча́mb, laß̧t uns julernen, cmáньme прїуча́mb, lernet i̧̧r zu,

ста́нbme онѝ прїуча́mb, ober пуска́i cmáнуmb прїуча́mb, laßt fie zulernen.

Imper. Futur. Simpl.

Singularis.

прїучй, mbx пріучй, lerne ou ju,

онb прїучй ober пуска́й пріу́чumb, laf

ið̧n julernen.

Pluralis.

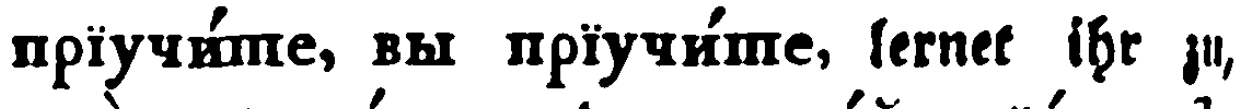
онй прїучи́mе, овеr пуска́й прїу́чаты,

laßst fie julernen.

Infinitivus modus.

пpїучámí, julernen (vielmal).

прїучи́mb, zulernen (einmal).

прїу́чивать, julernen (meţrmalen).

Participia.

Prxf. прїуча́юü̈й, einer ber julernet,

Imperfectum mangelt,

Prat. Perf. прїучи́вmїй, einer, ber jugelernet

Plusquamperfectum mangelt.

$$
\text { bat, }
$$

Gerun- 
Gerundia.

Przf, прїучивая, прїуча́s, inbem er, fie, es, zulernet,

Perf. прїучи́вb, прїучиввии, indem ex, fie, es jugelernet bुat,

Plusq. прїуччuвasb, indem er, fie, es juge. lernet batte.

$$
\text { \$. } 115 \text {. }
$$

Biele Bormoirter geben ben Verbis in ben Pralentibus, Perfectis und Fut, finpl. bes Indi cativi, Imperativi unb Infiuitivi eine befonbere Beteutung, bie fie in bem Prxe. Indicativi nidss baben.

\section{116.}

Das Bormore Bh bedeubet eine Erlan. gung, als; вhimsaxaub, id) habe es Duld Beitren erlanget; Bhímymmsb, id) babe eb mit Sdaerzen genoonuen.

$$
\text { 9. } 117 .
$$

Ao bebeutet bie Enbigung beffen, wab an einer Sadje nod) gefeblet, als: r sonzcásb, id) babe bab, was nod) feglte, bu Enbe gefdrieben; $я$ доméxs do morò мţ́cma, id) bin gall biż an felbigen Ort hingegan: gen; дополни́mb, bab, mas fehlt, hinju= thun,

$$
\text { §. } 118 .
$$




\section{118.}

3a bebeutet, 1) Den 21nfang einer Sanb: lung, als: saxpantimb, allfangen $\mathfrak{j} u$ (d)uar: d)en; заurpamb, anfangen zu fpielen; 32. свистб́mb, anfangen zu pfeiffen. 2) 3ei: get es eine $\mathfrak{B}$ ergitung an, als: s eмyे 32. писа́sb, iđ) gabe es iffm mit Sd)reiben ver: gitet; заходи́ b - mit gef)en - замо. Аomúsb - mit ore/d)en - 3) Briget ej eiuen ઊetoruß ilber eine wiorige Şandlung all, als: онb меня̀ заговори́яb, cr hat mid mit frinem Reden - задbлова́rb - mit feinen Fiuffen crmitiet. 4) Wenn am Ende eines foldsen $\mathfrak{W}$ orts bas $\mathrm{cb}$ ober $\mathrm{cr}$ angehángt

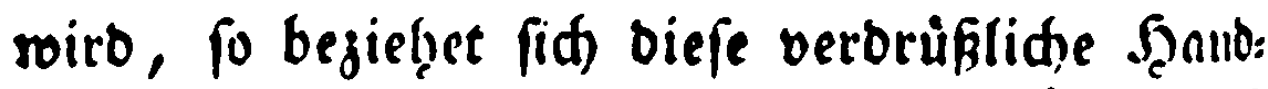
lung auf fid) felbft, als: $я$ заговори́scs, idf (felbit) fpied)e zil viel; я заспа́scs, id) babe zu vidl gefdlafen.

$$
\text { ๑. } 119 .
$$

Das Bormort usb jeiget an, Daß̧ eine Sadje vdllig alifgebraudt morben, als:

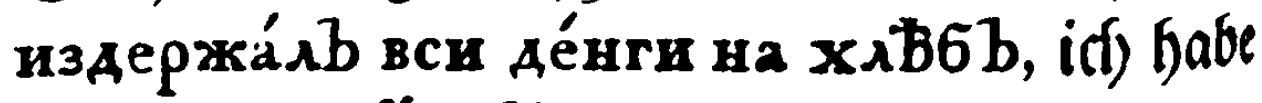
alles Seld firr Brodt nuzgegeben; изпr.

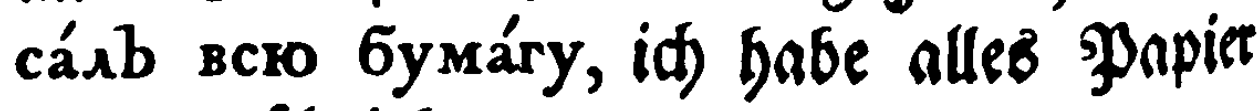
gallz veridurieben. 


\section{\$. 120.}

Das на bebeutet 1) Sdjaben, als: наи. гра́sb мно́го до́лгу, iđ habe mir Єdulloen

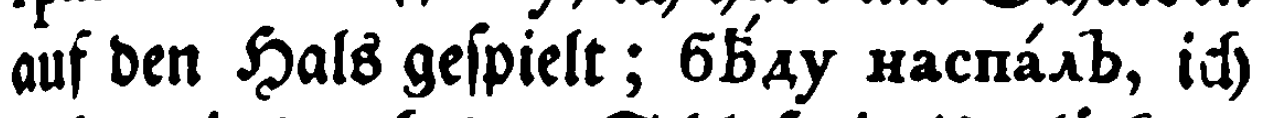
habe mir Durd) Den Sdblaf ein Unglied ju. gejogen. 2) Sáttigung, wenn ein cb oder cr angeţănget wirb, als: наигра́ics, (piele di(t) (att; напла́чеmcs, el wirb nod) genug ju weinen baben; наговори́cb, rede bid) fait

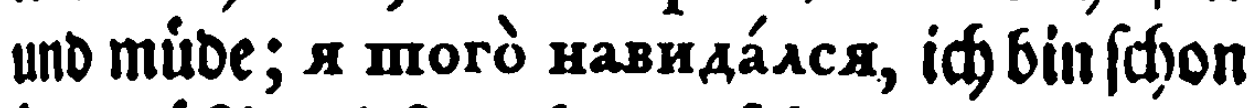
íferdrüsig dieß mebr zu fegen.

$$
\text { §. 121. }
$$

Omb bebeutet die Endigung einer Salld= lung, als: omburpásb, id) habe nulfgeforct ju fpielen; mit bem angeţängten cr aber eine Befrinung, als: omпла́кался omb наказа́.

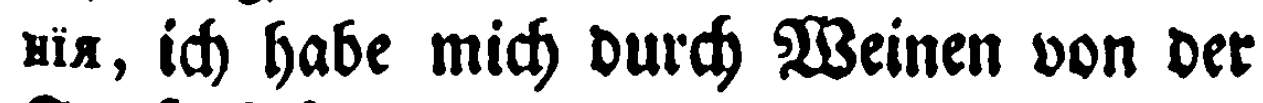
Strafe befievet.

$$
\text { ઈ. } 122 .
$$

To jeiget eine $\mathfrak{B e t r i n g e r u n g}$ an, als:

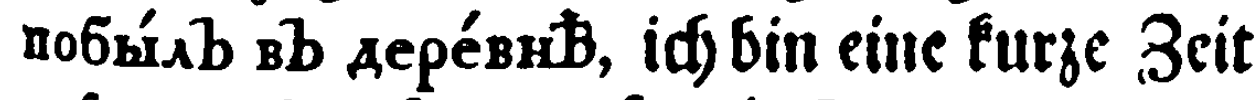
auf Dem Dorfe gewefen. Sonften bedeutet es auch eine verringernoe $\mathfrak{B}$ ervielfältigung, als : nonúchsamb, oft (etwas wenige $)$ ) fficeic ben; nоха́живапь, Gerumgeben; nonb. rámb - fingen.

$$
\$ 2123 \text {. }
$$




$$
\text { ઈ. } 123 .
$$

Inpo bebeutet eine Reraubung ober Ent:

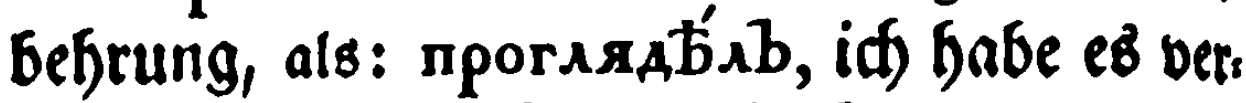
fefell; просиа cbsádb Durd) Racflásigteit verfåumet.

$$
\text { ઈ. } 124 \text {. }
$$

Pasb mit bem cя am Enbe bes $\mathfrak{B o r t s}$ bemertet eine Bergrdfferung Der Siraft oder Des Willens bey einer Sadbe, als: pazo. cnámcs, erft rectst in Den Ectaf fommen; разтовори́mся, nid)t aufforen tonnen fu

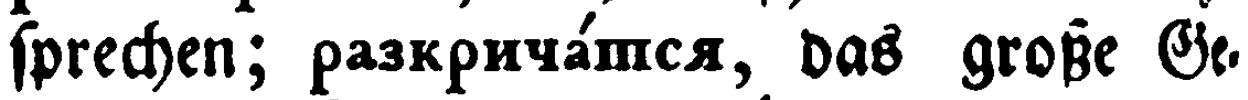
fdren fortferen; pasкачámcs, red)t ins Sdauteln bereinfommen.

$$
\text { ઈ. } 125 .
$$

Y bebeutet eine 2 fbnafme, als: y6'. вusb, id) babe etroab atgenommen; yn: cádb, id) babe etwas baran gefdrieben.

$$
\text { 6. } 126 .
$$

Wenn alle biefe Borwoirter unjertrennlid mit bem Verbo verbunben fino, fo haben fie eime ganj anbere Bebeutung, als: pacrucáscs von pacnúcbrвағось ḩeißit fo viel, als да rò pocnuc. ky, id) gebe eine Quitung. Fin anderes if pacracáucs wenn es nid) gum obigen Ve:bo geb̧öret, uno in biefem Falle bebeutet es: id 


\section{Bon Dem Verbo.}

fomme erft recht inz Sdyreiben berein. Eben fo heift sоговори́лся von догова́ривагось id) neigme 2 borede, made einen $\mathfrak{P e r g l e i d}$. Ein anderes aber ift sоговори́sся 子. F. Ao стынà, до ccóph; benn biejes ḩeift: iđd has be mir Durch mein vielez Reden Stande zus gefogen; iđ babe mir Beroruß und Şándel auf ben Şalb gerebet.

$$
\text { \$. } 127 .
$$

Fs fino bie Verba unridtig in Xanfeņung 1) Der Endungen in ben Perfonen, 2) Des Mangels der Temporum, 3) iffer zmeifel= baften Bebeutung; ba man bas eine Tempus ftatt bes anbern gebraudeen Eann.

$$
\text { §. } 128 .
$$

Die vornetgmften Verba, bie in ihren En. oungen von ben Regeln abreiden, finb aasò id) gebe, емb id effe, хочỳ id will.

Indicativus.

Prxfens.

Singularis.

\& хочỳ, id will,

mb xóvemb, ou willf,

онb, a, o, хо́чештb, онѝ хоп́я́mb, fie er, fie, es will,
Pluralis.

мы хоти́мb, тіr

roillen,

Bh xomúme, iq̨r roollet, ioollen.

\& 3 Imper- 
Imperfectum.

I xomb́s $\boldsymbol{b}$, id wollte. $2 c$. Prxteritum Perfectum.

s 3axomb́tıb, id ḩabe gewollt. sc.

Futurum.

Singularis.

x saxouy, id werbe wollen,

mb $32 x o ́$ yemb, bu wirft rollen,

онb, a, o, заxóyemb, ex, fie, es wirb nollen, Pluralis.

мы захоти́mb, wir werben wollen, вы заxomúme, iøgr werbet wollen, онѝ зaxomŕmb, fie werben wollen. Infinitivus.

xomb́mb, 32xomb́mb, wollen.

Participia.

Prxf. xomŕmü̈й, ein mollender, einer be ba will,

Imperf. xomb́вm

Prat. Perf, saxomb́,

Gerundia.

Prxf. xoms, im wollen,

Imperf. xomb́tвb, indem er, fie, es roolte, Prxt. Perf. зaxombsb, indem er, fie, es get wollt ḩat. 


\section{Bon Dem Verbo. \\ Indicativus modus. \\ Præfens.}

Singularis.

\& sarò, id) gebe, mb даémb, ou giebf, вы даéme, ił̧r gebet, онb, a, о, даémb, ет, онй дако́mb, fie ges fie, es giebt,

\section{Imperfectum.}

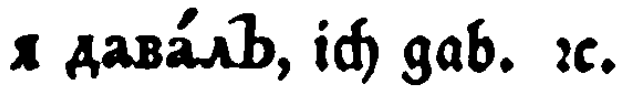

\section{Prateritum Perfectum.}

$s$ saxb, id b̨abe gegeben. $2 c$.

Plusquamperfectum.

\& да́вивахb, id batte gegeben. зс.

Futurum Simplex.

Singularis.

дамb, iq werbe ges м⿻ дадй́mb, wit ben;

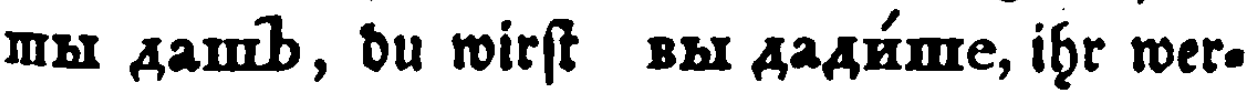
geben,

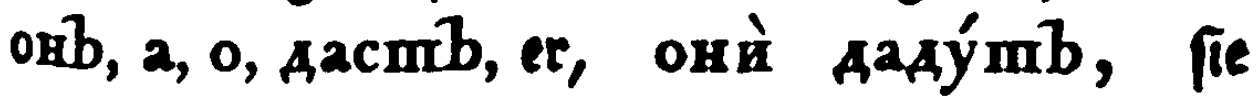
fie, es wirb geben,

\section{Imperativus.}

Præf. дава́й, gieb,

Futur. Aari, gieb bu. 
152

\section{Dierter $\mathfrak{A 6}$ /dnitt,}

Infinitivus.

Aasámb, mefrmalen geben,

Aamb, cinmul geben.

\section{Participia.}

Activum Praf. ancómï̈̈, einer ber giebt,

- Perfertum. á́вшїі, einer ber gegeben b̧at, Pallivun Profo azémmü, einer ber gegeben wiro,

- Inperf. да́вәный, einer ber gegeten mat, - Perfect. aа́нныи, einer ber gegeben mor. ben.

\section{Gerundia.}

Pral. Aаючѝ, im geben, Inverf дава́вb, дава́вшт, indẹm er gab, Perf. давb, Aásmu, indem er gegeben b̧at. Indicativus modus. Prxfens.

Singularis. $s$ emb, id effe, mbr ewb. ou iffeft, oнb, a o, ecmb, et, онй едя́mb, fie effen fie, es ifst,

$g$ exb. id $a \dot{\beta}, 3 c$.

\section{Imperfectum.}

Plusquamperfectum.

$\pi$ eAáxb, id ḩabe gegeffen, $3 c$.
Pluralis.

мы еди́mb, wir efiell, вh еá́me, iб̨r effet, 
Imperativus, eumb, effe bu. lufinitivus. ecmb, effen, едámb, rffen.

Participium Palfivum Imperf. е́денњй, einer ber gegeffen war. Gerund. Prxf. едучи, im effen, - Imperf. eвb, е́вши, inbem er aß́.

$$
\text { 6. } 129 .
$$

Biele Verba nef̧men aus andern einige Tempora an, als: npesocxomỳ, id úber: treffe, hat im Imperfecto fein eigenes nревос. ходи́лb vоп хожу̀, ходи́лb; in bem Prxt. Perfecto und Futuro aber превзопо́льb, пре. взйдỳ, von идỳ, шолb. 2) Сажу̀сь iđ() fise mid, bet in ber vergangenen uno jufünfs ligen Zeit vom alten Ctammmort çдáro gleid). folls cbגb i(t) babe gefeffen, ся́sy i(f) werde firen. 3) Cmaнoвarócb von cmaнoвגiò hat in bem Preteritu Perfecto cmasb, von cmorò id)feffe, als: cmaновл ко́cв cmapb iff werde alt, cmarb cmapb id bin alt geroorden.

$$
\text { 6. } 130 .
$$

Einige baben bas Futurum gleid bem Prxfenti, und Daḩer eine zroeifelf̧ıfte Bobeutung, als: cmb́rmaro ids velfebe, nud idf merde berfteben; powỳ id) gebáble, aud) ida werde sebábren.

$$
\text { R } 5 \text { S. } 131 \text {. }
$$




\section{ऽ. 131 .}

Die meḩreften ruffiffen Verba fino Irrego. laria. Ben benfelben tỏmmt es am meiften bars: auf an, baß man wiffe wie fie in bem Prafenti, in ben Prateritis, in bem Futuro, Imperativo unb Infinitivo abgeandert merben. Dahere babe id) zum Befdluabe biefes Capiels allbiet eine Tabelle in alpḩabetiffer Dronung anţan gen wollen, unb grwar erftens

Bon Den Verbis Der erften Conjugation.

Praf.

Imperf. Prxt. unit.

suкаяо, ешть, 2uкаль

id) bin hुungerig,

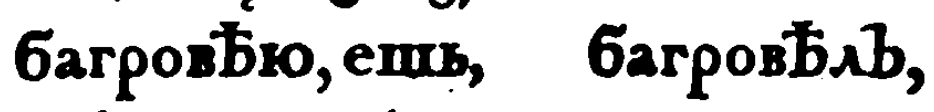

id) werbe rotb̧,

6epy,

eirb, 6parb,

взяль,

i由 nefme,

бледнбю, ешть, бледнбль, - - id) werbe bleid,

блекну, ешъ, блекнуль, - - id berwelfe,

блеко, ештb, блеяль, - id) blöafe,

блешу, щешъ, блескаль, блеснуль, id) fdimmere,

6x1010, 


\section{Bon Dem Verbo:}

\section{Prat.Perf. Futur: Imperat. Infin.} взаккаһ, взанкаго, алкай, 2икапв.

побагро- побагро- багровђй, багровbаb, вБю, побраль, возму, бери, в Bmb. 6рапाь, взяпвь.

поблед- поблед- бледней, бледнБлb, нБю, нбив. поблекъ, поблек- блекни, блекhy,

заблеялһ, заблею, блей, нymb. блеять. 32блес- блесну, блесни, блескапт, $\times 2 u b$, 6леснуть. 36ле. 
Prxe.

Imperf. Przt. unit. 6люг, ештb, блеваль, - id) berpene mid, 6огаmbю, emb, богаmbıb, - id) werbe reid,

болтаю, ешъ, болпаль, болкнулъ, id fóroage,

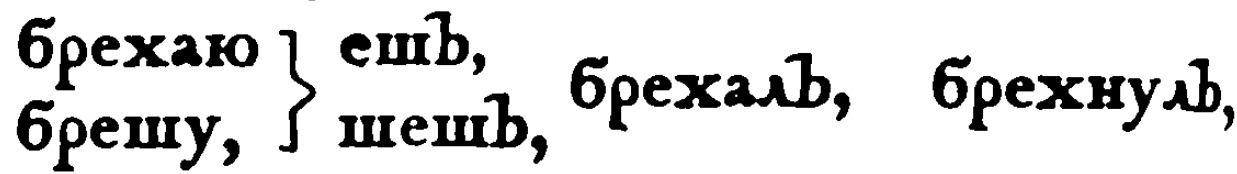
id) rebe ţ̧origt,

6рыхпху, жешв, брызгаль, брызнуль, i由 fpriz̧e,

6рБюо, emb, 6рилb,

id) rafire,

6ряхаю, ештb, брякаль, брякнуль, id Elinge, Elatidie, горчако, emb, rорчалb, id) werbe bitter, гребу, ешт, гре6b, гре6нуль, id) rubere,

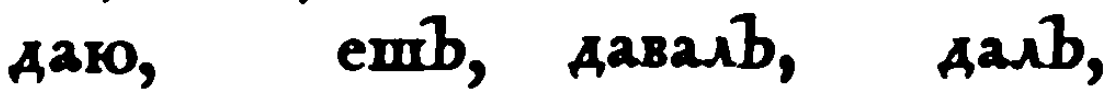
id gebe,

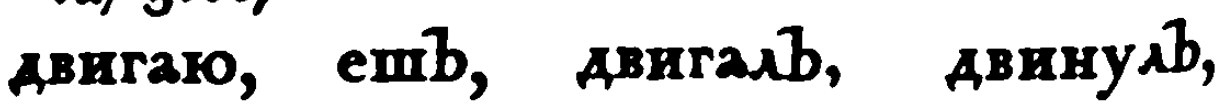
id) berwege,

дерзако, ешт, дерзаль, дерзнуяв, iđ) erfứ̧̨ne mid, деру, emb, aparb, id jerreiffe, 


\section{Bon Dem Verbo.}

rat.Perf. Futur. Imper.

Infin.

блеваль, блюну, блюй, блевапь.

236ога- разбога- Gогашбй, 6ога-

$\mathrm{mb} \boldsymbol{b}$, mbro,

mbmb.

6олталь,болкну, болтай, бол-

IIIIIIb.

забре- брехну, \{брехай, $\{$ брехапь, $\mathbf{x a r b}$,

โбреши, \{брешишь.

обрыз- брызну, брызни, брызгать, нуль,

обрияъ, обрђю, брђй, бришь.

г- брякну, бряхай, брдкашь.

огорчаль, огорчаг, торчай, торчашь.

- г гре6ну, греби, грести.

- АамВ, Аавай, Аай, даваМПъ.

- - авину, авинб, авигать.

- дерзну, дерзай, дерзашв,

изораль, издеру, дери, Арапь. Аерзнутв.
Аратвь.
ОАम. 


\section{8}

\section{Bietter 2afonitf,}

\section{Pref.}

Imperf.

Pret. unit.

Aич210, emb, Aичалb,

id) werbe wilb,

должако, ештb, долхкаль, - -

id) gerathe in Sduulben,

аремлк, ешт, аремаль,

id fiflummere,

думаго, eшmb, думаль,

id benfe,

Аую, ешb, Ауль, Аунуль,

id) blafe,

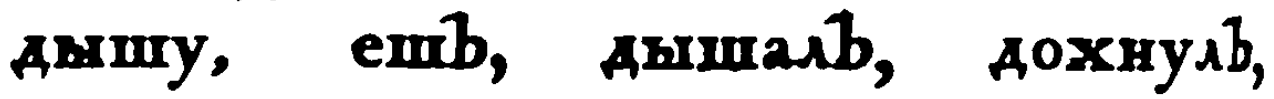
id) atţme,

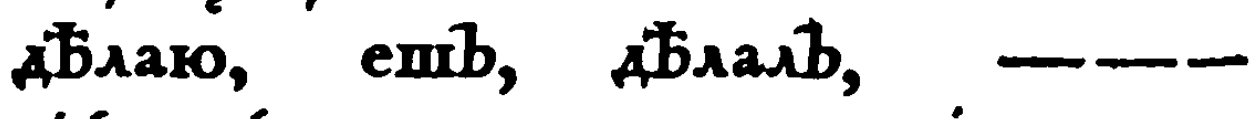
id madie,

жалугось, ештся, жаловался, - -

iक beflage mid,

жrгy, жкешь, жеег, жкегнуд, id) brenne,

желmbю, emb, желmbıb, - id) werbe gelb,

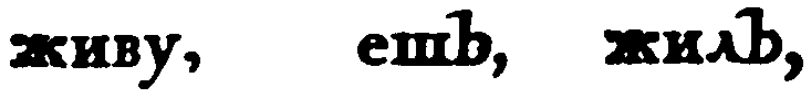

id) lebe,

жирђю, ештb, жирбль, - id werbe fett,

zory,

emb, xarb,

id) ernote, 
Prxt. Perf. Futur. Imper. Infin.

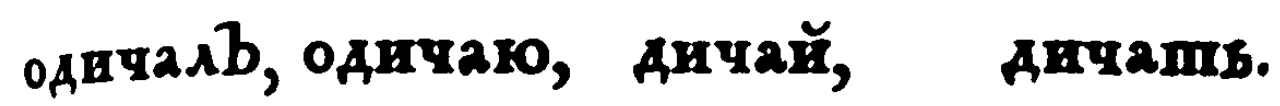

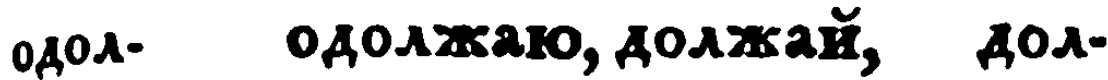
జaגb,

вздре- вздремлго,дремлг, дреммахb, גamb. вздумахъ,вздумаго, Аумай, думашь. подуль, дуну, дуй, Ауть. вздуліb,

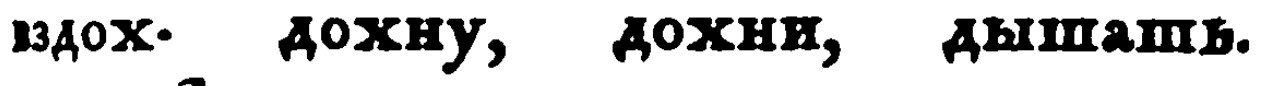
нул $\boldsymbol{\lambda}$,

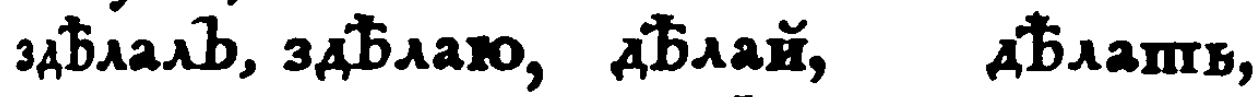

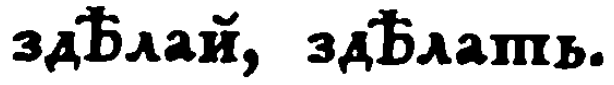
пожало- похкалу жкалуйся, жалова⿴囗 Baç, LOCD, Cs. ожегb, охку, жка, жкечь.

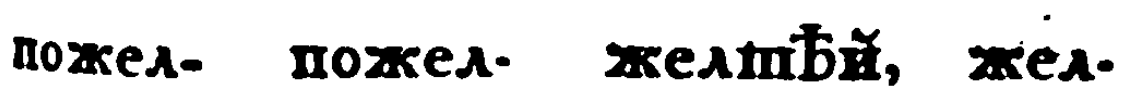
mbsb, mbro, mbmb. пожвґъ, пожкиу, жкиви, хкишь.

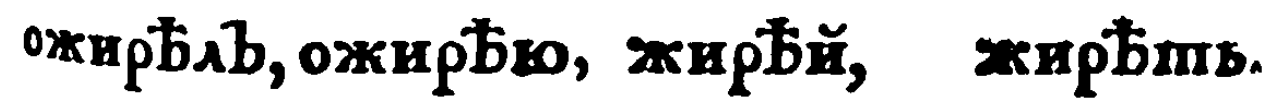

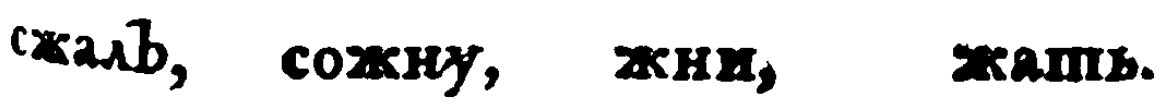


160

Bierter 26/ðnitt,

Prxe.

зеленбю, emb,
id) werbe grùn,

зову,

id) rufe,

збваго,

id) jäne,

nay,

id) geţe,

id) f(d)luce,

uny,

emrb, 38arb,

Imperf.

Prxt. unit.

зеленбль, - -

id) fudfe,

rry,

id) láge,

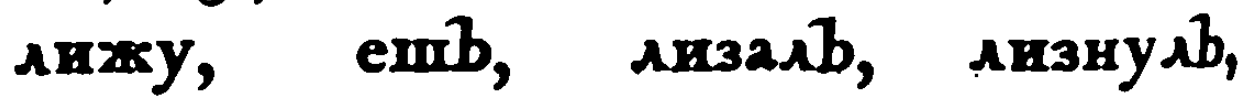
id lecte,

линяк, ештb, Анняль, - id) verfdiefe an Farbe,

10паг, ештb, лопаль, лопнуль, id) jerplazese,

ломаю, ештb, ломаль, - id) jerbredee,

мaху, emb, м2занъ, мазнудb, id fómiere,

малюо, ешт, малеваль, - id) maf̧le,

Mapara 


\section{Zon Dem Verbo.}

Prat. Perf. Futur. Imperat. Infin.

позеле- позеле. зеленбй, зеле-

нблb, нбю,

нб̆mb.

- - призову, зови,

382mb.

- - збвну, збгай, збвапь.

пошодъ, пойду, поди, ипти.

- - пкну, икни, икапь.

сискалb, сыну, ищи, искать.

солгань, солгу, Аги, Агапв.

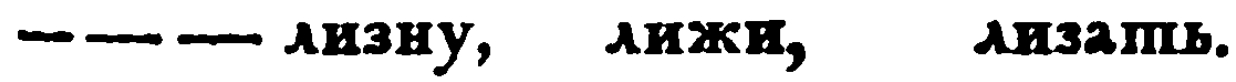

полн- Полиняю, Анняй, Аиняшб. няגb,

- - лопну, лопай, лопать, лопнушь.

«зло- изломак, ломай, ломаты. narb,

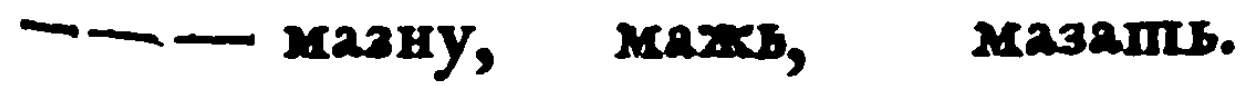

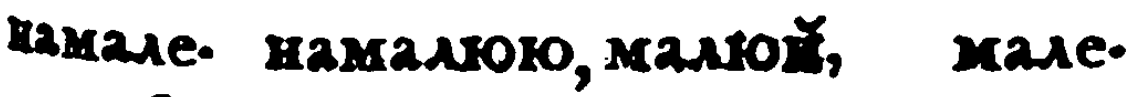
sarb, -amb. 
162

\section{Dierter 94b/đnitt,}

Prxfens.

Imperf. Prxt. unit мараю, emb, мара̇ $b$, марнуль, id) befamiere,

машу, eurb, махаль, махнуль, id) berwege,

мерзбю, emb, мерзбль, - id) werbe ab/denlid,

мечу̀, emb, метпаль, метнуль, id) werfe,

мигаiо, emb, мигалb, мигнуль, id blinjele mit ben 2Augen,

мory, жewb, мorb, id) fann,

молодЬю, ешт, молод id) rerbe jung,

мочу, emb, мочияb, мокнуа, id) madie naßs,

негодую, ешb, негодоваль-id) bin unroillig,

ниряко, ешт, ныряль, нырнуаб. id) taudbe unter,

одолжаю, ештb, одолаталь, - ic) verbinde,

opю, emb, oparb, - id) pfluge,

охаю, еmb, охаль, охнуль, iid) jeufze,

mamy; 


\section{Don Dem Verbo.}

Przt. Perf. Futur.

Imper.

Infin.

замараль, замараю, марой,

Mapo-

BaIIb.

- - MaxHy, MaIur,

Maxamb.

\section{MaXHE,}

омерзбль,омерзбю, мерзбй, мерзбпь.

- - меmну, мечв, мепапь.

- - мигну, мигай, мигаmb.

возмогb, позмогу, моге, мощи,

Mougb.

помоло- помо:о- молодб̆, моло-

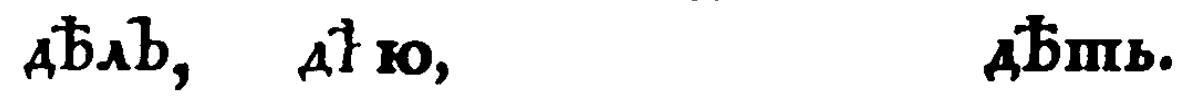

обмок- мокну, мочв, мочить.

нуль, обмокну,

вознето. вознето- нетодуй, нетодоАОВаль, Ауго,

- ширну, итряй, нирять.

BaIIs.

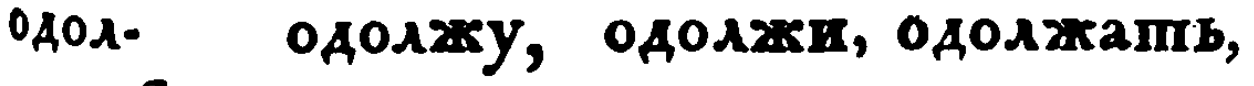
ara $\mathbf{b}$,

одолжrimu.

взоралb, взорго, орн, ораmв.

- - oxнy, oxa:, oxamb.

2 scris. 
164 Bierter $\mathfrak{A 6}$ fanitt,

Prxelens. Imperf. Prot. unit, nawy, emb, naxaib, - id) affere,

nихако, emb, nuxaגb, пихнулb, id ftofie fort, nхaגb, пхнулb, nишу, emb, писалb, писнулb, id) fóreibe,

плеснб- ешb, плеснбв $\vec{b} \boldsymbol{b},-$ Bظzo, iф rerbe fóimmlidt,

плыву, ешіb, плияb, - id fdroimme,

плко, ешъ, плеваль, плконуд, id fpene,

пляшу, ешb, плясалb, пхяснуль, id tange,

поздако, еmb, поздалb, - id) verfpäte mid,, noro, emb, nibab,

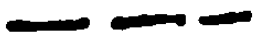

id) finge,

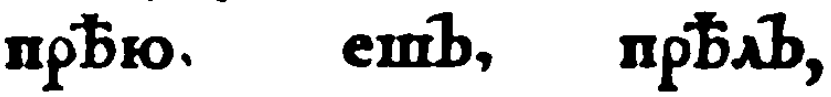

id) bin gang in Sdpreibe,

прячу, ешb, прямана, - id) nerffecte,

nycmbro, eub, nycmbab, - id werde muifte,

nupgiso, 


\section{Bon Dem Verbo.}

Pret. Perf. Futur. Imperat.

вспахаג В,вспахако, папrk,

-
nхxну, пrхай,

написаג в,напишу, пишк, писать. naxams.

Infin.

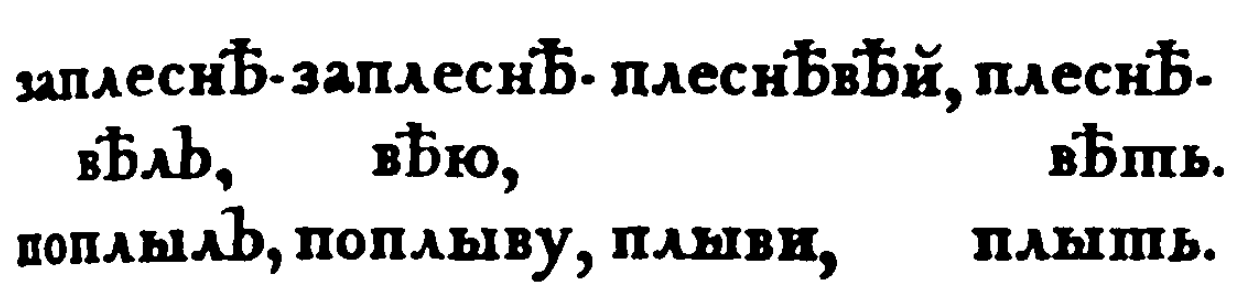

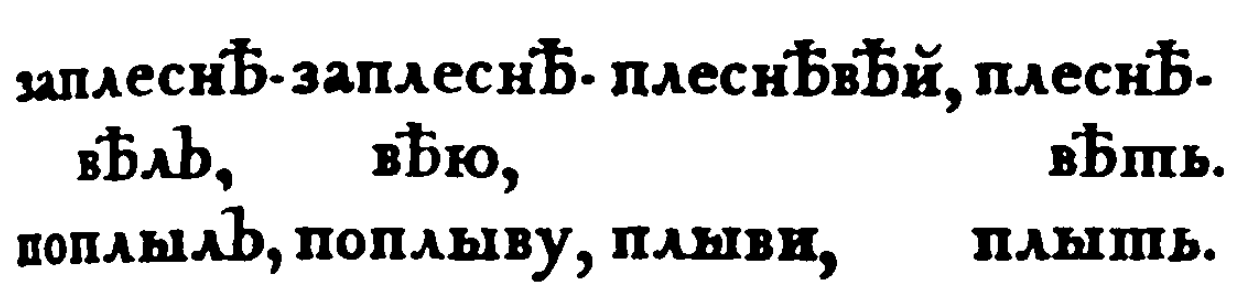
- - плюну, плюй, плевать. попля- попляшу,пляши, пля$c a \lambda b$, опоздаАЬ, опоздаке, Поздай, Поздать.

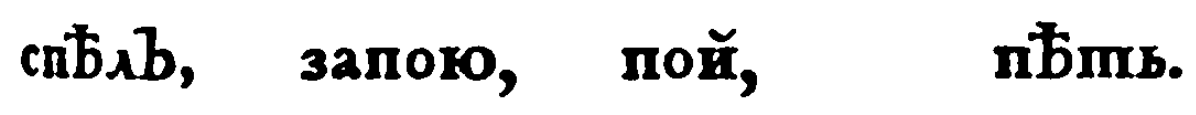
ззапрбаъ,взапрбюа, прбй, прђть. sапря- запрячу, спрячв, спря$\operatorname{ma\lambda b}$ mamb. 2anус- запус. пустьй, пусmbُb, mbro, mibmb. onyc. onycmibro, imbs,

$$
\text { \& 3ambi }
$$


165

Prxeens.

пыряго, emb,
id ftofie juricf,

paдуюсс, ештся, радовался, - id) freue mid,

pastio,
id) gơnne,

pocmy, ewr, pocb,

id) radffe,

pвy, eimb, pвarb,

id jerreipe,

реву, ешb, ревълb, ревнуль, id blöde,

рисую, emb, рисовалb, - id zeidine,

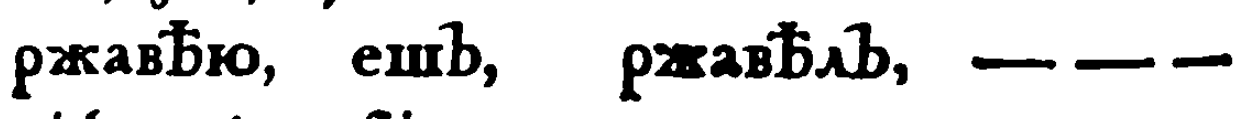
id) werbe roftig,

pжy, emb, paxarb, id) wieḩere wie ein Pfero,

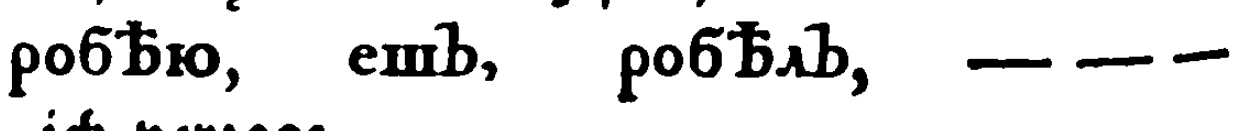
id) verjage,

ронко, ро- emb, роняль, HA:0, id laffe fallen,

ругако, emb, ругалb, ругнулb, id) trohe,

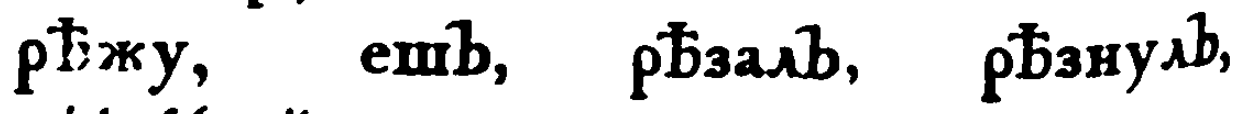
id) fanneibe, 
Prat.Perf. Futur. Imperat. Infin. запыр- запырну, пьряй, пырять. нуль,

возрадо- возраду- радуйся, радо-

вался, Гось,

samcs.

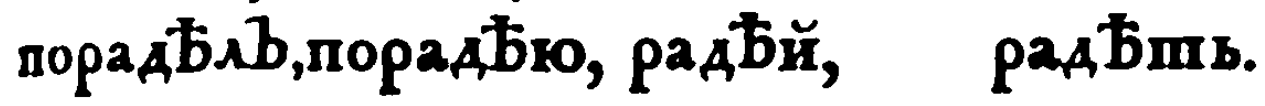
sspocb, выpocmy, pocma, pocmb. взорваль, изорву, рви, psamb. заревЂль, зареву, реви, ревъцв. нарисо- нарисую, рисуй, рисоваגb, - samb. заржа- заржка. ржавђй, ржкавђть. вЂ,b, вЂю, заржаль, заржу, ржки, рххапь. оребъль, оробБко, робБй, робБть. урония, уроню, роняй, ронять. 06ругаяb,o6ругаю, ругай, pyramb. - - рђзну, 14 сосва. 
Prxfens.

Imperf.

Prxt. unit.

свашаг, ешrb, свашалb, - id) ftifte eine Şey)raţ̧,

сверкаю, ешъ, сверкаль, сверквуль, id) blif̧ę, faimmere,

синбю, ешb, синбגb, - id) werbe blau,

сиротbro, emb, сиротіb八b, - id) berwaife,

скачу, ешт, скакан), скокнуль, id) fpringe,

сквернбю, ешт, сквериблб, - id) werbe befslid,

cxpezseny, eurb, cxpezse - id) Enirfate mit ben వą̧̊nen, mastb,

сльпну, ешт, - - сльвнуль, id) werbe blind,

сморкаг, ешb, смор- сморкid) fíneuze,

смбro, emb, смбаb, - id) unterfteḩe mid,,

смбось, ешься, смблася, - id) ladie,

снуко, ешb, снованы, - id) grünbe,

cocy, emb, сосан), соснулb, id fäuge, 
Pret. Perf. Futur. Imperat. Infin.

сосва- сосва- сватиай, сва-

marb, maro, mamb.

засвер- сверкиу, сверкай, свер-

калb, кать.

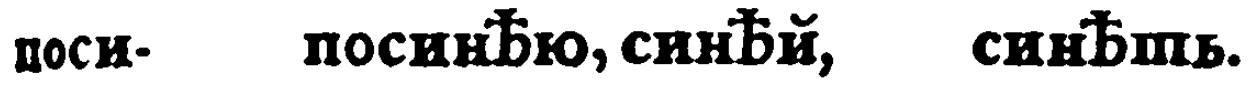

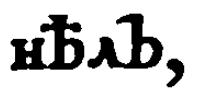

осиро- осиро- сиротїй, сиро-

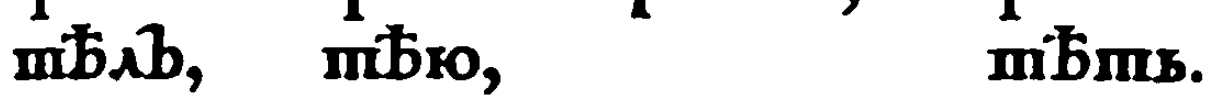

- - cbкокну, скачи, скакашь.

осквер- осквер- сквернбй, сквер-

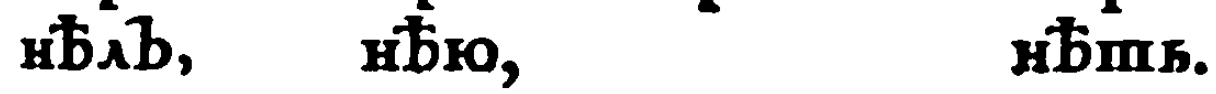

закреже- закреже- скрежеиди, скреже-

$\max \mathbf{b}, \mathbf{y y}$,

осльпb, осльпну, сльпни, сльп-

mamb.

нymb.

- - сморкну, сморкай, смор-

Kamb.

посмбАъ, посмбю, смбй, смбіпь.

засмђ. засмЂюсь,смбися, смб-

ялся,

яmcя:

основаль, осноко, сной, сновашь.

- - буду со- сосн, cocamb.

camb,

Is ocmpar. 
Prxfens.

cmpazxay, emb, id) leibe,

cmesto,

cmpexaro, чешb, стрекаль, стрек. id) fdinelle,

стригу, жешb, стригb, стригнуль, id) fdeere,

cmporaro, emb, cmpo- cmporнyаb, id bohele,

cmука10, emb,

id flopfe,

cimprnaro, emb,

id bereite bas Effen,

сую, ешт, соваль, сунуль, id) falebe ein,

cЂалако, emb, cあалалb, - id) fattele,

cbro,

emb, cbrab,

id) fäe,

прита- ешіb, прита. притах. каго, iđ beją̧e, каль, нуз, macyio, emb, maсовалb, - if) mifhe bie Rarten,

пемнбю, ешъ, пемнбл $\mathrm{b},--$ id merbe ounkel, 


\section{Bon Dem Verbo.}

Przt.Perf. Futur. Imperat. Infin. постра- пострахк-страхкди, страдахb, Ау, дапв. послаль, поспелго, стели, слашь.

- - cimperry, cmperm, cmpexaIIb. - - cmprarzy, cmpara, cmprws. обсmpo- oбcmpo- cmporă̆, cmporaib, raro, ramb. засту- сппкну, стукай, сшукать. чaub,

cостря- состря- стряпай, стряпаגb, паг, пашь. - - суну, сунв, совашв.

осБд- осБдлаго, сБдлаг̆, сБдлать. 1aAb,

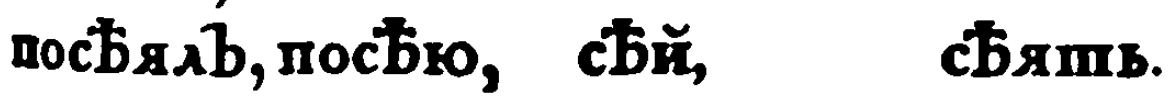

- - притах. притакай, прита-

$$
\text { Hy, }
$$

kaIIb.

cmaco. cmacyro, macyй. makamb. вarb,

попем- потек- пемнбй, пем-

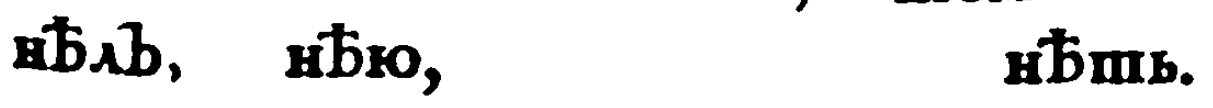


Prafens.

Imperf.

Prxt. unit.

mискаю, ешb, пискаль, писнуль, id) orude,

Imky,

myemb, mкarb,

id rebe,

mолкаю, еши, полкаль, полк-

id fope,

moxky, emb,

(id) ftoß̧e mit einen Gtämpfel,

mолкую. emb, mолко-

id erfläre,

вaגb,

mолсmbr, emb, mолc.

id) nerbe bic,

mонбю, ешb, поньлb, - id) werbe buinne,

mpe6yro, emb, mpe6o. - id) fobere,

mpeneyy, emb, mpenеmaxb, - id) zittere,

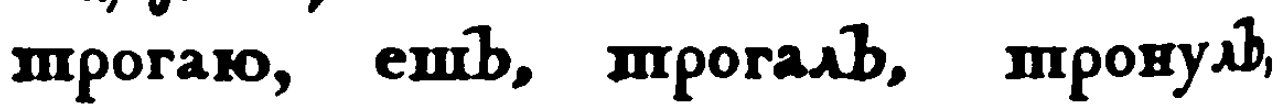
id) berübre,

mpy,

emb, mepb,

нуль,

id) reibe,

mрясу, ешb, трясb, шрясвуль, id) fáuttele,

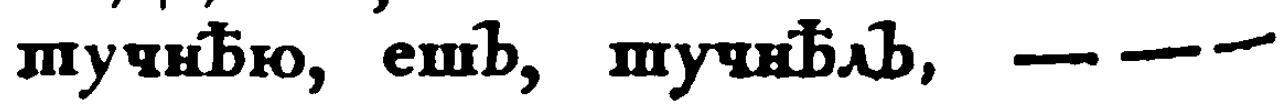
id roerbe fett,

my ribron 
Prxt. Perf. Futur. Imperat. Infin. - - писну, пискай, шискашь.

- - выmку, mкr, mкаmъ.

- - mолкну, mолкай, mолкапь.

сполокb, сmолку, полки, полочь.

зтолко- изтол- Молкуй, полковалb, кую, ватв. отолс- отолс- mолс- mоле-

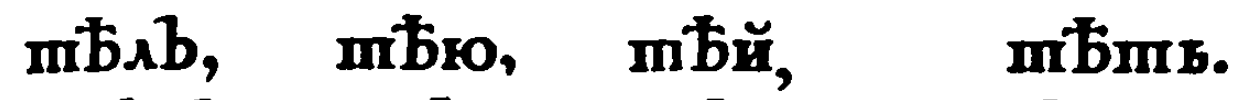

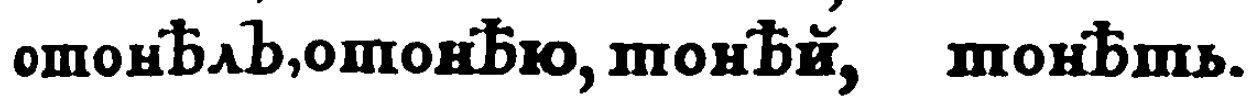

nотребо-потре іпребуй, іпребовалb, буко, ватв:

sсmрепе- встре- impene- mpenemaxb, пешу, ши, mamb.

- - mpoнy, mрогай, mporams. тронь,

cmepb, compy, mри, mереть.

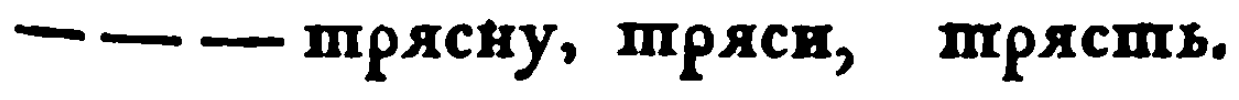

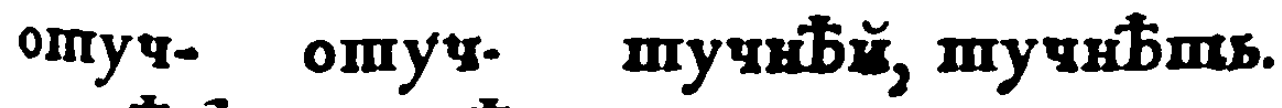

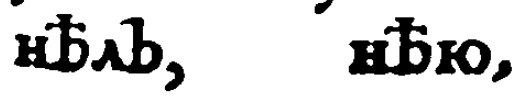

omy- 


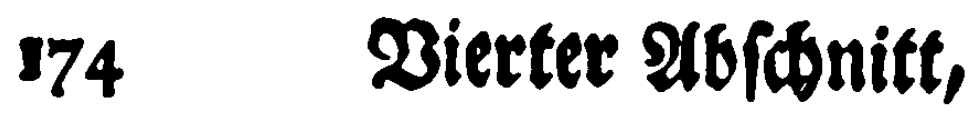

Prxeens. Imperf. Prxt. unit.

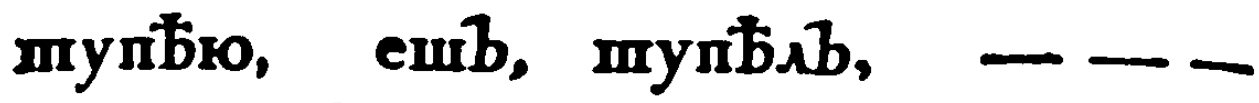
id) werbe ftumpf,

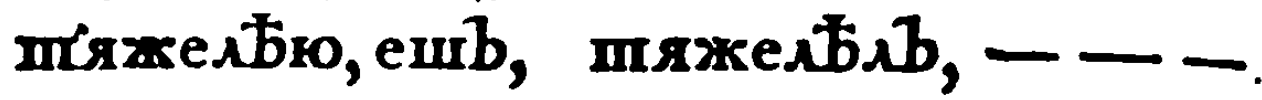
id) werbe fofwer,

хвастако, еши, хвасталь, хваснуль, id) rų̛̣me miđ,

хлђбаю, ешъ, хлђбаль, хлђбнуль, id effe binne Speifen,

хлопаю, ешъ, хлопаль, хлопнуль, id) Eradie,

xочy, emb, xоmbsb, - id) roill,

храплю, ешъ, храпьль, храпнуль, id) ráuppere,

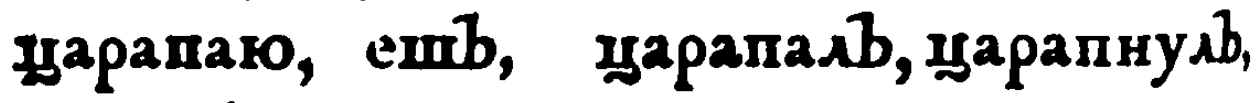
id) gerfrakese,

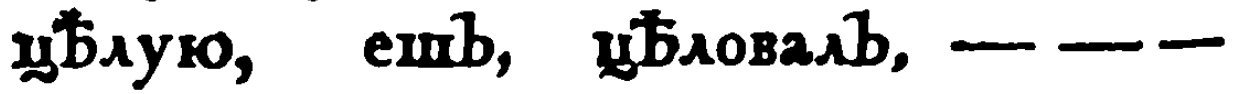
id fúffe,

чахну, emb, чaxb, чахнуль, id) bqabe bie Edwinojudt, чаю, eшr, чаяль,

id) glaube,

чернбю, ешъ, чернБлb, - id) werbe fowars,

чeiny, eшb, чесалb, чеснулb, id fảmme,

trmy, 


\section{2on Dem Verbo.}

Prxt.Perf. Futur. Imperat. Infin.

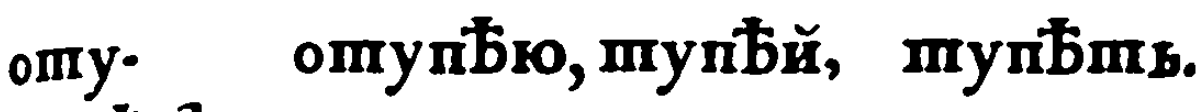
$\mathrm{nb} \wedge \mathrm{b}$,

отяже- отяже- пяже- пяже-

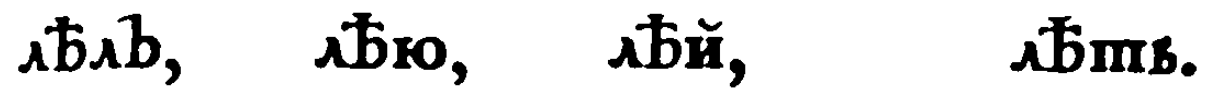
похвас- похвас- хвас. хвасmaxb, пако, пай, mamb. похлЂ. хлБбну, хлђбай, хлббать. $62 \times b$, похло- хлопну, хлопай, хлопашь. narb,

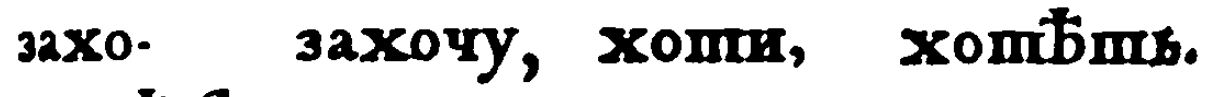
mbib,

захра. храпну, храпх, храпбшь. nbıb,

олара- царапну, парапай, парапапь. пияь,

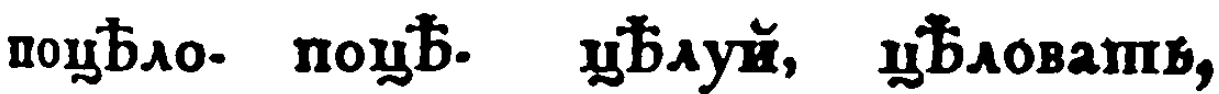

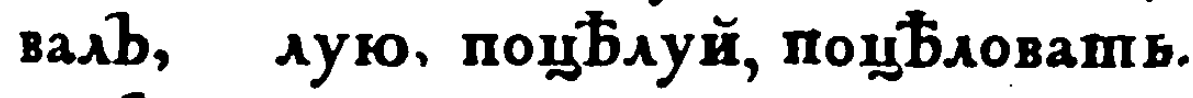
исчахъ, исчахну, чахни, чахнушь.

- — чаю, чай, чаящв.

почер- почер- чернбй, чернбмь.

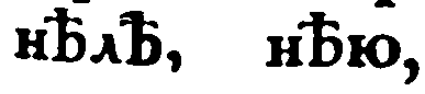

- - чесну, чеши, чесать. 
Prafens.

Imperf. Prxt. unit.

ymy,

$\mathrm{emb}$, челb, чолb, - -

id) ef̧re,

чувст- ешъ, ұувствво.

syro, id empfinbe, вarb,

чхаю, eшrb, чхаль, чхнуль,

id) niefe,

шагаю, ештb, шаганъ, шагнуль, id) trete,

шатако, emb, шаталb, шашнудb, (d) made wanten,

шuяо, emb, слаль,

id) fenbe,

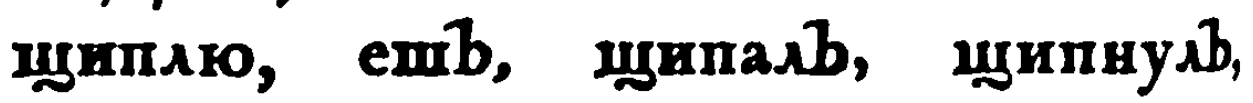
id) pflüfe,

bay, emb, நxarb,

id faţre,

Ђмb, emr, Ђsb,

id effe,

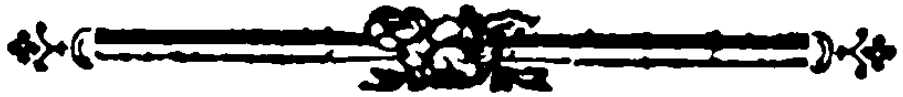

6. 132. 


\section{Bon Dem Verbo.}

Prxt.Perf. Futur. Imperat. Infin. почоль, почту, чіmи, честь. почувсп- почувсп- чувсп- тувспвоваяb, вую, вуй, воватв.

- - чхну, чхай, чхапь.

- - marнy, шагай, шагаmь.

поша- шапну, шгатай, шаташь. muגb,

послаль, пошнко, шили, слать.

ущип- щинну, щйай, щуипать.

нуль,

побхаגb, побАу, ЂАБ, Ђхаmb.

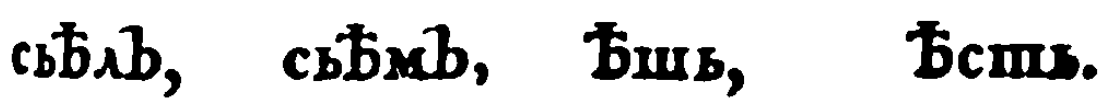




\section{Dierter 26 fanitt,}

$$
\text { §. } 132 .
$$

Die Verba Irregularia von bet

\section{Prxe.}

Imperf. Prat. unit,

6ожусь, жиишься,божкияся, id) fकroóre,

6ол10, nسb, 6олbАb,

id) empfinde einen Sdymerz,

бокось, nшься, боялся,

id) fürdfte mid,

браню, ишь, бранияъ,

id fódte,

6рђхxу, аитb, 6рђанив,

id fantafire,

брячу, чишъ, брячаль, брякнуль, id) flappere,

бужу, aиmb, будихb,

id) recfe,

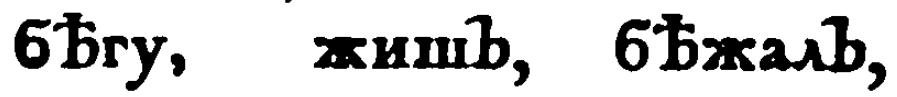
id) lauffe,

6Блю, иmb, 6Блнлb,

(đ) made meiß,

6Бшусь, сишься, 6Ђсияся, id) werbe rafend,

sapro, umb, варихъ,

id) Fodje,

sasto, umb, sastris, id) wailge, 
ywetsen Conjugation find folgente:

Prat. Perf. Futar. Imper. Infin.

no60. no6o- 6ozncb, 6охnIr.

швася, жусь, cя.

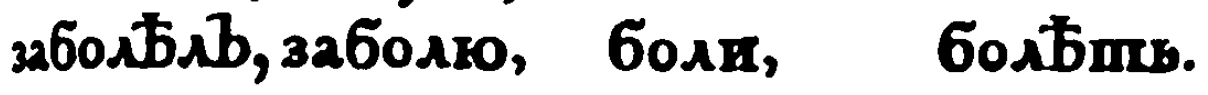

убоялся, убогося, бойся, бояпся.

ив:5ра. выбранко, брани, бранишь. Hसxb,

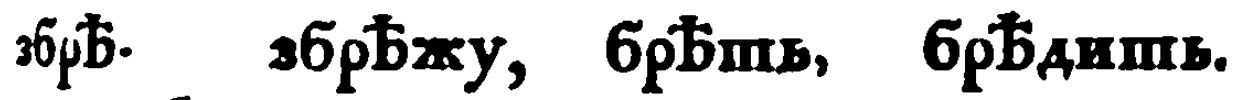
AHAb, ,

забря- забрячу, брячв, брячашь. чаль, брякну,

разбу- разбуаку, буди, будитв. AHAb,

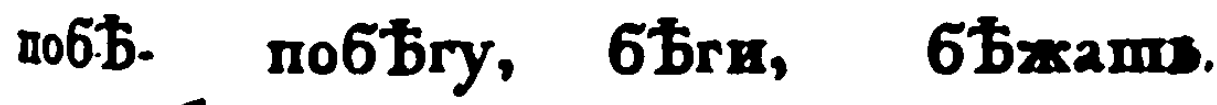
axarb,

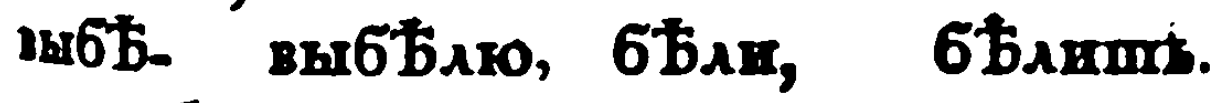
AHAb,

вбБсия-ваб Бшусь, 6 Бсись, бБстется. ся,

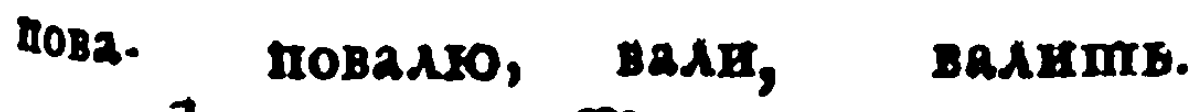
disb, $\mathfrak{M} a$ noze- 


\section{0

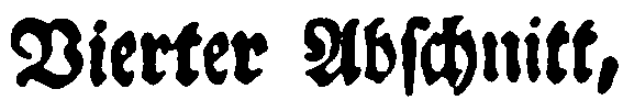

Praf.

sex fo, id befegle,

sерчу, mишb, верпйль, вернуль, id) oreţe,

вершуу ишт, вершияb,

id) enbige,

веселю, ишb, веселиль,

id) ergơgęe,

вижу, дишb, виябАb, id) Yehe,

вижжу, жишъ, вижжаль, визгнуд, id) flage ḩeinulia), feufze,

shiny, chumb, sucbib oder - - id) hange,

воплю, nmb,

id) beule,

ворожу, жишb, ворожкия,

id) zaubere,

sopчy, чиmb, ворчалb,

id grunje, murre,

rasky,

жumb, гадияb,

id) mađje ḩęllit),

гляжу, Аишһ, гАяАЬАЬ, взглянуа, id) Fegre, betradtete,

rHoro,

numb, sновнb

id) madie faulen, висb,

вопrגb,

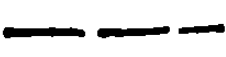




\section{Bon Dem Verbo.}

Prat. Perf. Futur. Imper.

Infin.

пове- повелю, вели, вельть.

$\wedge b \wedge b$,

повер- верну, верни, верпйты.

нуль,

совер. совершу, верши, вершить. шияв,

возвесе- возвесе- весели, веселить.

Аияь,

увнАЬАЬ, увижу, виАЬ, виАБть.

завиж- завижжку, вижкжи, вижхжашь. жaגb,

повись, повисну, висни, висђॄпь.

взопияһ,взвопльо, вопи, вопить.

cворо- свороzку, ворожки, ворожияb, $2 x n m b$. завор- заворчу, ворчи, ворчатыь. чалb,

घзга- изгажу, гадь, гадиіIв. And

погля- погляау, глядш, глядб̆б. $\mathrm{A} \mathrm{b} \wedge \mathrm{b}$,

згноиль, згного, гной, гноить. 
182

\section{Dierter $\mathfrak{A} b$ fdnitt,}

Prxf.

Imperf.

Prat. unit

голожу, Аишb, г голодияb,

id) laffe huungern,

голю, ищт, голияв,

id) madje fahl,

гоню, ишb, гналb,

id) verjage,

горжусь, Аншшся, Гордился,

id) bin $\mathrm{ftol}_{3}$,

ropro, umb, ropbsb,

id brenne,

граблю, ишт, грабиль

id) blünbere,

грежу, зиши, грезияb,

id) made etwas ungereimtes,

гремлю, иші, гремблъ, грянуяб, id) bonnere,

грублю, ишь, грубиль, id) bin grob,

Аавлю, ищи, Аавиль, Аавнуль, id orude,

A2pro, numb, Аариль,

id) fifenfe,

АВою, numb, АВонАЬ,

id) verosppele,

держу, ишb, держаль, - id) b̧alte, 
Prxt. Perf. Futur. Imper. Infin. yголо- y Aнגb, оголиль, оголко, голи, голить. прогналъ,прогоню, гони, тнать. sозгор- возтор- торапсв, тораитАнАся, жусь, ся. cropђаb, сторг, ropr, roptimb. ограбиль, ограблко, грабь, грабить. згрезиль, згрежу, грезь, грезить. возге- гряну, гремк, грембінь. $\mathbf{a b} \wedge \mathrm{b}$, corpy- corpy- гру6и, грубить. билb, баг, задавиА В, задавАК, Аави, Аавить. подариль, подарго, дари, даритв, уАвоилъ, УАвою, АВой, Авоить.

сдержаль, сдержу, держи, держать. удержаль,удержу,

$\mathfrak{M}_{4}$ вp0- 


\section{4}

Bierter 946fanitt,

Pref.

Imperf.

Prxt. unit.

Aגю,

nmb, Aлияb,

id) verjögere,

дорожу, ишb, дорожиль,

id madje eine Sinne,

до10,

numb, донгі,

id) melfe,

Арожку, ишb, Арожкан, арогнуль, id) jittere,

дружусь, ишься, Аругияся, - id) madje freundidjaft,

жарю, umb, жарияъ,

id) brate,

2кижу, иmb, жиянлb,

id) madpe buinne,

3вучу, чишb, звучалъ, - id) fidalle,

зеленю, нишb, зелениль, - - id) madie grin,

3גFCb,

Ишвсл, злдлся,

$--$

id) erbobe mid,

зноблю, nшb, знобияb, id) madte frieren,

зрюе,

numb, $3 p \bar{b} \boldsymbol{b} b$,

id Febre,

хазню, иmb, казнияв, - -

id) belege mit Tobesftrafe,

xsaify, 


\section{Bon Dem Verba.}

Prxt. Perf. Futur. Imperat. Infin.

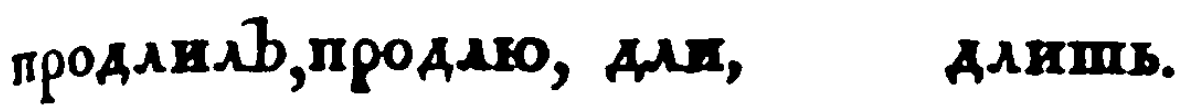

Вздоро- ВзАОРО- АОРОхКЕ, АОРОжияb, жу, жить. подоиАВ, подого, дой, доишь. задрожала,задрожу, Арожи, Арожашть подружил-подру- Аружисв, дружится, 2хусь, нзжарияъ, изжарго, жарь, жарить. ожиднАЬ, ожижу, жиди, жидить. зазвучалb, зазвучу, звучв, звучать. изеле- вызеле- зелеви, зеленить. ния $\mathbf{b}$, нго, 0зднлся, озАюся, зАися, зАится. 0знобнлъ, ознобиго,зноби, знобить. узрбль, узрго, зрк, зрбіть.

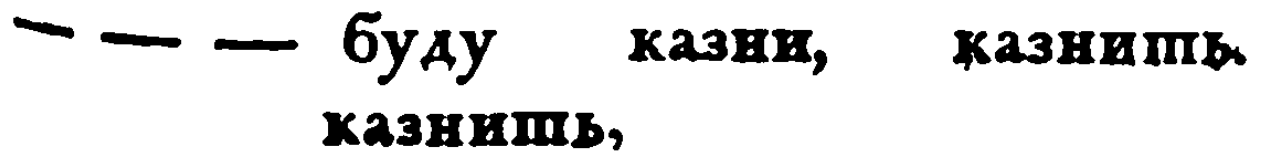
M 5 скD2- 
186

Praf.

квашry,

id) fäure,

хиплю,

id tode,

клеймю, ишb, клеймияb, - id made ein Merfjeiden,

холочу, mumb, холотшль,колонуль, id) flopfe,

xопл10,

мmb, хопнль,

id) fammle, ḩäufe,

коाтy,

mumb, хопmилb,

id beråudere,

кормлю, ишт, кормиль, - - id) fpeife, madje fatt,

sopuy,

чншиb, корчияb,

id) madfe frumm,

xomy,

cumb, коскар,

id mähe,

xpamy,

id färbe,

xpewy,

id) taufe,

xpryy, .

id fabrene,

xpowy,

cumb, храсияъ

сппиты, креспияb, - - -

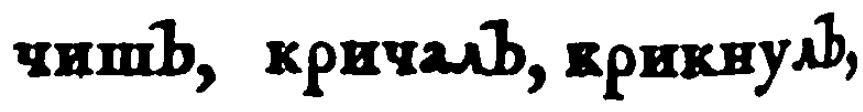

id f́nneibe, baafe Elein, numb, хрошивлb, - -

xposo, 


\section{Bon Dem Verbo.}

\section{7}

Pret. Perf. .Futur. Imper. Infin.

сквасих , сквашу, квасъ, квасить.

зскипђлъ, вскипльо, кити, хипђть.

заклей- заклей- клеймн, клей-

михb, мю, ' митв.

32к010- 32х6010- к010ImK, к010-

musb, уy, mumb.

схопияв, схоплю, копи, хопить.

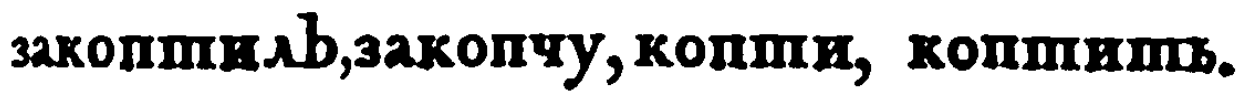

накор- накорм- хорме, хормияв, лю, мить.

схорчия б, скорчу, корчи, хорчишв.

скоснль, скошу, косн, косншь.

зикра. выкра- хрась, храсишь.

curb, my,

охреспия

закричаль, закричу, кричи, кричапш.

псхро- искро- хроши, кро-

$$
\begin{aligned}
& \text { щихь, шу, шить. } \\
& \text { cxporisb, }
\end{aligned}
$$


188

Bienter 96/4nitf,

Pref. Imperf. Prxt. unit.

xporo,

nimb, хроиль,

id) faneibe zu,

xрyжy,

иmb, хружияъ, - id) made runo,

хручннюсь, ишься, хручинился, -id) betrube inid,

кручу,

mиmb, крупияъ, - id) bref̧e,

кypro,

nmb, курияb,

id) råud)ere,

rexky,

nurb, лежкалb, легb,

id liege,

reuy,

mumb, sembsb,

id) fliege,

roчy,

nmb, локаль, 1окнулb,

id) trinte ledeno, wie ein Şunb,

^yæxy,

дишъ, худихb,

id) verginne,

лю6лю, ишъ, любияb, - id liebe,

маслю,

пшіb, маслияъ, - id) fámiere ein (mit Jette, Dele),

медлю, ишб, медлиль,

id) verzogere,

молчy,

numb, молчaגb, - id) fómeige,

mopozyy, 


\section{Dont Dem Verbo.}

Prst.Perf. Futur. Imperat. Infin. скроиль, скрого, крой, кроить. окружихъ, окруху, кружи, кружишь. закручи- закручи-кручинь- кручинияся, нось, ся, ниться. закрупияъ,закручу, круши, крушишь. накурихъ, накурго, кури, курить. полежкль, полежу, лежк, лежать, лягb, лечь. полетъль, полечу, лепи, летбшь. полокаль, локну, лочн, локашь. њиудиљљ, вилужу,лудк, лудить. полюбиль, полю- люобв, люобить. 6хко,

закаслилђ, замас- маслк, маслить. A10,

умедлилъ, умедлю,медли, медлить. 32молчалb, замолчу,молчи, молчати. 
190

Bierter $\mathfrak{A b}$ f

Pral.

Imperf. Prat. unit. морохуу, зиmb, морозиль, - id) laffe erfrieren,

морго, nmb, моргаb, - id) tóbte, (burd א̧unger, mit Bifte, )

muy, мсmumb,мсmияb, - id) rädbe,

nuayỳ,

mumb, пגamkגb, - id) bezaḩle,

norawo,

nimb, noraxurb, - id) enţ̧eilige,

nok0ro,

rimb, пококגb, - id made ruf̧ig,

abuy, iф) fकmeidele,

помнк, пmb, помния

id) erinnere mid,,

nopuy,

mrumb, поршинb, - id) verberbe,

myтy, id blafe auf,

casxy, id) verfege,

cBnyyy, id) pfeiffe,

cruxy, id fiģe, qumb, пучнגb,

дишб, саднגb, - -

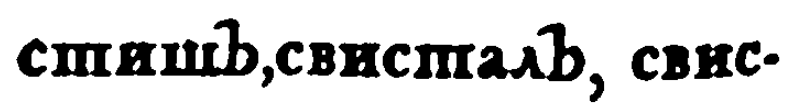
нуль, даmb, скAb八b, cbגb, 
Prxt. Perf. Futur. Imperat. Infin. заморозиль, замо- морозь, морозишь. рожу,

уморихь, уморю, мори, морить. опмстиль, отмиу, мсти, мстить. заплапилъ, заплачу, плати, платить. опогапияb, опоганк, опо- поганить. гань, успокоиль, успококо, покой, поконшь. польстиль, польнуу, льсти, льсшить. эспомния , вспомню, помни, помнить. испорпихъ, пспорчу, порти, порпишь. мпучиљ, sыпучу, пучь, пучишь. посадиль, посажу, сади, садитвь. засвистахb, засвиниу, свисти,свис. mamb.

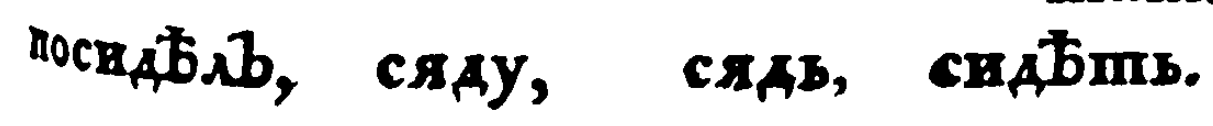


192

Bterter 2Ab/ditt,

Praf. Imperf. Prxt. nait

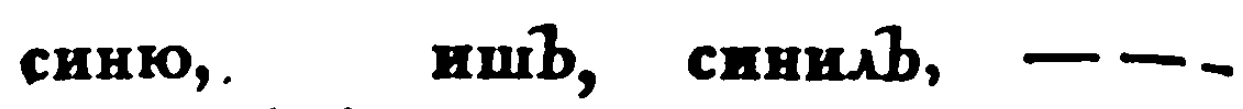
id) maçe blau,

синбю, ишb, синбגb, - id) werbe blau,

скарезку, анши, скаредиль, - id) made ḩeß̧lid,

cкоблго,

nши, скоблияв, - id) farabe,

cла6лго,

nurb, сла6ияb, - id) fdrraide,

craжsy,

даниb, сладияb, - id) verfüße,

crexsy,

заши, слезиль, - id) madje weineno,

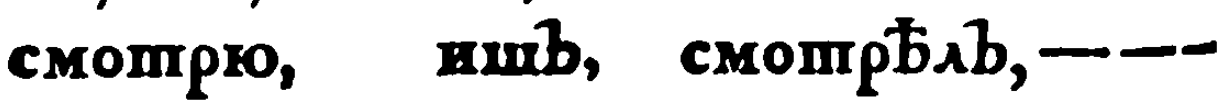
id febe,

cмbmy, ummi, схбшиль, - id) madje zu ladien,

criš,

numb, crarb,

id) (đ)lafe,

cmpoyy,

чиши, строчал], - id) náḩe aus,

сулю,

uub, суланb, - id) verfprectie,

cy wy,

питиb, суштав, - -

id) trociene,

mepras. 
Pret. Perf. Futur. Imper. Infin. зисинияb, высиню, сини, синить. посинбль, посинбю,синђй, синбть. оскаредиль, оска. ска- скарережу, реди, дить. вискоблиль,виско. скобли, скоблю, ослабиль, ослаблю, слабь, слабить. осладияъ, буду слади, сладитьв. cладить, прослезия п, прослежу, слези, слезить. посмотрђль,посмо- смотри, сморгзсмб- разсмђ-смбии,смбшишь. шилb, шиy, поспал, посплк, спи, спать.

выстрочияъ, выстро-строчи, стро-

$$
\text { чy, }
$$

чhmb.

посулиль, посулю, сули, сулить.

ысушиль, висушу, суши, сушить. 
194

Bierter $\mathfrak{A} 6$ ffannitt,

Praf.

Iinperf. Prxt. unit.

mерплю, пнmb, перлїлb, - id) Oulte, leibe,

monג10,

пишb, mопияb, - -

id) b̨eił̨e,

mpayy,

muшb, прапияb, - -

i(t) verliere,

impeny,

nшb, mрейasb, impec.

id Enarte, Elappere,

mynגкo,

numb, mупиль, - -

id) mad)e ftumpf,

mywy,

ишб, тушияb, - id) lofide aus,

mbury,

nub, mbшrиı, - id) trófte,

хоронко,

numb, хоронилb, - id) begrabe,

храплго,

пиш id) idnardfe,

хулю

ишъ, хулияb, - itf) tabele,

шиплю,

пишb, шипьља, шипнул $b$, id) jifde wie eine 5 d)lange,

myxy,

mишb, шушихb, - -

id fpafe;

6. '133. 
Don Dem Verbo.

Prat. Perf. Futur. Imperat. Infin.

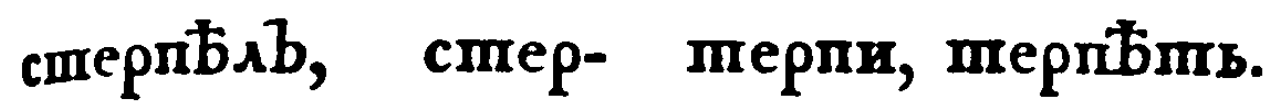
п人ю,

выпопиль, выпо- попи, попипь. плю,

потрапияb, истра- прапь, пра-

чу, пить. затрешаль, запре- треши,трешапь wy,

ымупиль, выпу- пупи, пупипь. пхю,

запу шиль, запушу, пуши, пу шить.

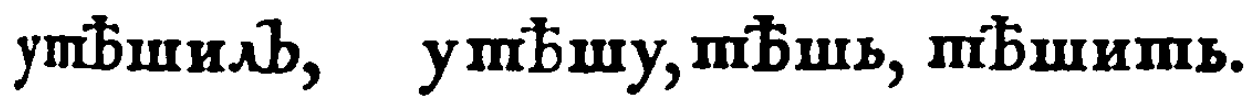
схоронияЬ, схоро- хорони, хороHю, Hить. захрапьль, захра- храпи, храпбпь . пл10, похулияъ, похулю,хули, хулипь. зашипђАЬ, зашиплю, шипи, шипђпь. досушиль, пошучу, шупи, шупипь. 
196 Bierter $\mathfrak{A b}$ 他. von Dem Verbo.

$$
\text { 6. } 133 .
$$

Es find in biefer Tabelfe frenlid nod nidp alle Verba irregularia angeführt; injwifden fann man, wenn man fid bie hier bemerften woll imprimiret ḩat, bie übrigen burd) aufmert/a. mes Sefen, unb jum \$̧̧eile aud aus ber Xna. logie ber $\mathfrak{B u d f f t a b e n}$ leidt erlernen. Man weißß wie viel es im Lateinifhen und Deutfden barauf ant'smmt, Daßi man im erftern bas Prs. fens, Perfectum und Supinum, und im lefts tern bas Prafens, Imperfectum unb Supinum wiffe. Die ruffiffen Verba aber find nod mę̧retn Abänberungen unterworfen.

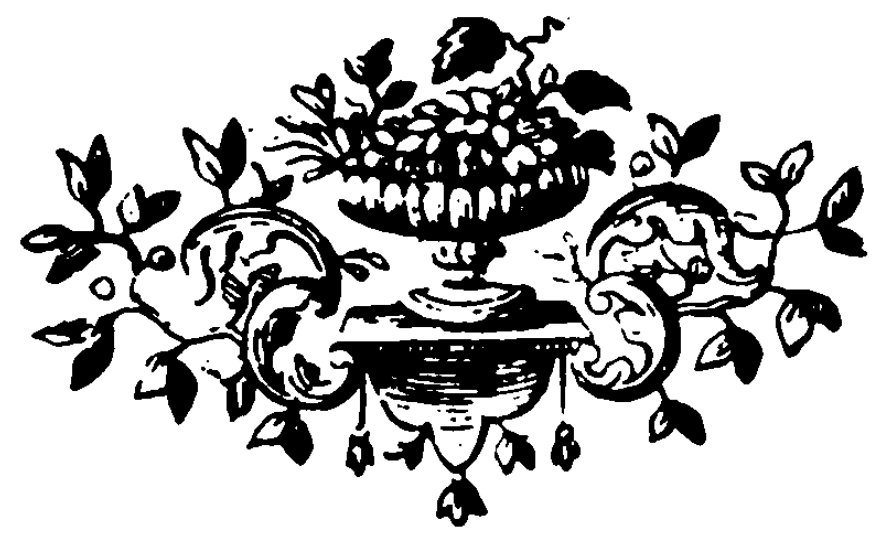

Der 


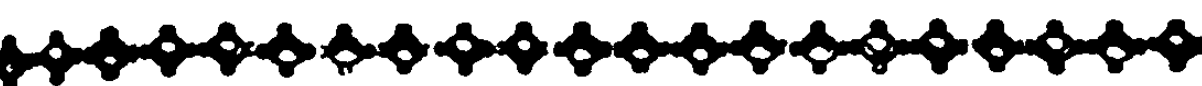 \\ Der fúnfte $\mathfrak{A}(\mathfrak{d}$ 何nitt. \\ De partibus auxil. orationis.
}

\section{Dab̉ erfte Şauptitúcf. \\ Bon Den Participiis.}

\author{
9. 134 .
}

Bon ben Participiis ift ju merten, baß fie funf Tempora b̧aben, nảmlid Das Przenens, Imperfectum, Prateritum unitatis, Prxteritum Perfectum, uno Plusquamperfectum. Bon Fę̧r menigen ift bas Futurum gebräudilid. Zuth haben fie brenerlen bef(d)lectite, námlid Malculinum, Foemininum, uno Neutrum; zroeen Numeros, Singularem und Pluralem; und fie. ben Calus, wie bie Nomina. Sie werben aud wie Die Adjectiva becliniret.

$$
\text { ๑. } 135 .
$$

Die auf nуїй ausgeģenben Participia Indicativi Prafentis werben blok bon folden Verbis gemadtt, bie aus bem Elawonifhen abftammen, als: вЂнча́ющüй, ein Яronender; пи́шу-

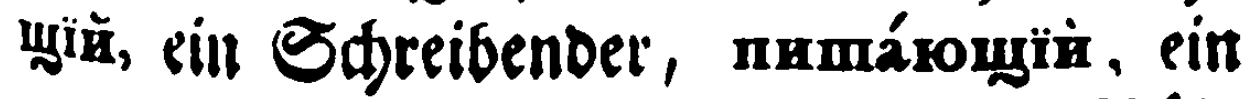

$$
\mathfrak{R}_{3} \quad \mathfrak{i} \mathfrak{i} \mathfrak{b}=
$$




\section{Ginfter $\mathfrak{A b}$ fdnitt,}

Rábrenber. Bon gemeinen $\mathfrak{B}$ ơrtern laffen fid bergleiden Participia nidgt füglid) maden. Diefe Participia werben folgendermaßen beca linirt:

Singularis.

\section{Mafe.}

Nom. пита́кощій,

Gen. пита́́ юшаго,

Dat. пита́ющему, пита́ющей,

Acc. пита́кощаго, пита́кощуюо,

$$
\text { щйй, }
$$

Voc. пита́юоциій, пита́ющая,

Inftr. пита́ющщимb, пита́ющеюю,

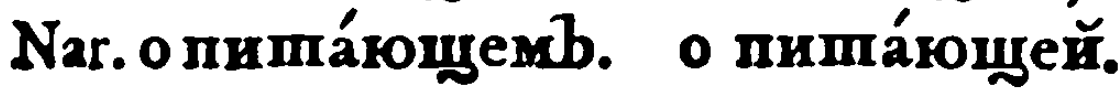

Neutr.

Nom. пита́кощеe,

Gen. пита́юшаго, пипа́ющих

Dat. пита́юшему, пита́ющимb,

Acc. пита́юuщeе, пита́ющи $\mathrm{xb}$, щиie,

Voc. пита́ющеe, пита́ющüe,

$$
\text { uis, }
$$

Inftr. пита́ющимb, пита́ющими,

Nar. о пита́iouemb. o numáкоџихb.

$$
\text { 6. } 136 .
$$

Eben bieß gilt aud) von ben Imperfectis unb Prxteritis Perfectis Participiorum, als worlo 


\section{De partibus auxil. orationis. 199}

he auf gleidje art beclinirt werben, als: пита́вшій, einer ber genáfret hat, пиmásшаго, пита́вшихъ, напита́вmїе, напи. máвmuxb, u. f. '.

\section{§. 137 .}

Es giebt nur nod) fẹtr menige flawonifde Verba, bie bas Prxteritum unitatis b̧aben. Ruf. ifide Verba bagegen, bie ben Slawoniern unbe. fannt fino, fönnen nid)t allemal im Participio das Prxteritum unitatis anneo̧men.

\section{138.}

Das Prafens Participii paffivi enbet fid auf мhй, unb wirb nur aus folden $\mathfrak{B}$ oittern gemadtt, bie flawonifden urfprungs fino, als:

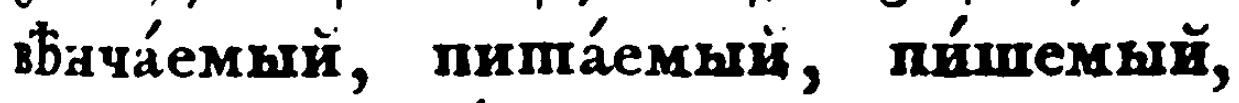
ВидимҢй, Носи́мњй.

$$
\text { §. I39. }
$$

Sumeilen wirb bas Participium Pafivum Prxfentis fratt ber zúfünftigen Zeit gebraudet, als: прода́ваемия на бу́ дущей неАН̆'Аи

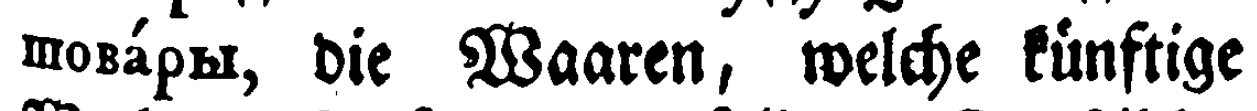
Sode verlauft werben follen. Die ábàn. berung Derfelben iff folgende: 


\title{
Günfter 2 Ab fanitt,
}

\author{
Singularis. \\ Mafc. \\ Fœm.
}

Nom. пита́емъй, пита́емал,

Gen. пипа́емaro, пита́емпя,

Dat. пита́емому, пита́емой,

Асc. пита́емaro, пита́емую,

мпrй,

Voc. пита́емый, пита́емая,

Infr. пита́емымb, пита́емою,

Nar. о numáeмомb. о пита́емой.

Neutr.

Pluralis.

Nom. numáemoe,

nиmáenße, мњя,

Gen. пиmáeмaro, пиmáeмmxb,

Dat. пита́eмому, пиmáeмmмb,

Aсc. пипа́смато, ое, пита́емих b, hre,

Voc. пипа́емое, пита́емье, (m),

Infr. пипа́емымb, пита́емъми,

Nar. o пита́eмомb. o пиmáeмuxb.

\section{140.}

Die Prxterita Imperfecta find in ben Participiis Paffivis, fo robl von neuen Ruffifden, als aud bon flawonifacen wortern, feb̧r ges bräuळlid, als: пи́maнный, eilter ber ge: náfret war; вڤ̆ча́нный, пи́санный, виденный, u. f. w. Dod Gaben bie Börter 


\section{De partibus auxil. orationis. 20I}

Nlawoniffer abfunft lieber bie Enbung auf sǔ, ruffiffoe aber auf oŭ. Sie geţen wie bie won ber gegenwätigen వeit.

$$
\text { 5. } 14 \mathrm{I} .
$$

Zuf gleide $\mathfrak{X}_{\text {rt }}$ gef̧en aud bie Prxterita perfecta Participii paffivi, als: напи́санныr̆, вапи́саннаго; sама́ранный, sама́ран. aro, u. f. w.

\section{142.}

Die Participia paffiva Plusquamp. fino von ruflifiden Verbis zroar feb̧e gebraudlid, jebod) meţrentḩeils mit $\mathfrak{a b f u u r g u n g ~ b e r ~ E n o f y l b e , ~ a l s : ~}$ сма́mриванb, на, но, einer ber oft gefefen worden.

\section{§. 143.}

Bon Verbis relde bas Prat. unitatis auf ayab haben, giebt es viele Participia paffiva eben berfelben Beit, als: von ки́нy aymb, geworfen; von Ави́нулb, Ави́нушт, beroget; von су́нудb, су́нуш⿱一兀, gefdoben.

$$
\text { 6. } 144 .
$$

Die Verba reciproca baben eben folde Participia als bie Activan nur Daß bie Enofilbe

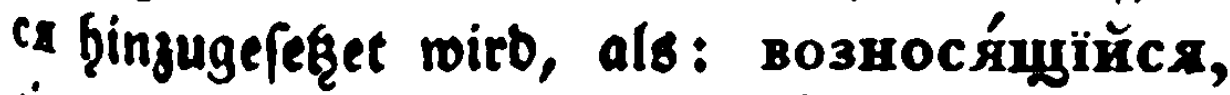
tiner ber fidf) erfebet; бoprómü̈ися - fid) 
ringet; боя́щуійсs - fiđ fürdftet; возно.

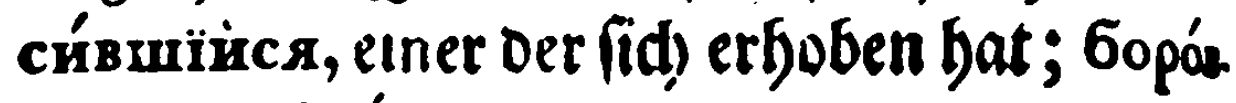
шійся, боя́вшіикся.

$$
\text { 9. } 145 .
$$

Xud haben bie Verba neutra bergleidfa Participia als bie Activa, als : crésüị̆, einer De 何låft ; ходи́шйй, — gefet; спи́шаго,

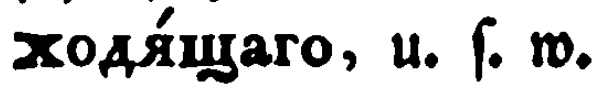

$$
\text { 6. } 146 .
$$

Die Tempora praterita ber jufammenge reşten $\mathfrak{B o b r t e r ~ l e i b e n ~ f e i n e ~ P a r t i c i p i a ~ ; ~ m a n ~ f a n n ~}$

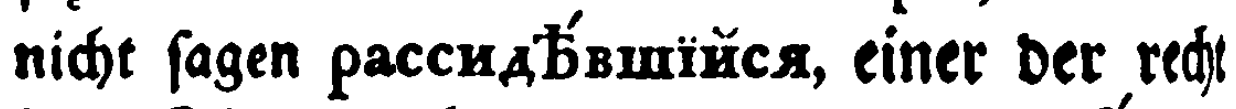

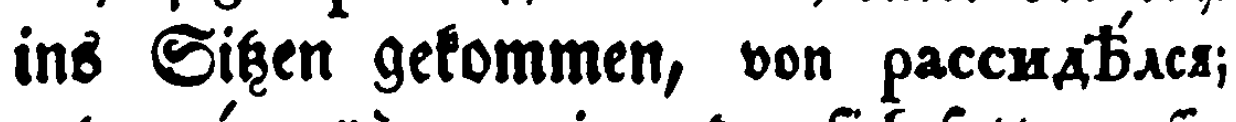

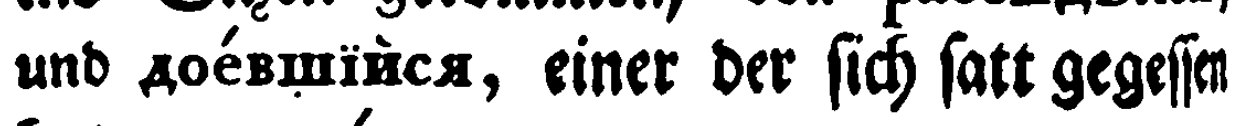
Gat, von дое́лсs.

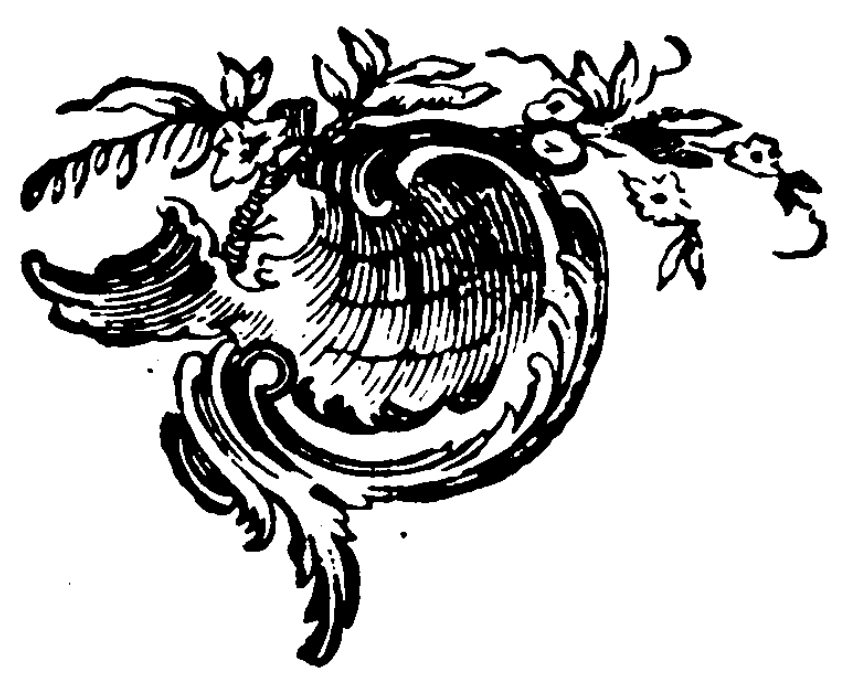

Da 


\title{
De partibus auxil. orationis. 203
}

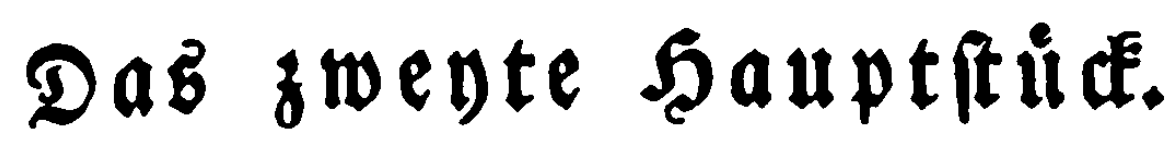
Bon Den Adverbiis.

\author{
6. 147.
}

Die Adverbia fino in ber ruffifíen Eprade been to wie in allen andern Spradien vielerley und jroar,

1) Adverbia temporis, bie eine. Seit

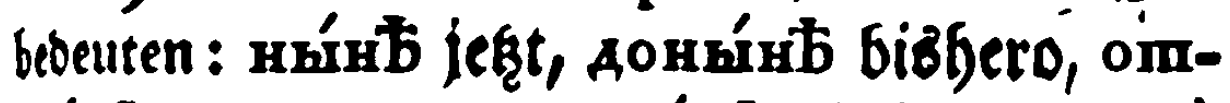
súrb von nun an, понhínb bis jef̧o, вcerAà allegeit, доко́лЂ biв zu weldher Zeit, за́вmpe motgen, páно frúbe, nósaно páát, вчерà ge=

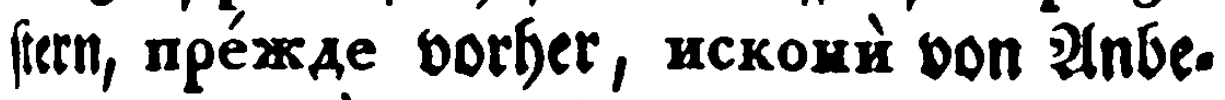
ginn, иногдà jumeilen.

2) Adverbia loci : rAb wo, зАбсь Gier, mymb Da, везА

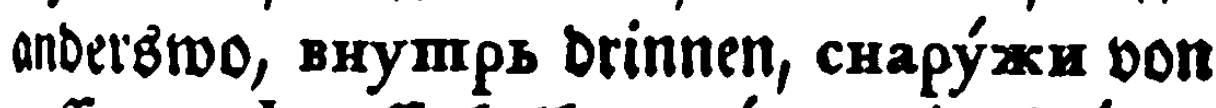
aufen, sнб aufferfalb, sале́че weit, бли́зко nabe, omкý да von wamien, omcrósa von

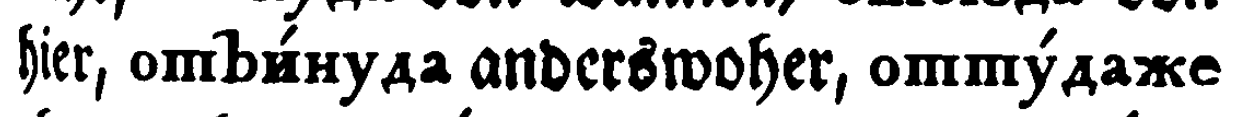
eben baber, crépeaи voll vornen, сза́ди von hinten, кудà mohin, crosà fiefer, myдà Dortfin, и́нуда anderzivofin.

3) Adverbia qualitatis \& quantitatis: $\mathbf{x a k b}$ wie, maxb fo, xopowò gut, xýдо (f)lecft, пря́мо redt, gerabe, наро́чно vorfeślid, befonderz, ókоло um, удо́бно bequem, scýe

umionit, 


\section{Günfter $\mathfrak{A} \mathfrak{G}$ fønitt,}

umionft, ckósko wie viel, cmósxo fo viel, дово́sно genug.

4) Adverbia numeri: одна́zжа einmal, многа́жаи vielmal, aвózah zwevmal, mро́жаы Drenmal, уепты́режаы viermal, деся́mью zefnmal, u. f. m.

5) Adverbia ordinis : npézxде vorf́er, no.

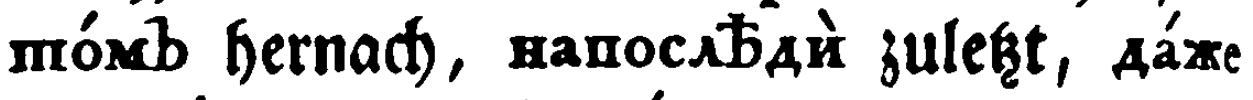
бів, па́ки abermal, сно́ва vот пеиеп, вновь aufв̈ neue, euè not), впервыre zum erifell: mal, вApyrïe fum andernmal, nocemb nach Diefem.

6) Adverbia affirmandi : maxb fo, úc. пинно wafrlid, ей wafrbaftig, весьма̀ fefr, по́даинно gewiß́.

7) Adverbia negandi : ne maxb mititio, ни какb gar nidjt, отнко́дb Durdjaub niđjt, ни мáso im geringltell nidft.

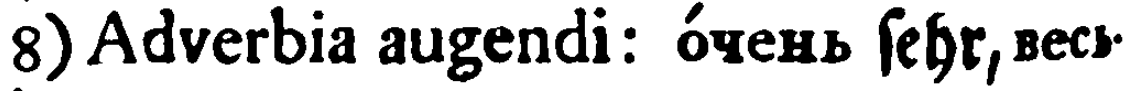
мà úberaub.

9) Adverbia comparandi: $\mathbf{k a k b}$, alb, wie, хакb 6ы fo wie, подо́6но ебen fo, áfnnlitifer weife, подо́бно какb eбen fo als, maxb [0, áки бы als wenn, коль fo féfr, mоль fo vieh.

10) Adverbia differentix: и́нако an: Derö, и́начe auf eine andere $\mathfrak{W}_{\text {eife, }}$ pázно

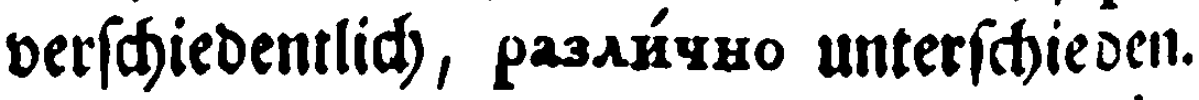

ii) Adver- 


\section{De partibus auxil. orationis. 205}

11) Adverbia interrogandi : чmo $\mathfrak{m a z}$ ? noqmò wozu? кaxb mie? aокósb bis wohin? omxósb von woher?

12) Adverbia dubitandi: sócsm6o viel= leidft, Hnxáxb ift ez̉ nididt etwaumn.

13) Adverbia Colligendi: smb́cmb $\mathfrak{u}_{\mathbf{u}}$ fammen, вкýnib beyfammeu, 320дно fúr eins, вapyrb zugleiff.

14) Adverbia celeritatis: sвezány uns verféfenz, sapyrb plóg̨liđ, нечásнно un. sermuthet.

15) Adverbia demonftrandi: somb firfe, mymb da.

16) Adverbia depellendi: sonb Jenaub, upoub fort, aánbe weiter.

\section{\$. 148.}

Die Adverbia, welde von Nọminibus ab.

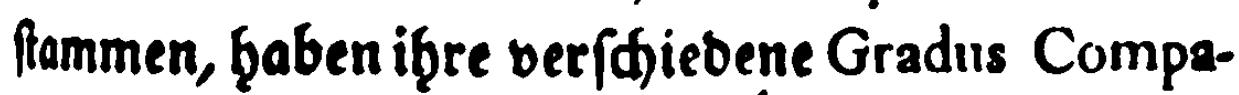

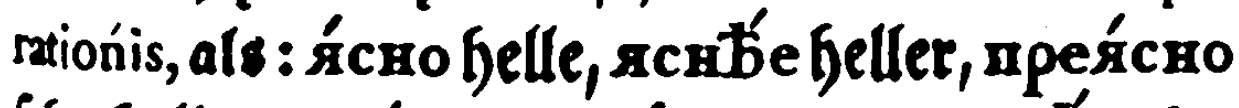

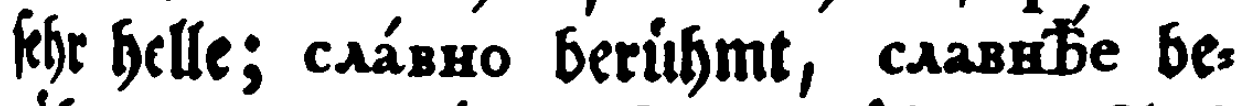
rúfmter, пресла́sнo febre berúfmt. Zü neţmen fie eine Berfleinerung an, als: понйze niebriger, пора́вђе friffer, вемно́ro

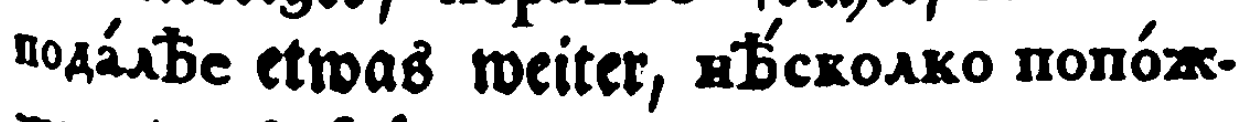
re etwas jpáter. 
206 Gunfter 246 fontitt,

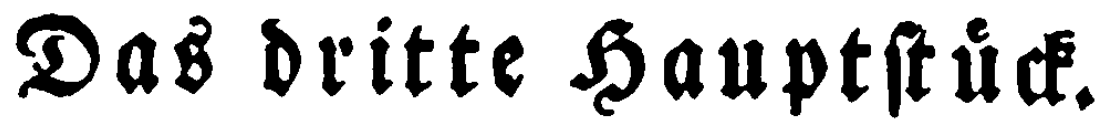
Bon den Præpofitionibus.

$$
\text { §. } 149 .
$$

Prxpofitiones ober Borwodrer werben, fo moḩl in zufammengefef̧ten $\mathfrak{W o j t t e r n , ~ a l s ~ a u \emptyset ~}$ in einer Rebe, ben Nominibus unb Verbis bor: gefegt, als: sb aоnб in bem ḩaufe, als

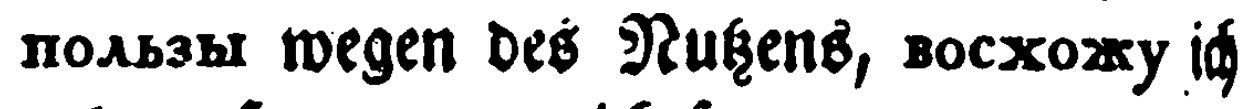
gefe auf, зачинако id) fange an.

$$
\text { 6. } 150 .
$$

Diefe Prepofitiones regieren. funf Calus, nàmlid) ben Genitivum, Dativum, Accufativum, Inftrumentalem uno Narrativum. Э̧̧rer einige regieren nur einen, andere aber zroeen Calus.

$$
\text { §. } 151 \text {. }
$$

Den Genitivum regieren y ben, inpézsate vor, npomŕrb gegen, miber, óxoso um,

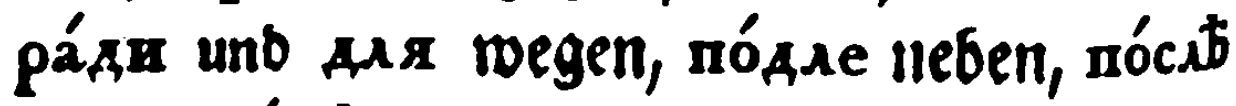

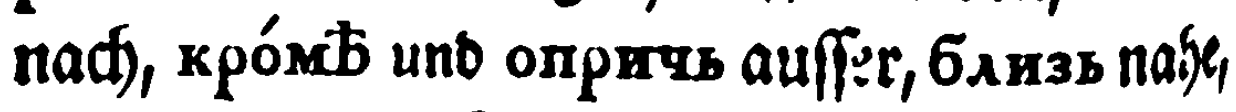

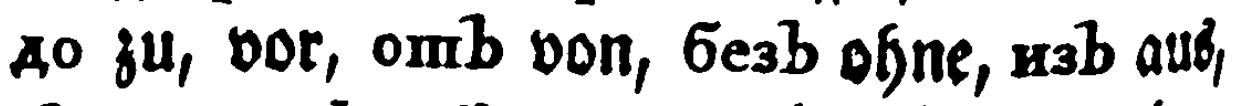
cb von, sub oufferfall, 6xkísxo nabe, súxo vorbed. 


\section{De partibus auxil. orationis. 207}

Den Dativum erforbern xo ober $\mathbf{k b}\}$ no Itadf), auf.

Den Accufativum ne⿻̧men ju fid zpesb unt сквозь Durळ, 32 für, no biล̈, npo von wegen.

Der Infrumeutalis folget auf mepéab ober предь vor, мéжay ober мезхь ober промежкь jwifa)en, co ober cb mit.

Der Narrativus miro conftruiret mit no nach, wenn es eine Jolge ber Beit bemerfet, o oder $06 \mathrm{~b}$ von, при bev.

Den Accufativum unb Infrumentalem b̧as ben за úber, binter, nодь unter, предb ober пере́ab vor; Dem Accufativo uno Narrativo aber merben vorgefeget so ober $\mathrm{Bb}$ in, $\mathrm{Hz}$ auf. Diefe ḩaben auf Die Frage, woḩin? Den AccuGativum, und auf bie Jrage, po? ben Inftumentalem ober Narrativum.

$$
\text { 6. } 152 .
$$

Einige Prepofitiones merben bisweilen mie Adverbia gebraudfe, indem fie zroifthen andern

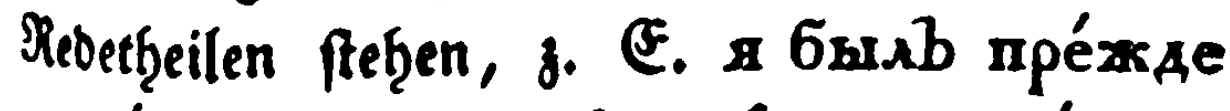
зноро́вb, iđ) wai vorfer gefund; оста́нься sнympiz 


\section{8

внутрй и́ли внб, Gleiб brinnen, ober Drals: feil; не подходй 6 Аи́з ко, fomme nidt na: be; вооруже́нъ проти и́ву, Dageyen gerüfet.

$$
\text { §. } 153 .
$$

Die Prxpofitiones выт, возb, низъ, разb fönnen niemahls bor fíd allein, als abgefondertt 23örter, gebraudit werben, fobern aud teinc bo fondern Endungen, fondern find allemal mit andern $\mathfrak{2}$ Börtern zufammengefeegt, als: st.

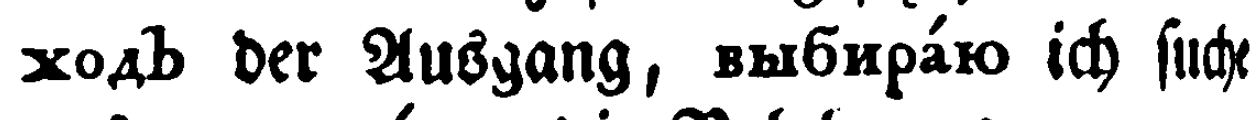
auz, воздая́нїе Die $\mathfrak{B}$ elobnumg, низвер. ráro id) ftúrze, passópb der âwieipalt.

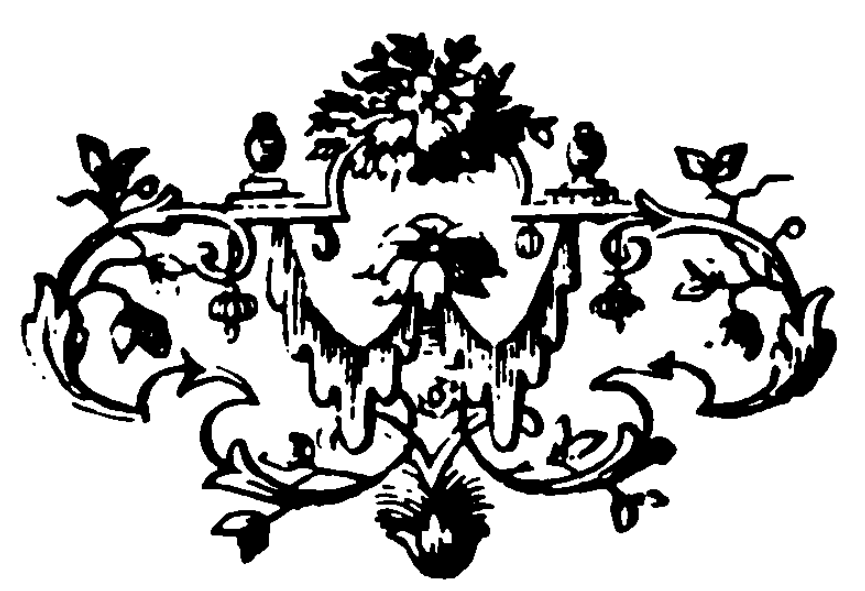


De partibus auxil. orationis. 209

\section{Da bierte Şauptít Bon Den Conjunctionibus.}

$$
\text { §. } 154 .
$$

Die Conjunctiones find entroeber einfadse, als: пре́жде juvor, и́6o benn; ober jufams mengeféste, als: éжexn weun, aa6h̀̀ Damit, mákжe bezgleitben; ober fie beftef̧en aus

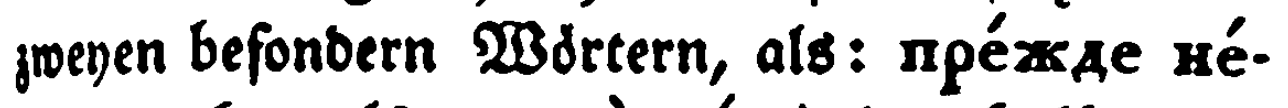
жели ef̧er alż, morò pádì derobalben.

Es fint bie Conjunctiones

\section{155.}

1) Copulativx : als: un uno zse alld, mákжe gleithfallb, кýпно bаzu aut(), какb, такb, fowohl alb aud), a имя́нно námlid).

2) Disjunctivx: и́ли entweber, DDer, Аи́60 ober, Аи DDer.

3) Conditionales: Gyдe wonn, éжели falls, korà̀ wenn, koraázke wenn aber, ézee1нжb Dafern nber, גи urb fo ferne, móкмо fo ferne nur, mo fo.

4) Adverfarix: aа ofier, однákохxb, одна́коже Dennođ), xom r̀ obgleid), Aa Dod).

5) Caufäles : ń6o denn, nонéze weil, ymo Daber, по пому чтmо Deß̧fallв Daß̧.

6) Conclufiva: n maxb und fo, nocemỳ Diefem ju folge, сль́доователно folglid.). 
210 Günfter $\mathfrak{A} 6$ f⿰丨. de part. auxil. orat.

\section{Dả füllfte Sauptitúč́. Bon Den Interjectionibus.$$
\text { \$. } 156 .
$$

Die Interjectiones find if̧rer Bebcutung nad entweder erfreuente, als: ra, ara, fa, fa; oder ellagende, oxb ad)! rópe of wef)! $6 b_{\text {ala }}$ leider! axmѝ мнb o wef) mir! verivun: Dernte; mómo, mómo Ha, воmb mómo, Dab ift wafb! ncnosámb red)t fo! etwoo utier. wartetes anzeigende, 6a, 6a, 6a, fiefe ein mal! verabfaffeuende; $\Phi$ e, $\Phi y, \mathfrak{P}$ ful); a, cry; verbietende, whmb, cmb, willit Du! eine Furd)t anzeigende, oй, yy, add)! ev en!

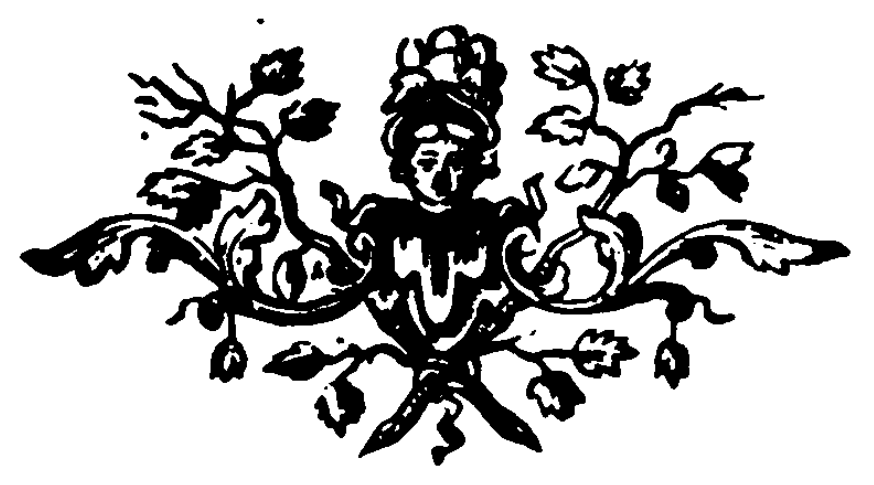

Del 


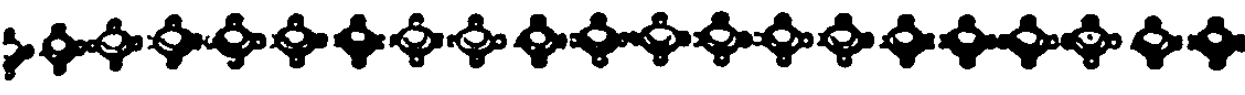 \\ Der fectife $\mathfrak{A} \mathfrak{g}$ (d) nitt. \\ Bon Der Syntaxi.}

\section{Das̉ erfte Şauptifúcf. \\ De fyntaxi Nominum.}

$$
\text { \$. } 157 \text {. }
$$

Die Adjectiva, Pronomina unb Participia fanmen mit bem verbundenen Subltantivo über. ein in gleidem Genere, Numero uno Cafu, als: и́скенной аругb, ein aufrid)tiger Freund;

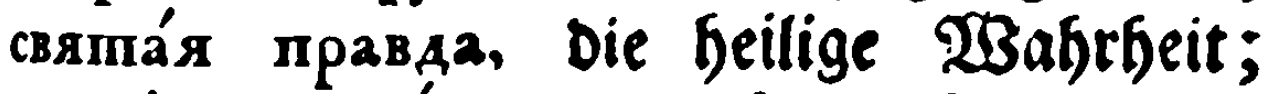

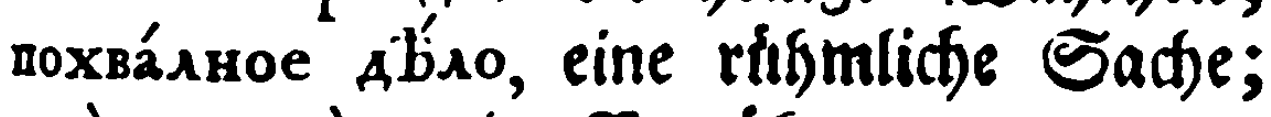
мой пाруды', meine B̈emifungen ; нелодsи́жные зако́ны, die unberánderlidjen Beperze.

$$
\text { §. } 158 .
$$

Benn zwel) Subfantiva mit einem Adjectivo ober Pronomine zufammen ftę̧en, fo ridf. tet fid) bas Adjectivum ober Pronomen im Genere nad) bem leģten Subltantivo, als: o6cmo. и́телспва клоня́ойїяся ко вре́ду ичи́госпи общенаро́дной, die umftánde,

$$
D_{2}
$$
Die 
bie fid zum allgemeinen Sffaben und $\mathfrak{R}_{e}$ oruct neigeten; б̆ Bruber und meine Sdiwefter.

$$
\text { S. } 159 .
$$

WBenn zroen ober meb̨r Subfrantiva of̧ne Conjunction alfo zufammen fteb̧en, baß eins bas an: bere erfláret, fo ftimmt bas Adjectivum ober Participium mit bem exften ober vornebgmften Dem Genere unb Numero nad) überein, als: Xрпсmосb, ра́досmь нáma, воскре́cb, Érifus, unfere Freube, if auferfanden; omếyb, ombxa нáma, yмépb, Der $\mathfrak{B a t e r , ~}$ unfer Troft, ift geftorben.

$$
\text { 5. } 160 .
$$

अenn verfđiebene Subftantiva mit einans ber im Singulari țeben, fo erfobern fie ben Plit. salem ber mit ifnen verbunbenen Adjectivorum, al6: Вирги́лb п Гоме́рb бйли сла́вныс cmroxomsópyn, Pirgi! uno Somer warell beribmte Poeten.

$$
\text { 5. } 16 \mathrm{~s} \text {. }
$$

Das Pronomen relativum muß mit bem vorbergefenden Subftantivo im Genere uno Niv mero ubereinftimmen, als: a súfbab xo. pá6ss, romóprnă ue дámo nab Голмáв. 


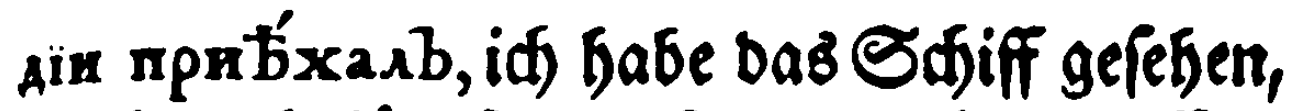
weldees ofnláng|t aus̉ Şolland eingelauffen.

\section{§. 162.}

Benn jwey Subftantiva, bie zu berffiebe. nen Eadjen geţdren, in ber Rebe of̧ne ein Bin, rewort gebraudit werben, fo mus bas eine im Genirivo fteḩen, als : mbмa нesb̆zxecmba, die Ginfternis ber Unwiffenteit; chrb omérecmia, ein Sofn Deß̉ Baterlanbeż. พBenn es aber einen Befig ober ben Urf̧eber ber Gade anjeiget, fo erfobert bas zrepte Subflantivum entweber ein Benwort, als: ABopb yеловظ́xa знámнaro, Das̉ Şaus̉ eines angefehenen Mannes; ober bas anbere Subllantivum mirb in ein Adjectivum berwanbelt, uno ftef̧et mit bem erfen in gleidem Genere, Numero und Cafu,

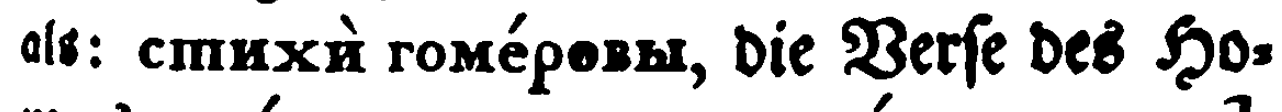
merż; уа́рспво константи́ново; Аомb

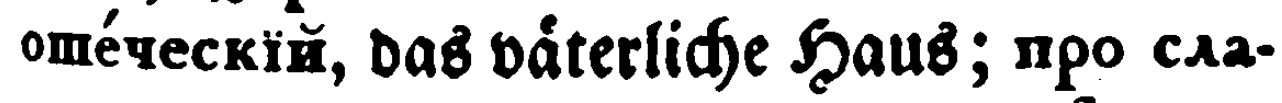
sенова сына, Bолхова, numemb, von

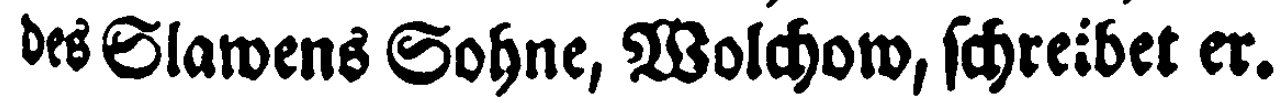

\section{§. 163.}

Der Infinitivus Verborum bienet fef̧r off ftatt eines Nominativi, als: Aramb He Háme ał́-

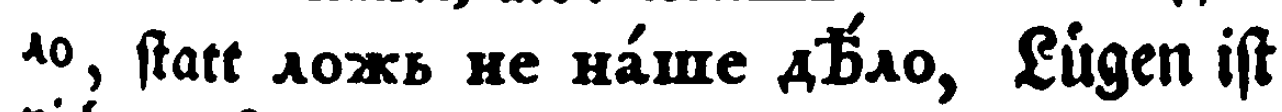
nidt unfere Sadje.

$$
\text { D } 3.164 \text {. }
$$




\section{4 \\ Sedffer $\mathfrak{A}$ fiduitf,}

\section{§. 164.}

Şauptroörter, bie jum loben ober jum $\xi_{\text {a }}$ Deln gehören, fooern ben Genitivum, als : чело. вঢ́кb че́сmнаго поведе́нїя, ein Meni币 von einer guten গuffúfrumg; младе́нещb cла́баго сложе́нїя, ein Sind von (đ)wád): lidfer Sefundfeit.

\section{§. 165.}

Die Zaffinodrter aBa, mpn, yembre, in Nominativo, erjobern den Genitivum Singularis, als: Ава чолов б́ка, jween Menffien; mpI ^и́cma, brel) Blátter; yemb́pe yácmu, vier $\mathfrak{T}$ feile. In ben übrigen Enoungen rido ten fie fid) nad bem Şauptworte, als: abyxb челов бкb, премb ли́стамb, четырьм' ча́стп口ми.

\section{§. 166.}

Benn bas mit tem Zaḩlwoorte berbunbene Subflantivum nod) ein Adjectivum bey fid bat, fo ftepen bende lestere im Genitivo und jwat Das Subllantivum im Singulari, bas Adjectivum aber im Plurali, als: yemb́́pe кора́бля вое́в-

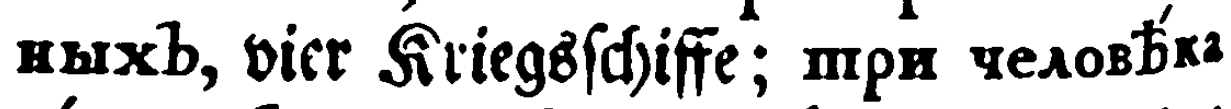
си́лных b, Drey ftarle Minnuer; ober bas leģtere fiteţet im Nominativo plur. als: yembípe хора́бля вое́нные, Ава человظ́ка си́s. 


\section{Bon Der Syntaxi.}

ныre. In ben übrigen cafibus ridgten fidq bie Adjectiva nad ben Subftantivis, als : yemb́rpeub кора́блямb вое́ннимb, вb чеши́́рехb хора́блях вое́нныхb.

$$
\text { 6. } 167 .
$$

Пrmb, нecmb, unb bie úbrigen Cardinalia, nef̧men im Nominativo ben Genitivum plur. bes barauf folgenben Subflantivi an, als: $\pi$ smb

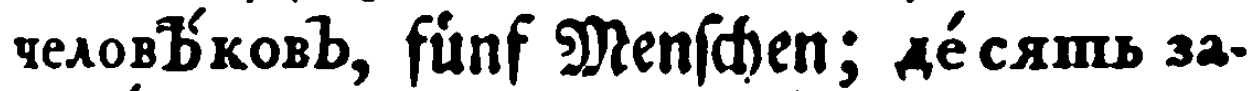

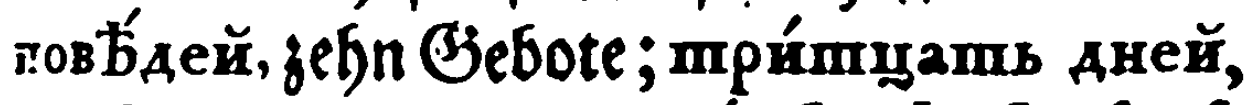

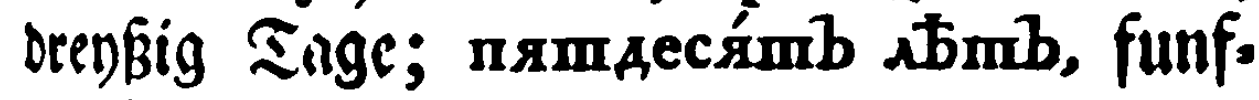
jig స̃afre.

\section{168.}

2luffer bem Nominativo ftef̧en fie in gleid)en Enoungen, jebod) in verfalebenem Numero, als: пятьюо чувспва́ми, mit den fúnf Sinnen;

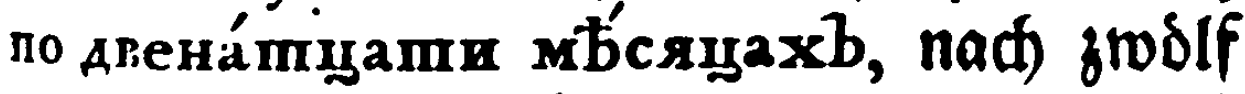
Monaten; по mpúmyama aнsxb, nad) orenkig Tagen.

\section{169.}

Man neந̧me aus cópokb, cmo, mbícsya, als: во cmb кора́бляхb, in Gundert Sđfif: fell; no cópoкy nýmekb, fu vierzig Canos "lel; на mb́csчy гале́pb, auf taufeno Baleeren.
$D 4$
5. 170. 
Asóe, mpóe, че́mверо, де́сяmеро fobern in allen Endungen ben Genitivum plur. bes Subftantivi, als: asoe крестья́нb, jwen) Bauern; mpoe 6b́rshxb, oren Berlauffene; де́сяmеро разбо́йниковb, зеђ Etraßen, ráuber. Zlllein biefe Bab̧lwörter werben nue bon Menfd)en, uno zroar gemeiniglid) nur bon gemeinen Seuten gefagt. Jeood) fort ber vers frorbene Şerr Staatsraţ Somonoffor in feiner ruffifden Befdidtre auf ber neun und funfzigften Seite двое знатныте Бояре gefeģt.

\section{§. 171.}

Diefe Baf̧liodrter veranteern in ber Berbin: bung von Subftantivis leblofer Dinge, bie nut ben Pluraleın baben, bas $c$ in $\mathbf{n}$, unb ftegen mit bem Subftantivo jebesmal in gleider Endung, als: aвón cámr, zwen Stflitten; mpóz

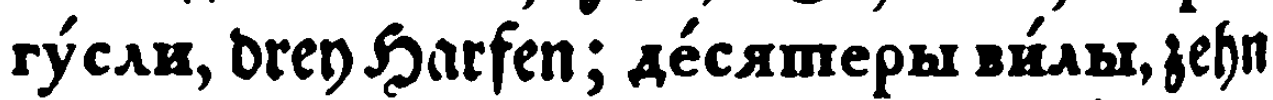
Gabeln. Man tann nidit fagen nx́mept cmoshi, weil cmosb aud einen Singularem hat, fonbern es muß heiß̧en nяmb cmosósb. Diefer Znḩlworter Eann man fid aud), auffet von Menfhen, ben Eeinen anbern belebten Din gen bebienen. Mann tann nidit lagen méc-

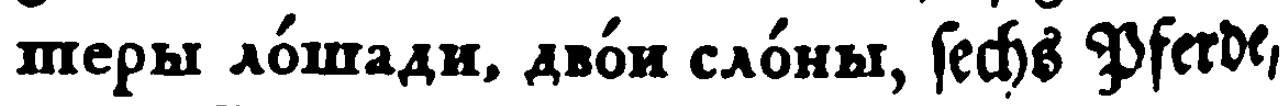
inel) Elephanten. 


\section{2on Der Syntaxi.}

$$
\text { \$. } 172 .
$$

Subfantiva bon leblofen Dingen, bie nur in ber meţreren Zah̨l gebräud)lid) finb, werben mit biefen Baflwoirtern in allen Enbungen naa) ber allgemeinen Regel abgeảnbert, als: asór

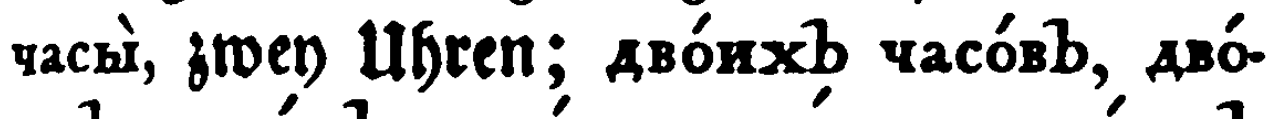
имb, часа́мb, Авойми часа́ми, О Аво́ихb чacáxb.

$$
\text { §. } 173 .
$$

Der Cumparativus gradus fobert ben Genitivum bes f̧auptroorts, als: 6epexsunocmb aýmue прибb́rmкa, die Sparfamteit ift

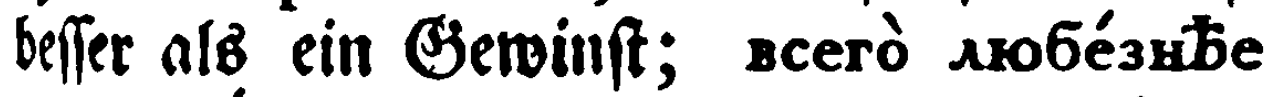
доброд б́mesь, Die Tugend ift liebensiıúrdi= ger alb alleż î́rige.

$$
\text { §. } 174 .
$$

Die Gradus Comparationis nef̧men auffer bem Gentivo aud ben Inftrumentalem an, menn biefer einen Mangel ober $\mathfrak{U}_{\text {eberflußs }}$ bebeutet, als: болшей 6раmb róдомb cmápђe менunáro, ber erfte Bruber ift ein Jabre álter als ber jüngete; ober fie fobern aud ben $\Lambda$ ccufativum mit Ha, befonders wenn es ein Maaß anjeiget, als: на вершо́кb sósЂe, um einten खer (đ)of lánger.

$$
\text { D } 5.175 \text {. }
$$




\section{175.}

Dic Prxpofition ha mit bem Acculativo wirb aud) gebraudt I) um anjuzeigen, wie weif ein Drt bon bem andern gelegen, als: cïr sepés. ня отстоитb на аве мияи оть Нирн. 6epra, biefez Dorf liegt zwey Meilen von Nürnberg; 2) auf bie Frage wie tief? als: судно ходить на чеmbre фуmа, Daß Fabrzeug gefet vier Fuß tief; 3) auf bie Frage wie hodf? als: shmиною сажени на ase, fwen Faben bod); 4) auf bie Frage wie groß̈? Aлиною сей осторовb на 165 sepcmb, Diefe Infel hat in Der seánge 165 IBerft.

\section{176.}

Der Inftrumentalis ftę̧et 1) auf bie frage um wie viel? als: киль cero корабля десятью футами долье протиих кораблей сей величины, Der fiel voll Diejem Sabiffe ift um zefnn Fuß lánger, alb bey allen, Die eben fo groß find, als̉ Daffelbe; mрепьеко частью болте какb наяб:Аисb, um ben britten Theil mefor, als wir vermutten gewefen. 2) 2luf bie Frage, weun uno zu welder Seit? als: Hhímbmmero зимо́ю вb городb прїБдеmb, er wirt

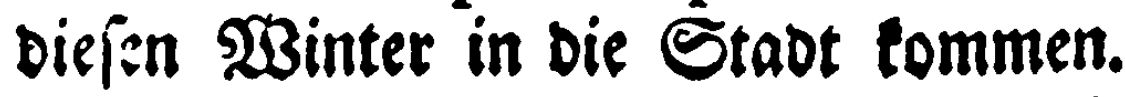




\section{Bon Der Syntaxi.}

\section{177.}

2luf bie Frage, wenn unb fu weldfer Zeit? ftehet aud $\mathrm{Bb}$, fo mohl mit bem Narrativo,

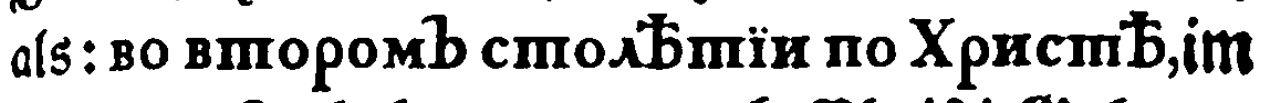
fwenten Jafrfunberte nad) Egrifti Seburt; als aud) mit bem Accufativo, als: Плинӥй свидБпелспвуешт, чпо вь ево время около Вислы обитали Венды и Сармаmhr, Yliniuz bezeuget, Daß zu feiner Zeit um bie $\mathfrak{W e i d}$ ) fel $\mathfrak{W}$ Benden und Sarmater ge. wobnt baben.

$$
\text { §. } 178 .
$$

Zup bie Frage, wie lange? wirb ber Accufativus oḩne Prxpofition gebraud)t, als: тввой omenb жилb copoxb $\lambda$ bmb, Dein $\mathfrak{\text { Bater }}$ hat viergig Jafre gelebet; десяпую зиму

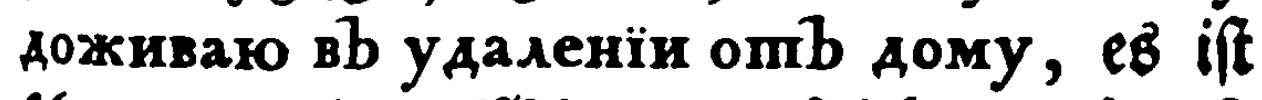

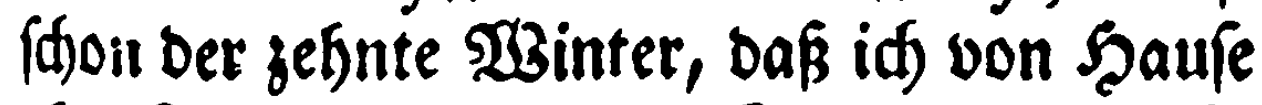
abrofent bin. Sober aud вb mit bem Accufa. tivo, als: онb во весb день трудился, hat ben ganzen Tag gearbeitet; онb cie

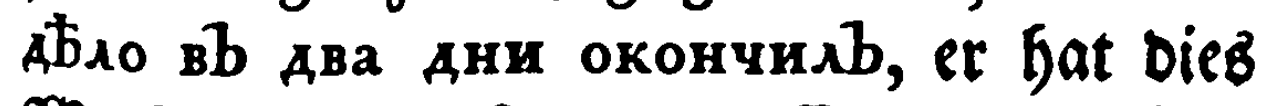
Wert in zreen Tagen zu Ende gebradt.

$$
\text { \$. } 79 .
$$

Yuf bie Frage, wie grofi? ftef̧et Bb mit Dem Accuftivo, als: вb куринное я⿱宀хуо 
sехичиною, fo groß alb ein Seinerey; obet cb mit bem Genitivo, величиноюо сb лоша. AH, TO gró̉ alB ein $\mathfrak{P}$ ferb.

$$
\text { §. } 180 .
$$

Die Yafre bes Zltters anjugeigen, wirb ber Genitivus ogne Borroort gebraudte, als: Asb.

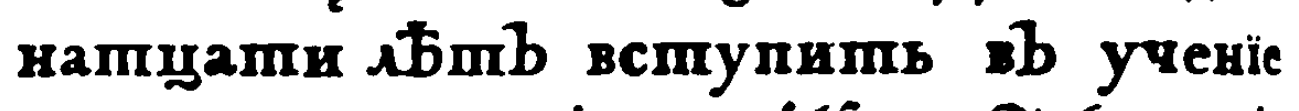
математики, im zwoblften Jafre bie Mathematil ju lernen anfangen; yмepbmb семидесяти А ferben.

$$
\text { \$. } 18 \mathrm{I} .
$$

In Xnfeģung ber Umftänbe bes Drts fobern bie Namen ber Sänder und Stäbte auf Die Frage, wo ? Die Prapofition sb im Narrativo, als: poдихся вb Ярославла, in Iaroflaw geboren;

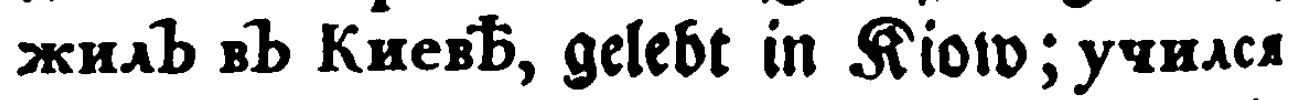
вb Германін, $\Phi$ раниіи и Аглї, gelernt in Deut(j)land, Frantreid) und Engellando.

$$
\text { S. } 182 .
$$

Die Namen ber Etäbte, bie bon Fluiffen benennet werben, werben im Narrativo mit на gebraudt, als: на Москвђ весело хиить, in Mofrau if angenefgm leben. 


\section{§. 183.}

Diefem Benfpiele folgen bie Ramen ber Etrajen, Berge, Felter, Seen unb Infeln, als: я аавно жкиву на Покровк $b$, if wohne f(d)on lange in Der Poltowta; rysь6ише на mpexb ropaxb, Die Sparzier: gánge auf Den Dreven Sergen; на ађвичьexb nosb, auf Dem Jungfernfelbe; бypя была на хапіискомb морб, Der Sturm war auf Dem cafpifáden MReere.

\section{§. 184.}

Eben biefe $\mathfrak{B d}$ rter fobern auf bie Frage, mofin? Das Bb ober нa mit bem Accufativo, als: nobxasb вb Mocksy, er ift nach Mof. cau gereift; sa Moxposxy, nad) Der গুos tromla.

$$
\text { §. } 185 .
$$

Die Namen ber Rirdfpiele neḩmen gerne Die Prapofition y mit bem Genitivo an, als: у илік пророка ва ворониовскомb поль, bey Der Sirde Deb Yropheten Elinz, auf Dem $\mathfrak{B}$ Boronzowifa)en Felde; y успенья на noxposkb, ben ber $\mathfrak{M}$ arien Shimmelfarths Sirde in Poltowla; у николая подкоחar, beg Dem Geiligen গicolaub. 


\section{\$. 186.}

Das $\mathfrak{\text { Bort }}$ somb fooert auf bie Frage, wo? Feine Prepofition, fondern wirb in ber 2 nntwort im Genitivo gefést, als: я дома былb, iqf war zu Saufe; ево sbmb домa, er ift nifft fu Şaufe. Er gieng nad Şaufe, beißst oub Аомой пошоль.

$$
\text { §. } 187 .
$$

Zuf bie Frage, weldjen $\mathfrak{W}$ Beg? wirb bet Infrumentalis ofgne Propofition gebratadt, als:

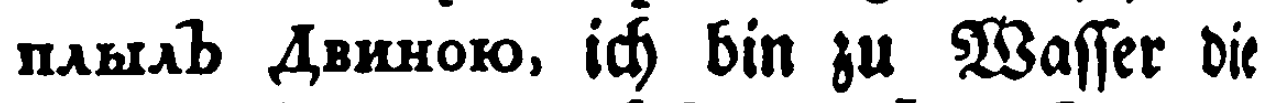
Drwina berunter gefafren; நxasb Moc. квою, улинею, деревнек, лугомь, іф fubr länglt Der Moffira, Der Safle, Dem Dorfe, Der $\mathfrak{T B}$ iefe.

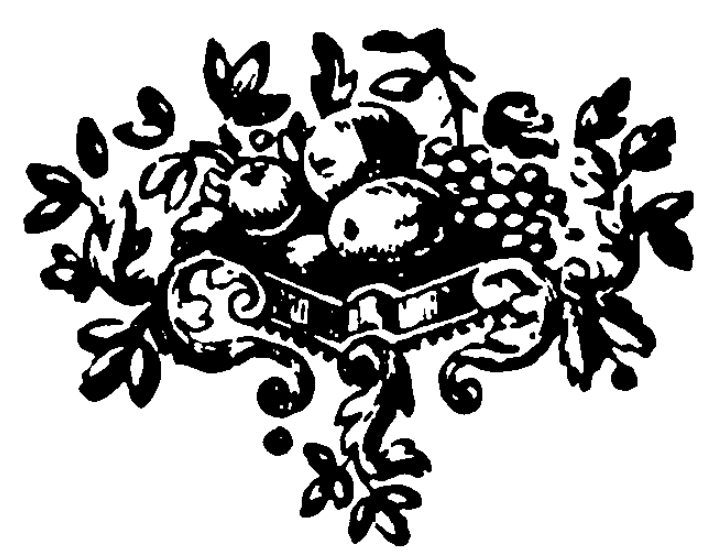

Dad 


\section{Bon Der Syntaxi.}

\section{Då̉ zwente Sauptftůcf.}

De fyntaxi Verborum.

\section{§. 188.}

Zalle Verba $\Lambda$ ctiva erfobern auffer bem No. minativo, ber entroeber ausgebrudt ober barun. ter verfitanden wirb; aud) ben Accufativum, als: хшо храниты захоны, захоны сохрааяюаmb ево взаймно, wer bie Geféze hálts, ber wirb Ginmiederum bon ben $\mathfrak{S e}$.

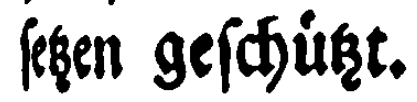

\section{§. 189.}

Benn aber bie Berneinung He borb̧ergeţet, fo folget an ftatt bes Accufativi ber Genitivus, als: не давай воли языху вЬ пхрованӥи, bei) Gafterenen laß̧ Deiner Bunge teinen freven Lauf; не умножайте зла своего, haufet eure Ulebeltbaten nidft nod) mefre; бешеному не давай ноха вb руки, еinem Miafenden gieb tein Miffer in die Şalld; ayyxb смертей пе будеmb, wir werden nidft jweenmal fterben; не рой аругому дмы, самb ввалишся, grabe feinem andern eine Grube, ou fannft felbft binein fallen. 


\section{4}

\section{Sedfer 9ubdonitf,}

So regieret aud) nbmb, eह ift nid)t, ben Genitivum, als: денегb много, да разума ubmb, es̉ ift ba viel Geld, aber tein Bet: ftano.

$$
\text { 8. } 19.0 .
$$

Man bebienet fid aud feb̧r zierlid bes Genitivi mit ben Verbis Activis, wenn bie Rebe nidjt auf bie ganze Sadje, fonbern nur auf eie nen Ţzeil, aud nidjt auf bie ganje Dauer, fonbern nur auf etwas weniges bon ber zeit fid) erftrecfet, als : Aaй soдhi, gieb mir etwas 2Baffer; дай хлЂ6a, gié mir etwas Brobt; aber принеси $\times \lambda \hbar 6 b$, beißst, bringe mir $D a b$ ganje $\mathfrak{B r o d t}$. Посулиmь хому 1ошада, beißst, jemanden ein $\mathfrak{P f e r D}$ nur auf eine Beit verfprecten; aber nocy 'imb souraAb, ein

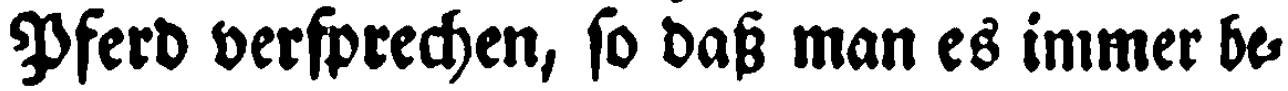
Galte. Xud ftefget ber Genitivus, wenn ein allgemeiner Saz̧ ausgebrudetet milto, als: 6eздонной кадки водоюо не наполнишъ, ein $\mathfrak{F} a \mathfrak{B}$, DaB teinen $\mathfrak{B o d e n}$ bat, wird man

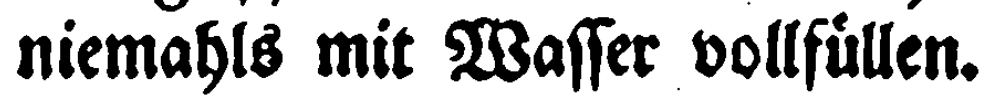

$$
\text { §. } 191 .
$$

Die Verba Activa, Die einen $\mathfrak{B B}_{\text {unf }}$, Ges fud), bas Bebenten unb bergleiden anbeuten, nef̧men mef̧rentheils ben Genitivum an, als: 


\section{Bon Der Syntaxi.}

Александерб славы искаль сb нескаэаннымb желанїемb, 2ulerander fuct)te Den $\Re u b m$ mit einer aufferordentlidjen $\mathfrak{B} e=$ gierde. Всякb желаетb чести, но не scяkb получаemb; ein jeder frebt nad) Ebre, aber nidht jebermann gelanget baju. Господи, не помяни грБховb моихb; Şerr, gedente nicft meiner Simben. Kun ученїя, благололучіе наидешb; бетйfe Did, was zu lernen, fo wirft ou beine GSluds. feligfeit Darinn finben. So regieret audi bas Verbum миноваmb ben Genitivum, als: aву $\mathrm{xb}$ смертеи не будетb, a одной не миновать; wir werben nidft zwenmal ferben, aber einmal werben wir bem Tobe nidgt entgetgen.

\section{\$. 192.}

Die Verba прилбахаmb obliegen, noсльдовапь folgen, повельвапь befehlen, erfodern ben Dativum, als: прих Ђжаmb наухамb, Den $\mathfrak{X B i f f e n f ( f ) a f t e n ~ o b l i e g e n ; ~ к а х к а о - ~}$ иу нешастию посльдовало благополуyie 6osuree, auf ein jebez ungliut folgte ein groffereฮ владђmель повелђваеmb, Die Bienell ha: ben nur einen Sínig, Dem fie geforctien. 
226

\section{Setffer $2 \mathfrak{d}$ f}

\section{§. 193.}

affe Verba paffiva regieren ben Genitivum mit ber Prxpofition omb, ober ben Inlirumentalem of̧ne Prxpofition, als: Дарїи по6бхx. денb оmb Александра, но убитb оть своихb pa6osb; Darius ift von Allerandern übermunden, aber bon feinen eigenen Sined): ten erfdlagen worden. Kнига твоя про. чтена мною со вниманїемb, bcin Rud) if von mir mit 2ufmertfamteit gelefen wor: ben. So fage id aud): родился волкомb, er ift fum $\mathfrak{2 B o l f e}$ géniten. Kmo pодилсх волкомb, mому лисиией не бывать; wer zum গBolfe geboren ift, aub Dem witb niemafls ein Fuds werbett.

$$
\text { 6. } 194 .
$$

Das Verbum называmb regieret ben Iafrumentalem, als: незови хрестьянина брапомb, 2 онb xочеmb оппомb; Fenne mur ben $\mathfrak{B a u e r} \mathfrak{B}$ ruber, er mird bald Bater beiben wollen.

$$
\text { ઈ. } 195 .
$$

Diefen Inftrumentalem muß man von bem Inftrumentali, weldjer ein $\mathfrak{B}$ erf́zeug anzeiget, unterfaciben, als ber bey aller Gelegenţuti, uno bey allen Verbis gebraudflid ift, wie aus folgen 


\section{Bon ber Syntaxi.}

folgenben Erempeln ju erfeben: хоснуmсs рукок, mit Der Sanb berúbren; подниматся веревкою, fid mit cinem Stricke ill die Shofe beben; py6nmcs ca6reю, fidf mit Dem Sibel berumbauen.

$$
\text { §. } 196 .
$$

Benn fid alfo oie Activa in Paffiva ver: wanbeln, fo wirb aus bem Acculativo ein Nominativus, und aus bem Nominativo ein Inftrumentalis ober Genitivus mit ber Prxpofition omb, als: (Active) yacmo спидమ преклоняетb mbxb, копорыхb разсужденіе не по6бжаaло; oft bált die Şaande dieje= nigen von etrvas ab, bev benen fonft leine Bernunft/thliffe bas geringfte gebolfen. (Paffive) часпо спыдомб преклонены mb, которые не поббадены разсушденїемb.

$$
\text { ఏ. } 197 .
$$

Benn ein Vesbum, beffen man fid beries nen will, im Paffivo nidge geloráud)lid ift, fo vers anbert man bie SYhrrafin burd bas Activum, als: Das Find wirb von ber Mlutter geipieget, fann iđ nid)t überfegen диms omb мamepn хачremcr; rocil es fo viel beiken wurbe als: Das Sino woicget fid, um von ber झutter

$$
\text { P } 2
$$

(ourd 
(Durd bas $\mathfrak{B i e g e n )}$ ) immer weiter afjufom: men. Dahero veránbert man das Verbum in ein Activum, und fpridt: мamb aиmr $\mathbf{x}$. yaemb, Die. Mutter wieget oas জiilı. Mo. rось оmb слуги ift fein ruffiff; ; еs muß̧ hęis Gen: меня слуга моemb, bet Bediente

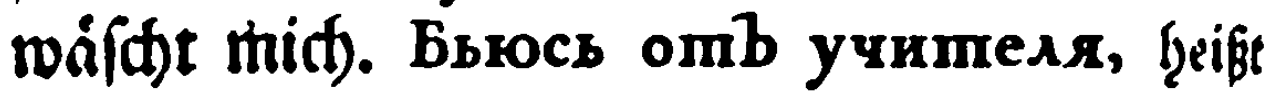
nidft, id werbe von bem Kef̧rmeiffer gefflagen: fonbern id) f(f)lage midf mit bem Eefrmeiffer,

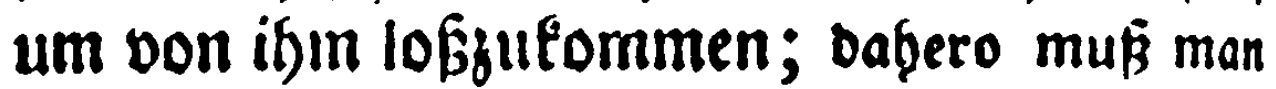
ragen: учитель меня бьетb, ber Refret id)lágt midd.

\section{§. 198.}

Es ift oben fürtylid gefagt: baß man bie $\Lambda$ ctiva nidet fíled)teroings burd bie angeţangte Enoung $c r$ in Pafiva berwandeln fönne. Ino zroifthen nimt biefe Enoung $\mathrm{c} \pi$ in einigen Siet $^{2}$ Densarten, wenn bie $\mathfrak{B}$ Bendung berfelben nath ber Slavonifhen Spradie eingeriditet iff, bie Fraft bes Palfivi an; allein man muß fid beren mit vieler $\mathfrak{B o r}$ (iditt bebienen, uno fid haủten, baß man bie Reciproca nidte mit ben Paffivis vero wedffele. Eo fpridt man zmar:

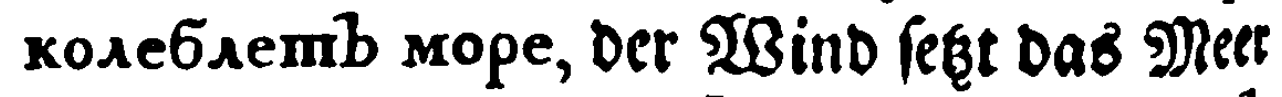
in Bewregung; und sbmpomb ober omb

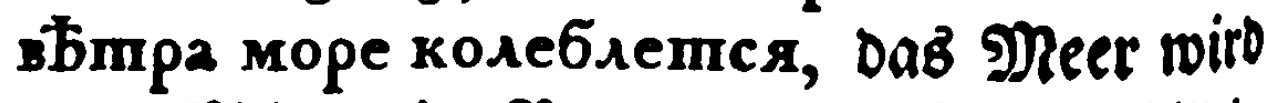

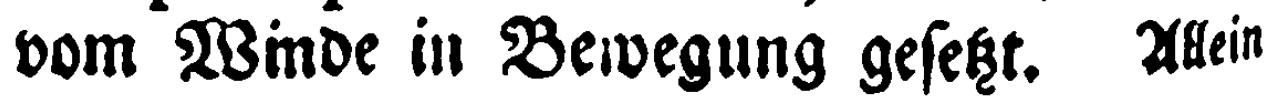




\section{Bon Der Syntaxi.}

man fann nidjt fagen: винà емy omb насb прощаеmcs, fein Fef̧ler wirb îm von uns vergeben; fonbern man muk im Activo fagen: ма ему вину̀ прощуемb, wir bergeben ifm feinen Febler.

\section{199.}

Die Verba reciproca regieren ben Infrumentalem mit ber Prxpofition cb, \&. E. во вско хизнь со страстьми боремся; оав ganzе Seben Ginburd) freiten wir mit ben Leiben: fđaften; знаться cb добрыми лгодми похвално, ев if rufgmlid), mit red)t(d)affe= nen Leuten llmgang zu Gaben.

$$
\text { §. } 200 \text {. }
$$

Das Verbum neutrum fann vor unb nad, fid einen Nominativum ḩaben, als : cmapocmb сама есть 6ользн, Daв श्Alter ift an fíd felbit fdoon eine Srantfeit. Мандана 6 қrла дочь Асmїага, уаря кидскаго, и мать кирова; Mandana toar eine Tod)ter Deş aftiagez, Sonigez ber Meden, uno bie Mutter dez Ciruż. Ирb бнлb человђкb 6Ђдной, Jนus war ein armer Mann.

$$
\text { ઈ. 2or. }
$$

Der nad bem Verbo ftef̧enbe Nominativus beranbert fid oft in einen Inftumentalem, befon.

$$
\mathfrak{P} 3
$$

Ders 


\section{0}

\section{Sedffer 9 (bfanitt,}

bers mit ben Verbis живу̀ iff) lefe, casny

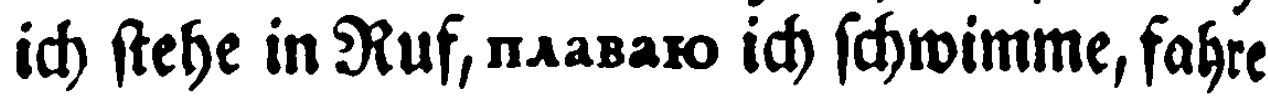
allf Der Sie, als: плылх Apxипелагомb, fie nafmen ifren $\mathfrak{X B e g}$ úber den 2Ard)ipelag; Сарданапаль жилb свиньеко, Sarbana: pal lebte wie ein Stfwein; Семпроніn cussemb силнымb, Den Sempronius Gált man fúr einen farken $\mathfrak{D}$ \&nun.

$$
\text { ๖. } 202 .
$$

Das Verbum ecms wirb in ber ruffifden Epradie felten ausbrudflid) gebraud)t, fondern befonbers im gemeinen Reben uno Edreiben ausgelaffen, als: я знаюо чmо mы apyrb

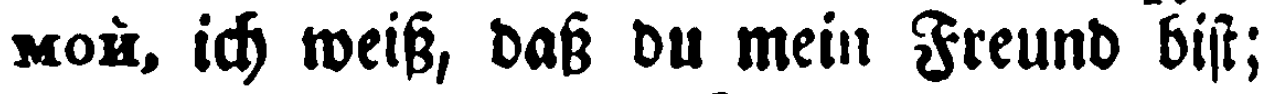
Aгриппа 6езпамяmенb, 2grippa ift ofne

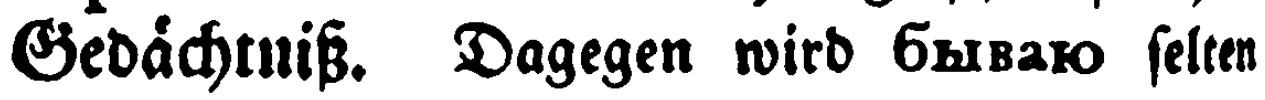
ausgelaffen, als: Arpunna 6rsaemb 6es. пaмsmemb, Agrippa ift zuweilen obne $\mathfrak{b} b$ båd)ıní̧.

$$
\text { ๑. } 203 .
$$

Die Verba communia ober Deponentia, als: касавось id) betreffe, молхось iff bete,

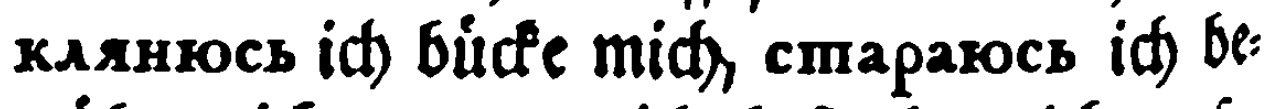
mufe mid), musycb id beftrebe mid), erfos bern meţrentḩeils ben Dativum, als: oHb momosb нe молясь 6ory, er gieng weg 


\section{Bon Der Syntaxi.}

ofme Gebet. Ехтели вы никому не кла. няетесь, по и вамы никто кланится не будетb; wenn ihr eudb) vor niemanden butfet, fo wirb fid aud niemano vor eudf budéen.

$$
\text { S. } 204 .
$$

Faft alle Verba Imperfonalia, als: c^yч2.

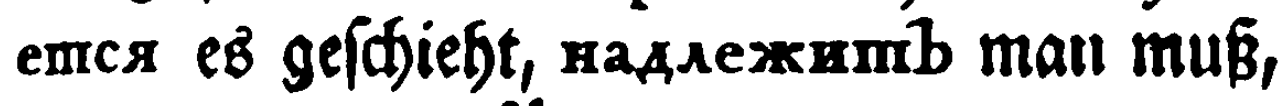
нравится еह̉ gefállt, erfobern den Dativum Der Perfon, und ḩaben mệrentḩeils den Infinitivun nadi fid, als: случаemcr nemyxy наити жемчужину (ez gefdieft wofl, Daß́ ein Shabn eine $\mathfrak{P e r l e}$ findet), aud ein blinbez Şufn findet ein Sorn; ему надлежить презирапь сb перпіниіемb про-

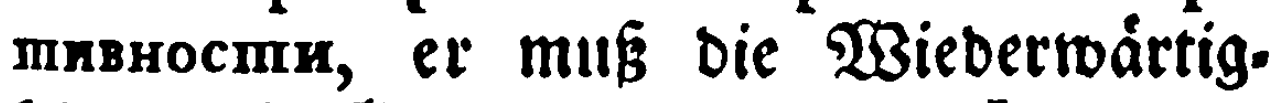
feiten mit ङ̧ebult ertragen; мнб понраsumcr, eß̉ gefállt mir.

\section{§. 205.}

Die Tempora und Modi Imperf. und beren Unterfdeio bon ben Temporibus und Modis unitatis fint wohl gu merfen. Heberḩaupt wirb Das Imperfectum in ben Temporibus uno Modis gebraudt, wenn bon einer unbeftimmten $\mathfrak{S}$ and. lung, bie ju meţrêten malen mieberḩolet morben, ober ju wiebergolen iff, gerebet wirb, als:

$$
\mathfrak{P}_{4}
$$

emy 
ему нынб прислать и впредв всетад

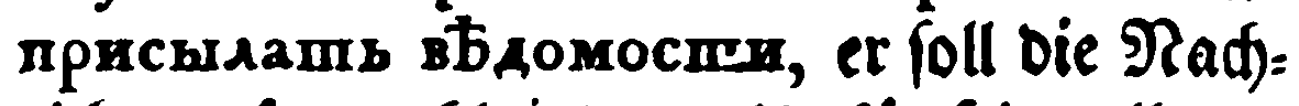
ridften to wohl jeşt, als túnftig allemal einfenden. Венды и Анты соединясь со сродными се6Ђ Славянами умножали uxb cray, die $\mathfrak{B}$ Benden und 2 inten verei: nigten fich mit ben ifnen verwanden Sla: wen, bie Dadurd mádtiger wurben.

Умножали brúdt aus, baß́ bie Madft der Elamen nidt auf einmal empor geftiegen, fondern nad) und nadh gervadfien; fonft müвte es heisen умножили.

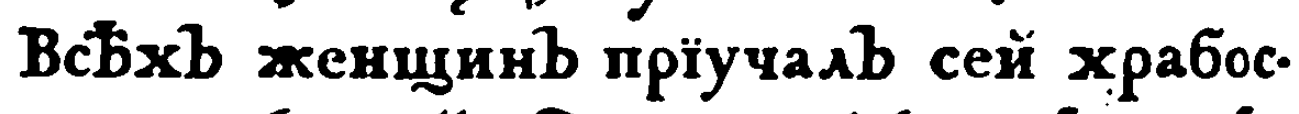
ImI, er bat alle Frauen gelefret, fo tapfer zu fenn.

Ilpiyynsb wurbe fo viel bebeuten, als wenn biefe Şanolung auf einmal gefdetgen máre.

\section{206.}

Das Plusquamperfectum primun frefeet, wenn bon einer unbeftimmten langen Folge Der vergangenen Beit bie Rebe iff, befonters wenn negative gefproden wirb, als: Hикогда cmosхо знатныхb людей не умирало, ев fint miemables fo viele berúfmte Reute geftor: ben; $\pi$ cero никотаz не вндhrasb, i由 babe bergleiden niemaflaz géeben.

6. 207. 


\section{§. 207.}

Die Praterita Perfecta unb unitatis ftểen, wenn von einer in $2(b f i d) t$ ber Beit beftimmten Şandlung gerebet wirb, als : ropawmb omsb.

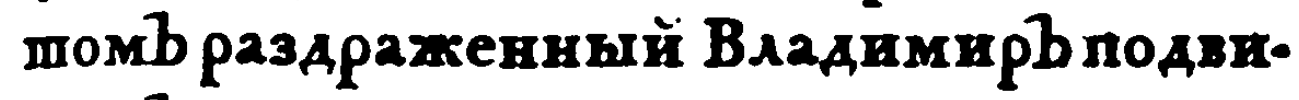
гнуль вско своко силу на полопкую зем-

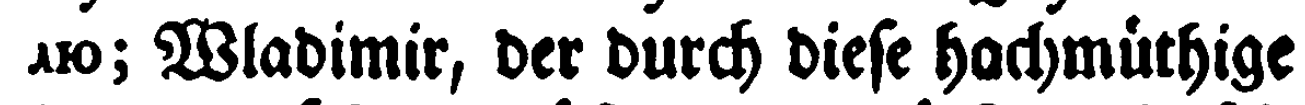
antwort fefre entruftet war, rúcte mit fei. nem ganjen Arriegbibeere in Dab Polozeifdje Bebiet ein. Яponoגxb 32 неимbнїемb доволнаго числа вопска не. дерзиуль smmin проптвв Bладимира, Jaropolt wagte fid) nidft mit feiner ou (idroadten Miannffhaft wiber $\mathfrak{B}$ ladimir ins $\mathfrak{F}$ felb.

\section{§. 208.}

Benn vor einem Verbo ein anberes Verbum ober ein Subftantivum vorb̧ergehet, fo feget man im Ruffifden bas folgente Verbum im Infinitivo; ba fonft im Deutfden, Sateinifden unb Sranzoffifhen bas Gerundium gefeget wirb, als: прошу меня пзвннить, id bitte mid entid)uldigen; nopa cramb, es ift Beit 价las fen zu geben.

\section{209.}

Der Infinitivus bienet im $\Re$ iufiffen an ftate bes Imperativi, wenn etbas gebieterifd, unb ofgne. zu beftimmen, men ber Befef̧l angeḩet,

$$
\text { P } 5 \text { befoglen }
$$




\section{4

befoffen wirb, nls: привести передb насb, er foll bor unz gebradtt werben; пожало. вапть вb чинb, mall gebe ifin eine $\mathfrak{B} c$ : bienung; 6ыm по семy, ez foul hiefrev) fein Rewenden haben; публиковапь во все. нарадное извbcmie, ez foll fu jebermatins Rad)rid)t betannt gemadts metben. Jit ein Nomen ober Pronomen babey, fo frelect baf: felbe im Dativo, als: пзыскиватьв ему все cnoco6bs, er foll alle Mittel ausfinbig ju madjen fudfen; ему на крепко смотрбіпь, er foll fóarf Darauf fegen.

$$
\text { 5. } 210 .
$$

Der Dativus wirb aud in manden Jällen gebraudft, wenn bie Rebe nidfet Imperative ju berftehen ift, als: Абнивому всегда праз. днихb (ecmb) Der Faule bat alle Tage Fer). ertage; не всякому стариу вb игумнахb 6hmb, nidt jeber Mond wirb 216t; Non ex quovis ligao fit Mercurius.

$$
\text { G. 2ir. }
$$

Die Infinitivi, Gerundia und Participia ers fobern eben bie Calus als if̧re Verba, als: храниті правду, не боятся враговь; auf Die $\mathfrak{X a b r b}$ eit balten, uno fid für teine Feinde füctten; храня правау не 6ои. 


\section{Bon Der Syntaxi.}

mecs sparosb, wenn ifr auf die $\mathfrak{X B a f r b e i}$ baltet, to furctetet teine feinbe; храняиій uравду не 6onmcr sparosb, wer auf bie Mabrbeit bált, fürdtet leine Feinde.

$$
\text { 5. } 212 .
$$

Benn bas ah vor einem Imperfecto Infinitivi feefet, to zeiget es eine ungeroiffe Solge an,

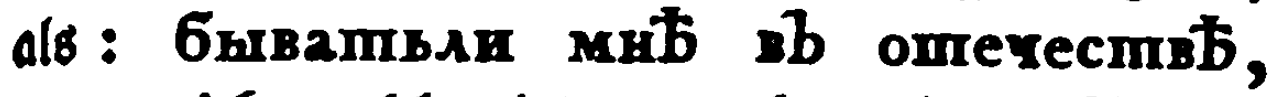
werbe id wohl wieber nad meinem $\mathfrak{\text { Bater: }}$ lande fommen? shammbar emy cвоихb posnmeseй, wirb er wobl feine Eltern wie. Deriegen?

$$
\text { §. } 213 .
$$

Wenn aber, an ftatt bes $\lambda$, bas He fteţet, fo mad)t es bie Bebeutung, baß man an bem Beḩoften ftart zroeifelt, als : нe 6hrsamb мнb bb omreyecmsb! id) werbe wohl nidft wieber nad) Dem Baterlande fommen; не видатьs свонхъ родителей, iф werbe die Elterit wobl nidft wieberfében.

$$
\text { \$. } 214 .
$$

Eben biefer Infinitivus Imperf. erhăalt bie Sraft eines anfangenben 3eitroorts, wenn bas 6hro hinjugefę̧t wirb, als: мub 6hro roso. pumb, id follte eben anfangen zu rebels. Eteḩet aber bas 6brio ḩinter bem Verbo, fo 


\section{6

bebeutet es ein 2 ebauren besjenigen bas nidtet gefdeţen, als : rosopumb (мнб) 6ыло, iф) bátte reden folten; nucamb 6bruo - fdrei: ben follen.

$$
\text { ๑. } 215 \text {. }
$$

Die Verba anxiliaria 6yay uno cmany fönnen nidte immer eins für bas anbere ges braudbet werben. Будy (ficift fid) fo woht ju ben Activis, als zu oen Paffivis; allein cmany tann nidbt bey bem Paffivo fteģen, als: 6yаy писаmb uno cmaнy nucamb, id) werde (d)reiben; bod fagt man nid): : cmaнemb на. писано, eв wird gefárieben werden.

$$
\text { \$. } 216 .
$$

Die Rebensart im Deurforen mit foll z. E. er foll ein weifer $\mathfrak{D a n n}$ getwefen fevul, bruden bie $\mathfrak{R u f f e n}$ mit rоворяmb aus, to wie im lateinifden mit dicitur, rosopsmb ymo onb быль мудрой человБкъ; говоряты что много Аюдей побиmо, ев follen viele פMens jäen geblieben fegn.

$$
\text { §. } 217 .
$$

Die Adverbia cжелn, когда разв a. a. m. erfobern im $\Re$ uffiffen bas Futurum, wenn im beutfden bas Przefens ftepet, als : ezre. an кmо предпочmешb суепную по- 


\section{Bon Der Syntaxi.}

хвалу настояшей славђ, теen jemand Deil citeln Siubm ber wabren (Egre vorjieft; ежели кпо междуусобныя и отb внб нанесенныя воиног разсудиты, вb великое удивленіе придеmb; wenn man die innerlitben und auswairtigen Sriege bebens $\mathrm{ltt}_{\text {, }}$ (o mus man fid) billig munbern. Koraa кпо правду скажетb, по ево никто не crywaemb; wenn einer bie $\mathfrak{2 B a f r h e i t}$ fagt, fo foret man ifn nidgt. Mоха прїиауmb n начнуmb, bis fie fommen uno anfan: gen.

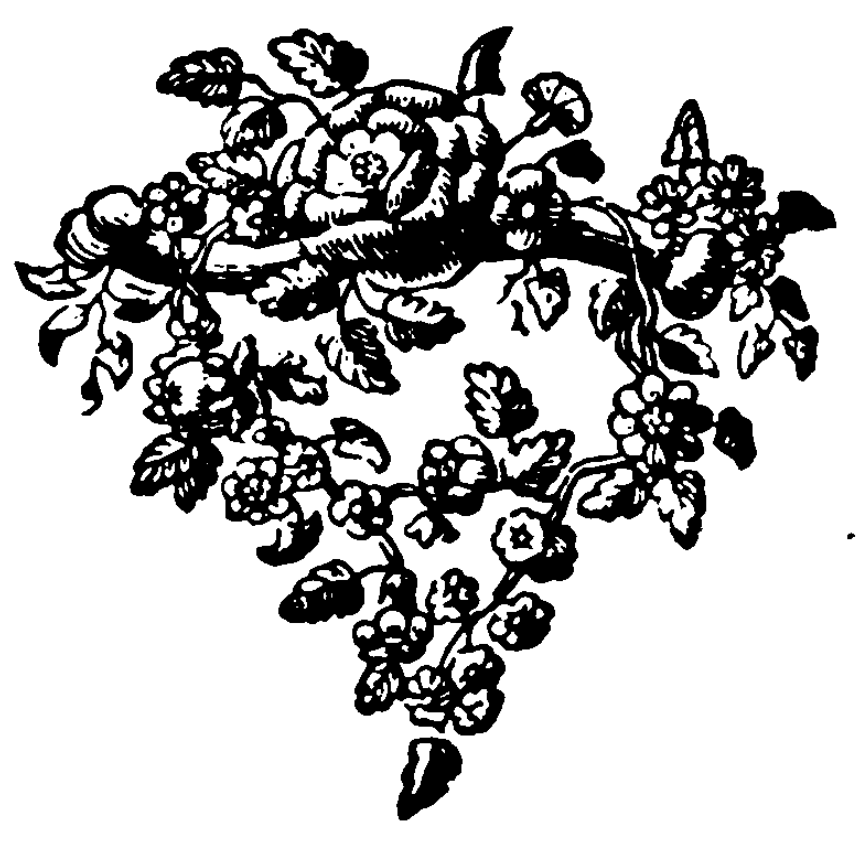

Das 


\section{8}

\section{Sedfifer 9xb/finitt,}

\section{Dab̉ Dritte Sauptifúc:.}

De fyntaxi part. auxil. orationis.

$$
\text { §. } 218 .
$$

Die Pronomina perfonalia s, mbr, онb, sch, sh, онR, id), Du, er, wir, ifre, fie, fỏn. nen vor ben Verbis ùberall berfdpiegen werben, wenn burd beren Enbfilbe ber Unterfaeio ber Perfonen angejeiget mirb, als: shaxy socxOAsшуго брани mучy, id lebe ein finjteres Bewdle zum Streit auffeigen, an ftatt $\pi$ suxy u. T. w.

$$
\text { \$. } 219 .
$$

Wenn aber bie Enofylbe bie. Perfon nidft anbeutet, fo barf aud bas Pronomen nidte ausges

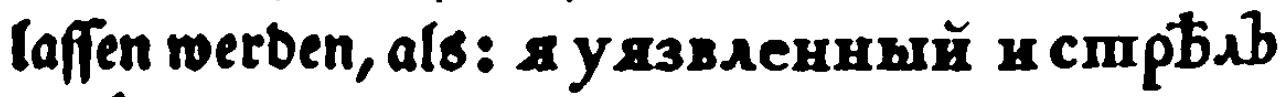
yæxb ne бокосb, id) bin vermunbet, uno furchte mid midft mefre bor ben $\mathfrak{P}$ feilen; x предлагалb saxb csoe мrbнïe, id babe eud) meine Megnung entbecft.

\section{\$. 220.}

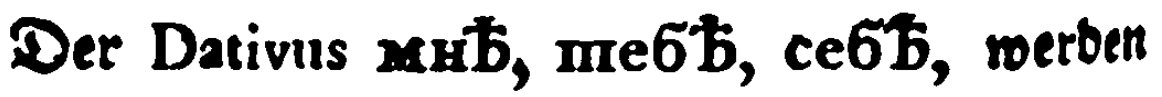
ftatt мой, mвой, свой in allen Gefddledten uno Beitell mit ben Subliantivis, bie im Nominativo fteţen, zufammengefüget, als: онb мнb omenb, er if mein $\mathfrak{B a t e r}$; me6Ђ 6pamb, Dein 


\section{Bon Der Syntaxi.}

Dein $\mathfrak{B r u b e r}$; онb ему кумb, er iff fein Gisvatter.

$$
\text { §. } 221 .
$$

Meţitern Nadbruds wegen mirb zu felbigen das Pronomen camb, felbit, b̧inzugefést,

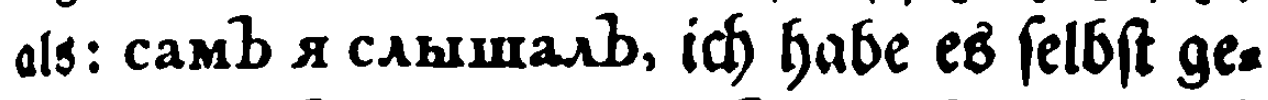
horet; camb ce5r знаешrb, Du Eenneft did) kiloft.

\section{§. 222.}

Die Pronomina relativa, копाорой, коппрая, копооре; кой, коя, кое, и. b. gl. ftehen mit bein vorbergebenden Subftantivo in gleidem Genere und Numero; iebod) in bem Cafu, ben das barauf folgende Verbum regieret, als: человъкb, которой $\mathrm{cb}$ вами говоpuab, Der Menif(), Der mit eud) (prad); счас. плива па земля, которой премудрая власть повельваетb; glúflich iff dab

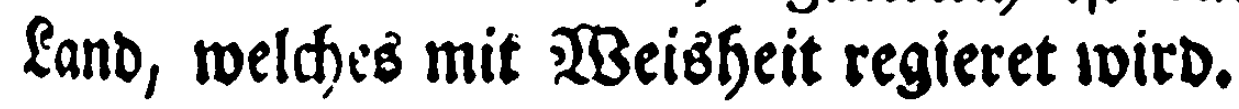

$$
\text { §. } 223 .
$$

Das Pronomen interrogativum wirb alle. mal im mánnlid)en Gef(d)lect)te verftanden, es mag in ber $\mathfrak{Z}_{\text {ntwort ein }}$ Beffhled)t forgen, weldses molle, als : кmо основияb pumb? ромуль; wer bat Rom erbauet? Romuluz. Kmo оспавихb Tupb? Дидона; wer hat $\mathfrak{T}$ ys 
240

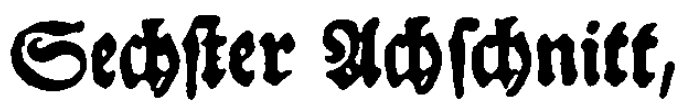

rub verlaffen? die Dido. Kmo крачаab! Auma; toer bat gefárien? Das Rinb.

$$
\text { 5. } 224 .
$$

Das Pronomen ymo muß bon leblofen Dingen aller Befdledte verfanben werben, als: qmo слабило члени? Impy ab; wab bat bie Slieber gefdyroåd)r? die शrbeit. Ymo взнy. pи́ло mвое сераде? aгобовb; toaв́ bat deil Serz berzefret? Die Kiebe.

$$
\text { \$. } 225 .
$$

Ymo, wenn es die Rraft eines Subfantivi hat, erfobert ben Genitivum, als: ymo me6b Imaxb A6ra? was baft bu ba zu thun? ymo денегb издеракан на покупху? wie biel Seld ift fur bie eingetauften Saden aub: gegebien.

$$
\text { ๑. } 226 .
$$

Das Bort man, z. E. man fagt, man fpridft; oruiden bie $\Re$ Rffen mit ber britten PerTona Pluralis bes barauf folgenoen Verbi aus, als: ^кобяmb умныхb, а незнакоцихb npeзzparomb; man liebet die, fo was wiffen, uno beradftet bie unviffenden. Moxemb биmь не скажуты чmо мы худо зА sasx; man toird bielleidgt nid)t fagen, was wir Rdfes getban baben. Oик 6и ymo 


\section{Bon Det Syntaxi.}

ни будь больше сказали, ежкелиб я не пришелb makb скоро; man wúrde mebr gelagt baben, wenn id) nidjt fo balb oafll ge: tommell ioáre. Увид ymо онb чеспной челов bкb; toenn man ifn fiebet, fo follte imall dentien, er fer) ein efre lider Mann. Дураковb ни орготі ни ‘bоmb, сами родятся; man fáet ullo planget die Narren nitht, fie wadfen von felbft. ODer man bruatt bas beutf(t) mall im Ruffifden mit bem blofen Infinitivo aus, als: лсшкои рђки не вычерпать, mall fann ben Strom mit Dem Ldffel nid)t ausjitjopfen.

$$
\text { §. } 227 .
$$

Die In Trumentales y $\mathbf{b} \mathbf{m b}, \mathbf{m} \mathbf{b} \mathbf{m b}$ merben gebraud)t, bie beut(d) in Berbindungswoirter is, belio mefre ausjubricten, als: чbмb sautie пропбкаетb, тбмb обилнбишимк водами разливается; je tweiter er lort fleest, Defto reidjer wirb er an $\mathfrak{Z}$ affer.

$$
\text { ઈ. } 228 .
$$

Adverbia, bie von Subftantivis ந̧erfommen, erfodern ben Cafum, ben iḩre Primitiva ḩaben, als: достойно воздаянїя, einer $\mathfrak{B}$ elof: nung wúrdig; любезно Богу म людямb, Gott und Menldjent lieb.

$\mathfrak{Q}$

$$
\text { §. } 229 \text {. }
$$




$$
\text { §. } 229 .
$$

Adverbia, bie einen Ueberflußs ober Mangel anjeigen, fobern ben Genitivum, als: доволно 6латоразумїя, genug $\mathfrak{B e r n u n f t ; ~ м а л о ~}$

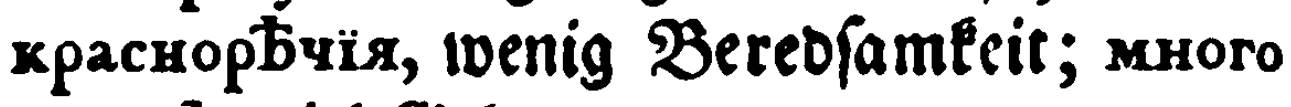

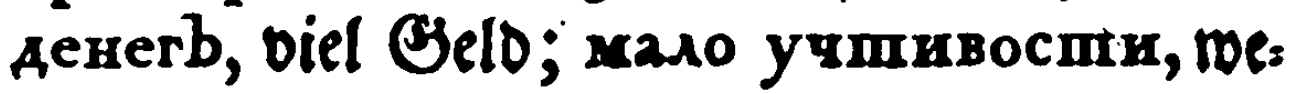
nig Soffid)leit.

$$
\text { 5. } 230 \text {. }
$$

Znbere Adverbia regieren verfáiebene Calus, nad) bem Unterfheide ifgrer Bebeutung, als:

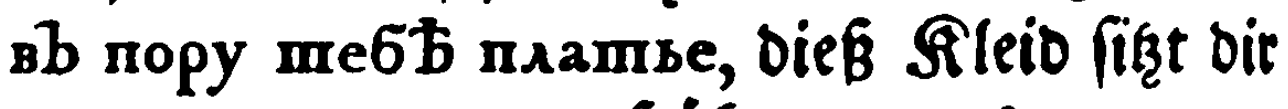
gut; рано по у mpy, frith morgens; поздно ночью, fpát in bet Radjt.

$$
\text { f. } 23 \text { I. }
$$

Die Prxpofition pasu fann fo roobl vor als b̧inter bem Subltantivo ftę̧en, uno beḩált uberall niefelbe Siraft, als: paAn 66дносmr unб 6Бдности ради, Der Xrmuth toegen.

$$
\text { ઈ. } 232 .
$$

Den Dativimm fodert ko, kb $\mathfrak{j} u$, no gemáa, allż, wegen: кb А

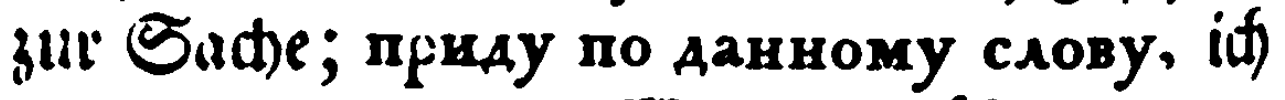
weroe Dem gegebenen Worte gemáslommen; по сльпому предувБреник, аив сіпем blinden Pornttbeile; no.cra6ocima uзнy. реннаго здоровья, ıреgcil Sd)mád)lid)leit Deb 


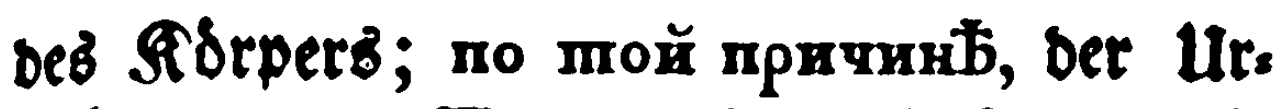
fade wegen. Wenn no fo viel freist als nad). hero, fo regieret es ben Narrativum, als: no поль многих раздбленїя $\mathrm{xb}$, утбсне. нія $\mathrm{xb}$, п нестроенїяхb, nad fo vielen Trennungen, Drangfalen und Berwirrun. gen. Zud) regieret no ben Accufativum, 1) wenn es eine Zeit bebeutet, als: no cie sремя, bis auf diefe 3eit. 2) in ber Rebens. art: er reidft ifm bis an bie Sdultec, oHb ему по плечо. 3) in ber Rebensart: nact) etroab coer nath jemanden fafiten, als:

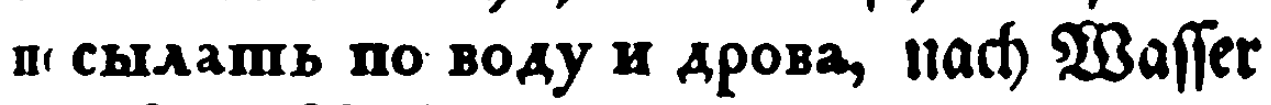
U. D ŞO.'s (d)iden; no sокmора, nad) Dem Doctor laficfen.

$$
\text { §. } 233 \text {. }
$$

$\mathrm{Bb}$, Bo in, $\mathbf{H a}$ auf, etfobern in betfaices benem $\mathfrak{B e r f t a n b e}$ entweber ben Accufativum ober ben Narrativum; aber 32 hinter, HaAb íber, no $\mathrm{A}$ unter, npeab vor, co, cb mit, ent. meber ben Accufativum ober ben Iuftrumentalem. Benn es eine Berwegung auf eben ber Stelle, ober aud) einen Stilleftano anjeiget, folget nad) ben beyben erften Prapofitionen ber Narrativus, nad) ben legetern aber ber Inftrumentalis, als: so aворђ pa6omamb, im Şofe arbeiten; на плонади ходить, auf bem Marlte gefen; 


\section{Sectifter 2 (6)}

32 aвopomb cbamb, Ginter Dem Şaufe fíell; надb мертвымb плакапь, über einen Todten weinen; подb бременемb стена́mb, unter Der Laft feuffen; предb

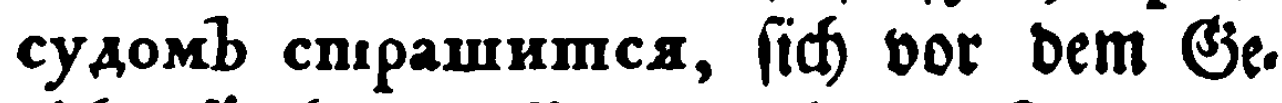
ridfte fürdsten. $\mathfrak{B}$ (nn es aber eine Bervegung bon einem Drte nad) bem anbern anjeigt, fo folo

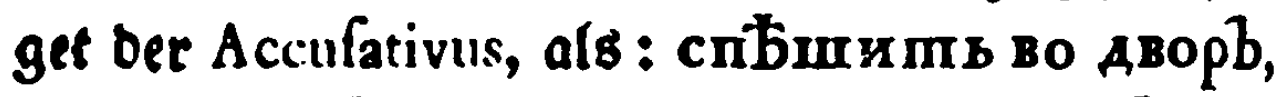
in ben ŞOf herein eilen; постави mb на cmosb, nuf den Tifá fefzen; sзsembmb zaab s屯cb, úber ben $\mathfrak{W}$ Bald hernuf fliefen.

$$
\text { §. } 234 .
$$

Bb unb cb fobern ben Accufativum, wenn bas erfte eine Xtȩ̣nlidffeit, bas leşte aber eine Bleiøg̨eit bebeutet, als: Arpunna aиnемb sb mamepb, pocmomb cb omya; Pgrippa

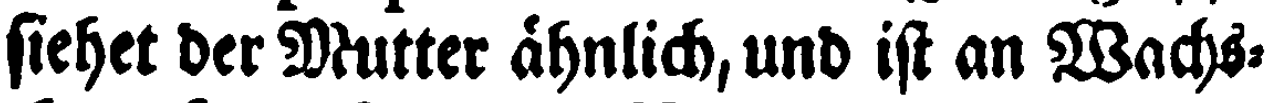
thum fo groß als Der ßater.

$$
\text { §. } 235 .
$$

$\mathrm{Cb}$ fobert ben Accufativum, wenn bie Dauer einer Beit angebeutet witb, als: продолжкалось $\mathrm{cb}$ недЂлғ, ев Dnurete ofngefáfi eille Wост); cb Ава года жиль вb puмb, et hat (id) ofngefebr jwey Jabre in Soin all: gebalten.

$$
\text { 5. } 236 \text {. }
$$




\section{Zon ber Syntaxi.}

§. 236.

Ko, so und co fieţen an ftatt $\mathbf{k b}, \mathrm{sb}$, unb $c b$, wenn nad benfelben viele confonantes auf einander folgen, als: ко мнб, niđft кb мнб, ju mir ; ко pвy 6лrзко, nabe beg bem G̈raben; во мракБ забвенїя покрыто, in ber Finfterniß̈ Der Pergeffenbeit begraben; co yног, uno nidgt $\mathrm{cb}$ много, mit mix.

$$
\text { 5. } 237 .
$$

Противb regieret ben Genitivum unb heifit, 1) gegen, wider, als : nрomnвb непрїsmелs, wiber ben feind; nротивb воли omya cвoero, wiber ben $\mathfrak{W}$ illen feinç $\mathfrak{B} a=$ ters. 2) Beiget eine $\mathfrak{B e r g l e i}$ )ung an, als : roродЬ и гавань Калкао не находились вb лупчемb соспоянїи пропивЫ Панамы, Die Stabt und ber Şafen Calcao befanden fid in fécinem beffern 3uftande als Panama.

$$
\text { §. } 238 .
$$

Meaxb uno mexasy regieret ben Infrumentaleon, als: мехау ropaмu, jwiffien bent Bergen. Dod finbet aud ber Genitivus ftatt, als: мexay ropb, мexbb pbkb, zwif(t) Den Bergen, zwifdjen Den Fluffen. Oft

$$
23
$$

noirb 


\section{Sedfter 2 (6)}

wirb aud, bas Borwort npo vorgefez̧t, orzne baßs bie Bebeutung baburd) im geringlien veränert rirb, als: промежb лгдьми обраудатся, mit Reuten fenn. $\mathfrak{W}$ enn es eine $\mathfrak{B}$ rregung von einem Drte nad bem anbcin onjeiget, fo folget ber Accufativus, als: scm ynumb мexbb неприятелскї полки, in bie feindlidyen Regimeirter einoringen.

$$
\text { §. } 239 .
$$

Die Prxpofition o oder o6b fobert ben Narrativum, als : сказываmb о А ныxb, oon berúlmten Thatell erzáblen;

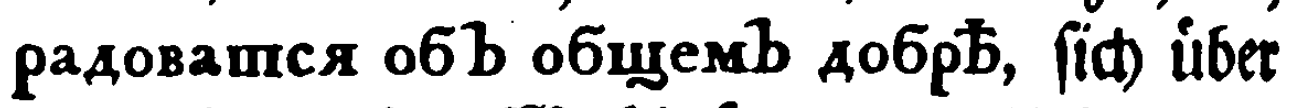
Daš allgemeine $\mathfrak{2}$ bohl fretten. Ueber bem zeiget biefe Prxpofition aud bie- Injahl Der Theile einer belebten Sadje an, als: o двyxb poraxb, (ein Thier) mit juben Şornccil; - чеmmpexb noraxb, mit vier Jíken. Sciernäd)ft regieret fie aud) ben Accufativum in folgenden Rebensarten: o6b камень, an ci. nen Stein; o дереso, all einen Bunm ; нашb ботb о6b корабелнуго корму разбнло, IIIIfer Root mard all Das Sintertheil dez Sajiffes zeriaflagen.

$$
\text { §. } 240 .
$$

Nidgt felten ftȩ̧en zroey Prxpofitiones vor einem Subftantivo, in weldem Falle fid oer calins 


\section{Don Der Syntaxi.}

nad) bem erfien riqtet, als: nepebxamb изb

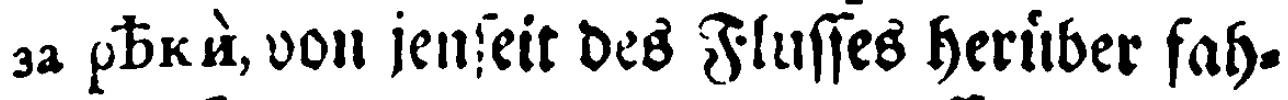
rill; изb за границы, von Diaufen, alls ei= nem liemoen jicit)e; поднять изb подb cmosa, unter Dem Tijale auffeben.

\section{ઈ. 241.}

Die bebingenden und theilenden Conjunctiones theilen bon einander und verbinben glei. de Arten ber Verbol um uno gleide Enoungen ber Subilantivorum, als: npïo6pbגb чеспь и славу, er bat (F)re und Siubm erworben; или похвалякотb или поносяты, тай lobet elttweder, oder fprict) übelb.

$$
\text { §. } 242 \text {. }
$$

Die Interjectiones воmb, momo, $\Phi y$, fo= bern ben Nominativum, als: Bomb книга! fiefe Da Das Bud)! momo дорогая вешь !

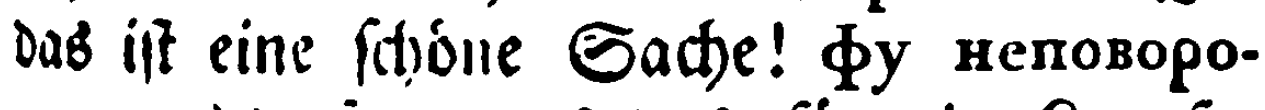
mливой! p广uy, mas daš fúr ein Rangla= mer ift!

$$
\text { ઈ. } 243 \text {. }
$$

Горе, испола́mb, на, вотыb на, frę̣en vor Dem Dativo, als : rope вамb 6Банымb! wehe ell() Armen! исполаmь молодиу ! rect)

2urtide! 


\section{Sedffer $2 \mathfrak{d}$ /4. von ber Syntaxi.}

Burfafe! на, воты на mебЂ рука! Gier! Da baft Du Die Şant.

$$
\text { \$. } 244 .
$$

Mit bem Vocativo ftȩ̧en ynub, прочь, ren, нy, als: yыnb mы не san! willit du! belle mir nid)t! прочb назо́иливои! 'weg,

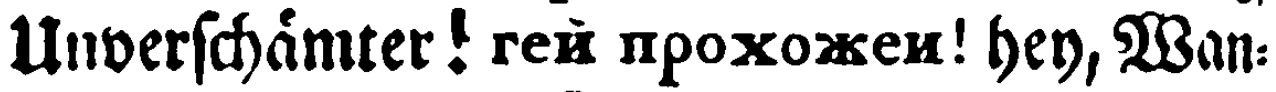
Dersmaili! нy Abнивеyb! bo Du Faul. lenjer!

$$
\text { §. } 245 \text {. }
$$

Die úbrigen Interjectiones ftȩ̧en gemeinig. lid) für fiđ allein, of̧ne mit anbern Rebetheilen jufammen gefüget zu werben.

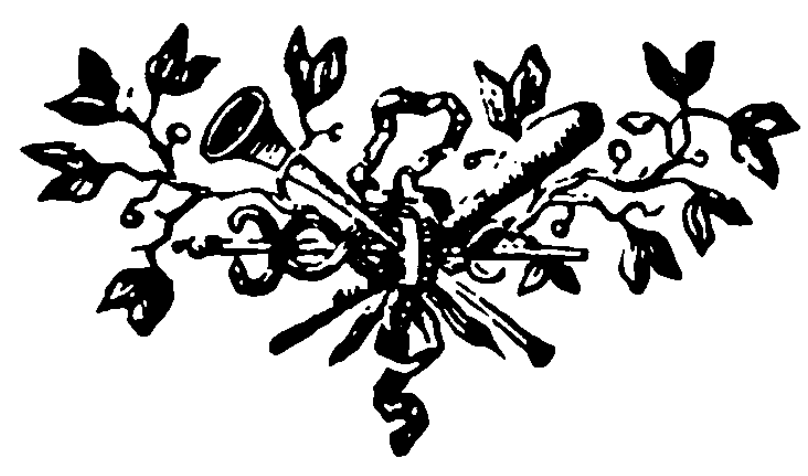

Reivgig,

gebructe bey $\mathfrak{B}$. C. Breitfopf unb Eoţn.

1773. 


\section{Errata.}

5. 3. anftatt

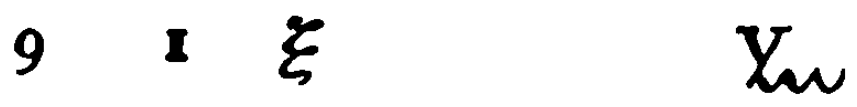

7 15 Аюбить

лю6и́mb

716 ^юбитb

^ю́биmb

15 I III

Ira

163 yoroגb

yoroxb

$\begin{array}{lll}68 & 2 & \text { me6b }\end{array}$

пе6я

$\begin{array}{lll}78 & 6 & \text { иль }\end{array}$

criab

159 4.5. Аремлапть

Аремать

1632 марой маро- марай, марапь

Bamb

1637 позмогу

1644 писнуль

$169 \quad 9$ ськокну

$171 \quad 19$ maḱamb

18021 жиmb

18312 corpyбaю

1867 колонуль

19519 посупиль

210 6.7. vermunbernte

212 II ombxa

2218 Капїискомb Каспїискомb

22521 нешастию неџастїю.

Bo3mory

fällt gang roeg

crokry

IIIacoвamb

AnImb

corpy6rio

faillt ganz weg

nomymr $\boldsymbol{\imath} \mathbf{b}$

berwunbernde

ymbxa 